\title{
FLEET DYNAMICS \\ IN A CHANGING \\ POLICY ENVIRONMENT
}

J. BATSLEER

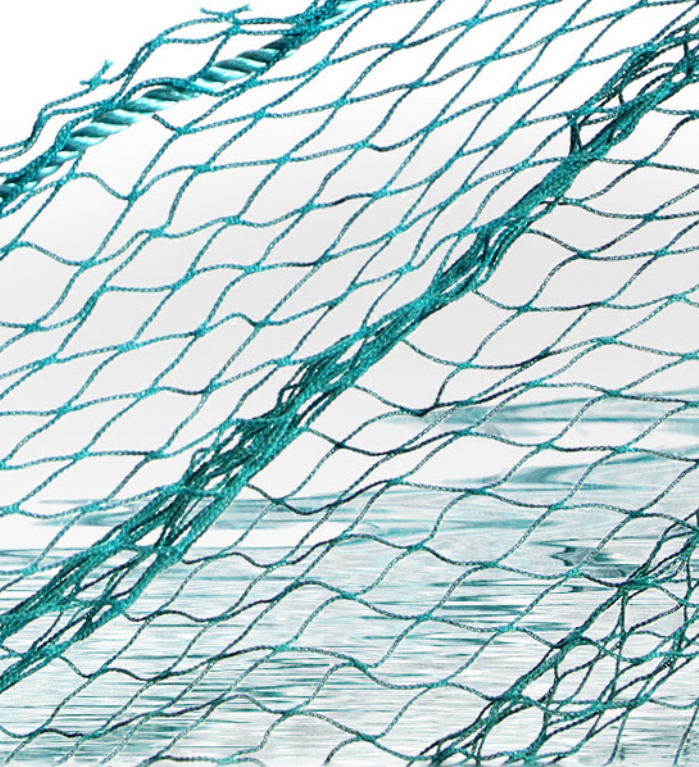



FLEET DYNAMICS IN A CHANGING POLICY ENVIRONMENT

J. Batsleer 


\section{THESIS COMMITTEE}

\section{PROMOTOR}

Prof. Dr A.D. Rijnsdorp

Professor for Sustainable Fisheries Management

Wageningen University

\section{CO-PROMOTOR}

Dr J.J. Poos

Senior scientist, Wageningen Marine Research

\section{OTHER MEMBERS}

Prof. Dr C. Ulrich, Technical University of Denmark

Dr Polet, Institute for Agricultural and Fisheries Research (ILVO), Vlaanderen, Belgium

Dr R.A. Groeneveld, Wageningen University

Prof Dr A.J. Murk, Wageningen University

This research was conducted under the auspices of the Graduate Wageningen institute of Animal Sciences 


\section{Fleet dynamics in a changing policy environment}

\section{J. BATSLEER}

\section{Thesis}

submitted in fulfilment of the requirements for the degree of doctor at Wageningen University by the authority of the Rector Magnificus,

Prof. Dr A.P.J. Mol, in the presence of the

Thesis Committee appointed by the Academic Board

to be defended in public

on Wednesday 23 November 2016

at 11 a.m. in the Aula 


\section{Jurgen Batsleer}

Fleet dynamics in a changing policy environment,

172 pages.

PhD thesis, Wageningen University, Wageningen, NL (2016)

With references, with summary in English and Dutch

ISBN 978-94-6257-952-1

DOI http://dx.doi.org/10.18174/391925 
Dit proefschrift is opgedragen aan mijn ouders en gezin.

"Waar je ook bent

Ik zou het niet weten

Niet in afstand of tijd te meten

Maar ik heb je bij me

Diep in mij

Daarom ben je zo dichtbij"

Toon Hermans 



\section{CONTENTS}

CHAPTER 1

Introduction 9

\section{CHAPTER 2}

Mixed fisheries management: Protecting the weakest link

\section{CHAPTER 3}

High-grading and over-quota discarding in mixed fisheries

\section{CHAPTER 4}

Mixed fisheries management: Is the ban on discarding likely to promote more

selective and fuel efficient fishing in the Dutch flatfish fishery? 83

\section{CHAPTER 5}

Exploring habitat credits to manage the benthic impact in a mixed fishery 107

\section{CHAPTER 6}

General discussion

\section{ADDENDUM}

Summary 156

Samenvatting

Curriculum Vitae 161

List of Abbreviations 162

Dankwoord 166

Training and Supervision Plan 171 


\section{BACKGROUND}

Human fish consumption has been surging in the past five decades. This increased demand for fish is reflected in the global annual catches of marine fish. Global marine catches increased from 20 to 60 million tonnes between the early 1950s and 1970s but stabilized around 80 million tonnes per year since the 1990s (FAO, 2014). In Europe however, annual catches have been declining in the past decade, while the economic performance of the EU fishing fleet shows a positive trend (STECF, 2014). This improved economic situation of the EU fishing fleet can be partially attributed to positive effects of the European fisheries policy (for instance stock recovery and capacity reduction) as well as innovation towards more selective and fuel efficient fishing techniques and favourable market conditions (e.g. higher average first-sale prices).

European fisheries policy originates from the Treaty of Rome (1957) where fisheries were regarded as an agricultural product, forming part of the Common Agricultural Policy (CAP). This policy focused primarily on the social and economic interests of the fishing industry. In the 1970s the European Community expanded with the accession of big fishing nations such as Denmark, Ireland and the UK (Symes, 1997). Enlargement of the European Community entailed the development of an individual policy for fisheries, establishing a common organisation of the market for fish and fish products, and adopting a Community structural policy regulating access and conservation to common resources (Holden, 1994).

In 1983 the European Community formally established the European Common Fisheries Policy (CFP). The policy adopted a more conservation oriented approach, directed on the sustainable exploitation of fish stocks while ensuring an economic viable European fishing fleet providing employment and opportunities for coastal communities (Holden, 1994). To evaluate policy objectives the CFP would be revised every 10 years. Hence, during the first two terms of the CFP (i.e. 1983 and 1992) a set of measures, including annual total allowable catches (TAC), multi-annual guidance programs (MAGPS) (i.e. to find a balance between the fleets fishing capacity and the available fishing opportunities) and technical measures (for instance area or mesh size restrictions) were introduced for the conservation and management of fish stocks (Daan, 1997). Especially implementation of the TAC-system, providing access to the resources, had a big impact on fisheries as shared resources had to be divided among EU Member States (national quota). To prevent arguments between Member States over how national quota should be allocated, quota were based on a historical proportion of the catches and special provisions for communities depending on fishing, i.e. relative stability (Holden, 1994).

At the turn of the 21 th century it became clear the CFP regulations had not met expectations. Many stocks were being exploited at unsustainable levels and fishing fleets still had an overcapacity, producing a negative economic effect in the fishing industry (Daan, 1997, Frost and Andersen, 2006). This failure was attributed to the lack of long-term strategies, the political decision process, low enforcement and non-compliance with management measures (Arts and Tatenhove, 2004, Daw and Gray, 2005). This critical situation required a major 
reform of the CFP in 2002 which introduced four fundamental changes: (1) multi-annual recovery and management plans, (2) the opportunity to restrain fishing pressure by limiting the days-at-sea, (3) creation of the Regional Advisory Councils (RACs) giving stakeholders (i.e. fishing industry and environmental groups) a greater say in the decisions making process and (4) a progressive implementation of an ecosystem-based approach to fisheries (Symes, 2005).

When the ecosystem-based approach to fisheries was introduced in the CFP reform in 2002, it was unclear how it could be made operational. There was a clear gap between theory (i.e. knowledge) and practice (i.e. management plans) (Arkema et al., 2006). Parallel to the changing CFP a myriad of secondary legislations, including the Habitat Directive (HD, 92/43/ EEC) and the Marine Strategy Framework Directive (MSFD, 2008/56/EC) have been adopted. These directives are oriented towards nature conservation and comprise of a framework to manage human impact on vulnerable habitats and sensitive species, biodiversity and the integrity of marine ecosystems. While the HD and MSFD adopted ecosystem-based considerations, the CFP failed to integrate the wider ecosystem effects of fishing into policy making such as reducing pressure on non-target species and habitats.

The latest CFP reform was adopted in December 2013 and came into force in January 2014. This reform adopted an ecosystem-based approach and includes ambitious measures to achieve long term environmental, economic and social sustainable fisheries. These measures include restoring and maintaining all fish stock to sustainable levels by 2020, phasing out discarding (i.e. throwing back unwanted catches at sea) by introducing a discard ban, and implementing multi-annual fisheries plans which includes establishing marine protected areas. In addition, the CFP will need to be harmonised with the objectives of environmental legislation such as the MSFD.

Recognizing European fisheries policy went through some profound changes in the past decades, it is vital to explore how policy decisions may influence the dynamics of the fleet (Hilborn, 1985). The dynamics of a fleet is a result of individual skippers making choices on when and where to fish, while competing for similar resources. An individual's choice will predominantly depend on the spatio-temporal distribution of the resources, the costs exploiting different fishing grounds, market value of the resources, and constraints imposed by management (Gillis et al., 1995a, Rijnsdorp et al., 2008, Poos et al., 2010). All too often, policy makers assume management decisions will deliver the obvious results (Walters, 2007), ignoring the potential influence of fleet responses to uncertainty associated with management. This thesis will study how location choice and discard decisions made by individual fishers in a mixed fishery are influenced by management, (uncertainty in) resource distribution and technological innovations. This knowledge will provide a basis for predicting the response of the fleet to management measures attempted to reduce the ecosystem impact of fisheries and improve the sustainable use of marine ecosystems. 


\section{DISCARDS IN MIXED FISHERIES}

A target species is a species which is intentionally caught by a fishery. Most gears, however, are not able to retain one specific target species in the net, but catch multiple target species simultaneously (mixed fisheries). The targeted species often have a similar body morphology and spatial and seasonal (at least for a certain period during the year) distribution. An example is the Dutch flatfish fishery targeting plaice (Pleuronectes platessa) and sole (Solea solea), where the distribution of sole overlaps the distribution of plaice in winter (de Veen, 1976, de Veen, 1978).

The choice of gear with its specific selectivity properties (e.g. mesh size) will determine the characteristics of the catch. Inevitably, the catch will be diverse in terms of species, age and size categories. Species having no or little commercial value as well as commercial species constrained from landing are not of primary interest to the fishery and are referred to as by-catch. Subsequently, restrictive management regulations and economic motives urge fishers to return the by-catch to sea (Alverson et al., 1994, Jennings et al., 2001, Catchpole et al., 2005).

Management measure can directly effect discarding decisions in a mixed fishery. Minimum landing size (MLS) regulations have been introduced, prohibiting landing species below a fixed reference size. The regulation had the intention of encouraging fishers to fish more selective reducing the catch of juvenile fish by for example increasing mesh sizes. In mixed fisheries however, discarding occurs because of a mismatch between MLSs of the different target species and the selectivity of the gear for those species (Cook, 2003, Catchpole et al., 2005). For example in the Dutch flatfish fishery the MLSs for sole and plaice are $24 \mathrm{~cm}$ and $27 \mathrm{~cm}$, respectively. The selectivity of the gear is tailored by using smaller mesh sizes to retain the more valuable sole. As a result, substantial numbers of undersized plaice are caught and discarded compulsory (Van Beek et al., 1983, Rijnsdorp and Millner, 1996).

Each year the European Commission requests scientific advise on the total allowable catch (TAC), being the amount of fish that can be caught for most commercial fish stocks in European waters. The size of the annual TAC for each individual stock is decided by the Council of Ministers. Each Member State may decide how the national quotas are shared among the fishing industry. In the Netherlands, national quota for plaice and sole are divided in individual transferable quotas (ITQs) owned by individual fishing companies (Salz, 1996). ITQs enable fishing companies to trade (i.e. selling, leasing of buying) quota, depending on how fishing activities are developing throughout the year.

TACs intend to control fishing mortality by limiting the amount of fish that can be harvested from a single stock. Basically, TACs assume fishers will align their fishing activities with the imposed catch limitations, and fishers will stop catching a given species when the quota is fully exploited (Holden, 1994, Daan, 1997, Branch and Hilborn, 2008, Ulrich et al., 2011). In mixed fisheries, however, fishers have different quota for each target species and will continue their fishing activities until all unused quota are exhausted. In this process marketable fish for which quota have already been fully exploited will be discarded (Pascoe, 
1997, Poos et al., 2010). Hence, the effectiveness of single-species TACs to control fishing mortality in mixed fisheries has been criticised because TACs limit the landings but not the catch of a fishery, resulting in excessive discarding of marketable fish (Daan, 1997, Rijnsdorp et al., 2007).

Commercial fishing is driven by economic considerations, whereby the commercial market plays a crucial role in determining the price for fish. Generally, the price for fish is quality related and size-dependent, with a lower market value for damaged and small individuals (Zimmermann et al., 2011). Hence, it is in the interest of the fisher to optimize the catch retained on board with market demands. Consequentially, fishers deter from holding and landing non market or low-valued fish especially when the costs of the process (i.e. sorting, storage and landing) of keeping the fish on board exceeds the financial gains from selling the fish. Economic motives can also induce discarding of lower valued marketable fish in order to make room for more higher valued (larger) fish while quota are still available (high-grading) (Gillis et al., 1995b). Empirical evidence for high-grading is scarce as fishers do not report these discards, however studies have shown high-grading is a mainly a result of the interplay between economic motivations and management constraints (Pikitch et al., 1988, Gillis et al., 1995b). Constraining quota for conservation benefits could be counteracted by increased high-grading as fishers will try to maximize the value of their catch by discarding lower valued marketable fish. High-grading is perceived as a wasteful practice and the EU has declared high-grading an illegal practice in 2009 (Council Regulation (EC) 43/2009 (EC., 2009a)).

There is a general concern about the extent of discarding in mixed fisheries. For example, mixed demersal fisheries on flatfish, round fish and Nephrops contribute substantially to an estimated 1 million tonnes of annually discarded organisms in the North Sea (Catchpole et al., 2005). In Europe, Member States are required to provide estimates on the amount of discarding of their most important commercial fisheries through the Data Collection Framework (DCF, Council Regulation (EC) No 1543/2000 (EC., 2000)), which is used to feed and improve stock assessments. The availability and quality of discard data, however, is still low as Member States use different data formats, sampling protocols and intensities, and do not share information (Uhlmann et al., 2014). Hence, imprecise estimates of actual numbers may lead to incorrect assessments of the stock and thus hamper the confidence of management advice (Crowder and Murawski, 1998, Dickey-Collas et al., 2007). In addition, discards can be subject to high mortality rates (Van Beek et al., 1990). Mortality rates will vary between species and depends on many factors including the type of fishery, haul duration, sorting and handling process on board, depth of the catch but also location (i.e. type of substrate) and season of the fishing activity (Van Beek et al., 1990, Berghahn et al., 1992, Evans et al., 1994, Sangster et al., 1996, Smith and Scharf, 2011, Enever et al., 2009, Marçalo et al., 2013). In this context, the substantial amounts of discarding of small and juvenile fish is a major concern for the sustainability of population and the future yield of fisheries. In addition, high mortality rates instigate the debate concerning the loss of valuable resources due to discarding of marketable fish. 
Discard reduction has become a key element in fisheries management. In the latest reform of the CFP (2013) the EU accepted the implementation of a discard ban in 2015 for European fisheries. The discard ban will be introduced in phases and will prohibit discarding of all species subject to catch limits in 2019. The ban primarily aims at reducing discards by incentivising fisheries to become more selective, avoiding non-target species, juvenile and over-quota catches. Improving selectivity to reduce the by-catch can be achieved by technological innovations. Technological innovations can range from net-innovations such as
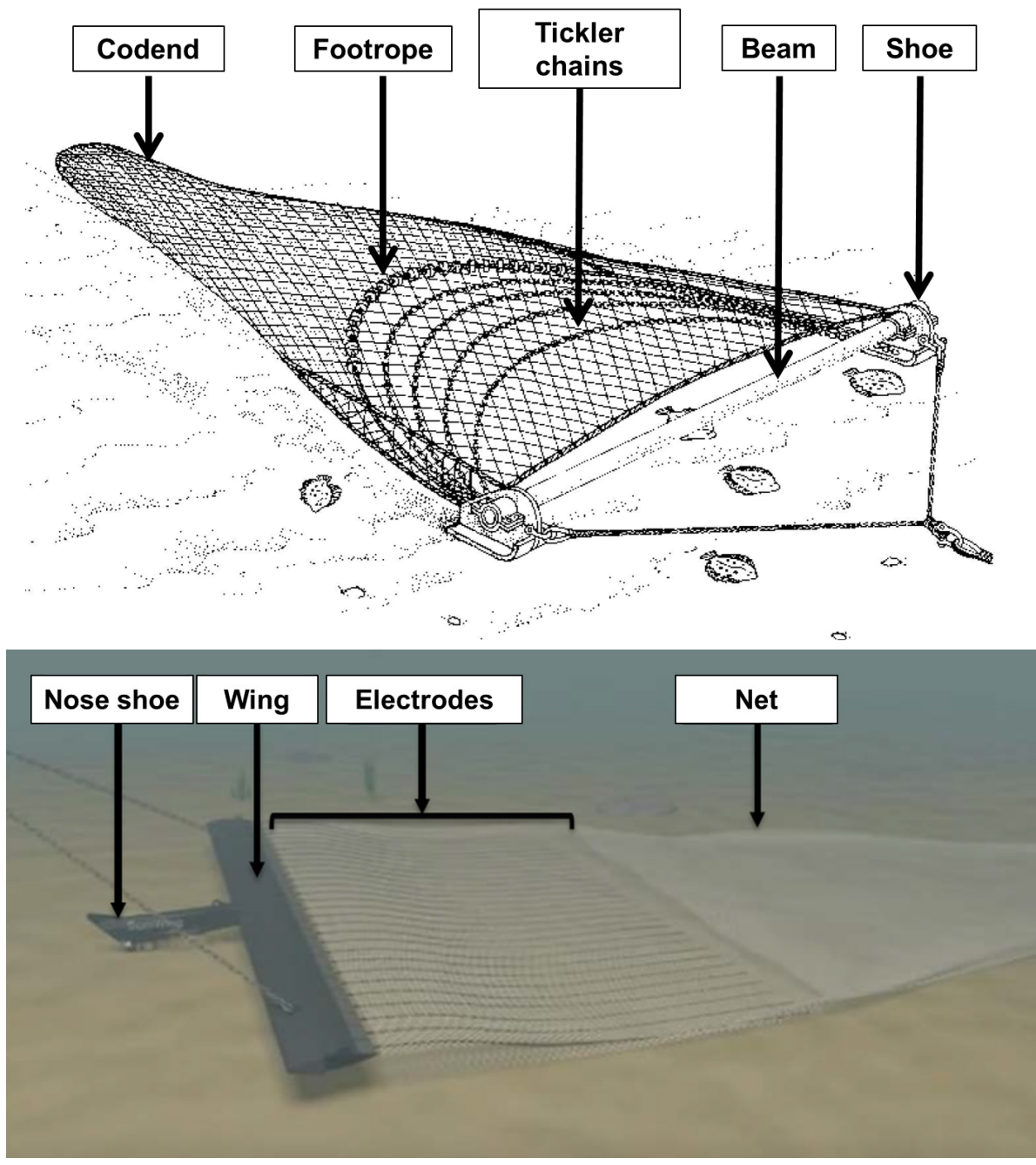

Figure 1.1

The flatfish beam trawl (top) (source: Jennings et al.(2001)) and flatfish pulse trawl (bottom) (source: ABPmer and lchthys Marine (2015)) 
increased mesh sizes or separation panels (van Marlen, 2003, Nikolic et al., 2015), to a switch of fishing gear used. The latter has been observed in for example the Alaskan groundfish fishery where a switch to just using a pelagic trawl has been observed (Graham et al., 2007); and in the Dutch flatfish fishery with a transition from using a beam trawl to a pulse trawl (figure. 1.1) (van Marlen et al., 2014). Alternatively, fishers can decide to adapt their fishing strategies resulting in a more selective fishery (Eliasen et al., 2014). Studies have shown fishers can respond to management constraints by changing their discarding decisions, choices on where, when and what to fish (effort allocation) and tow duration (Gillis et al., 1995b, Babcock and Pikitch, 2000, Branch and Hilborn, 2008, Poos et al., 2010). Few studies, however, have explored the response as well as environmental and socioeconomic consequences of behavioural choices in relation to the implementation of a discard ban (Condie et al., 2013, Simons et al., 2015).

\section{ECOSYSTEM APPROACH TO FISHERIES MANAGEMENT}

The initial objective of the European Common Fisheries Policy was to conserve fish stocks and ensure economic viability for European fisheries. In recent years many fish stocks in the North-East Atlantic have shown a positive trend, as $48 \%$ of the assessed stocks are fished at or below the maximum sustainable fishing mortality levels (EC, 2015). Despite the improvement in the status of many of the commercially exploited stocks, fisheries management is still criticised for not taking into account the ecosystem consequences of fishing (EC, 2009b). The impact of fishing goes beyond the removal of individual target species as fishing interacts with other ecosystem components such as the seabed and (vulnerable) non-target species (Kaiser et al., 2002, Shephard et al., 2015).

The main ecosystem impacts of fisheries are the modification of seabed habitats due to the impact of the gear, the loss of biodiversity and changes in food web dynamics (i.e. changes in the species, age and size compositions) due to mortality of target as well as bycatch species (Jennings and Kaiser, 1998, Murawski, 2000). The impact will largely depend on the type of gear and the operational methods (e.g. mesh size, rigging, towing speed and depth) being used (Valdemarsen et al., 2007). Bottom trawls, for example, are towed over the substrate to target a mix of species living or feeding close to the seabed (i.e. demersal fish). This type of fishery is known to have a substantial amount of by-catch and discards of both target and non-target species, generating additional unintended mortality (Pascoe, 1997). In addition, various gear components make contact to the seabed, disturbing the sediment as well as the organisms living close to (epifauna) or within (infauna) the sediment (de Groot, 1984, Collie et al., 2000). Alternatively, passive gears, such as longlines, gillnets and trammel nets can be anchored to the substrate and left to fish passively, hooking, trapping or entangling species (Jennings and Kaiser, 1998, Valdemarsen et al., 2007). These gears will have a lower impact on the substrate, but are known to have a relatively high by-catch of mega-fauna, such as cetaceans, sea turtles, elasmobranches and seabirds (Jennings et al., 2001). 
Holding fisheries accountable for having an impact on marine ecosystems emphasised the need to shift fisheries management from a single-species management approach to an ecosystem-based approach to fisheries (EAF). The EAF strives to sustain healthy ecosystems and the fisheries they support. The EAF should thus provide (i) environmental protection (ii) socioeconomic prosperity and (iii) accumulate knowledge (Pikitch et al., 2004, Rice, 2011). These three elements are pursued in the 2013 reform of the CFP which obliges stocks to be exploited at sustainable levels by 2020, prohibits discarding and urges Member States to protect vulnerable habitats. These obligations should contribute to avoid degradation and minimizing the risk of serious harm to the ecosystem as well as ensuring long-term benefits from harvesting marine resources for fisheries. In addition, the role of science will need to be reinforced by generating knowledge and sharing information in order to assess the status of the ecosystem and the fisheries.

The 2002 reform of the CFP was criticised for insufficient integration of marine management preventing the EAF to get foothold (EC, 2009b). Now that the CFP has adopted an EAF, placing fisheries in an ecosystem context, objectives have to be complementary to goals defined in other Community legislation. This requires the integration of fisheries policy with environmental policies such as the Habitat (HD, 92/43/EEC) and the Marine strategy Framework Directive (MSFD, 2008/56/EC). The MSFD demands management measures contributing to achieve a Good Environmental Status (GES) of the EU's marine waters by 2020. GES relates to the assessment of the quality of the structure and functioning of marine ecosystems to restore or resist anthropogenic environmental changes (Borja et al., 2013). GES is assessed based on 11 descriptors including biological, hydrological and chemical components. The CFP can thus be an important tool for achieving GES under the MSFD. Management measures relating to the exploitation of stocks and the protection of sensitive habitats from fishing, for example can contribute to improve or maintain, habitat and population condition (i.e. size and age distribution) which are important criteria determining GES.

\section{FLEET DYNAMICS}

Fisheries managers traditionally implement measures (e.g. catch or effort limitations) controlling the impact of fisheries on exploited species and the environment. However, the influence of measures on the individual fisher and fishing communities are often overlooked. Fishers can adapt and change their behaviour in relation to imposed constraints, which can lead to unintended and unexpected consequences of fisheries management (Hilborn, 1985, Salas and Gaertner, 2004, Branch et al., 2006). However, for a long time the effect of adaptive behaviour of fishers on the success of fisheries management has been neglected and only a few studies addressed the behaviour of fishing fleets (Gordon, 1953, Hilborn and Ledbetter, 1979).

Hilborn (1985) was one of the first scientist to point out that the lack of knowledge on fishers behaviour may underlie the failure of fisheries management. The study drew atten- 
tion to the importance of the role of individuals choices within a fleet and argued that fleet dynamics should be an integral part of fisheries management. In addition, four principal elements were recognized which should be studied to increase our knowledge on fleet dynamics: (1) the process of investment, providing insight in why and when fishers will invest in new vessels or gear; (2) effort allocation to provide insight in decisions when, where and what to fish for; (3) harvesting efficiencies to increase knowledge on the differences in catching process between gear and vessel types; and (4) discarding to improve our understanding on the decision why species are kept or thrown back overboard.

The study of Hilborn (1985) created awareness about the influence of fisheries behaviour on the effectiveness of fisheries management. In many studies on fishers behaviour economics are used as the main driver for the choices of individuals (Gordon, 1953, Gillis et al., 1995b, Babcock and Pikitch, 2000, Poos et al., 2010, Dowling et al., 2012). It is assumed fishers will adapt their behaviour and trade-off cost and benefits in order to maximize their profits. While the assumption of profit-maximization is supported by observations and interviews (Hilborn and Kennedy, 1992, Robinson and Pascoe, 1997), it is questioned whether fishers will prioritise profits over other metrics such as maximizing landings, or risk aversion or simply follow personal habits (Eggert and Tveteras, 2004, Salas and Gaertner, 2004, Holland, 2008).

Another aspect is the decision of fishers to comply or non-comply with management measures. Non-compliance, by for example high-grading, quota busting and data-fouling, can pose a serious challenge to the success of management measures. Compliance behaviour in fisheries is not well studied as fishers are often reluctant to disclose the underlying reasons for non-complying. Available studies, however, indicate that compliance will depend on the stringency and efficiency of measures, possibility of being detected, height or severity of sanctions as well as an individuals norms and values (Sutinen et al., 1990, Hønneland, 1999, Hatcher, 2000, Raakjær Nielsen and Mathiesen, 2003). To reduce the resistance to comply with management measures, fisheries managers should require more knowledge and understanding of the implications of imposed management and enforcement measures on compliance decisions with the fleet.

This thesis will contribute to the understanding of adaptive behaviour of fishers by exploring the implications of European fisheries management on decisions of individual vessels active in mixed demersal fisheries. We will address three of Hilborns elements of fleet dynamics including decisions on effort allocation, discarding and harvest efficiency. In addition, the deterrent effect of monetary fines on non-compliance will be addressed. Understanding processes that determine the dynamics of fisheries and choices fishers make, are necessary to assess and understand the impact of fishing on fish stocks and ecosystems, but will also aid in understanding how fishers respond to regulation changes. In the context of ecosystem-based management, these insights are highly relevant to develop management strategies to mitigate the adverse environmental effects of the fisheries while maintaining a sustainable exploitation of the fisheries resources and economic profitability. 


\section{MODELLING APPROACH}

Many different models have been developed for modelling decision making processes in fisheries and these have proven to be helpful tools to explain and predict fisheries dynamics (van Putten et al., 2012). In this thesis the dynamics of a fishing fleet is studied using a dynamic state variable model (DSVM, (Houston and McNamara, 1999, Clark and Mangel, 2000)). Dynamic state variable models have been applied in a broad range of ecological (Clark and Butler, 1999, Marescot et al., 2013) and fisheries related problems (Gillis et al., 1995b, Babcock and Pikitch, 2000, Poos et al., 2010, Dowling et al., 2012). The DSVM uses an individual based modelling approach in which individuals are modelled by formulating specified behavioural rules, allowing the estimation of an individual's optimal choice. This modelling technique allows the evaluation of a utility function at the end of a time period while sequences of choices are made that have to result in reaching the maximum of that utility function within constraints. In the context of fisheries, constraints can be set by management regulations (Clark and Mangel, 2000).

The model used in this thesis has been developed by Poos et al. (2010) to explore the mechanisms and patterns of effort allocation of the Dutch beam trawl fleet. Here, the model is extended in several steps to address the behavioural dynamics for the Dutch North Sea flatfish fisheries and the French mixed demersal fisheries in the Channel in response to new management regulations and economic opportunities. Initially, the model is expanded by expanding the number of species that can be included and allowing fishers to switch gears. In order to evaluate high-grading and over-quota discarding I increased model complexity by including size-structured populations which vary in their spatio-temporal distribution. In addition, seasonal variation in size specific ex-vessel prices (i.e. the price received the point of landing the fish) was included. The final adaptation of the model comprises of adding individual habitat credits to address the wider ecosystem effects (i.e. habitat and benthic ecosystem impact) of fishing. Extending the DSVM model contributes to the aim of this thesis which is to develop a generic model to explore the implication of management measures on short-term decisions such as discarding, gear choice and the spatial and temporal distribution effort and the environmental and socioeconomic consequence thereof for a wider range of demersal fisheries.

\section{OUTLINE OF THE THESIS}

This thesis explores how management measures can mitigate the adverse effects of fishing to support the development of an ecosystem-based approach to fisheries management. The study focusses on fishers behaviour, in particular effort allocation, discarding decisions, and harvest efficiency, and explores how behavioural adaptations may influence the performance of management measures aimed at reducing the adverse side effects of the fisheries characterised by a substantial bycatch of target and non-target species and impact 
on the seafloor and benthic ecosystem. Using a generic Dynamic State Variable model, specific applications are build to address different research questions inspired by the North Sea flatfish fishery and the French demersal fishery in the Channel.

For many years North Sea cod (Gadus morhua) is harvest unsustainably. The stock is exploited above sustainable mortality levels (Fmsy), and its spawning stock biomass has been well below the conservation limit (Blim). Despite signs of recovery following the recovery plan imposed in 2003, the stock has remained the weakest component of the demersal fish assemblage (Ulrich et al., 2011, Kraak et al., 2013). In chapter 2 of this thesis we explore how quota management in combination with a discard ban may improve the regulation of fishing mortality for a depleted stock that is exploited in a mixed fishery. This is studied using a dynamic state variable model (DSVM) to evaluate the behavioural response, i.e. effort allocation, discard behaviour and compliance, of French mixed fisheries operating in the Eastern English Channel. The trade-off between socio-economic benefits of fisheries and the protection of the weakest links in the ecosystem is clarified.

Fishers discard parts of their catch due to policy or market driven incentives. Discarding marketable resources is of particular interest as this is seen as a wasteful practice. Fishers will discard marketable fish when quota are exhausted (over-quota discarding) or by trying to optimize their economic return by discarding size or age classes with the lowest economic value (high-grading) (Gillis et al., 1995b, Poos et al., 2010). The occurrence of high-grading is often based on anecdotal information from the fishing industry, while empirical evidence is scarce (Poos et al., 2010). In chapter $\mathbf{3}$ I review the literature on observations of over-quota discarding and high-grading to gain insight in the conditions under which discard decisions may occur. In addition we apply a behavioural model to the Dutch demersal beam trawl fleet to explore the implications of discard decisions in a mixed fishery on the stock structure and assessment.

The discard ban aims at reducing discarding of fisheries resources and encourages fisheries to fish more selective. Selectivity can be improved by using more selective gears and by reallocation of fishing activities to areas with lower catch rates of certain species, size or age classes. It is expected technical and behavioural adaptations may reduce the catch of undersized or unwanted catches but may also lead to a reduction in the economic profitability of the fishing fleet, reducing the incentive to fish more selective. In chapter $\mathbf{4}$ of this thesis we address the question how a new management measures, such as the discard, ban may promote the transition towards more selective fishing gears. The Dutch demersal fisheries is used as a case study as the fishery is undergoing a transition from using a conventional beam trawl to using the more selective (i.e. for undersized fish) and fuel efficient pulse trawl. We explore the annual fishing strategies of both fleets targeting size-structured populations to evaluate the economic profitability under quota management in combination with a discard ban.

The EAF strives to sustain healthy ecosystems while providing optimal output for fisheries (Pikitch et al., 2004). The EAF has a prominent role in European fisheries management, requiring fisheries managers to assure the sustainable use of resources while ecosystem 
composition, structure and functioning are safeguarded. Because bottom trawl fisheries affect both fish populations as well as the benthic habitat, fisheries managers resort to technical management measures, such as gear restrictions or spatial measures to limit the impact of fishing activities on the benthic habitat and ecosystems. However, these limitation often count on resistance from the fishing industry as these limitations constrain fishing activities and socioeconomic benefits are limited or reduced (Caveen et al., 2015). In chapter 5 we apply a behavioural model used in the previous chapters, adapted to include individual habitat credits, to study decisions on effort allocation of the French multipurpose bottom trawl fleet in the Eastern English Channel. As such we explore the potential of an alternative approach of implementing a habitat credit system in combination with quota management to achieve sustainable exploitation of target species while minimizing the impact on the benthic ecosystem.

Chapter $\mathbf{6}$ includes the general discussion of this thesis. Here I will summarize the findings of the various studies and elaborate on some of the main assumptions made. In addition, an overview of the introduction and current state of play of the discard ban is provided. 


\section{REFERENCES}

ABPmer and Ichthys Marine (2015). Supporting Risk-Based Fisheries Assessments for MPAs, Assessment of Beam Trawling Activity in North Norfolk Sandbanks and Saturn Reef SCI. ABPmer Report No. R.2551A. A report produced by ABPmer and Ichthys Marine Ecological Consulting Ltd. for National Federation of Fishermen's Organisations, December 2015.

Alverson, D.L., Freeberg, M.H., Murawski, S.A., Pope, G.J. (1994) A global assessment of fisheries bycatch and discards. FAO Fisheries Technical Paper 339

Arkema, K.K., Abramson, S.C., Dewsbury, B.M. (2006) Marine ecosystem-based management: from characterization to implementation. Frontiers in Ecology and the Environment4, 525-532.

Arts, B., Tatenhove, J. (2004) Policy and power: A conceptual framework between the 'old' and 'new' policy idioms. Policy Sciences 37, 339-356.

Babcock, E.A., Pikitch, E.K. (2000) A dynamic programming model of fishing strategy choice in a multispecies trawl fishery with trip limits. Canadian Journal of Fisheries and Aquatic Sciences 57, 357370.

Berghahn, R., Waltemath, M., Rijndsorp, A.D. (1992) Mortality of fish from the by-catch of shrimp vessels in the North-Sea Journal of Applied IChthyology-Zeitschrift Fur Angewandte Ichthyologie 8, 293-306.

Borja, A., Elliott, M., Andersen, J.H., et al. (2013) Good Environmental Status of marine ecosystems: What is it and how do we know when we have attained it? Marine Pollution Bulletin 76, 16-27.

Branch, T.A., Hilborn, R. (2008) Matching catches to quotas in a multispecies trawl fishery: targeting and avoidance behavior under individual transferable quotas. Canadian Journal of Fisheries and Aquatic Sciences 65, 1435-1446.

Branch, T.A., Hilborn, R., Haynie, A.C., et al. (2006) Fleet dynamics and fishermen behavior: lessons for fisheries managers. Canadian Journal of Fisheries and Aquatic Sciences 63, 1647-1668.

Catchpole, T.L., Frid, C.L.J., Gray, T.S. (2005) Discards in North Sea fisheries: Causes, consequences and solutions. Marine Policy 29, 421-430.
Caveen, A., Polunin, N., Gray, T., Stead, S.M. (2015) The Controversy over Marine Protected Areas Science Meets Policy, Springer New York.

Clark, C.W., Butler, R.W. (1999) Fitness components of avian migration: A dynamic model of Western Sandpiper migration. Evolutionary Ecology Research 1, 443-457.

Clark, C.W., Mangel, M. (2000) Dynamic state variable models in ecology: Methods and applications, Vol., Oxford University Press.

Collie, J.S., Hall, S.J., Kaiser, M.J., Poiner, I.R. (2000) A quantitative analysis of fishing impacts on shelf-sea benthos. Journal of Animal Ecology 69, 785-798.

EC (2015) Communication from the Commission to the European parliament and the Council. Consultation on the Fishing Opportunities for 2016 under the Common Fisheries Policy. COM (2015) 239 final

Condie, H.M., Grant, A., Catchpole, T.L. (2013) Does banning discards in an otter trawler fishery create incentives for more selective fishing? Fisheries Research 148, 137-146.

Cook, R. (2003). The magnitude and impact of bycatch mortality by fishing gear. In M. Sinclair, \& G. Valdimarsson (Eds.), Responsible Fisheries in the Marine Ecosystem. Oxford.

Crowder, L.B., Murawski, S.A. (1998) Fisheries bycatch: Implications for management. Fisheries 23, 8-17.

Daan, N. (1997) TAC management in North Sea flatfish fisheries. Journal of Sea Research 37, 321-341.

Daw, T., Gray, T. (2005) Fisheries science and sustainability in international policy: a study of failure in the European Union's Common Fisheries Policy. Marine Policy 29, 189-197.

de Groot, S.J. (1984) The impact of bottom trawling on benthic fauna of the North Sea. Ocean Management 9, 177-190.

de Veen, J.F. (1976) On the exploitation pattern in the Dutch North Sea sole fishery. ICES Document CM 1976/F: 19., 29 pp.

de Veen, J.F. (1978) On selective tidal transport in the migration of North Sea plaice (Pleuronectes platessa L.) and other flatfish species. . Netherlands Journal of Sea Research 12, 115-147. 
Dickey-Collas, M., Pastoors, M.A., van Keeken, O.A. (2007) Precisely wrong or vaguely right: simulations of noisy discard data and trends in fishing effort being included in the stock assessment of North Sea plaice. ICES Journal of Marine Science 64, 16411649.

Dowling, N.A., Wilcox, C., Mangel, M., Pascoe, S. (2012) Assessing opportunity and relocation costs of marine protected areas using a behavioural model of longline fleet dynamics. Fish and Fisheries 13, 139-157.

EC. (2000) Council Regulation (EC) No 1543/2000 of 29 June 2000 establishing a Community framework for the collection and management of the data needed to conduct the common fisheries policy. Brussels. Official Journal of the European Union, L 176: 1-16.

EC (2009) Council regulation (EC) No 43/2009 (Annex III). Official Journal of the European Union L 22/1, 16 January 2009. , p. 205 pp.

EC (2009) Green Paper: Reform of the Common Fisheries Policy. 27 pp.

Eggert, H., Tveteras, R. (2004) Stochastic production and heterogeneous risk preferences: Commercial fishers' gear choices. American Journal of Agricultural Economics 86, 199-212.

Eliasen, S.Q., Papadopoulou, K.-N., Vassilopoulou, V., Catchpole, T.L. (2014) Socio-economic and institutional incentives influencing fishers' behaviour in relation to fishing practices and discard. ICES Journal of Marine Science 71, 1298-1307.

Enever, R., Catchpole, T.L., Ellis, J.R., Grant, A. (2009) The survival of skates (Rajidae) caught by demersal trawlers fishing in UK waters. Fisheries Research 97 72-76.

Evans, S.M., Hunter, J.E., Elizal, Wahju, R.I. (1994) Composition and fate of the catch and bycatch in the Farne Deep (North Sea) Nephrops fishery. ICES Journal of Marine Science 51, 155-168.

FAO (2014) The state of world fisheries and aquaculture Opportunities and challenges.

Frost, H., Andersen, P. (2006) The Common Fisheries Policy of the European Union and fisheries economics. Marine Policy 30, 737-746.
Gillis, D.M., Peterman, R.M., Pikitch, E.K. (1995a) Implications of Trip Regulations for High Grading - a Model of the Behavior of Fishermen. Canadian Journal of Fisheries and Aquatic Sciences 52, 402415.

Gillis, D.M., Pikitch, E.K., Peterman, R.M. (1995b) Dynamic discarding decisions - foraging theory for high-grading in a trawl fishery. Behavioral Ecology 6, 146-154

Gordon, H.S. (1953) An economic approach to the optimum utilization of fishery resources. Journal of Fisheries Research Board of Canada, 10, 442 - 457.

Graham, N., Ferro, R.S.T., Karp, W.A., MacMullen, P. (2007) Fishing practice, gear design, and the ecosystem approach — three case studies demonstrating the effect of management strategy on gear selectivity and discards. ICES Journal of Marine Science 64, 744-750.

Hatcher, A. (2000) Subsidies for European fishing fleets: the European Community's structural policy for fisheries 1971-1999. Marine Policy 24, 129-140.

Hilborn, R. (1985) Fleet Dynamics and Individual Variation - Why Some People Catch More Fish Than Others. Canadian Journal of Fisheries and Aquatic Sciences 42, 2-13.

Hilborn, R., Kennedy, R.B. (1992) Spatial pattern in catch rates - a test of economic-theory Bulletin of Mathematical Biology 54, 263-273.

Hilborn, R., Ledbetter, M. (1979) Analysis of the British-Columbia salmon purse-seine fleet - dynamics of movemement. Journal of the Fisheries Research Board of Canada 36, 384-391.

Holden, M.J.T. (1994) The Common Fisheries Policy. Origin, Evaluation and Future, Vol., Fishing News Books, Oxford.

Holland, D.S. (2008) Are Fishermen Rational? A Fishing Expedition. Marine Resource Economics 23, 325-344.

Hønneland, G. (1999) A model of compliance in fisheries: theoretical foundations and practical application. Ocean \& Coastal Management 42, 699-716.

Houston, A.I., McNamara, J.M. (1999) Models of Adaptive Behaviour, Cambridge University press.

Jennings, S., Kaiser, M., Reynolds, J.D. (2001) Marine Fisheries Ecology, Blackwell Science, Oxford. 
Jennings, S., Kaiser, M.J. (1998) The Effects of Fishing on Marine Ecosystems. In: Advances in Marine Biology. Vol. Volume 34. Academic Press, pp. 201-352.

Kaiser, M.J., Collie, J.S., Hall, S.J., Jennings, S., Poiner, I.R. (2002) Modification of marine habitats by trawling activities: prognosis and solutions. Fish and Fisheries 3, 114-136

Kraak, S.B.M., Bailey, N., Cardinale, M., et al. (2013) Lessons for fisheries management from the EU cod recovery plan. Marine Policy 37, 200-213.

Marçalo, A., Araújo, J., Pousão-Ferreira, P., Pierce, G.J., Stratoudakis, Y., Erzini, K. (2013) Behavioural responses of sardines Sardina pilchardus to simulated purse-seine capture and slipping. Journal of Fish Biology 83, 480-500.

Marescot, L., Chapron, G., Chadès, I., et al. (2013) Complex decisions made simple: a primer on stochastic dynamic programming. Methods in Ecology and Evolution 4, 872-884.

Murawski, S.A. (2000) Definitions of overfishing from an ecosystem perspective. ICES Journal of Marine Science 57, 649-658.

Nikolic, N., Diméet, J., Fifas, S., et al. (2015) Efficacy of selective devices in reducing discards in the Nephrops trawl fishery in the Bay of Biscay. ICES Journal of Marine Science 72, 1869-1881.

Pascoe, S. (1997) Bycatch management and the economics of discarding. FAO Fisheries Technical Paper370, 153.

Pikitch, E.K., Erickson, D.L., Wallace, J.R. (1988) An evaluation of the effectiveness of trip limits as a management tool. NWAFC Processed report 88-27, $37 \mathrm{pp}$.

Pikitch, E.K., Santora, C., Babcock, E.A., et al. (2004) Ecosystem-Based Fishery Management. Science 305, 346-347.

Poos, J.J., Bogaards, J.A., Quirijns, F.J., Gillis, D.M., Rijnsdorp, A.D. (2010) Individual quotas, fishing effort allocation, and over-quota discarding in mixed fisheries. ICES Journal of Marine Science 67, 323333.

Raakjær Nielsen, J., Mathiesen, C. (2003) Important factors influencing rule compliance in fisheries lessons from Denmark. Marine Policy 27, 409-416.

Rice, J. (2011) Managing fisheries well: delivering the promises of an ecosystem approach. Fish and Fisheries 12, 209-231.
Rijnsdorp, A.D., Daan, N., Dekker, W., Poos, J.J., Van Densen, W.L.T. (2007) Sustainable use of flatfish resources: Addressing the credibility crisis in mixed fisheries management. Journal of Sea Research 57, 114-125.

Rijnsdorp, A.D., Millner, R.S. (1996) Trends in population dynamics and exploitation of North Sea plaice (Pleuronectes platessa L) since the late 1800s. ICES Journal of Marine Science 53, 1170-1184.

Rijnsdorp, A.D., Poos, J.J., Quirijns, F.J., Hille Ris Lambers, R., De Wilde, J.W., Den Heijer, W.M. (2008) The arms race between fishers. Journal of Sea Research 60, 126-138.

Robinson, C., Pascoe, S. (1997) Fisher behaviour: exploring the validity of the profit maximising assumption. CEMARE Res. pap. 110, 16.

Salas, S., Gaertner, D. (2004) The behavioural dynamics of fishers: management implications. Fish and Fisheries 5, 153-167.

Salz, P. (1996) ITQs in the Netherlands; 20 years of experience. ICES CM 1996/P:18.

Sangster, G.l., Lehmann, K., Breen, M. (1996) Commercial fishing experiments to assess the survival of haddock and whiting after escape from four sizes of diamond mesh cod-ends. Fisheries Research 25, 323-345.

STECF. (2014) The 2014 Annual Economic Report on the EU Fishing Fleet (STECF-14-16). Publications Office of the European Union, Luxembourg, EUR 26901 EN, JRC 92507, 363 pp.

Shephard, S., Reid, D.G., Gerritsen, H.D., Farnsworth, K.D. (2015) Estimating biomass, fishing mortality, and "total allowable discards" for surveyed non-target fish. ICES Journal of Marine Science 72, 458-466.

Simons, S.L., Döring, R., Temming, A. (2015) Modelling fishers' response to discard prevention strategies: the case of the North Sea saithe fishery. ICES Journal of Marine Science 72, 1530-1544.

Smith, W.E., Scharf, F.S. (2011) Postrelease survival of sublegal southern flounder captured in a commercial gill-net fishery. North American Journal of Fisheries Management 31, 445-454.

Sutinen, J.G., Rieser, A., Gauvin, J.R. (1990) Measuring and explaining noncompliance in federally managed fisheries. Ocean Development \& International Law21, 335-372. 
Symes, D. (1997) The European Community's common fisheries policy. Ocean \& Coastal Management 35, 137-155.

Symes, D. (2005) Altering course: future directions for Europe's fisheries policy. Fisheries Research 71, 259-265.

Uhlmann, S.S., van Helmond, A.T.M., Kemp Stefánsdóttir, E., et al. (2014) Discarded fish in European waters: general patterns and contrasts. ICES Journal of Marine Science 71, 1235-1245.

Ulrich, C., Reeves, S.A., Vermard, Y., Holmes, S.J., Vanhee, W. (2011) Reconciling single-species TACs in the North Sea demersal fisheries using the Fcube mixed-fisheries advice framework. ICES Journal of Marine Science 68, 1535-1547.

Valdemarsen, J.W., JØrgensen, T., Engås, A. (2007) Options to mitigate bottom habitat impact of draged gears. FAO Fisheries Technical Paper 506, 29.

Van Beek, F.A., Rijnsdorp, A.D., Van Leeuwen, P.I. (1983) Results of the mesh selection experiments on sole and plaice with commercial beam-trawl vessels in the North Sea in 1981. , International Council for the Exploration of the Sea. C.M. 1983/B : 16 .
Van Beek, F.A., Van Leeuwen, P.I., Rijnsdorp, A.D. (1990) On the survival of plaice and sole discards in the otter-trawl and beam-trawl fisheries in the North Sea. Netherlands Journal of Sea Research 26, 151-160.

van Marlen, B. (2003) Improving the selectivity of beam trawls in The Netherlands - The effect of large mesh top panels on the catch rates of sole, plaice, cod and whiting. Fisheries Research 63, 155-168.

van Marlen, B., Wiegerinck, J.A.M., van Os-Koomen, E., van Barneveld, E. (2014) Catch comparison of flatfish pulse trawls and a tickler chain beam trawl. Fisheries Research 151, 57-69.

van Putten, I.E., Kulmala, S., Thebaud, O., et al. (2012) Theories and behavioural drivers underlying fleet dynamics models. Fish and Fisheries 13, 216-235.

Walters, C.J. (2007) Is Adaptive Management Helping to Solve Fisheries Problems? Ambio 36, $304-$ 307.

Zimmermann, F., Heino, M., Steinshamn, S.I. (2011) Does size matter? A bioeconomic perspective on optimal harvesting when price is size-dependent. Canadian Journal of Fisheries and Aquatic Sciences 68, 1651-1659. 


\section{CHAPTER 2}

\section{MIXED FISHERIES MANAGEMENT: PROTECTING THE WEAKEST LINK}

Batsleer J., Poos J.J., Marchal P., Vermard Y. , Rijnsdorp A.D. 


\section{ABSTRACT}

North Sea cod (Gadus morhua) stock is outside safe biological limits and total allowable catch (TAC) management has proved ineffective to rebuild the stock. The European Commission is considering to impose a discard ban to preserve vulnerable and economically important fish stocks. We explore the potential effects of a discard ban in mixed fisheries management using the French mixed fisheries in the Eastern English Channel as a model system. We examine in particular the performance of two different management scenarios, (i) individual quota management with a tolerance for discarding and, (ii) individual quota management in combination with a discard ban, using a dynamic state variable model. The model evaluates a time series of decisions taken by fishers to maximize profits within management constraints. Compliance to management was tested by applying an in height varying fine for exceeding the quota. We then evaluate the consequences of individual cod quota in both scenarios, with respect to over-quota discarding, spatial and temporal effort allocation and switching between métiers. Individual quota management without a discard ban hardly influenced fishers' behaviour, as they could fully utilise cod quota and continue fishing other species while discarding cod. In contrast, a discard ban forced fishers to reallocate effort to areas and weeks where cod catch is low, at the expense of lower revenue. In general, a restrictive policy for individual quota for cod needs to be combined with a discard ban and a high fine ( $>20$ times the sale price) to reduce over-quota discarding.

\section{KEYWORDS:}

discard ban,

TAC,

Dynamic State Variable Modelling,

eastern English Channel,

cod (Gadus morhua),

mixed fisheries,

fleet dynamics. 


\section{INTRODUCTION}

Fishing is an important socio-economic activity providing food and employment (FAO 2008) but is criticized because of its adverse impact on exploited fish stocks and marine ecosystems. In this context, throwing overboard dead fish that have been caught in the net ("discarding") is often considered a wasteful practice that has adverse effects on fish stocks while not contributing to the harvesting of food (Alverson et al. 1994, Kelleher 2005I).

Discarding is mainly driven by economics and management. From an economic perspective, low valued fish of quota species are discarded (high-grading) in the expectation to catch more valued fish later (Gillis et al. 1995b), while regulation of mesh size and minimum landing size determine the discarding of undersized fish (Cappell 2001, Graham \& Fryer 2006). TAC regulations also create an incentive for fishers to discard the over-quota caught fish, especially in mixed fisheries (Daan, 1997, Reis et al., 2010), and they have often proved unable to control fishing mortality around sustainable levels (Ulrich et al. 2011).

Discard reduction is high on the agenda of EU fisheries managers, and the European Commission is implementing a discard ban. Under a discard ban, all catches of both target and by-catch species should be landed and will be deducted from the individual quotas. A discard ban in combination with individual, and possibly transferable, quota (ITQ) aims to prevent the waste of food, reduce fishing impacts on the ecosystem, preserve vulnerable and economically important fish stocks and improve scientific advice (Anonymous 2011, Buisman et al. 2011). Despite of the implementation of ITQ management with a discard ban in some countries, few studies have address the performance of this combination. However, results have shown that discarding, albeit at a significantly lower level, still occurs, but that the ban can aid to the recovery of exploited stocks (Kristofersson \& Rickertsen 2005, 2009, Diamond \& Beukers-Stewart 2011).

Given prevalent management regulations, fishers are expected to adjust their behaviour to maximise their utility (Gordon 1953, Hilborn \& Kennedy 1992). Hence, fishers may respond to management regulations by trading-off economic gain against the cost of non-compliance. Adaptive behaviour of fishers, e.g. reallocation of effort to other species, fishing grounds or seasons, is an important management concern (Salas \& Gaertner 2004, Poos et al. 2010). Further studies on adaptive behaviour of fishers may be useful to explore the scope for responses that undermine the effectiveness of a certain management system. A fisheries manager needs to trade-off socio-economic benefits of a fishery against protection of the weakest links in the ecosystem. Unveiling these trade-offs will support fisheries management.

The present study describes how a discard ban in combination with individual quota may improve the regulation of fishing mortality for a depleted stock that is exploited in a mixed fishery. Using a dynamic state variable model (DSVM; Clark \& Mangel 2000), we study the over-quota discarding of cod (Gadus morhua) in the eastern English Channel and the southern North Sea. Despite signs of recovery following the recovery plan imposed in 2003 the stock has remained the weakest component of the demersal fish assemblage (Ulrich et 
al. 2011, Kraak et al. 2012). We compared the performance of (1) quota management that allows over-quota discarding and (2) quota management in combination with a discard ban, using the French otter trawl and net fisheries as a case study. The consequences of individual quota for cod in both management regimes are studied based on a number of indicators of the fishery system such as the catch of cod, the spatial and temporal distribution of fishing effort, the changes in métiers and the economic performance of the fishery.

\section{METHODS}

\section{THE ENGLISH CHANNEL MIXED FISHERIES}

The English Channel is a corridor between the Atlantic and the North Sea. The eastern English Channel (ICES division VIId) is the narrowest part of the Channel and it is an important fishing area (Vaz et al. 2007). The French fishing fleets are most active in this area with a total of 641 vessels in 2005, landing over 90,000 t of fish with a total value of $€ 218$ million. Boulogne-Sur-Mer is the main French fishing harbour, both in number of vessels and total landings (Carpentier et al. 2009).

\section{DATA}

Effort and landings data from logbooks and sales slips were made available over the period 2001 - 2005. The data set included information by fishing trip on vessel length, vessel tonnage, engine power, gear type, mesh size, fishing ground (ICES rectangle, $1^{\circ}$ longitude $\times 0.5^{\circ}$ latitude, approximately $30 \times 30$ nautical miles), fishing effort (hours fished for trawlers, days absent from port for netters), and the weight and value of the landings per species. We se-

\section{Figure 2.1}

Map of the eastern English Channel (ICES division VIId) and southern North Sea (ICES division IVC), showing the ICES rectangles where both fleets may fish. The star indicates the location of the port of Boulogne-sur-Mer

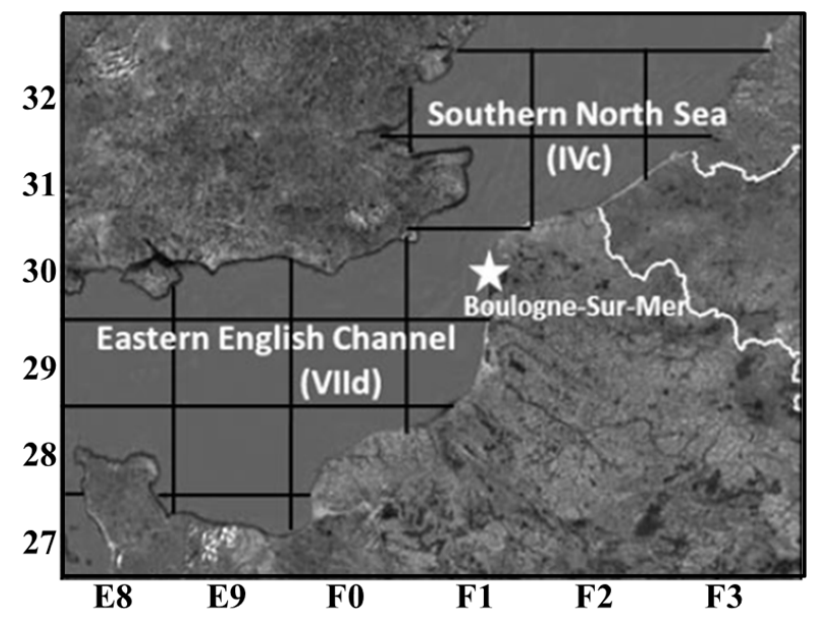


lected two fleets: the French otter trawl fleet and netting fleet. These fleets fish in the eastern English Channel and most southern part of the North Sea between $49^{\circ} \mathrm{N}, 2^{\circ} \mathrm{W}$ and $52^{\circ} \mathrm{N} 4^{\circ} \mathrm{E}$, for which most of the above-mentioned data available (Fig. 2.1).

\section{OTTER TRAWLERS}

The otter trawl fleet is one of the main demersal fishing fleets operating in the eastern English Channel. Vessels in this fleet are predominantly rigged with $80 \mathrm{~mm}$ mesh size nets (Carpentier et al. 2009). The dataset consists of 120 vessels with an average engine power of 440 $\mathrm{kW}$ and average vessel length of $21 \mathrm{~m}$.

The otter trawl fleet operates two separate métiers using: (1) demersal otter trawls (OTBD, 25591 trips) and, (2) mixed demersal/pelagic trawls (OTBM, 725 trips). Métiers are derived from the observed landings and largely based on DCF level 5 metiers (Ulrich et al. 2012). Both métiers land a mix of species, of which whiting, cod, plaice, sole, mackerel and mullet make up $65 \%$. Whiting and mackerel contribute to the bulk of landings of OTBD and OTBM, respectively (Table 2.1). Fishers are capable of switching métiers during the year. Both métiers are operated inside and outside the 12 nautical mile zone (Carpentier et al. 2009), with fishing grounds in ICES rectangles 30F1 and 29F0 being the most frequently visited.

Table 2.1 Proportion (\%) of 6 commercial species in the catch composition of both fishing fleets, separated by métiers. OTBD: demersal otter trawl; OTBM: mixed demersal/pelagic trawl; TN: trammel net; GN: gillnet.

\begin{tabular}{lcccc}
\hline & \multicolumn{2}{c}{ Otter trawl } & \multicolumn{2}{c}{ Static net } \\
\hline Sole (\%) & OTBD & OTBM & TN & GN \\
Plaice (\%) & 0.4 & 0 & 54.9 & 14.8 \\
Cod (\%) & 4.1 & 2.1 & 15.4 & 15.7 \\
Mackerel (\%) & 5.3 & 2.6 & 8 & 45.3 \\
Whiting (\%) & 15.6 & 44.9 & 0 & 0 \\
Mullet (\%) & 29.4 & 12.1 & 0.9 & 2.7 \\
Other (\%) & 6.8 & 4.0 & 0.1 & 0.1 \\
\hline
\end{tabular}

\section{STATIC NETTERS}

The netting fleet in the study area consists of 107 vessels, with an average engine power of $160 \mathrm{~kW}$ and average length of $12 \mathrm{~m}$. The most common gear is the trammel net (TN, 10449 trips), being used interchangeably with gillnets (GN, 632 trips) (Carpentier et al. 2009). Both nets are anchored to the bottom but differ in their structure and target species. TN have three sets of netting, of which the outer nets have a large mesh and the inner net has a small mesh size, whereas GN have only one net. This difference makes TN less selective in terms of size and variety of fish species caught (Carpentier et al. 2009). The most commonly used mesh size for both nets is $90 \mathrm{~mm}$, used mainly to catch sole; however, larger mesh sizes 
$(100 \mathrm{~mm}-180 \mathrm{~mm})$ may be used when plaice or cod are targeted. Although sole, plaice, and cod are the main target species and account for approximately $80 \%$ of the landings, sole is the main target species for TN, whereas cod is the primary target species for GN. Most netting activities occur close to the port of Boulogne-sur-Mer (ICES rectangles 30F1, 31F2). A few (2.7\%) observations in the data set consisted of multiple aggregated trips, and these were not included in the analysis.

\section{STATISTICAL ANALYSIS}

Our aim is to parameterize a simulation model by estimating the spatial and temporal distribution of landings per unit effort $\left(l_{i}\right)$ of six species: plaice (Pleuronectes platessa), sole (Solea solea), cod (Gadus morhua), whiting (Merlangius merlangus), Atlantic mackerel (Scomber scombrus) and mullet (Mullus spp.). Our dataset contains measurements of landings $\left(y_{i}\right)$ in weight $(\mathrm{kg})$ by species and fishing effort $\left(E_{i}\right)$ per trip $i$ :

$l_{i}=\frac{y_{i}}{E_{i}}$

We apply Generalized Additive Models (GAMs) to allow for non-linearity in the relationships between the response variable and multiple explanatory variables (Wood 2006, Zuur et al. 2009). The actual value of the landings per trip is used as the response variable while the fishing effort serves as offset. By analysing the six species separately, we ignore potential covariance structure among species. We use the negative binomial distribution with a logarithmic link function to correct for over-dispersion while allowing zero-observations. The logarithmic link ensures the fitted values are always non-negative (Zuur et al. 2009):

$y_{i} \sim$ Negative Binomial $\left(\mu_{i}, \theta\right)$

$\mu_{i}=l_{i} E_{i}=e^{\eta_{i}} E_{i}=e^{\eta_{i}+\log \left(E_{i}\right)}$

where, $\mu_{i}$ is the expected landings per trip and $\theta$ is the dispersion parameter, which accounts for under- or over-dispersion. $\log \left(E_{i}\right)$ is the known offset and $\eta_{i}$ is the linear predictor modelled as follows:

$\eta_{i}=$ métiers + year $+f($ engine power/fleet $)+f($ mesh size/fleet $)+f(D o Y)+$ $f($ lat,lon $)+f($ lat,lon, $D o Y)$

Métiers and year were entered as discrete variables (Table 2.2). The term $f$ (engine power/fleet) are for estimating the smooth function of engine power by tactic and $f$ (mesh size/fleet) for mesh size by tactic. The term fleet indicates the difference between trawlers and netters. $f(D o Y)$ and $f(l a t, I o n)$ indicate the main effects of day of the year (DoY) and space (latitude and longitude based on geographic midpoint of the ICES rectangle). $f$ (lat,lon,DoY) 
Table 2.2 Model components used to describe variation in landing rates. Variables métier and year are discrete variables and engine power, mesh size, latitude (lat) and longitude (long) (based on geographic midpoint of the ICES rectangle) and day of the year (DOY) are continuous variables. The term fleet represents a segregation of the fleet by trawlers or netters. The term $k$ denotes the maximum number of knots in each smoothing.

\begin{tabular}{llll}
\hline Nominator & Model component & Description & $\boldsymbol{k}$ \\
\hline$A$ & Métier & Effect of métier & - \\
$B$ & Year & Effect of year & - \\
$C$ & f(engine powerffleet $)$ & Effect of engine power by fleet & 4 \\
$D$ & $f($ Mesh size/fleet $)$ & Effect of mesh size by fleet & 4 \\
$E$ & $f($ DoY $)$ & Variability in time & 4 \\
$F$ & $f($ lat,lon) & Variability in space & 4 \\
$G$ & $f($ lat,lon,DoY) & Variability in catch rates in space and time & 5 \\
\hline
\end{tabular}

is the spline for the interaction term of latitude, longitude and DoY. The main effects and the interaction between latitude, longitude and DoY are included to model the seasonal changes in distribution. We limited the number of knots in each smoothing to reduce the possibility of over-fitting (Table 2.2). Because vessel length and engine power are highly correlated, we decided to only include engine power because of its presumed larger influence on the catch efficiency (Rijnsdorp et al. 2006). Mesh size was included as it may indicate the target species, i.e. the predominant $80 \mathrm{~mm}$ and $90 \mathrm{~mm}$ mesh sizes to target whiting and sole for otter trawls and TN respectively, while larger mesh sizes $(120 \mathrm{~mm}-180 \mathrm{~mm})$ are fitted when targeting cod. Finally, the variable year was used to capture differences in landings per unit of effort between the years.

Forward selection based on the Bayesian Information Criterion (BIC) is used to select a model for each species. Forward selection starts with an empty model, fitted with the intercept only. Then covariates are added sequentially based on the BIC in order to obtain the "best" model. The results of the best model were used to predict the spatial and temporal patterns in catch rates for each of the species and vessel-gear combinations to be used in the simulation model.

\section{SIMULATION MODEL}

Our model is based on Dynamic State Variable Modelling (DSVM) (Houston \& McNamara 1999, Clark \& Mangel 2000). The DSVM is an individual based model that has been used to predict behaviour of animals (Mangel 1987, Clark \& Butler 1999) as well as fishers (Gillis et al. 1995b, Poos et al. 2010, Dowling et al. 2011). We expanded the model of Poos et al. (2010) in which each individual vessel in the model has a set of choices, allowing it to respond to management regulations and economic opportunities. In the expanded model individuals choose simultaneously: (1) to go out to fish or to stay in port, (2) a métier, (3) a fishing ground and (4) to discard or land the catch.

A vessel evaluates its optimal annual strategy in terms of biweekly (i.e. every 2 weeks) behavioural choices, based on a utility function. We use the annual net revenue $(\varphi)$ as the utility that a fisher wants to optimize (Gordon 1953, Poos et al. 2010). 
$\varphi$ is defined as the total quantity landed of each species $\left(L_{s}\right)$ weighted by each species price $\left(p_{s}\right)$ minus the variable fishing costs and a fine for overshooting the quota:

$\varphi\left(L_{1-6}, E\right)=\sum_{s=1}^{6}\left(L_{s} p_{s}\right)-\left(E p_{e}+D\left(L_{s}\right)\right)$

-Variable fishing costs consist of total fuel cost; i.e. total effort $(E)$ (in days) times fuel costs per day $\left(€\right.$ day $\left.^{-1}\right)\left(p_{e}\right)$. The fine for overshooting the quota $\left(D\left(L_{s}\right)\right)$ is zero as long as landings are within quota, and increase linearly with over-quota landings. Given the utility function at the end of the year, the dynamic programming equation is used to calculate the optimal decision in each time step given the state of the individual. In our case, the state is determined by the proportion of the cod quota fished, landings of the five other species, and the fishing effort. All vessels within a fleet are equal at the beginning of the year. As a result of the variability in catch rates in the model, the vessels will differ in their state as time progresses. The details for this procedure can be found in Poos et al. 2010.

Compliance to management was tested by exploring the effect of different fine values. Fines $\left(€ \mathrm{~kg}^{-1}\right)$ increased from one to twenty times the cod price per $\mathrm{kg}$. These fines are equivalent to those imposed for catching abalones illegally, i.e. 10-fold the landing price (Bose \& Crees-Morris 2009).

For each time step, a vessel chooses a métier and one fishing ground (out of 20) based on the optimal choice given the vessel's state. Each combination of métier and fishing ground within a time step is characterized by a mean $(\mu)$ and variance $(\theta)$ of the catch rates for each species estimated by the GAM. Catch rates were calculated from the GAM results by setting the offset equal to the average fishing effort for trawlers or netters within two-week periods. The catch rates are assumed independent of previous fishing activities in that area. We arbitrarily chose 2005 as a basis of our simulations. Further parameterisation of the model in terms of variable costs was done assuming Boulogne-sur-Mer was the home harbour of the vessels.

The combination of métier and fishing ground determines the amount of effort required for the fishing operation. Fishing effort consists of the summed actual fishing time and travel time required to reach the fishing ground. The average fishing time was estimated from the 2001 data at 3.1 days for a trawler and 3 days for a netter. Travel time depends on the distance from port and was calculated from the distance in nautical miles in a straight line from the harbour of Boulogne-sur-Mer to each fishing ground. Assuming a steaming speed of $10 \mathrm{n}$ miles $\mathrm{h}^{-1}$ for an otter trawl and $6 \mathrm{n}$ miles $\mathrm{h}^{-1}$ for a netter (Messina \& Notti 2007) and taking account of the number of trips observed per time step (2-week period), we calculated the travel time needed to reach a fishing ground. If a fisher decides to stay in the harbour, nothing is caught and no effort is used.

The costs associated with using fishing effort depend on the fuel use in the model. Fuel costs per day are estimated to be $€ 1800$ for trawlers and $€ 1300$ for netters and are equivalent to approximately $35 \%$ of the gross revenue (Taal et al. 2009). The final element for the parameterization is the market value of the target species. We chose to use fixed market 
values for each species, determined by the average price per $\mathrm{kg}$ within our dataset. Table 2.3 provides detailed information on the parameters and their values used in the model.

Table 2.3 Summary of parameter values included in the model.

\begin{tabular}{lcc}
\hline & Trawl & Net \\
\hline Engine power $(\mathrm{kW})$ & 440 & 160 \\
Mesh Size $(\mathrm{mm})$ & 80 & 90 \\
Fuel costs per day $(€)$ & 1800 & 1300 \\
Fishing effort (hours) & 75 & 72 \\
\hline Market value (€ per kg) & & 9.42 \\
Sole & & 2.43 \\
Cod & & 1.99 \\
Plaice & & 1.40 \\
Whiting & & 0.99 \\
Mackerel & & 5.40 \\
Mullet & & \\
\hline
\end{tabular}

\section{MANAGEMENT SCENARIOS}

This study compares the performance of individual cod quota (IQ) management combined with two discard scenarios for both fisheries: (1) over-quota discarding is allowed; (2) overquota discarding is not allowed (discard ban) (Table 2.4). IQ gradually increase from 0 to $27 \mathrm{t}$ $\mathrm{yr}^{-1}$ for trawlers and 0 to $20 \mathrm{t} \mathrm{yr}^{-1}$ for netters. In addition, different fine values are used to test the compliance of trawlers to the imposed discard ban.

Table 2.4 Description of scenarios. IQ: individual cod quota.

\begin{tabular}{llcc}
\hline Scenario & Fleet & Individual cod quota $\left(\mathbf{t} \mathbf{~}^{-1}\right)$ & Fine $\left(\boldsymbol{(} \mathbf{k g}^{-1}\right)$ \\
\hline Discard ban & Trawlers & $0-27$ & $2.43-200$ \\
& Netters & $0-20$ & 0 \\
\hline Discards allowed & Trawlers & $0-27$ & \\
& Netters & $0-20$ & \\
\hline
\end{tabular}

\section{RESULTS}

\section{STATISTICAL ANALYSES}

All 6 GAM models exhibit similarities in selecting covariates, based on BIC results, that best explain the variation in landings (Table 2.5). The model for whiting, besides having the lowest $(28.3 \%)$ explained deviance, diverges from the other models because the DoY as a main effect did not improve the model. 
Table 2.5 Model selection results for the 6 species, based on the Bayesian information criterion (BIC). Numbers indicate the difference between the previous obtained BIC associated with the previous variable and the newly acquired BIC of the newly selected variable. If negative, the variable is excluded from the best model. For the model descriptions, the offset has been omitted. The estimated theta $(\theta)$ is also given. The letters are referenced by the letters used for the variables in Table 2.2

\begin{tabular}{|c|c|c|c|c|c|c|c|c|c|}
\hline Species & model structure & $\mathrm{BIC1}$ & BIC2 & BIC3 & BIC4 & BIC5 & BIC6 & $\mathrm{BIC7}$ & Theta $(\theta)$ \\
\hline Cod & intercept $+\mathrm{D}+\mathrm{G}+\mathrm{B}+\mathrm{C}+\mathrm{A}+\mathrm{E}+\mathrm{F}$ & 7095.8 & 2845.9 & 1554.5 & 1636.7 & 663.0 & 121.3 & -1.5 & 0.185 \\
\hline Plaice & intercept $+C+A+G+B+D+E+F$ & 18002.6 & 3205.2 & 3119.3 & 932.6 & 324.3 & 290.4 & -1.4 & 0.393 \\
\hline Sole & intercept $+A+C+G+B+D+E+F$ & 22990.1 & 12189.5 & 886.6 & 444.4 & 258 & 118.7 & -4.6 & 0.193 \\
\hline Whiting & intercept $+C+G+A+D+B+F+E$ & 5302.3 & 6073.5 & 1044.2 & 299.3 & 40.5 & 0.2 & -8.7 & 0.252 \\
\hline Mackerel & intercept $+\mathrm{A}+\mathrm{G}+\mathrm{C}+\mathrm{B}+\mathrm{D}+\mathrm{E}+\mathrm{F}$ & 15575.5 & 3143.5 & 2272.3 & 402 & 279.9 & 10.5 & -1.7 & 0.234 \\
\hline Mullet & intercept $+C+G+E+B+A+D+F$ & 5415.7 & 4104.7 & 2293.9 & 1580.1 & 360.7 & 170.1 & -1.2 & 0.231 \\
\hline
\end{tabular}

Within the cod model, mesh size was added as first variable, which confirms our expectations that larger mesh sizes are preferred when fishing for cod. A remarkable result for cod is that landings are significantly $(p<0.001)$ lower in the years 2004 and 2005. Lower landings are likely related to the low abundances and weak recruitments of cod during that period (ICES 2010). For plaice, whiting and mullet, the variable engine power was selected and added as first variable in explaining the landings. The first variable selected for mackerel and sole was the métiers. This result confirms our chosen métiers classifications, whereby mackerel was mainly targeted by mixed demersal/pelagic trawls while sole was the main target species for trammel netters. In addition, for sole the variable engine power was selected as the second variable confirming vessels with low engine power (i.e. netters) target sole. The simulation model results based on the GAM predictions are presented below.

\section{COD CATCH}

Cod catches depend on the fishing fleet and management scenario (Fig. 2.2). For trawlers, IQ lower than $10 \mathrm{t} \mathrm{yr}^{-1}$ result in full utilization of quota by almost all vessels, while over-quota catches are being discarded. Hence, holding cod catches at a high level (ca. $10 \mathrm{t} \mathrm{yr}^{-1}$ ). Increasing IQ above $10 \mathrm{t}$ results in trawlers progressively being unable to use all their quota: all cod catches (ca. $12 \mathrm{t} \mathrm{yr}^{-1}$ ) are landed and none are discarded. The variability in cod catches in the model causes some fishers to be more or less successful catching cod than others. Successful fishers will fully exploit their quota and discard their over-quota catch, while less successful fishers will land all their cod catches and will not use all quota. When a discard ban is introduced (in combination with a high fine $\left(200 € \mathrm{~kg}^{-1}\right)$, IQ may reduce catches considerably. At IQ below $4 \mathrm{t} \mathrm{yr}^{-1}$, the cod catch is $<1 \mathrm{t} \mathrm{yr}^{-1}$. Increasing IQ results in an increase in landings, but vessels rarely utilize their quota completely. As for the first scenario, catches level off towards ca. $12 \mathrm{t} \mathrm{yr}^{-1}$.

There are two main periods, during which cod is caught by trawlers (Fig. 23 ). The first period is around the end and beginning of the year, while the second period occurs halfway during the year. Fishers constrained by a discard ban switch to other fishing grounds during these periods, resulting in lower annual cod catches. 


\section{Figure 2.2}

Modelled average annual cod catches (i.e. landings plus discards) per vessel for both trawlers and netters in relation to the available individual cod quota (dashed line). Upper panels (a) and (b) are for trawlers; lower panels (c) and (d) for netters. In the left panels (a) and (c) discarding is allowed, while in the right panels (b) and (d) discarding is banned. Average annual landings (black line) with confidence area (dark grey shaded area) are separated from average annual cod catches (light grey line) with confidence area (light grey shaded area), depicting the amount of cod discards.

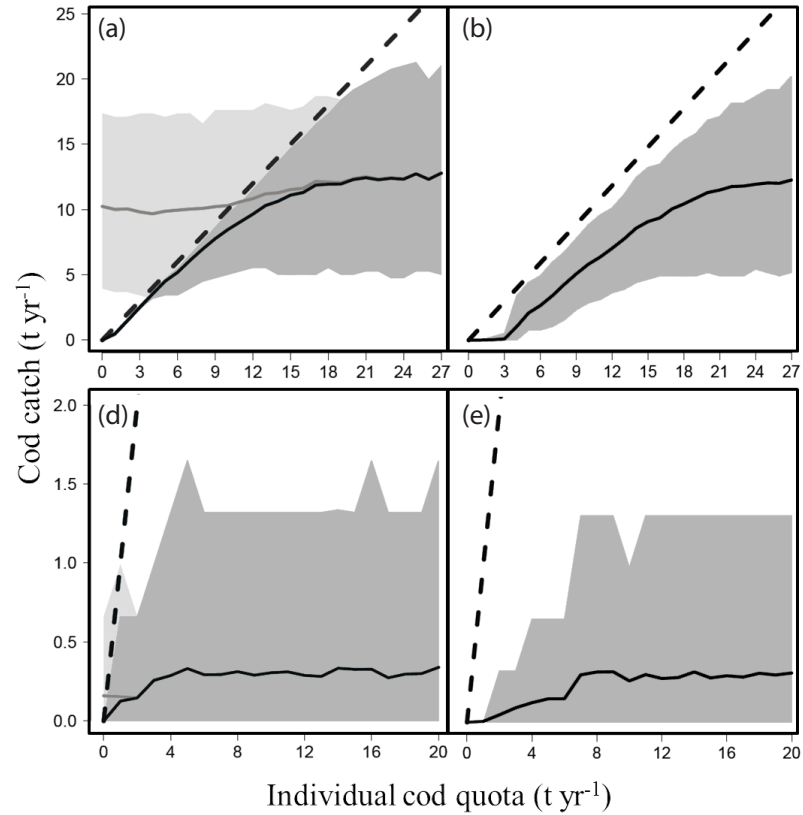

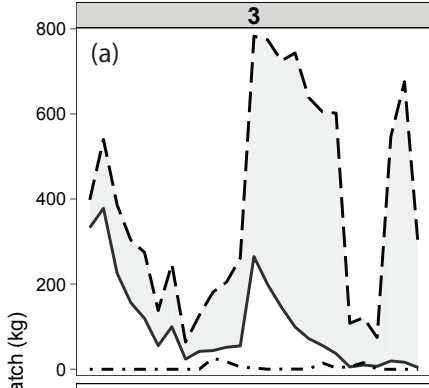

(d)

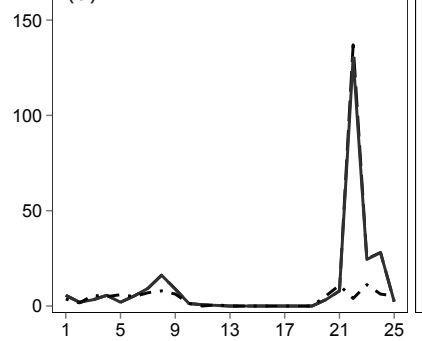

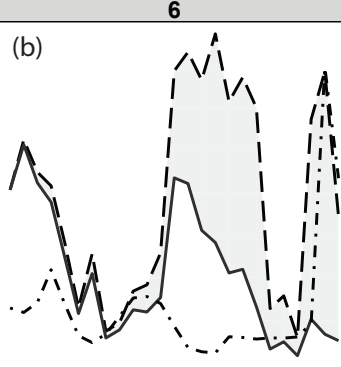

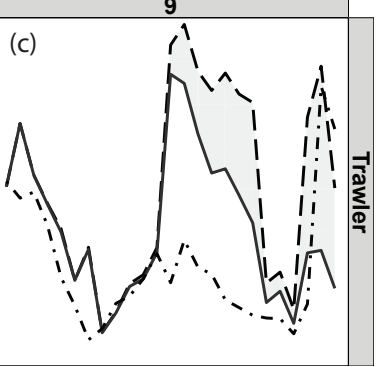

(e)

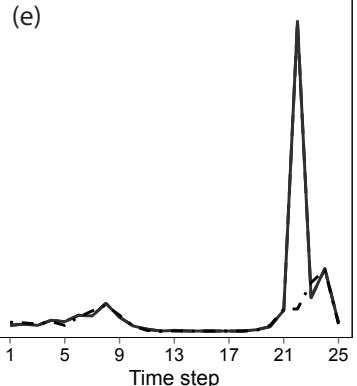

(f)

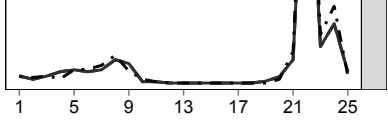

Figure 2.3

Modelled temporal variation in cod catches for both management scenarios at individual quota of 3, 6 and $9 \mathrm{tyr}^{-1}$, including a fine equal to $€ 200 \mathrm{~kg}^{-1}$. The average cod catch of an individual $(a-c)$ trawler or $(d-f)$ netter per time-step (2 wk period) is illustrated. The shaded area quantifies cod discards, being the difference between cod catches (dashed black line) and cod landings (black line), when discarding is allowed. The dot-dashed line indicates cod catches when a discard ban is imposed. 
Despite much lower cod catches $\left(<2 \mathrm{t} \mathrm{yr}^{-1}\right)$ for netters (Fig. $2.2 \mathrm{c} \& \mathrm{~d}$ ), similar results are observed as for trawlers. While the netting fleet shows more spatial overlap under both management scenarios, deviations of the choice of fishing grounds occur during periods when cod is more frequently caught (Fig. $2.3 \mathrm{~d}$-f). So, netters also switch fishing grounds to avoid catching cod.

When IQ for cod are reasonably high $\left(\sim 9 \mathrm{t} \mathrm{yr}^{-1}\right)$, trawlers only become limited in landing cod at the end of the year, and only discard when quota are almost fully exploited. When less quota is available, the amount of cod being discarded increases and fishers discard earlier in the year as well. When quota are low $\left(\sim 3 \mathrm{t} \mathrm{yr}^{-1}\right)$ cod is discarded throughout the year, with the highest amounts of discards occurring during both periods when cod is mainly caught. Netters barely discard cod due to their low catches. However, if cod is discarded, it occurs at the end of the year during the period when cod catches are higher. These results show that fishers are able to regulate their landings by switching fishing ground, switching métier and discard their over-quota catch. When discarding is banned, fishers can only regulate their landings by switching fishing grounds and targeting other species.

\section{EFFORT}

If discarding is allowed, annual allocation of fishing effort of a trawler is independent of the cod quota (Fig. 2.4). The total days at sea (DAS) increase marginally from an average of 108 days to 110 days when more quota becomes available. Effort is mainly allocated near the English coast (30E9) and in the southern North Sea (30F1 and 32F1) (Fig. 2.5). Imposing a discard

\section{Figure 2.4}

Modelled average annual effort per vessel for both fleets and both management scenarios for $(a, b)$ trawlers and $(c, d)$ for netters. (a, c) Discarding is allowed, $(b, d)$ discarding is banned. The area between the upper (95\%) and lower (5\%) confidence intervals is shaded. DAS: days at sea

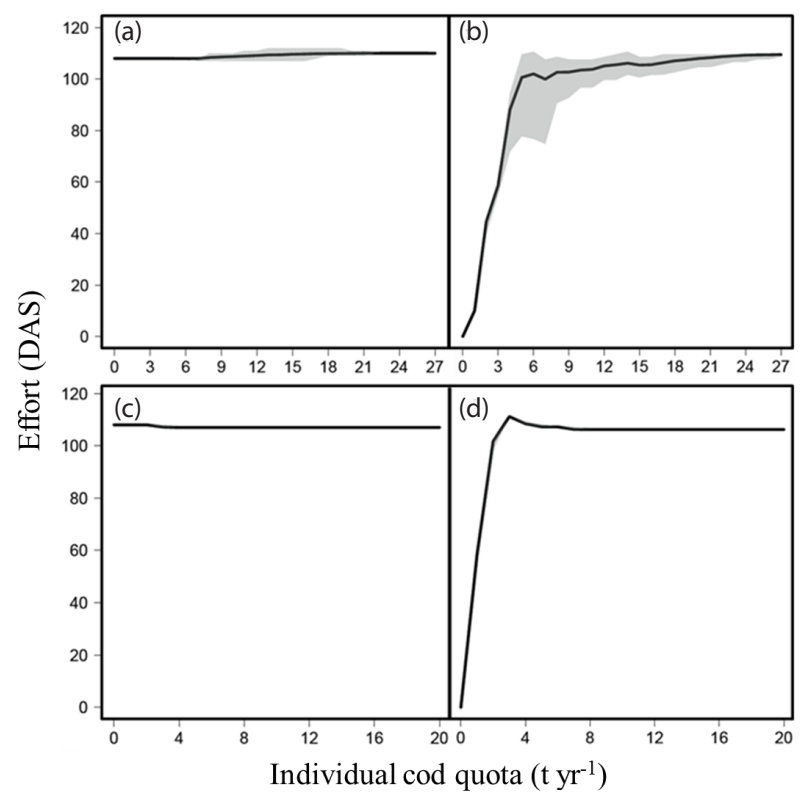



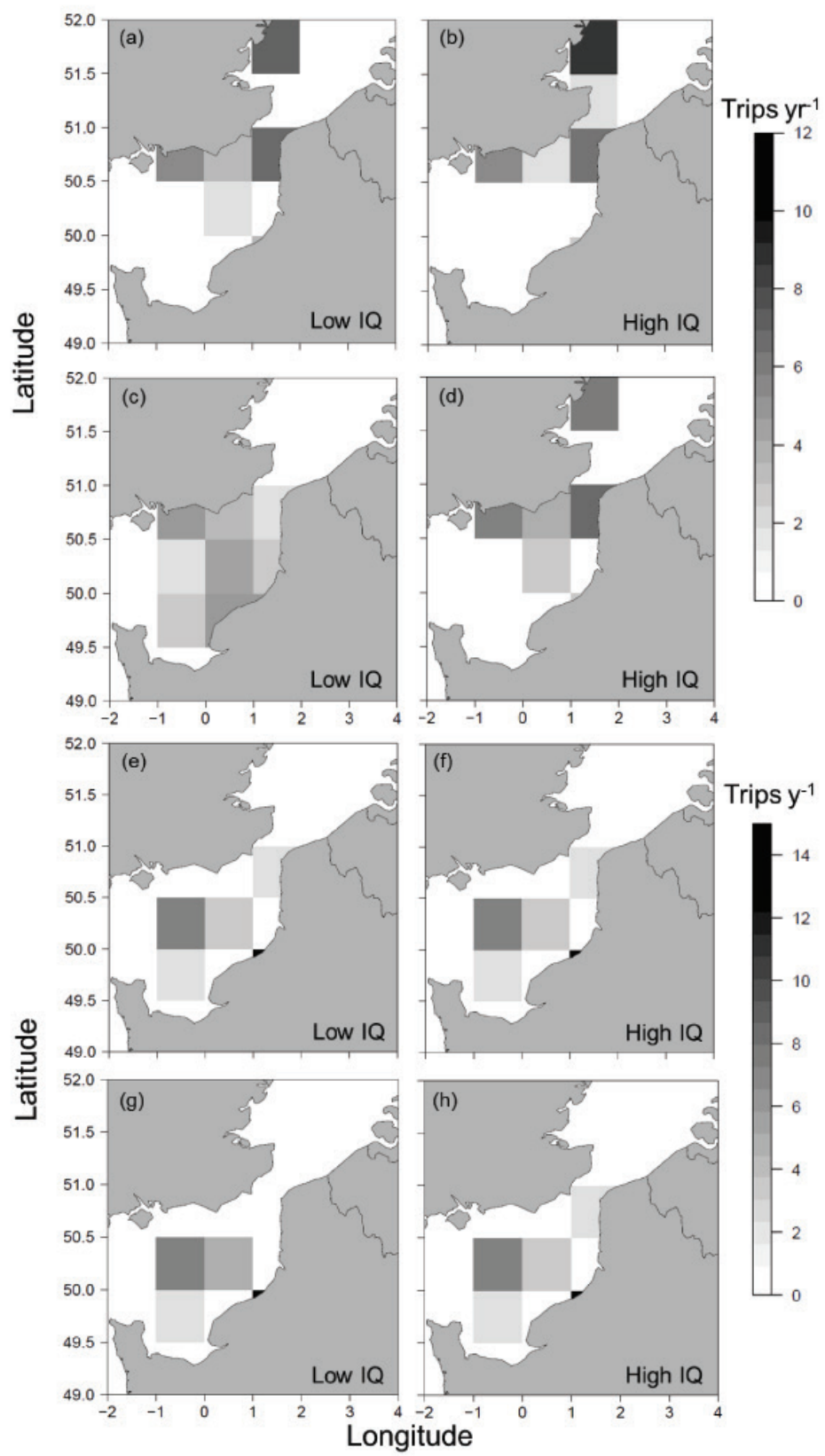

Figure 2.5

Modelled spatial allocation of effort by average number of trips per year for $(a-d)$ trawlers and (e-h) netters at low (5 $(a, b)$ (trawlers) and $(e, f)$ (netters) are based on the first ma$\left.t y r^{-1}\right)$ and high (15 tyr $\left.r^{-1}\right)$ individual cod quotas (IQ). Panels nagement scenario (discarding), while $(c, d)$ and $(g, h)$ are based on scenarios with a discard ban. 
ban in combination with low IQ has a clear impact on effort and setting IQ to 0 results in a complete stop of fishing. At quota below $6 \mathrm{t} \mathrm{yr}^{-1}$, there is a steep increase of effort with increasing quota. As more quota become available the increase in effort slows down and stabilizes towards an average effort of 110 DAS. Introducing a discard ban causes a spatial shift in the distribution of fishing. At low IQ levels, trawlers make fewer trips (21 trips) and effort is concentrated in more southern and distant fishing grounds such as 28F0, 28F1, 30E9 and 29F0. At a higher IQ level, the spatial distribution resembles that found when discarding is allowed.

In the absence of a discard ban, netters spend 108 DAS, regardless of the quota. As for trawlers, cod quota management on its own has no influence on the spatial distribution of netters that predominantly fish in the eastern English Channel (56\% in 28F1). With a discard ban, effort is only influenced at low $\left(<8 \mathrm{t} \mathrm{yr}^{-1}\right)$ quota. Fishing stops when IQ is zero, but rapidly increases up to 111 DAS when IQ is less than $3 \mathrm{t} \mathrm{yr}^{-1}$. Yet effort gradually decreases again and remains fixed at an average annual effort of 107 DAS. The peak at low quota may reflect a reallocation of effort away from the southern North Sea (30F1) to more distant fishing grounds into the eastern English Channel (29E9). At higher IQ levels, spatial distribution of fishing effort is equal to the distribution when discarding is allowed.

The shift in spatial distribution of fishing effort from the southern North Sea to the eastern English Channel is related to the spatial distribution of cod. Cod is more frequently caught in the southern North Sea fishing grounds compared to the Channel. When cod quota is high a fisher can continue to fish in the northern fishing grounds until the cod quota becomes depleted. Implementing low cod quota and a discard ban, however, makes Channel fishing grounds more attractive, because of a reduced risk of catching cod, while targeting other commercial fish species.

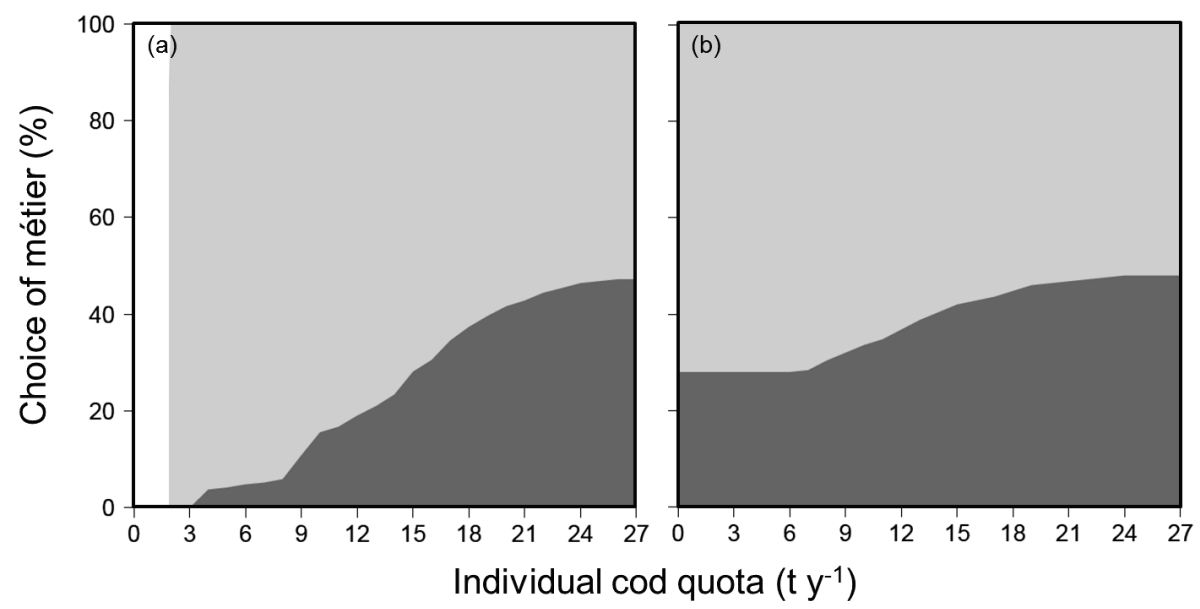

Figure 2.6

The proportion of effort allotted to each métier operated by trawlers, (a) when discarding is banned and (b) when discarding is allowed. (light grey: mixed demersal/pelagic trawl, dark grey: demersal otter trawl) 
Besides spatial effort allocation to reduce cod catches, trawlers change their preference for a métier in response to IQ (Fig. 2.6). When constrained by a discard ban and IQ below $4 \mathrm{t} \mathrm{yr}^{-1}$, there is no fishing at all or trips are done only choosing OTBM. As IQ increases, fishers increasingly choose for OTBD ( $0 \%$ to $47 \%$ ). An IQ of $27 \mathrm{t} \mathrm{yr}^{-1}$ results in similar operation levels as observed for the scenario when discarding is allowed. Also in this scenario, less quota, reduces ( $48 \%$ to $28 \%$ ) the choice to operate the OTBD métier. Netters choose, regardless of the management scenario, to fish using a trammel net throughout the year.

\section{CATCH COMPOSITION}

For trawlers constrained by a discard ban and low individual cod quota, mackerel is the most dominant $(>90 \%)$ species in the catch supplemented with mullet (ca. $8 \%)$ and plaice $(1 \%)$ (Fig. 2.7). With increasing $I Q$, whiting catches gradually increase (0\%-53\%), while the propor-

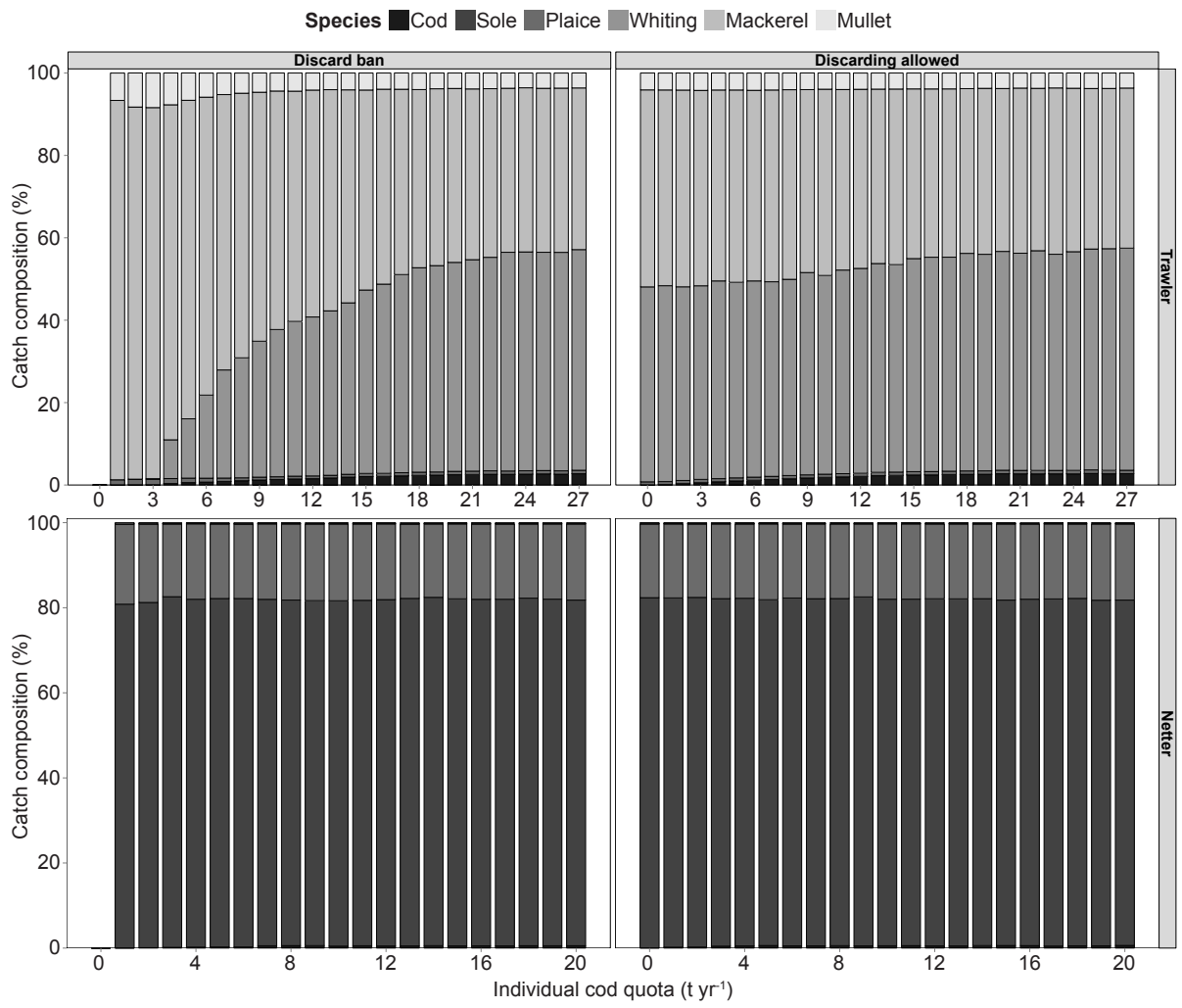

Figure 2.7

Proportion of each of the 6 species contributing to the total catch for trawlers and netters. Modelled catch compositions for both management scenario's. 
tion of mackerel in the catch decreases (> $90 \%$ to $40 \%$ ). Other species such as mullet (4\%), $\operatorname{cod}(3 \%)$ and plaice $(<1 \%)$ contribute marginally to the catches.

Allowing discards eliminates the effect of low IQ on the catch composition. For trawlers, whiting and mackerel are the main contributors whether a low or high cod quota is implemented. Yet, less quota ensures a slight decrease in whiting and a small increase in the proportion of mackerel.

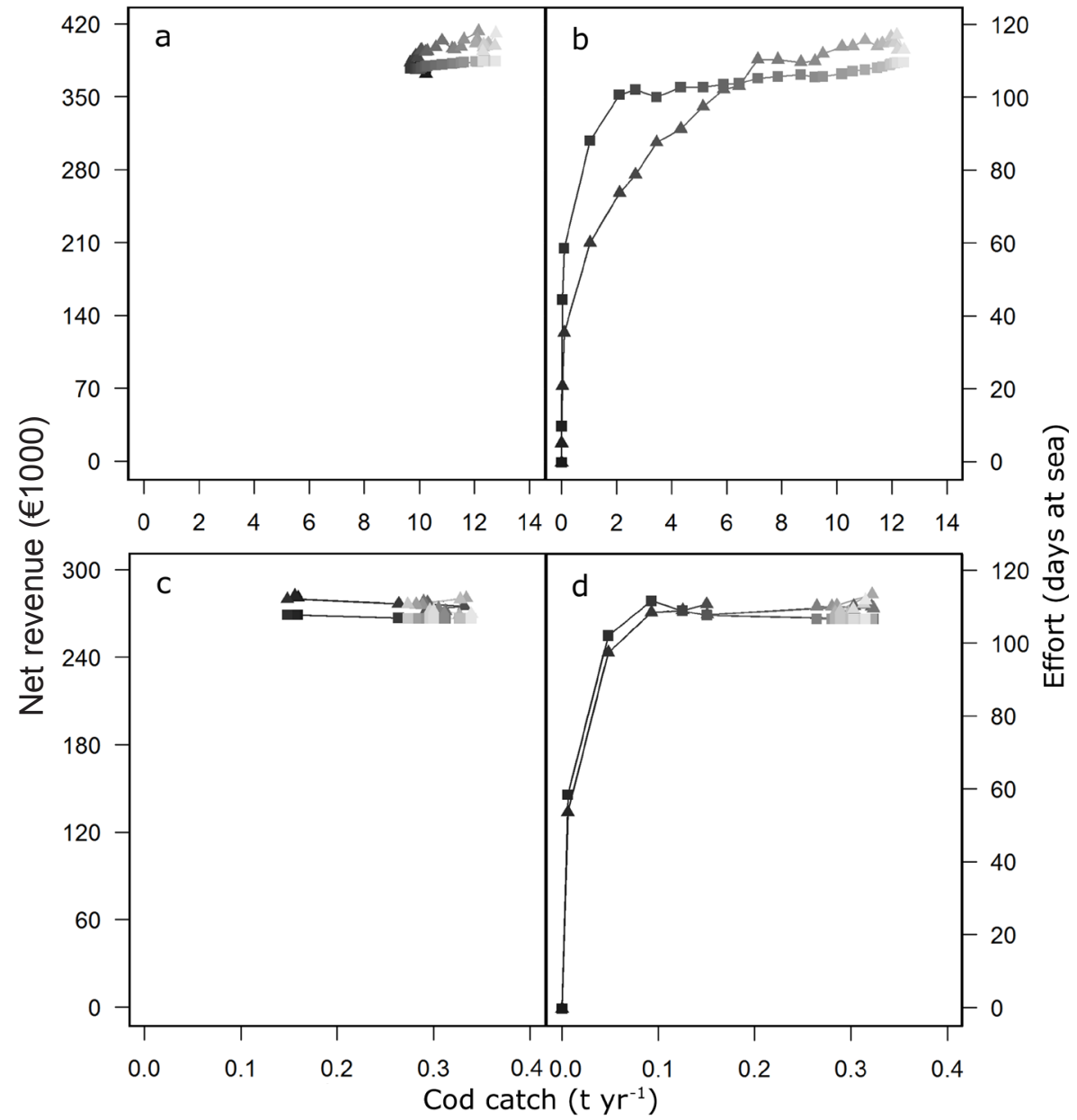

Figure 2.8

Trade-offs between $(\mathbf{\Delta})$ net revenue, (- $)$ effort and cod catches $\left(t y^{\prime}\right)$ for $(a, b)$ trawlers and $(c, d)$ netters. $(a, c)$ Dis- 
Netters mainly catch sole $(>80 \%)$ and plaice $(\sim 18 \%)$, while cod is caught in small quantities and contributes less than $1 \%$ to the entire catch. Hence, introducing a discard ban on top of individual cod quota has little impact on the catch composition of netters.

\section{TRADE-OFFS}

In the present study, 2 indicators of fishery success,, i.e. effort and net revenue, were weighed against cod catch (Fig. 2.8). Reducing IQ while allowing cod discards upholds effort, net revenue and cod catches for both fleets (Fig. $2.8 \mathrm{a}$ and c). The slight decrease in net revenue (from ca. $420.000 €$ to ca. $373.000 €$ ) for trawlers can be related to reduced cod landings.

In contrast, imposing a discard ban clearly affects both indicators and cod catch (Fig. $2.8 \mathrm{~b}$ and d). When IQ is below $1 \mathrm{t} \mathrm{yr}^{-1}$, fishers stay in port and do not generate revenue. Setting a low IQ ensures that fishers avoid cod catches by targeting other commercial species with lower market value (e.g. mackerel) in more distant fishing grounds. Consequently, a trawler generates less revenue (ca. 73.000€) in proportion to the amount of fishing effort (ca. $44 \mathrm{DAS}$ at an IQ of $2 \mathrm{t} \mathrm{yr}^{-1}$ ). At an IQ of $4 \mathrm{t} \mathrm{yr}^{-1}$, trawlers allocate some fishing effort to cod fishing grounds, increasing the catch of cod to $1 \mathrm{t} \mathrm{yr}^{-1}$. Effort doubles (88DAS), while net revenue almost triples (211.000€). As more quota is made available, effort increases and levels off at $\sim 110$ DAS. This increase in effort leads to an increased cod catch, because gradually more cod fishing grounds are fished. In addition, landings of commercially valuable and co-occurring species such as whiting increase likewise and contribute substantially to the revenue. Hence, while effort levels off, net revenue continues to increase until the point where IQ are no longer constraining i.e. $18 \mathrm{t} \mathrm{yr}^{-1}$.

Trade-offs as seen with trawlers are less frequently observed for netters. Increasing IQ to $1 \mathrm{t} \mathrm{yr}^{-1}$, fishing (58 DAS) resumes, generating revenue (ca. 135.000€) by fishing for sole and plaice while cod catches remain substantially low $(<6 \mathrm{~kg})$. With higher IQ, effort and net revenue level off to 107 DAS and ca. $270.000 €$, respectively. Revenue is maintained regardless of the IQ level, indicating that netters are to an extent economically independent of cod catches when avoiding the use of a GN. Netters mainly generated revenue by fishing for sole and plaice, while whiting and cod are by-catch species.

In general, permitting cod discarding, fishers will uphold effort and maintain their net revenue at the expense of cod conservation. In contrast, with a discard ban, fishers avoid cod but maintain a reduced fishing effort targeting lower valued species, such as mackerel, to compensate the loss in revenue.

\section{OVER-QUOTA FINE}

The results above assumed that the discard ban was fully enforced, corresponding to a very high fine. The response of the fishers in terms of over-quota discarding of cod for a range of different fines is shown in figure 2.9. With a low fine equal to the market value of cod (2.43€ per

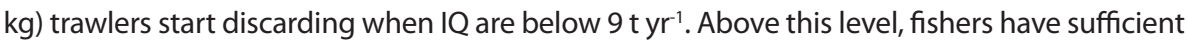




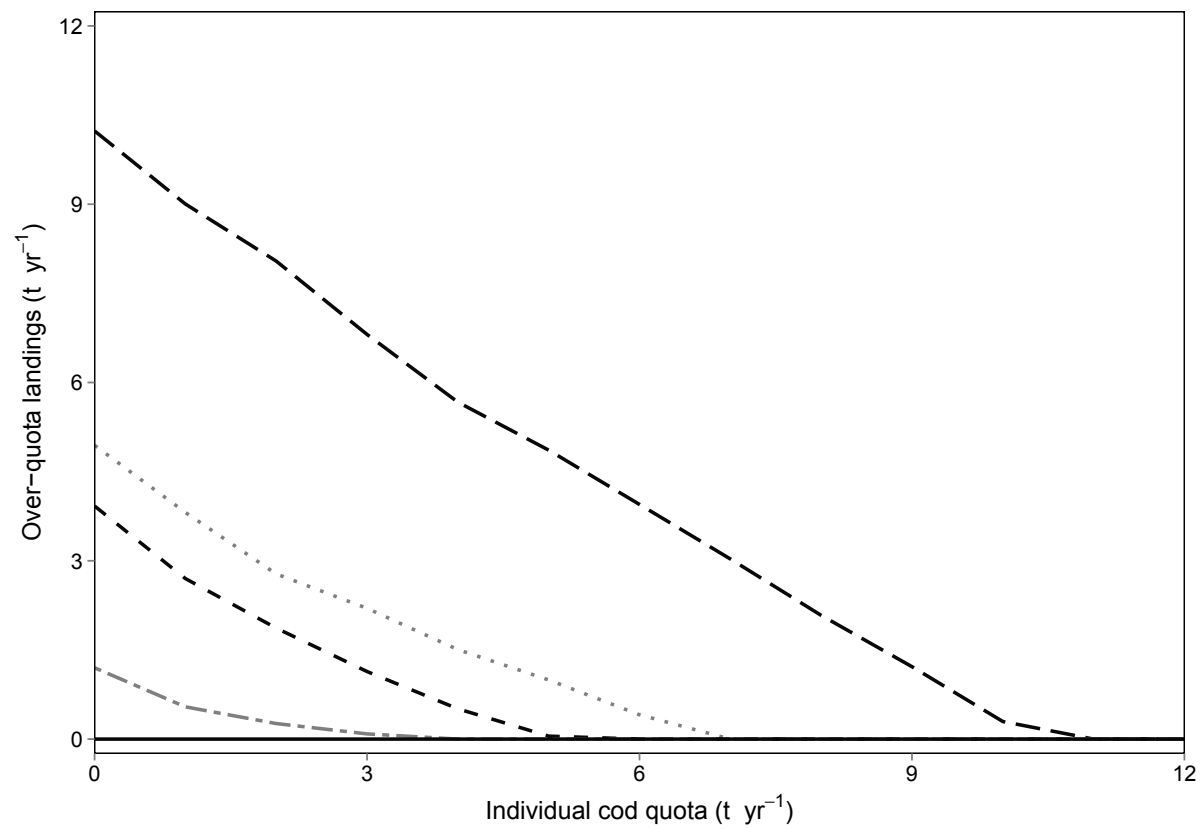

Figure 2.9

Average over-quota cod catches in relation to fine levels. The thick dashed line represents a free-fishing situation (fine $=0$ ). The thin lines represent different levels of fines imposed, ranging from 5-fold the market value of cod ( $€$

$\left.12.5 \mathrm{~kg}^{-1}\right)$ up to 20 -fold the market value $\left(€ 48.6 \mathrm{~kg}^{-1}\right)$. The solid black line with no over-quota catches represents a situation with an extremely high fine $(€ 200 \mathrm{~kg}-1)$ for overshooting the quotas

quota available to uphold their revenue and switch to other target species when their quota is fully exploited. Increasing the fine shifts the threshold, IQ below which fishers start discarding the over-quota catch, towards a lower level. In our model, the fine needs to be sufficiently high, e.g. 20-fold the price of cod, to reduce discarding of over-quota cod below $6 \mathrm{t} \mathrm{yr}^{-1}$.

\section{DISCUSSION}

This study explored the effects of a discard ban in combination with individual quota in mixed fisheries. Under a management regime that allows over-quota discarding, quota for by-catch species such as cod may have little effect on the effort allocation, and catch composition of fishing fleets. Fish that is caught without quota provision are discarded. IQ management with a discard ban can reduce over-quota discarding of cod when properly enforced. In that case, fishers will reallocate effort to fishing grounds and weeks when the cod catch is low at the expense of lower revenue. 
The methods and results of this study will be generally applicable for mixed fisheries systems because the main results will not be affected by a number of simplifying assumptions necessary in our modelling approach, but the results cannot be directly applied in the management of the Channel fisheries. First, we assume that catching fish in an area has no effect on the amount of fish available in that area later in the year. Second, only variable costs related to fuel use were incorporated. In addition, these fuel costs were set at $\sim 35 \%$ of gross revenue, whereas operating costs of gill-netters and beam trawlers are estimated to be $20 \%$ and $50 \%$, respectively (Marchal et al. 2011). If costs are higher fishers may spend less time at sea or fish closer to port (Poos et al. 2010). Hence, differences in fuel costs may influence the catch composition and discard rate. Third, revenue was determined by the modelled six species, although other commercially valuable species including squid, sea bass and herring also contribute to the revenue. Fourth, the quota system imposed on the French eastern Channel fisheries is more complicated than the system of individual quota explored with our model. In France, yearly quotas are allotted to public organisations and are either distributed to members (individual quota), or are available for all fishers, in which case it is competitive (generating a race for fish). Both mechanisms occur, and we lack precise quantitative information on how much each one occurs and for which species. In that sense, we also assume that only cod quota affect behaviour, while in reality also other species are managed by quota. Fifth, we considered the study area as a single management unit, although it belongs to two different management units (subdivisions IVC and VIId). Since 2009 the eastern English Channel (subdivision VIId) was allocated a separate cod TAC (i.e. $1600 \mathrm{t}$ in 2011) from the North Sea (subdivision IV) cod TAC (i.e. 26800 t) (ICES 2011) and the French fleet receives a larger proportion of cod TAC (ca. 84\%) in VIId, compared to that in IV (ca. 4\%). Finally, we did not account for physical (e.g. depth, substrate) and natural (e.g. weather, wave height) elements of the environment making certain areas inaccessible to certain fleets or métiers. Due to these assumptions results may not fully correspond to the observed data. If we want to adjust the model to make it operational for practical use then the management questions should be specified first, because they will dictate the amount of detail required in the model. As indicated above, better understanding of the economic costs and returns and a more detailed implementation of the management regulations are likely candidates for addressing specific management questions.

Our model showed that, when forced by a fine, fishers have to some extent the ability to avoid over-quota discarding by reallocating their effort in space and time. Empirical support for this response comes from Branch \& Hilborn (2008) and Branch (2009), who showed that when TACs were increased for some species and reduced for others, fishers were able to adjust the species mixture in their catches by reallocating their fishing effort. In the eastern Channel, landings of non-regulated species such as striped red mullet (Mullus surmuletus), sea bass (Dicentrarchus labrax) and squid (Loligo spp.) have increased following the decline of cod landings and may reflect a response of fishers to the change in resource composition (Carpentier et al. 2009). 
An important consideration when exploring management regulations is the compliance of fishers to regulations. Results show that compliance of the fishery to restrictive quota is influenced by the fine for overshooting the IQ. The fine as currently imposed in our model does not explicitly penalizes discarding, but applies to overshooting the specified maximum landing quotas. We hypothesise that the fine for discarding should be equal to the fine for over-quota landings minus the fish price to have similar effects in the observed patterns. This hypothesis results from the observation that the difference between discarding and over-quota-landing is the price of the over-quota fish. Our results indicate that fines, in order to be efficient, should be much higher than fish price. Imposing a high fine would be a contributing factor to deter fishers from rule-breaking behaviour (Bose \& Crees-Morris 2009, Jagers et al. 2012). In our model, we assume a $100 \%$ detection rate, while realistically, rule-breaking behaviour of fishers may not necessarily be detected. This implies even higher fines should be considered to obtain full fisheries compliance. Yet, assessing the risk of being detected is beyond the scope of the present study.

Catches in this study are estimated on the basis of landings per unit effort of French commercial vessels. High resolution estimates of spatial and temporal distribution from independent sources like scientific research surveys are lacking for this area. The drawback of using commercial landing data of stocks which are managed with TAC remains the lack of information on high-grading, over-quota discarding and misreported catches (Rijnsdorp et al. 2007). Due to this missing information estimated catches may suffer a degree of bias, especially for species with a restrictive TAC such as cod (Ulrich et al. 2011).

In the present study, we have focussed only on one component of the discard problem, the over-quota discarding. Fishers may also be forced to discard catches below the minimum landing size (MLS) or discard non-commercial species. These discards are particularly high in mixed fisheries that target multiple species with different selectivity characteristics relative to the minimum landing size, such as in the roundfish, flatfish and Norway lobster fisheries (Rijnsdorp \& Millner 1996, Cappell 2001, Catchpole et al. 2005). By ignoring these other discards, we will underestimate the overall level of discarding in these fisheries (Gillis et al. 1995a, Poos et al. 2010, Depestele et al. 2011).

The DSVM approach could also be applied to the problem of high-grading as well as discarding undersized and non-commercial fish. In the present study, each species was modelled as a homogeneous group of marketable fish, but key descriptors such as abundance, catch and market price could be classified into different size classes in the future. Also, by including price dynamics into a stochastic dynamic programming model the behavioural response of fishers towards market value fluctuations may be studied (Dowling et al. 2012). Like many other studies of fishers' behaviour we have presumed that fishers are entirely driven by economic interests (Gordon 1953, Hilborn \& Walters 1987, Poos et al. 2010). The relevance, however, of tradition, past experiences and information exchange on fishers' behaviour (Holland \& Sutinen 2000, Little et al. 2004, Marchal et al. 2009) could be taken into account. 
Currently most of the advice in mixed-fisheries is based on single-stock biological objectives (e.g. keep species above a certain biomass, obtain desired fishing mortality), although in a mixed fisheries context the single species objectives cannot be achieved for multiple species simultaneously (Gröger et al. 2007, Ulrich et al. 2011, Da Rocha et al. 2012, Rijnsdorp et al. 2012). The model presented in this study allows trade-offs between multiple objectives in a mixed fisheries context. By introducing a length structure or age structure for different species, management scenarios can be tested to estimate (1) the bycatch of undersize commercially important species such as plaice; (2) over-exploitation of vulnerable species and (3) link predictions to existing stock assessment models and contribute to the improvement of mixed fisheries management.

Mechanistic models are increasingly being used to analyse vessel fishing behaviour (Little et al. 2004, Poos et al. 2010, Dowling et al. 2011). Commonly, fishers behaviour is based on economic interests while alternative utility functions with less emphasis on economic interests, such as tradition or information sharing could be included (Little et al. 2009). However, this would require a more extensive understanding of the rationale of fishers' behaviour. Fisheries management is a complex system, whereby a manager must take interests and concerns of many stakeholders into account. Our spatially explicit effort allocation model proves to be a useful tool to evaluate conservation and economic trade-offs and enables managers to visualize consequences of new management scenarios, such as a discard ban. Hence, our conclusions are important for fisheries in Europe as well as fisheries globally, contributing to an Ecosystem Approach to Fisheries Management where one tries to mitigate overfishing and low economic resilience of the fishing industry.

\section{ACKNOWLEDGEMENTS}

This research was supported by the European Community's Seventh Framework Programme (FP7/2007-2013) under Grant Agreement No. 266445 for the project Vectors of Change in Oceans and Seas Marine Life, Impact on Economic Sectors (VECTORS). 


\section{REFERENCES}

Alverson D.L., Freeberg M.H., Murawski S.A., Pope G.J. (1994) A global assessment of fisheries bycatch and discards. FAO Fisheries Technical Paper 339

Anonymous (2011) High level meeting on banning discards. Brussels 1 March 2011. Commission of the European Communities, Brussels.

Bose S., Crees-Morris A. (2009) Stakeholder's views on fisheries compliance: An Australian case study. Marine Policy 33:248-253

Branch T.A. (2009) How do individual transferable quotas affect marine ecosystems? Fish and Fisheries 10:39-57

Branch T.A., Hilborn R. (2008) Matching catches to quotas in a multispecies trawl fishery: targeting and avoidance behavior under individual transferable quotas. Canadian Journal of Fisheries and Aquatic Sciences 65:1435-1446

Buisman F.C., Bakker T., Bos E., Kuhlman T., Poos J.J. (2011) Effecten van een verbod op discards in de Nederlandse platvisvisserij. LEi-rapport 2011-014

Cappell R. (2001) Economic aspects of discarding - UK case study: Discarding by North Sea Whitefish Trawlers. In: Final report for DG Fish, European Communities, and MAFF. UK: Nautilus Consultants, Edinburgh

Carpentier A., Coppin F., Dupuis L., Engelhard G., Gardel L., Martin C., Meaden G., Morin J., Rostiaux E., Vaz S., Vérin Y., Walton J. (2009) chap. 5, Partie"Engins, navires \& resources halieutique exploitées"/ section "Gears, vessels \& exploited species". In Carpentier A, Martin CS, Vaz S (eds), Channel Habitat Atlas for Marine Resource Management, final report (CHARM phase II):626 pp. \& CD-rom

Catchpole T.L., Frid C.L.J., Gray T.S. (2005) Discarding in the English north-east coast Nephrops norvegicus fishery: the role of social and environmental factors. Fisheries Research 72:45-54

Clark C.W., Butler R.W. (1999) Fitness components of avian migration: A dynamic model of Western Sandpiper migration. Evol Ecol Res 1:443-457

Clark CW, Mangel M (2000) Dynamic state variable models in ecology: Methods and applications, Vol. Oxford University Press

Daan, N. (1997) TAC management in North Sea flatfish fisheries. Journal of Sea Research 37:321-341
Da Rocha J-M., Gutiérrez M-J., Cerviño S. (2012) Reference points based on dynamic optimization: a versatile algorithm for mixed-fishery management with bioeconomic age-structured models. ICES Journal of Marine Science 69:660-669

Depestele J., Vandemaele S., Vanhee W., Polet $H_{\text {., }}$ Torreele E., Leirs H., Vincx M. (2011) Quantifying causes of discard variability: an indispensable assistance to discard estimation and a paramount need for policy measures. ICES Journal of Marine Science 68:1719-1725

Diamond B., Beukers-Stewart B.D. (2011) Fisheries Discards in the North Sea: Waste of Resources or a Necessary Evil? Reviews in Fisheries Science 19:231-245

Dowling N.A., Wilcox C., Mangel M., Pascoe S. (2012) Assessing opportunity and relocation costs of marine protected areas using a behavioural model of longline fleet dynamics. Fish and Fisheries.13: 139157

FAO (2009) The state of world fisheries and aquaculture (SOFIA 2008). FAO Fisheries and Aquaculture Department, Rome

Gillis D.M., Peterman R.M., Pikitch E.K. (1995a) Implications of Trip Regulations for High Grading - a Model of the Behavior of Fishermen. Canadian Journal of Fishieries and Aquatic Sciences 52:402415

Gillis D.M., Pikitch E.K., Peterman R.M. (1995b) Dynamic discarding decisions - foraging theory for high-grading in a trawl fishery. Behavioural Ecology 6:146-154

Gordon H.S. (1953) An economic approach to the optimum utilization of fishery resources. Journal of Fisheries Research Board Canada 10:442 - 457

Graham N., Fryer R.J. (2006) Separation of fish from Nephrops norvegicus into a two-tier cod-end using a selection grid. Fisheries Research 82:111-118

Gröger J.P., Rountree R.A., Missong M., Rätz H-J. (2007) A stock rebuilding algorithm featuring risk assessment and an optimization strategy of single or multispecies fisheries. ICES Journal of Marine Science 64:1101-1115

Hilborn R., Kennedy R.B. (1992) Spatial pattern in catch rates - a test of economic-theory. Bulletin of Mathematical Biology 54:263-273 
Hilborn R., Walters C.J. (1987) A general-model for simulation of stock and fleet dynamics in spatially heterogeneous fisheries. Canadian Journal of Fisheries and Aquatic Sciences 44:1366-1369

Holland D.S., Sutinen J.G. (2000) Location choice in New England trawl fisheries: Old habits die hard. Land Economics 76:133-150

Houston A.I., McNamara J.M. (1999) Models of Adaptive Behaviour, Vol. Cambridge University press

ICES (2010) Report of the ICES Advisory Committee 2010. In: ICES Advice, 2010, Book Book 6, North Sea. ICES, Copenhagen

ICES (2011) Report on the ICES Advisory Committee 2011. In: ICES Advice, 2011, Book Book 6, North Sea. ICES, Copenhagen

Jagers S.C., Berlin D., Jentoft S. (2012) Why comply? Attitudes towards harvest regulations among Swedish fishers. Marine Policy 36:969-976

Kelleher K. (2005) Discards in the world's marine fisheries. An update. FAO Fisheries Technical Paper T470. FAO, Rome

Kraak S.B.M., Bailey N., Cardinale M., Darby C., and others (2012) Lessons for fisheries management from the EU cod recovery plan. Marine Policy 37:200-213

Kristofersson D, Rickertsen K (2005) High-Grading in a Quota-Regulated Fishery, with Empirical Evidence from the Icelandic Cod Fishery. In: European Association of Agricultural Economists 2005 International Congress, August 23-27, 2005, Copenhagen, Denmark

Kristofersson D., Rickertsen K. (2009) High-grading in Quota-Regulated Fisheries: Evidence from the Icelandic Cod Fishery. American Journal of Agricultural Economics 91:335-346

Little L.R., Kuikka S., Punt A.E., Pantus F., Davies C.R., Mapstone B.D. (2004) Information flow among fishing vessels modelled using a Bayesian network. Environmental Modelling \& Software 19:27-34

Little L.R., Punt A.E., Mapstone B.D., Begg G.A., Goldman B., Williams A.J. (2009) An agent-based model for simulating trading of multi-species fisheries quota. Ecological Modelling 220:3404-341

Mangel M. (1987) Oviposition site selection and clutch size in insects. Journal of Mathematical Biology 25:1-22
Marchal P., Lallemand P., Stokes K. (2009) The relative weight of traditions, economics, and catch plans in New Zealand fleet dynamics. Canadian Journal of Fisheries and Aquatic Sciences 66:291-311

Marchal P., Little L.R., Thebaud O. (2011) Quota allocation in mixed fisheries: a bioeconomic modelling approach applied to the Channel flatfish fisheries. ICES Journal of Marine Science 68:1580-1591

Messina G., Notti E. (2007) Energy Saving In Trawlers: Practical And Theoretical Approaches. In: ICMRT 2007 Final Report

Poos J.J., Bogaards J.A., Quirijns F.J., Gillis D.M., Rijnsdorp A.D. (2010) Individual quotas, fishing effort allocation, and over-quota discarding in mixed fisheries. ICES Journal of Marine Science 67: 323-333.

Reiss H., Greenstreet S.P.R., Robinson L., Ehrich S., Jørgensen L.L., Piet G.J., Wolff W.J. (2010) Unsuitability of TAC management within an ecosystem approach to fisheries: an ecological perspective. Journal of Sea Research 63: 85-92

Rijnsdorp A.D., Millner R.S. (1996) Trends in population dynamics and exploitation of North Sea plaice (Pleuronectes platessa $\mathrm{L}$ ) since the late 1800s. /CES Journal of Marine Science 53:1170-1184

Rijnsdorp A.D., Daan N., Dekker W. (2006) Partial fishing mortality per fishing trip: a useful indicator of effective fishing effort in mixed demersal fisheries. ICES Journal of Marine Science 63:556-566

Rijnsdorp A.D., Daan N., Dekker W., Poos J.J., Van Densen W.L.T. (2007) Sustainable use of flatfish resources: Addressing the credibility crisis in mixed fisheries management. Journal of Sea Research 57:114-125

Rijnsdorp A.D., van Overzee H.M.J., Poos J.J. (2012) Ecological and economic trade-offs in the management of mixed fisheries: a case study of spawning closures in flatfish fisheries. Marine Ecology Progress Series 447:179-194

Salas S., Gaertner D. (2004) The behavioural dynamics of fishers: management implications. Fish and Fisheries 5:153-167

Taal C., Bartelings $H_{\text {., }}$ Beukers R., van Duijn A.J., klok A.J., van Oostenbrugge J.A.E., Smit J.P.G (2009) Visserij in cijfers 2009. In, Book Rapport 2009-070. Landbouw Economisch Instituut Den Haag 
Ulrich C., Reeves S.A., Vermard Y., Holmes S.J., Vanhee W. (2011) Reconciling single-species TACs in the North Sea demersal fisheries using the Fcube mixed-fisheries advice framework. ICES Journal of Marine Science 68:1535-1547

Ulrich C., Wilson D.C.K., Nielsen J.R., Bastardie F., Reeves S.A., Andersen B.S., Eigaard O.R. (2012) Challenges and opportunities for fleet- and métier-based approaches for fisheries management under the European Common Fishery Policy. Ocean Coastal Management, 70:38-47
Vaz S., Carpentier A., Coppin F. (2007) Eastern English Channel fish assemblages: measuring the structuring effect of habitats on distinct sub-communities. ICES Journal of Marine Science 64:271287

Wood, S.N. (2006). Generalized Additive Models, An Introduction with R. London: Chapman and Hall.

Zuur A.F., leno E.N., Walker N.J., Saveliev A.A., Smith G.M. (2009) Mixed effect models and extensions in ecology in R, Vol, New York 


\section{CHAPTER 3}

\section{HIGH-GRADING AND OVER-QUOTA DISCARDING IN MIXED FISHERIES}

Batsleer J., Hamon K. G., Overzee H.M.J. van, Rijnsdorp A.D., Poos J.J. 


\section{ABSTRACT}

High-grading is the decision by fishers to discard fish of low value that allows them to land more valuable fish. A literature review showed high-grading is reported in commercial and non-commercial fisheries around the world, although the number of observations is small. High-grading occurs in fisheries that are restricted to land their total catch due to management, market or physical constraints. Using the mixed flatfish fishery as a model system, a dynamic state variable model simulation showed that high-grading of certain grades occurs throughout the year when their ex-vessel price is low. High-grading increases with the degree of quota restriction, while the level of over-quota discarding is unrelated to the quota level. The size composition of the high-graded catch differs from the landed catch. Due to the differences in the seasonal variation in size specific ex-vessel price, the effect of quota restrictions on the size composition of the discarded catch is non-linear. High-grading is difficult to detect for the fishery inspection as it occurs on-board during the short period when the catch is processed. We conclude that high-grading is under-reported in fish stocks managed by restrictive quota, undermining the quality of stock assessments and sustainable management of exploited fish stocks.

\section{KEYWORDS:}

By-catch,

discards,

Common Fisheries Policy,

fisheries management,

flatfish. 


\section{INTRODUCTION}

Many fisheries around the world capture fish that are subsequently discarded back into the sea (Kelleher 2005). Discarding is mainly policy or market driven. Policy measures such as legal landings sizes or catch quota may forbid selling small fish (Harley et al. 2000; Rochet and Trenkel 2005; Depestele et al. 2011; Feekings et al. 2012) or over-quota catches (Copes 1986; Branch 2009; Poos et al. 2010), while market incentives prevent the sale of certain (by-catch) species or size classes (Gray and Kennelly 2003; Hara 2013; Eliasen et al. 2014).

Discarding of marketable fish in fisheries that are under catch quota management are of particular interest. Catch quotas or "Total Allowable Catches" (TAC) are used worldwide to regulate fisheries. The intention of catch quotas is to control fishing mortality of a given stock to a specified level (e.g. to prevent overfishing). The use of such quotas relies on the premise that fishers adjust their fishing behaviour according to imposed catch limitations (Holden 1994; Daan 1997; Punt et al. 2006; Branch and Hilborn 2008). However, in reality TACs may control landings of fish but not the catch, because fishers may continue to fish and discard marketable fish exceeding the quota, as is likely in mixed fisheries (Pascoe 1997; Poos et al. 2010). As a result, the effectiveness of TAC management of mixed fisheries is questionable (Daan 1997).

As a refinement of the TAC system, individual transferable quotas (ITQs) (Christy 1973) have been introduced world-wide to stop the "race for fish" (Copes 1986; Arnason 1993; Squires et al. 1998). ITQs provide a share of the TAC to participants in a fishery who are allowed to sell and lease their share of the quota (Davies 1992). Having rights to predetermined shares of the resource output, fishers can plan their fishing effort to secure their share of the catch, without having to account for the catches of other fishers. Although the ITQs have generally been considered successful (Branch 2009; Hamon et al. 2009; Hannesson 2013; Soliman 2014), they have not completely taken away the incentive for discarding parts of the marketable catch. Given that the quota is a predetermined share, fishers can optimize the economic return by "high-grading" their catch: that is to say, discarding those parts of the marketable catch that have the lowest value while quota is still available. Also in mixed fisheries, fishers can discard marketable fish once their quotas have been reached, termed "over-quota discarding". The survival of the discarded fish can be low (Van Beek et al. 1990; Yergey et al. 2012), depending on the type of fishery (Van Beek et al. 1990; Campbell et al. 2014), depth of catch (Sauls 2014), and other factors (Smith and Scharf 2011; Marçalo et al. 2013). Because the survival of the discarded fish can be low, high-grading is considered to be a waste of resources. In response, in 2009 the EU declared high-grading an illegal practice (Regulation (EU) 43/2009).

Theoretical studies suggest over-quota discarding and high-grading occur under specific conditions (Anderson 1994; Turner 1997; Parslow 2010; van Putten et al. 2012). However, empirical evidence for high-grading is scarce, although there is anecdotal information from the fishing industry. High-grading is not only an unknown contribution to the waste of food resources, it may also reduce the accuracy of stock assessments that underpin the manage- 
ment of many fish stocks. Such stock assessments often rely on the age or length structure of the catches to estimate mortality in fish stocks. In the absence of observations of catches, landings are sometimes used as a proxy for catches. Since high-grading affects the age and length structure of the landed fish, the resulting stock assessment may lose accuracy in estimating the mortality and stock size, undermining the credibility of fisheries management (McCay 1995; Daan 1997; Rijnsdorp et al. 2007). Several studies have highlighted the importance of incorporating discards in stock assessments and propose methodologies for their inclusion (Punt et al. 2006; Aarts and Poos 2009).

This paper reviews literature on high-grading and over-quota discarding observations from different fisheries around the world, collating empirical evidence from a wide range of fisheries to study the conditions under which this may occur. In addition, we present a case study that applies a behavioural model to study high-grading decisions of fishers in a Dutch beam trawl mixed fishery under individual quota management (Gillis et al. 2008). This fishery is known for discarding marketable fish (Quirijns et al. 2008, Poos et al. 2010). The model assumes that a fisher chooses a strategy that maximizes annual net revenue. Size structured catches allow exploring the consequences of quota management on discarding of less valuable market size classes in time. The results allow us to forecast over-quota discarding and high-grading and explore the effect on age composition and the implications for stock assessment.

\section{LITERATURE REVIEW}

A list of original publications on observations of high-grading and over-quota discarding was derived from literature searches. First a search in Scopus on high-grading was done using the query 'TITLE-ABS-KEY ((("high-grading" OR "highgrading") OR "individual quotas" OR ("individual" AND "quotas" AND "strategy") OR (discard* AND ("minimum landings size" OR "minimum legal length" OR "commercial species" OR "legislation"))) AND (fish*))'. This query thus included search terms for high-grading, and for terms that were expected to be linked to high-grading observations. Papers that contained observations on high-grading, such as on-board observations, interviews, or skipper logbooks were included in the review. Papers hypothesizing high-grading based on conceptual models were not considered. Review papers were not included, but the original references were evaluated. In total, 336 papers were screened from which 44 contained observations on high-grading. For each of these 44 papers, the gear type, main species, geographical area, management system, type of observation, and a short description of the observation were recorded. Table 3.1 summarises the papers that report empirical observations of high-grading. Thirty of these reported observations were made by on-board observers. The fourteen other observations were mostly obtained by interviews, or self-sampling. In most cases where on-board observers were present, high-grading was inferred by generating sigmoid curves describing the 


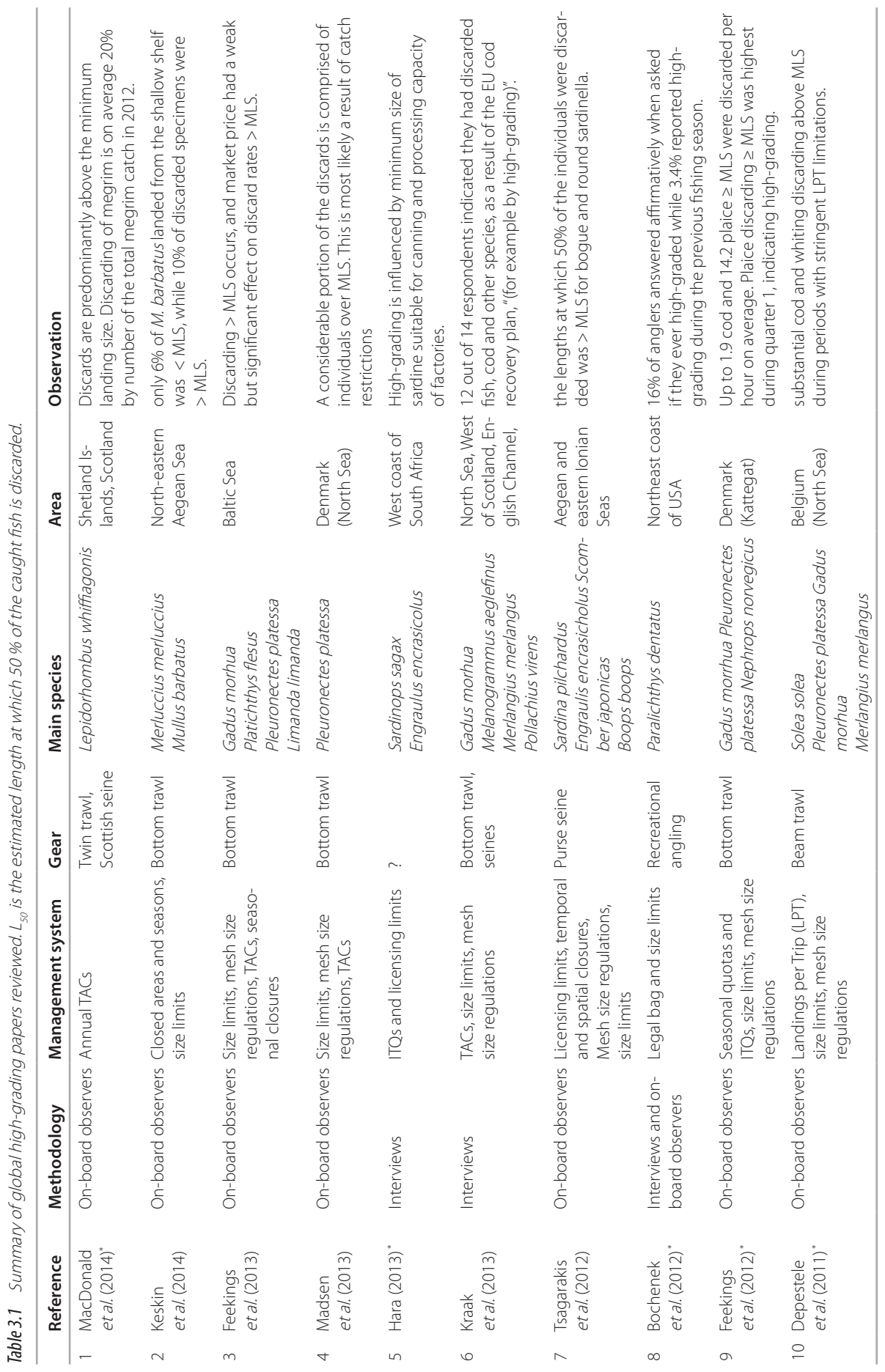




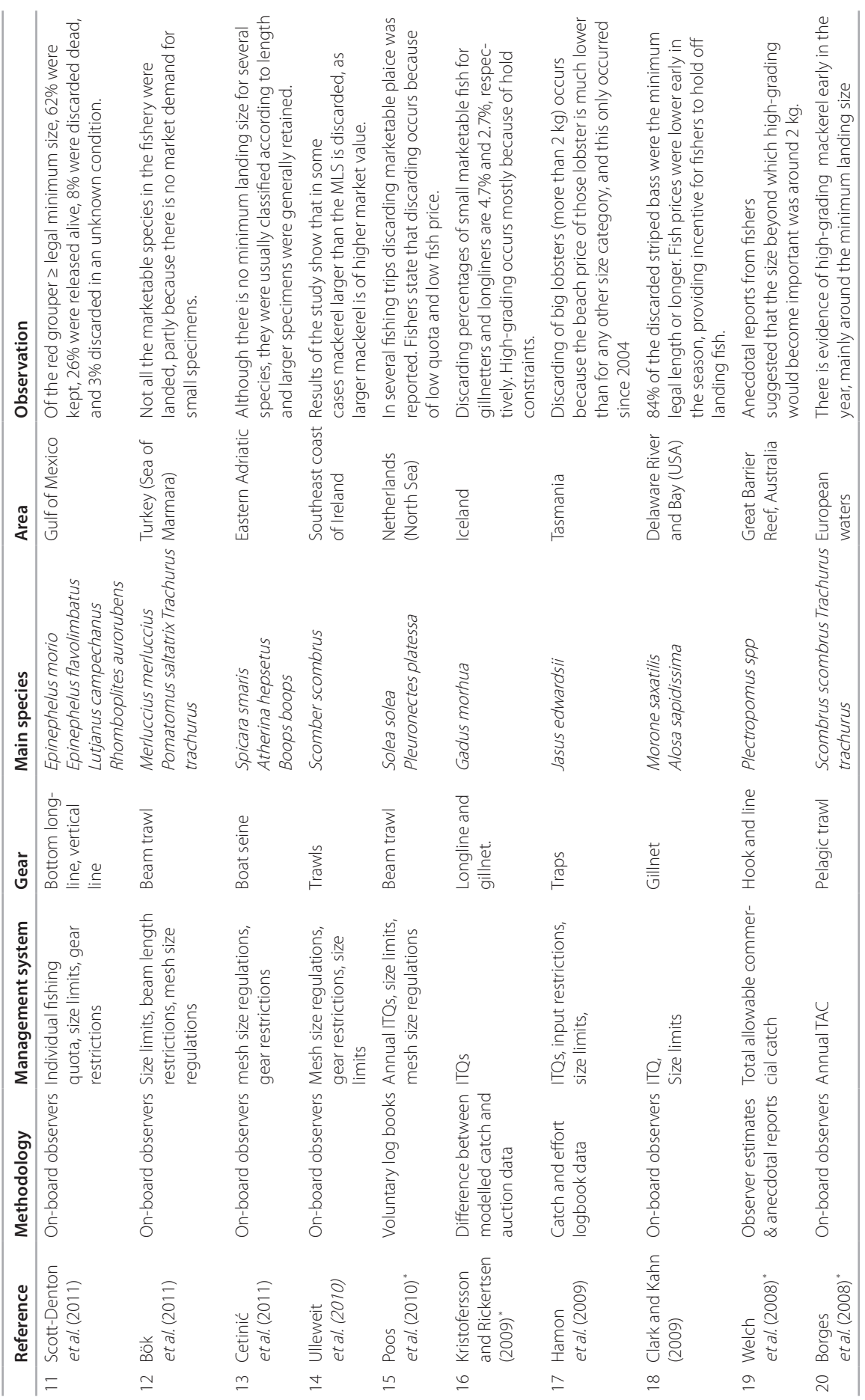




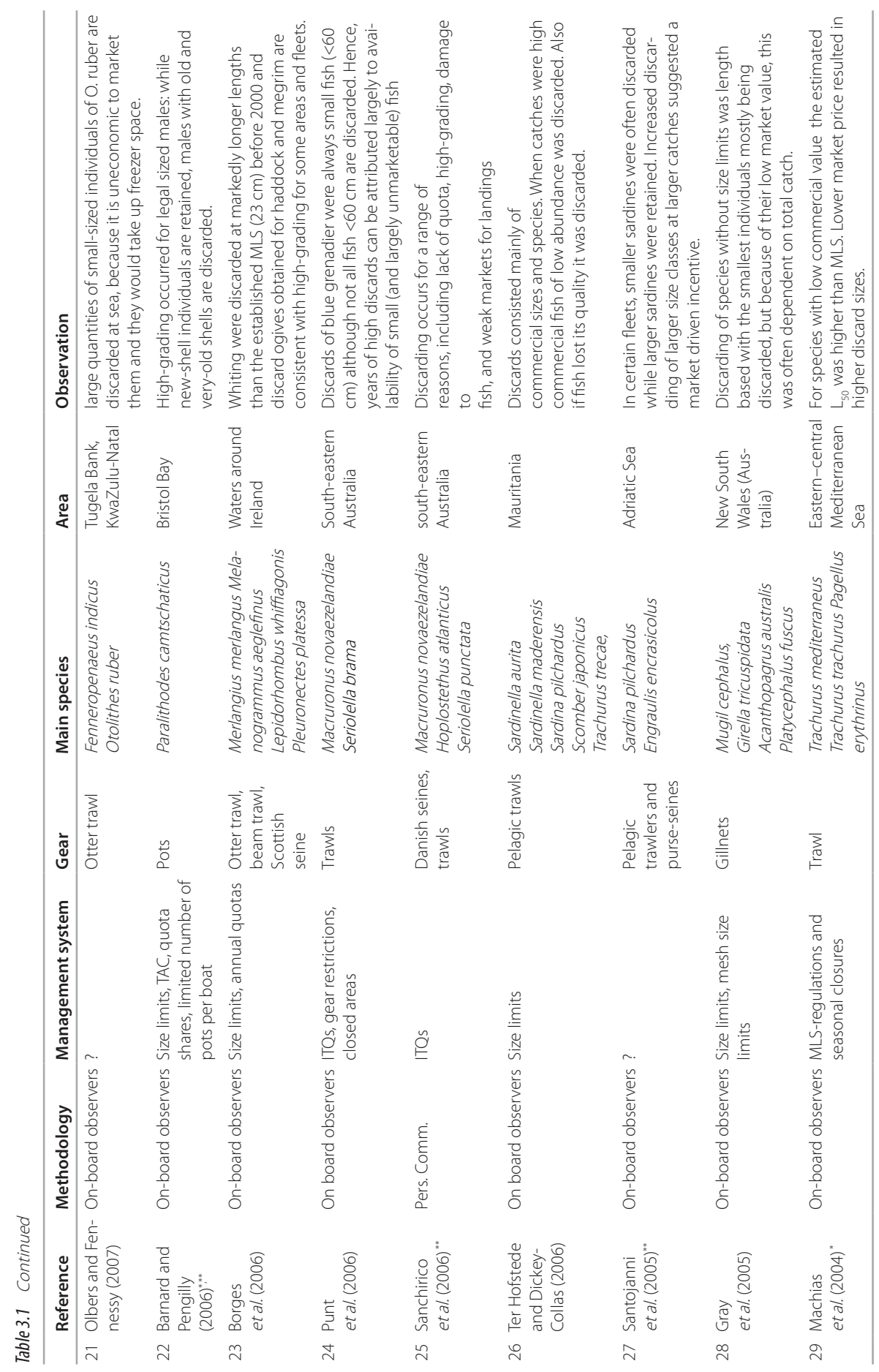




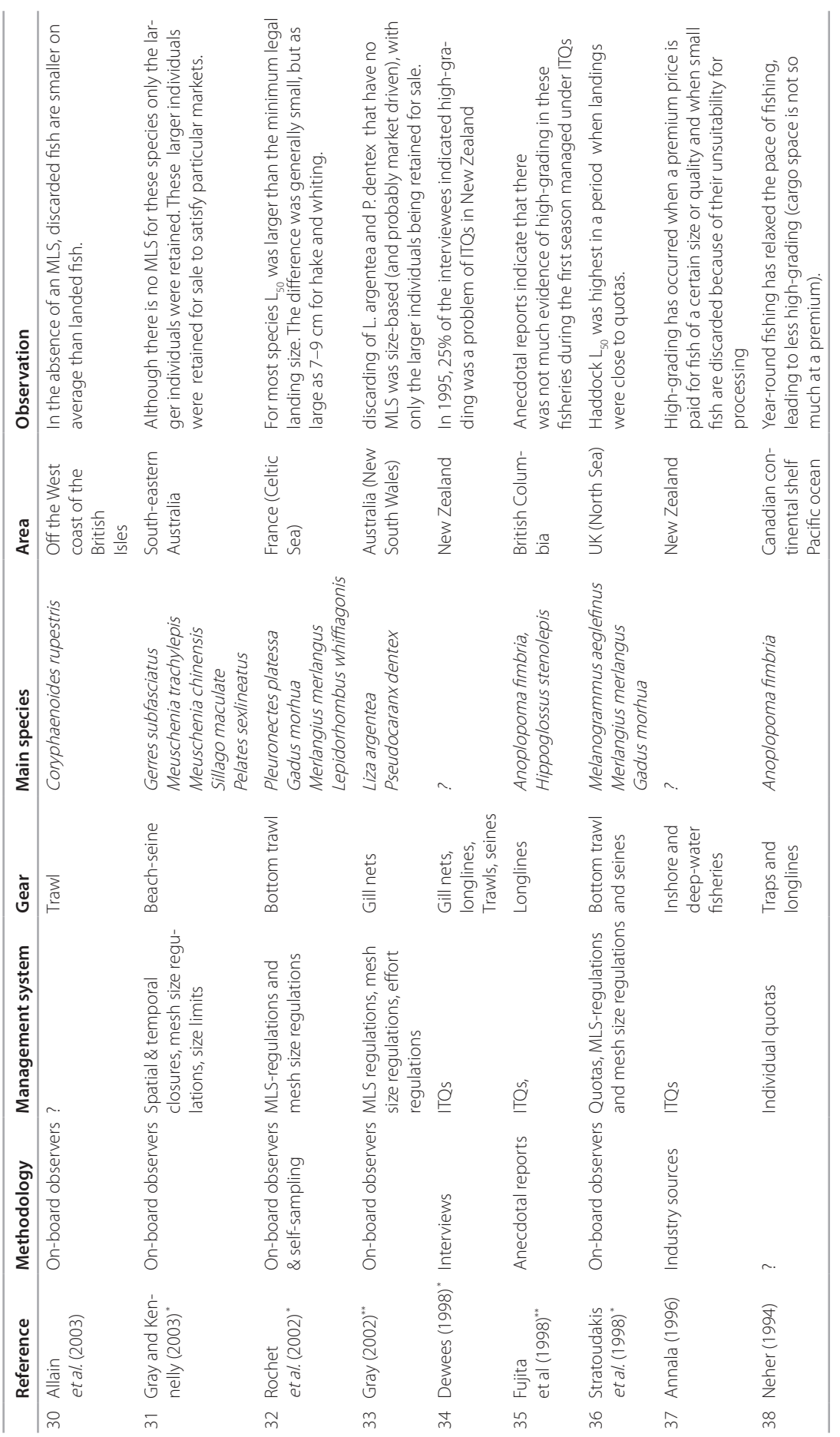




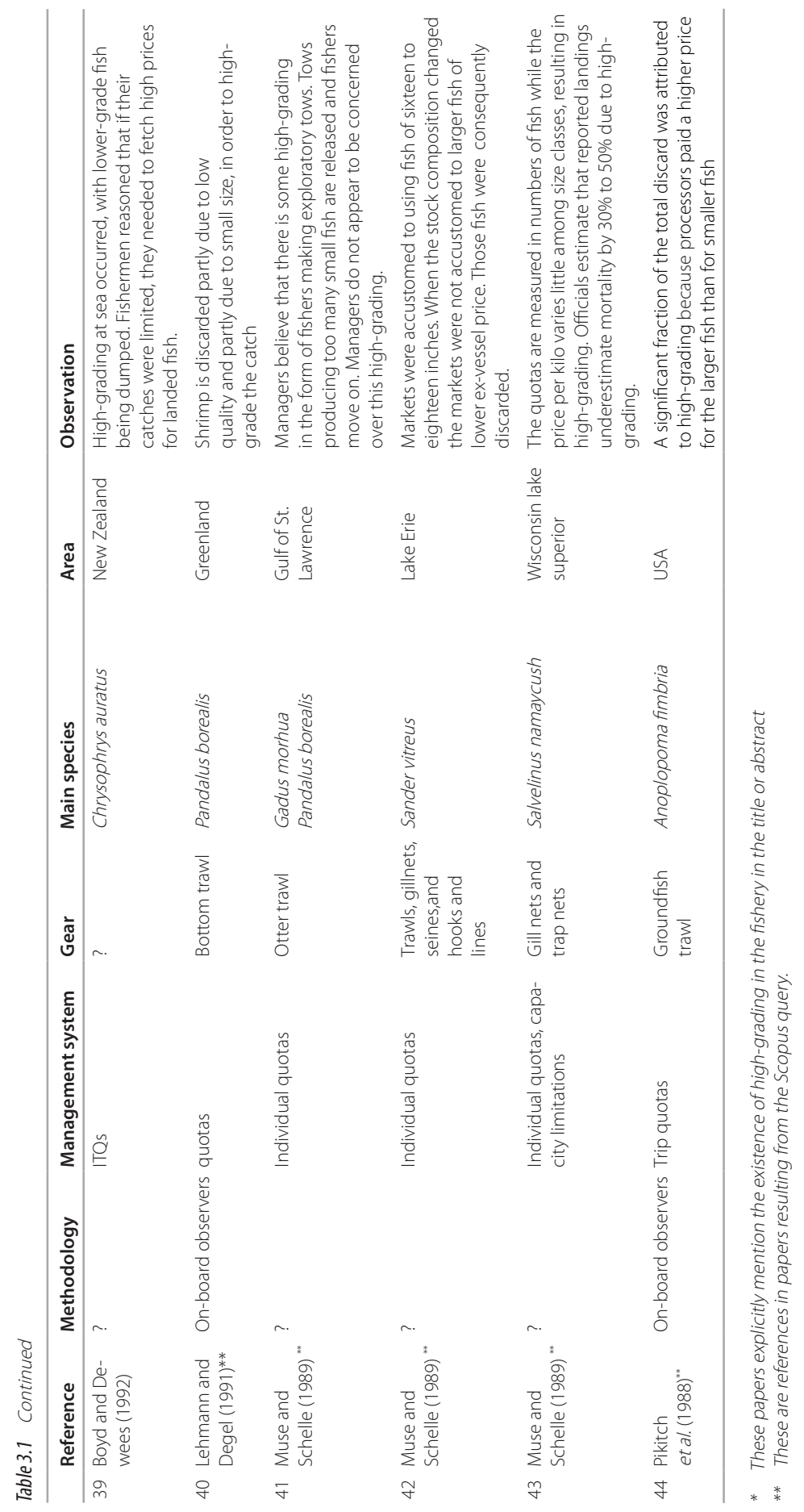


length-based retention of individuals, and comparing these to minimum landing size (MLS) regulations. If the length at which $50 \%$ of the individuals was retained was higher than the MLS, this indicates high-grading. In 16 of the papers, the authors mentioned the existence of high-grading in the title or abstract of paper. For the remaining 28 papers, the existence of high-grading was mentioned in the text of 17 papers, or inferred by us in the other 11 . In general we inferred the existence of high-grading when (1) length-structured discards observations showed that fish larger than the MLS was discarded, or (2) there was a clear size difference between landings and discards in the absence of an MLS.

High-grading is reported from a wide range of areas and jurisdictions. In Europe, high-grading is observed in fisheries ranging from the Mediterranean Sea to the North-east Atlantic. In North-America, high-grading is reported in the Gulf of Mexico and the East coast. Additional observations are from Turkey, Greenland, New Zealand, Australia, and South Africa. The existence of some form of individual quotas in the fishery was mentioned in 18 papers. Other fisheries where individual vessels were able to plan the use of quota, such as trip limits and bag limits, also reported high-grading. The relatively large number of papers that are associated with ITQs may in part result from our query. Also, the concerns about high-grading in ITQ fisheries may have spurred empirical research into high-grading in those fisheries. Especially in New Zealand, the benefits and costs of adopting ITQs (and associated problems with high-grading) appear to have been well studied. Finally, high-grading was present in at least five fisheries with TAC management. The exact number cannot be inferred from the literature because not all studies exactly specify the management system, while even national annual quota are sometimes subdivided and made available to individual vessels by e.g. producer organisations. High-grading was not always related to fisheries management, even if extensive management was in place: the literature review resulted in seven papers that explicitly mentioned high-grading because of market condition. Four studies mentioned the constraining hold of the vessel to be a driver for high-grading (Pikitch et al. 1988; Neher 1994; Olbers and Fennessy 2007; Kristofersson and Rickertsen 2009). Lower price categories are high-graded, most often the smaller individuals. However, high-grading of larger individuals is also observed. Most of the observations on high-grading in the literature represent commercial fisheries using a wide range of gears. One paper explicitly studied and mentioned the existence of high-grading in recreational angling.

A second search was done for over-quota discarding, using the query 'TITLE-ABS-KEY (( "over-quota" OR "overquota") OR "individual quotas" OR ( "individual" AND "quotas" AND "strategy") OR (discard* AND ("minimum landings size" OR "minimum legal length" OR "commercial species" OR "legislation"))) AND (fish*)). The resulting papers were treated similar to the high-grading literature review. However, from the 314 papers resulting from this query, we found only five papers where over-quota discarding could be unequivocally inferred. Those papers where wording was sufficiently strong to suggest discarding of marketable fish after quota were exhausted are collated in Table 3.2. Some of these papers were also included in the high-grading observations. Many papers are not included in table 2, because the discarding that resulted from constraining quotas can either be high-grading or 


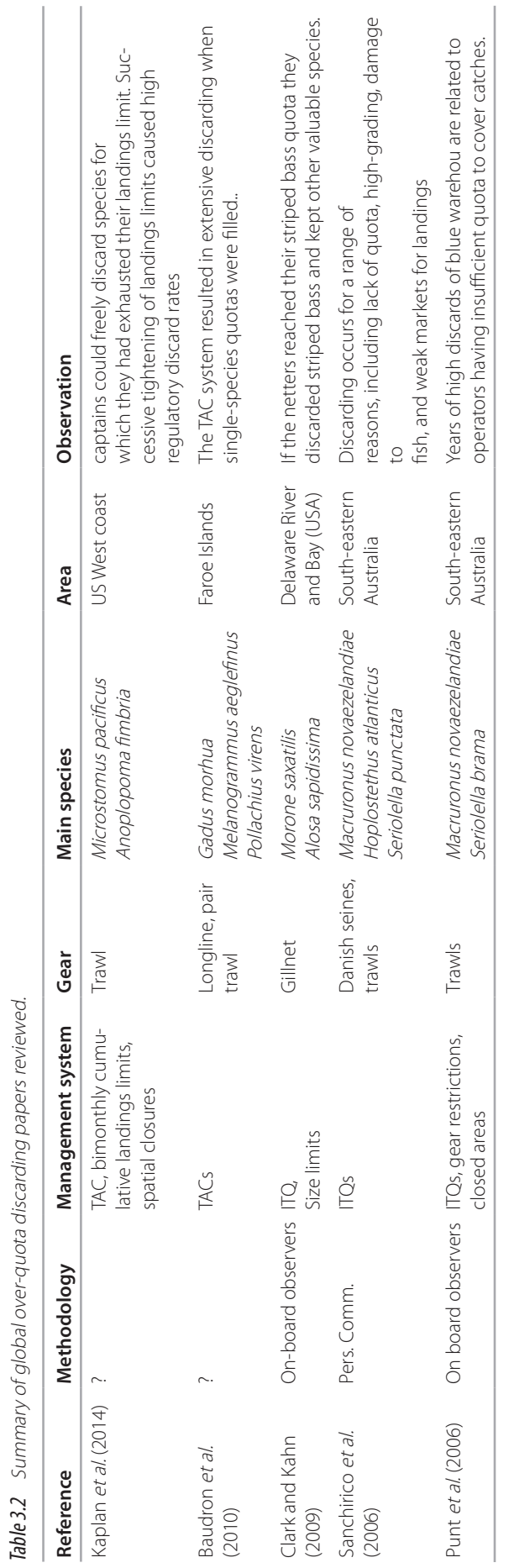


over-quota discarding (e.g. , Richards 1994; Baelde 2001; Brewer 2011; Cullis-Suzuki et al. 2012; Catchpole et al. 2014; Mace et al. 2014).

To summarise, the literature review shows that high-grading is reported from all over the world in a broad range of fisheries, although the number of reports with empirical evidence is small. High-grading occurs in fisheries that are restricted in landing their total catch due to management, market or physical constraints. In the following sections, we will describe a conceptual model for quantifying high-grading and over-quota discarding.

\section{SIMULATION MODEL}

In order to gain insight as to the mechanisms inducing high-grading and over-quota discarding behaviour, we used a dynamic-state variable model (DSVM) (Houston and McNamara 1999; Clark and Mangel 2000). Dynamic state variable models have been applied in a variety of fisheries to analyse vessel fishing behaviour (Gillis et al. 1995; Poos et al. 2010; Dowling et al. 2012; Batsleer et al. 2013). In such models, the optimal annual strategy of fishing vessels operating in fisheries under individual quotas and in a stochastic environment is evaluated. Our model differs from earlier models in that: 1 ) it includes size structured fish catches, and 2) ex-vessel price by size class fluctuates over time. The utility function assumes that fishers are profit maximizers. Although other incentives may play a role in decision making, there is empirical evidence for profit as a useful metric of utility (Robinson and Pascoe 1997).

We model bottom trawl fishers targeting three size-structured fish species (sole, plaice and cod), where catches are divided into market categories based on size (Table 3.3). The size classes have seasonally variable auction prices (Fig. 3.1). The size structure and species composition of the catch is thus an important determinant of the value of a catch. The expected catch rates of each species/size class combination is defined by probability distributions that are functions of fishing location and season, reflecting spatial and seasonal variations in abundance. Parameters describing the probability distributions are estimated from historic data.

Table 3.3 Marketable size classes of the three target species.

\begin{tabular}{cccc}
\hline Size class & Plaice & Sole & Cod \\
\hline 1 & $>41 \mathrm{~cm}$ & $>38 \mathrm{~cm}$ & $>88 \mathrm{~cm}$ \\
2 & $35-41 \mathrm{~cm}$ & $33-38 \mathrm{~cm}$ & $72-88 \mathrm{~cm}$ \\
3 & $31-35 \mathrm{~cm}$ & $30-33 \mathrm{~cm}$ & $55-72 \mathrm{~cm}$ \\
4 & $27-31 \mathrm{~cm}$ & $27-30 \mathrm{~cm}$ & $46-55 \mathrm{~cm}$ \\
5 & & $24-27 \mathrm{~cm}$ & $35-46 \mathrm{~cm}$ \\
\hline
\end{tabular}



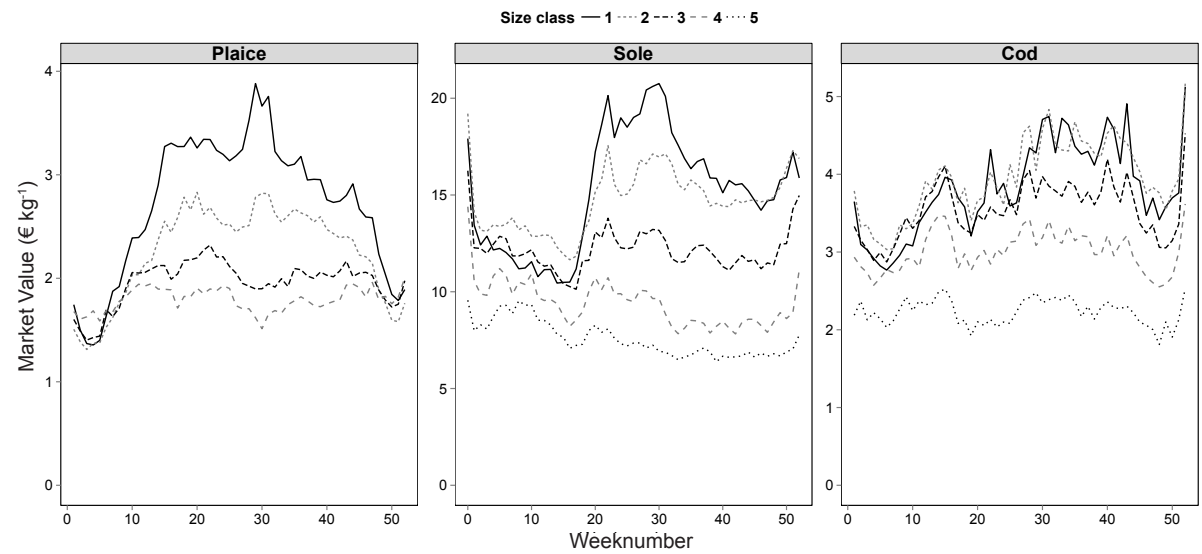

Figure 3.1

Seasonal variation in the ex-vessel price of the five size clas-

In the model fishers maximise their annual net revenue ${ }^{1}$ by making weekly decisions on (i) to go fishing or not; (ii) fishing location; and (iii) how much to discard given their annual landing quota and restrictions on discarding. A weekly time scale is chosen because most fishing trips last from Monday to Friday in the bottom trawl fishery that serves as a case-study (Rijnsdorp et al. 2011).

For simplicity we assume that there is one individual quota restricting a single species. In this case we chose plaice given observations of discarding of marketable plaice in the Dutch beam trawl fishery (Poos et al. 2010). Historically, the plaice quota constrained the fishery in the 1990s, leading to changes in the targeting behaviour of the fleet (Quirijns et al. 2008). The cumulative landings in weight of species s of the set of species $S$ and size class $n$ of $N$ size classes is denoted by $L_{s, n}$. The cumulative landings in weight of the quota constrained species, that we define by $s=1$, represents the state of the individual, denoted by $L$ and equal to $\sum_{N} L_{1, n}$.

The landings are determined by the discarding decision and the catches which in turn depend on the spatial and temporal distribution of all size classes within the 3 species. Each week $t$ individuals choose to visit fishing area $a$ and to keep or discard any combination of the size classes caught of the different species. This behaviour is defined by a matrix $d$, of dimension $S$ and $N$. Catches above $d_{s, n}$ are discarded. To limit the number of discarding options, the values of $d_{s, n}$ are restricted to 0 (all catches are discarded) or $2^{31}$ (all catches are landed) for each combination of species and size class. The catches are modelled as a random variable having a negative binomial distribution with a mean $m_{s, n, a, t}$ per area, week, species and size

1 i.e. the revenue minus variable costs, given that fixed costs do not impact short term decisions 
class, and a dispersion parameter per species $r_{s}$. The means and dispersion parameters are estimated from logbook data from the case study fleet. The probability $\lambda_{s, n}\left(l_{s, n}, d_{s, n}, a, t\right)$ of making a landings $l_{s, n}$ of amount $\chi$ is a function of the area choice in a given week, and the discarding decisions such that it has following cumulative distribution function:

$$
\begin{gathered}
\lambda_{s, n}\left(l_{s, n} \leq \chi, d_{s, n}, a, t\right)=f\left(\chi ; d_{s, n}, m_{s, n, a, t}, r_{s}\right)= \\
\left\{\begin{array}{cl}
\sum_{l_{s, n}=0}^{\chi}\left(\frac{r_{s}}{r_{s}+m_{s, n, a, t}}\right)^{r_{s}} \frac{\Gamma\left(r_{s}+l_{s, n}\right)}{l_{s, n} ! \Gamma\left(l_{s, n}\right)}\left(\frac{m_{s, n, a, t}}{r_{s}+m_{s, n, a, t}}\right)^{l_{s, n}}, & \text {, for } 0 \leq \chi<d_{s, n} \\
1 & , \text { for } \chi \geq d_{s, n}
\end{array}\right.
\end{gathered}
$$

where $\Gamma(\cdot)$ is the gamma function (Press et al. 2002). The optimal strategy in each week of the year, denoted by $t$ depends on the cumulative landings of the quota species. These landings affect the possibility to continue fishing and land fish without exceeding the annual quota. The expected net revenue at the end of the year is linked to the choices in the preceding weeks through a value function between time $t$ and the end of year $T$. The value function represents the maximum expected net revenue to be made between week $t$ and the end of the year $T$ and depends on the state of the individual $L$, the amount of quota $U$ for the quota species, the fine per unit weight for exceeding the quota $F$, and is expressed as $V(L, U, F, t)$. Individuals exceeding their quota get a fine that depends on the quota overshoot. At the end of the year $T$, after all fishing has been completed, the value function $V(L, U, F, T)$ is defined by the fine of overshooting the quota:

$\Phi(L, U, F)=\left\{\begin{aligned} 0, & L \leq U \\ -(L-U) F, & L>U\end{aligned}\right.$

For each week before $T$, the expected net revenue is determined by the value function, the weekly gross revenue and the costs of fishing.

For all times $t$ preceding $T$ we use stochastic dynamic programming to find the optimal solution by backward iteration of the net expected revenue $H$ from $t$ to the end of the year considering the choices $a$ and $d$ and the state $L$ at $t$ and optimal choices in subsequent weeks:

$H(L, U, F, t ; a, d)=R(a, d, t) * \kappa-C(a)+\mathbb{E}_{a, d}\left[V\left(L^{\prime}, U, F, t+1\right)\right]$

where $R(a, d, t)$ is the expected direct contribution of the gross revenue that follows from the

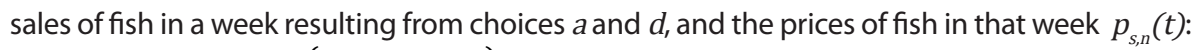
$R(a, d, t)=\sum_{s} \sum_{N} \lambda_{s, n}\left(l_{s, n}, d_{s, n}, a, t\right) * l_{s, n} * p_{s, n}(t)$. The term $\kappa$ represents a factor accounting for the additional revenue obtained from landing marketable species that are not explicitly modelled. The term $C(a)$ represents the variable costs in a week resulting from the choice of fishing area $a$. The term $L^{\prime}$ reflects the change of the state $L$ resulting from the weekly landings for the quota species, $\sum_{N} l_{1, n}$. The term $\mathbb{E}_{a, d}\left[V\left(L^{\prime}, U, F, t+1\right)\right]$ denotes the expected future value taken over all possible states resulting from choices $a$ and $d$. The optimal choice is given by: 
$V(L, U, F, t)=\max _{a, d}\{H(L, U, F, t ; a, d)\}$

Hence, starting with $V(L, U, F, T)=\Phi(L, U, F)$ we can iterate backwards in time and find the optimal choice in terms of location and discarding behaviour for all possible states, combining the net revenue obtained from the sale of fish and costs of a fishing trip and the effect of the annual fines when exceeding annual quota.

We explore high-grading and over-quota discarding decisions of conventional beam trawlers under a range of individual plaice quota (100 to 800 tonnes per year).

\section{CASE STUDY DATA}

Marketable catch and effort data by fishing trip are obtained from logbooks and individual sale slips for large Dutch beam trawl mixed fishery $(>1500 \mathrm{hp})$. Restrictive TACs in recent years may bias port-based catch rate observations of marketable fish because of over-quota discarding and high-grading (Rijnsdorp et al. 2008; Poos et al. 2010). Therefore, log book data from 1970-1974 are used, a period where there were minimum mesh and landing sizes, but no TACs (Daan 1997). TACs were introduced only in 1975 for this fishery (Salz 1996). The data are collected on a trip by trip basis and include the landed weight of marketable fish by species and size category, fishing ground (ICES rectangle, ca. 30×30 nautical miles), fishing effort (hours fished) fishing gear, vessel length, and engine power. Data for plaice, sole and cod are analysed.

Figure 3.2

Fishing areas, black point indicates the location of the fishing harbour used in the model

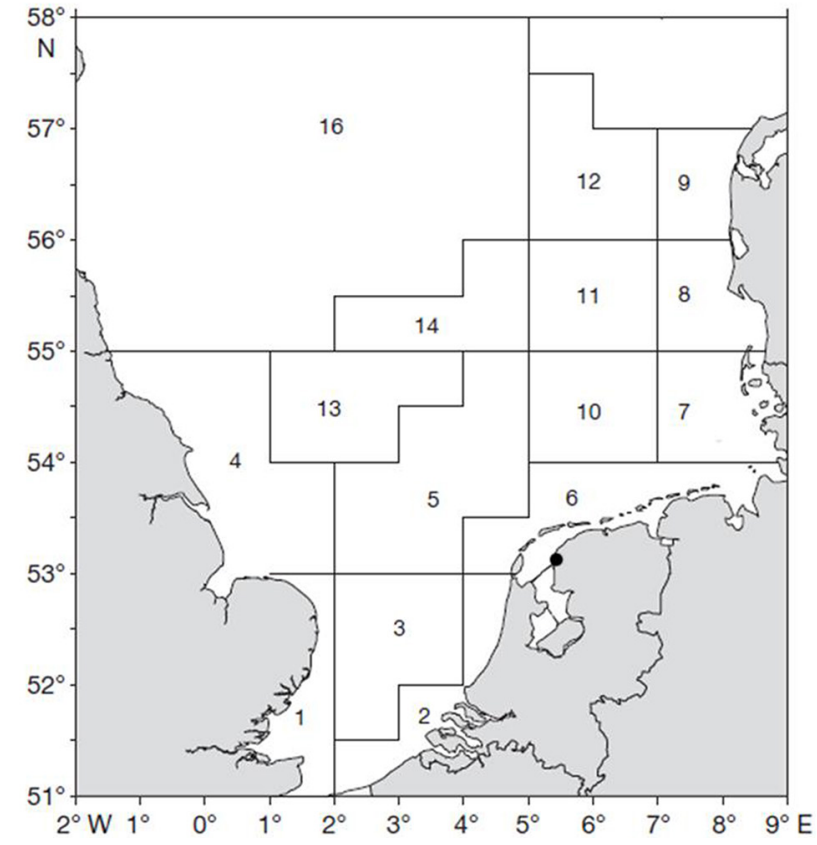


Fishing areas are defined by aggregating ICES rectangles, similar to (Rijnsdorp et al. 2012) (Fig. 3.2). The large Dutch beam trawlers are prohibited from fishing in the Plaice Box (areas 6 - 9) and the 12 nautical mile zones (areas 1 and 2). These areas are excluded from further analysis. Fishing effort is determined by summing the fishing time and the travel time per week. The fishing time for large trawlers is estimated at 65 hours per week based on the effort dataset. Travel time is calculated by taking the distance from the harbour of departure to each of the fishing grounds and assuming a steaming speed of 12 nautical miles $\mathrm{h}^{-1}$ (Poos et al. 2013).

\section{TRAWL CATCH RATES}

Seasonal catch rates per fishing area for the different size classes of plaice, sole, and cod in the beam trawl fleet are described using generalized additive models (GAM, Wood 2006). Catch rates are modelled using the weight of the catches $(\mathrm{kg})$ from the logbooks per size class per fishing trip as a response variable while effort (hr) is used as offset variable (Wood 2006). By using a negative binomial GAM with a logarithmic link function we allow over-dispersed data and zero-observations (Wood 2006; Zuur et al.; 2009). The model to estimate catch by size class $n$ and area $a$ per week is applied to the data per species $s$ :

$m_{s, n, a, t}=a+$ gear $+f_{1}(n, t \mid a)+\log ($ engine power $)+f_{2}($ sweek, $n)+\operatorname{offset}(\log ($ effort $)) \quad 3.5$

where $f_{1}$ and $f_{2}$ are smooth functions based on a tensor product smoother (Wood 2006). The tensor product smoother $f_{1}(n, t / a)$ is based on a cubic regression spline for size class and a cyclic cubic regression spline for week by area. The cubic regression spline for week by area results in equal values and slopes at the beginning and end of the year (Wood 2006). The maximum degrees of freedom for both smoothing terms is limited $(k=4)$ to prevent over-fitting. The covariate engine power is the log-transformed horse power and is included because of its influence on the catch efficiency. The covariate gear is included to differentiate the catch efficiencies between the beam and otter trawl. The covariate sweek within the second smoothing term $f_{2}$ (sweek, $n$ ) is week number since the start of the data collection (1 January 1970) and captures the gradual changes in biomass for each size class over time as a result of recruitment and mortality. In addition to the estimates of the mean catches $m_{s, n, a, t}$ the model also returns the estimated dispersion parameter per species $r_{s}$. All analyses were done using the R statistical program (version 2.12.1; R Core Development Team 2013). The "mgcv 1.7-29" package was used for the GAM model for trawl catch rates (Wood 2011).

The GAM model is used to estimate the spatial and temporal patterns in catch rates $\left(\mathrm{kg}\right.$ week $\left.^{-1}\right)$ for each size class of each target species in the period 1970-1974. To obtain values representative for the time period in which the economic data is collected, the predictions are rescaled with a factor calculated by dividing the mean of the absolute values of the spawning stock biomass (SSB) of 1970 to 1979 by the mean of the absolute values of the SSB of the past 10 years (2004-2013). 


\section{ECONOMIC DATA}

The three species modelled represent $82 \%$ of the gross revenue of the Dutch beam trawl fleet. Mean weekly market values for the marketable size classes are calculated from sale slip data from 2003-2007 (Fig. 3.1). The fine for overshooting the individual quota is set to $320 €$ $\mathrm{kg}^{-1}$. Such a high fine ensures full compliance to the individual quotas in the model. Costs of discarding in terms of additional sorting time are assumed to be negligible.

Information on the cost structure of large beam trawl vessels (2008-2010) is obtained from LEI (Agricultural Economic Research Institute). The variable costs represent about 75\% to $80 \%$ of the total annual costs and include fuel costs, gear maintenance costs, cost of handling and transportation of landings, crew shares and other variable costs, such as auction and harbour fees. Fuel costs depend on effort and fuel price and is estimated to be approximately $€ 6400$ day $^{-1}$ (van Marlen et al. 2014). Gear maintenance cost is assumed proportional to fishing effort, landing costs proportional to the total weight landed, and other variable costs proportional to the gross revenue. Crew shares are predominantly determined by an agreement between the owner and his crew. Crew share is calculated after fuel, handling and transportation costs are deducted from the gross revenue. Values used for variable costs in the simulation model are presented in Table 3.4.

Table 3.4 Variable costs of the beam trawl used in the simulation

\begin{tabular}{lcc}
\hline Variable fishing costs & Value & Units \\
\hline Fuel costs & 6400 & $€ \mathrm{~d}^{-1}$ \\
Gear maintenance & 347 & $€ \mathrm{~d}^{-1}$ \\
Landing costs & 0.24 & $€ \mathrm{~kg}^{-1}$ \\
Employment costs & 33 & $\%$ \\
Other variable costs & 0.05 & \\
\hline
\end{tabular}

\section{RESULTS}

\section{TRAWL CATCH RATES}

The input data of the simulation model consists of the estimates of the weekly catch rates for the different size classes of plaice, sole and cod. Distinct seasonal patterns between the different size classes for each of the three target species are observed (Fig. 3.3). Large plaice ( $>31 \mathrm{~cm}$, size classes 1,2 and 3) exhibit a similar seasonal distribution in most areas with low catch rates during spring and summer and high catch rates in the winter months. The smallest marketable size class $(27-31 \mathrm{~cm}$, size class 4$)$ exhibits the opposite pattern with higher catch rates in spring and summer and lower catch rates in winter months. In addition, the catchability of large plaice appears to be higher in the more central and northern areas of the North Sea (e.g. area 13, Southern Dogger Bank) compared to the more coastal areas (e.g. area 3, Southern Bight). 


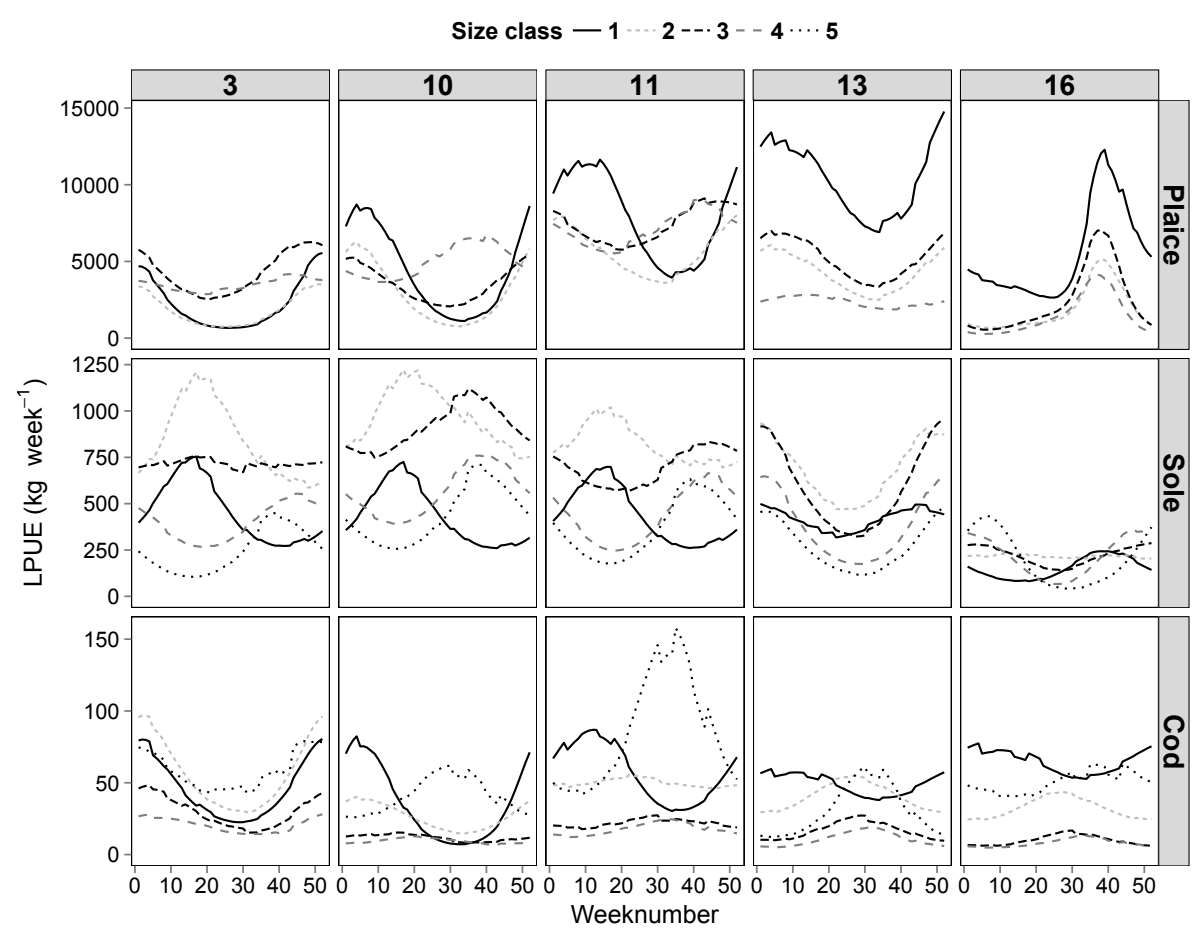

Figure 3.3

Seasonal variations in the landings per unit of effort (LPUE

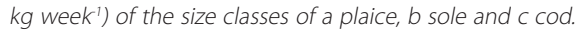

Size classes are ordered from 1-large to 5-small

For sole, the catch rates of the larger size classes ( $>33 \mathrm{~cm}$, size class 1 and 2$)$ peak in winter and early spring, while the smaller size classes (size classes 3, 4, and 5) show a seasonal pattern, with a peak in summer and early autumn similar to that for smaller plaice. Sole catch rates are highest in the North Sea areas closer to the coast such as the Southern and German Bight (areas 3 and 10). Within the more central and northern areas of the North Sea catch rates are lower.

The highest catch rates of cod (all size classes) within the coastal areas (area 3, southern Bight) are observed in December and January. A different pattern emerges for the offshore areas such as the German Bight (area 10 and 11) where the catch rates of the smallest size class $(35-46 \mathrm{~cm})$ peak in late spring and summer while large cod $(88+\mathrm{cm})$ catch rates peak in winter and early spring. These patterns although still present, level off in most northern areas such as the Dogger Bank and Central North Sea (area 13 and 16). Catch rates of intermediate size classes ( 3 and 4 ) of cod are consistently low throughout the year for all areas. 


\section{SIMULATION MODEL}

The catch rates for the different size classes of plaice, sole, and cod are used as input to the model, together with the cost structure for the different choices. The model is run for individual plaice quotas ranging from 100 to 800 t. No publicly available information exists on the amount of individual quotas per vessel, hence we used the 2013 plaice landings of the fishing vessels of the Dutch harbor Urk as a proxy for individual quotas. The landings ranged between 160 and 795 t per vessel, with a median of 629 t. Runs are used to evaluate the effects of different landing ITQ levels on effort allocation, and discarding behavior.

\section{EFFORT ALLOCATION}

Increasing individual quota for the limiting species results in a very small increase in overall fishing effort per vessel. However, there is a substantial reallocation of fishing effort over the fishing areas (Fig. 3.4). A low individual quota results in a concentration of fishing effort in the German Bight (area 10) which is one of the areas open for fishing close to the harbor As individual quotas increase, more effort is allocated to areas 11 and 13 at the expense of effort in area 10. This shift to northern fishing grounds can be explained by the availability of large plaice in those areas.

Figure 3.4

Annual fishing effort (days at sea) and fishing areas selected as a function of the plaice quota for a beam trawler under a management regime where discarding is allowed. Area 4 is only selected for quotas $>300$ tonnes year ?. The effort allocated to this area is extremely limited. The majority of effort is allocated to areas 10,11 , and 13

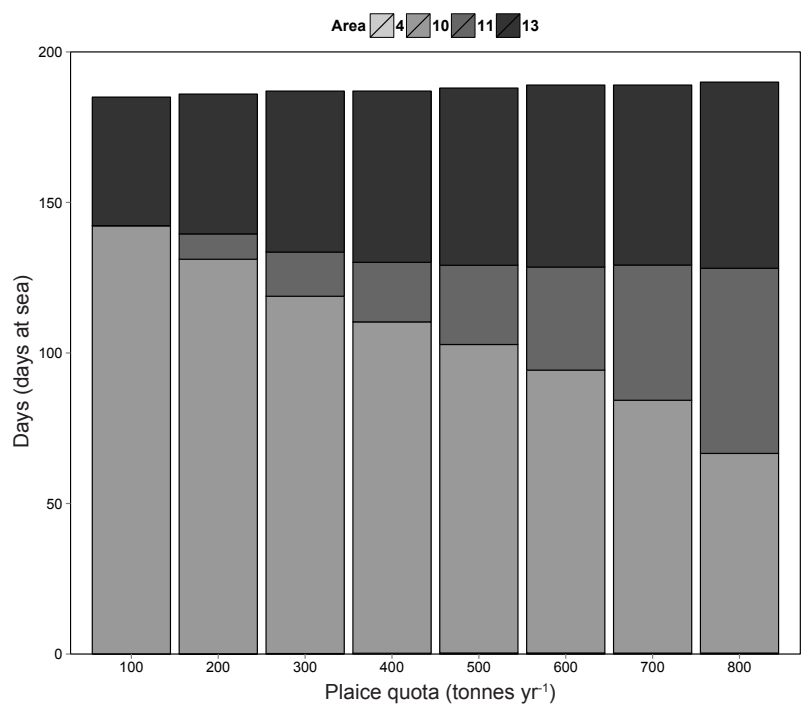

\section{CATCHES OF MARKETABLE FISH}

The marketable catches comprise landings and discards (over-quota and high-graded fish). Landings are perfectly controlled by the individual quota because fines for overshooting quota are much higher than the value of the extra catch and the risk of getting fined for overshooting is $100 \%$ in the model. Discarding of marketable plaice occurs in two different ways: over-quota discarding, when quota is exhausted and discarding occurs for all size clas- 
ses, and high-grading, when fishers have quota available and discard certain size classes. The model results indicate that over-quota discarding is largely unaffected by the amount of quota available, while high-grading increases with a decreasing quota (Fig. 3.5).

All over-quota discarding occurs at the end of the year (Fig. 3.6). When more quota is available, fishers take more time to reach their quota limit and therefore over-quota discarding occurs later in the year. In our case study system, there is substantial seasonal variation in the prices of the different size classes for the limiting species. At the beginning of the year prices for all size classes are lower than later in the year. In addition, larger fish generally fetch higher prices than smaller fish, except for the beginning of the year when the opposite is observed. As a result of the seasonal variability in prices, the highest amount of fish being high-graded is in the first weeks and at the end of the year when fish prices are low (Fig. 3.6). With low quota fishers will high-grade year-round. An increase in quota systematically reduces the occurrence of high-grading throughout the year. The decrease in high-grading first occurs in the middle of the year (price of fish is highest) and then at the end of the year.

The size distribution of the catches, landings and discards of marketable plaice is influenced by the amount of quota (Fig. 3.7). Each of these distributions depends on the allocation of effort to areas or weeks characterised by different size composition and the discarding choices made by the individual skippers. At high quota, there are relatively few discards of the smallest size classes. Reductions in quotas result in an increasing amount of small fish being high-graded. The relationship between the discarding of small fish and the quota is far from linear and results from the interplay between the seasonal differences in availability and ex-vessel price of the different market categories.

\section{Figure 3.5}

Landings and discards (tonnes year ${ }^{1}$ ) of a beam trawler as a function of the plaice quota. Discards are distinguished between high-grading and overquota discarding

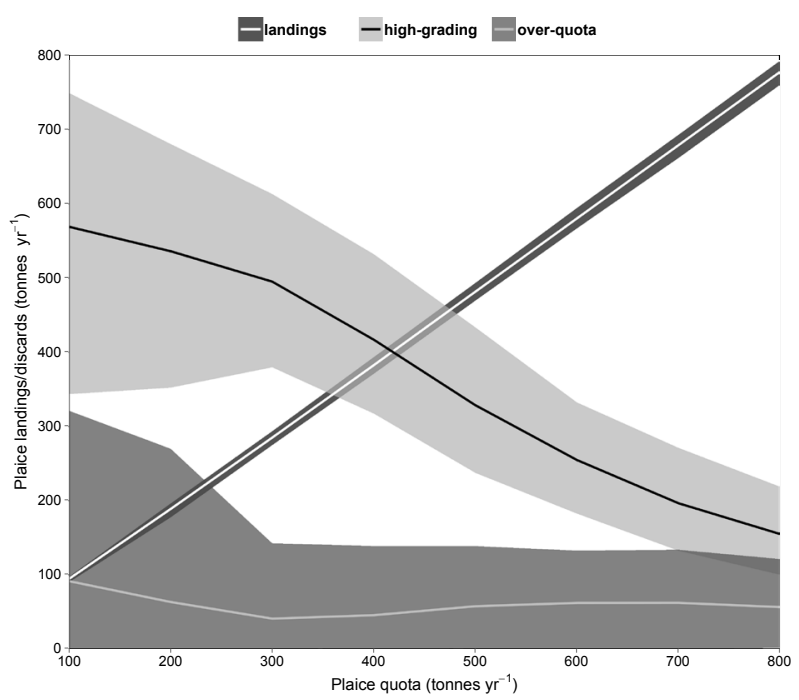



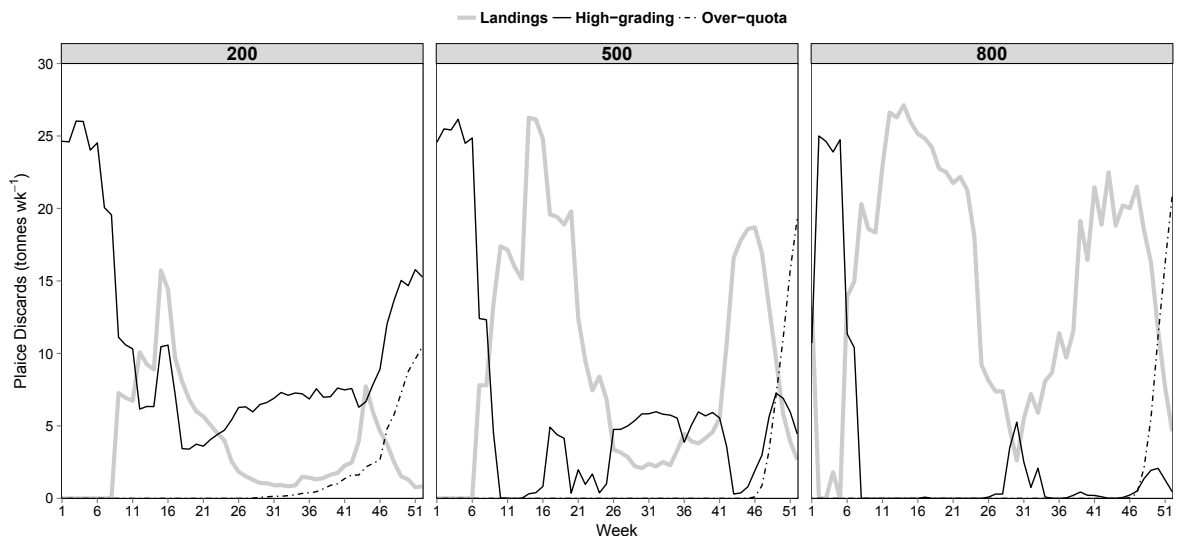

Figure 3.6

Weekly landings and discards for a beam trawler at a plaice quota of 200, 500 and 800 tonnes year'. High-grading and over-quota discarding are depicted separately

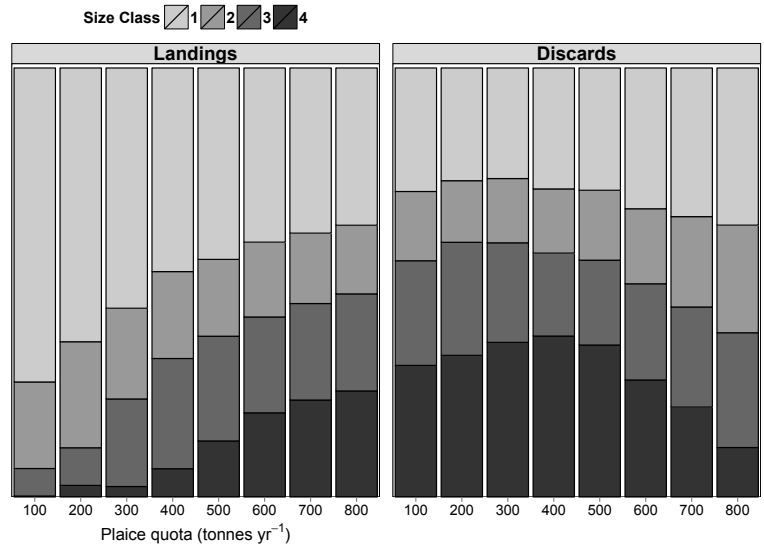

Figure 3.7

Proportion of marketable size classes in the catch, landings and discards for a beam trawler as a function of plaice quota

\section{DISCUSSION}

Having started with a broad query which produced 336 papers, our review of literature resulted in 44 papers describing observations of high-grading. Our findings that only 44 papers contained high-grading observations corroborates Boyd and Dewees (1992), who stated that even if high-grading is expected, it is difficult to detect and prove: on board 
observers may influence the fishing behaviour of skippers and reduce the probability of detection (Liggins et al. 1997, Benoît and Allard 2009). Despite this problem, the positive reports reviewed shows that high-grading occurs worldwide in both pelagic and demersal fisheries, in fisheries with and without ITQs, in commercial and recreational fisheries, and in single-species and mixed fisheries. In all these fisheries, we expect differences in utility among different size classes of fish (Zimmermann and Heino 2013) or among different periods within the quota planning horizon (Rijnsdorp et al. 2012), being one of the prerequisites for high-grading (Branch et al. 2006). We expect the incentive to high-grade to depend on the price differential among the different size classes (Kingsley 2002).

Most of the fisheries in which high-grading was observed are mixed fisheries managed under individual catch quota systems. This is not surprising given that individual quotas allow individuals to maximise the economic return on their quota by high-grading the cheaper parts of the catch and increasing the average return per unit quota (Gillis et al. 1995; Squires and Kirkley 1995). These fisheries allow individual fishers to plan the use of their quota, being it on an annual, trip or other time-period. The mixed nature of the fishery allows income from a fishery even if parts of the limiting quota species are discarded. Meanwhile, discarding of undersized fish may also occur in mixed fisheries if minimum size limits of different species and mesh size regulations do not match (Daan 1997).

Our review suggests that high-grading often occurs because of quota constraints. For example, in the North Sea, megrim (Lepidorhombus whiffiagonis) is high-graded and the likelihood of this species being discarded decreases significantly with increasing quota (Macdonald et al. 2014). Likewise, the amount of high-grading for cod in the North Sea by Belgian fishers decreased nearly linearly with trip quota (Depestele et al. 2011). Elsewhere, high-grading is suggested as a problem of limiting individual quota (Dewees, 1989; Dewees, 1998). In a few cases, market conditions were pinpointed as the important driving force for high-grading. This difference in the frequency of occurrence could suggest that fisheries strive to find markets for as much of their catch as possible.

We found substantially fewer papers that described observations of over-quota discarding than those describing observations of high-grading. This could be due to several reasons. First, high-grading can occur for reasons of constraining quota or market conditions, while over-quota discarding only occurs because of limiting quota. Second, we decided to only include papers where the wording unequivocally indicated that discarding occurred after quotas were depleted. Finally, we expect that fishers will use price differences in market classes and fishing seasons to high-grade their catches, rather than discard the entire catch including the high-valued market categories at the end of the year.

The dynamic state variable model simulates a mixed fishery under individual quota constraints with a price differential among different size classes. Seasonal and size variations of the prices result in the discarding of specific size classes if quota are restrictive. Importantly, the model results indicate that the amount of high-grading is sensitive to the amount of quota, while over-quota discarding is almost constant irrespective of the quota level. The reason for this difference is that high-grading is the result of fishers planning their use of 
available quota. Over-quota discarding is the result of the stochastic nature of the catches which prevents fishers from planning their catches perfectly. Hence, we hypothesize that the amount of over quota discarding is a function of the variability in the catch rates. In an environment with price differences among size classes or seasons, over-quota discarding will decrease with decreasing uncertainty in catch rates.

By incorporating size structure in the resources, seasonally variable catch rates and fish prices we have improved the ability to explore the consequences of quota management on the discarding of marketable size classes compared to earlier studies (e.g. Gillis et al. 1995; Poos et al.; 2010; Batsleer et al., 2013). Some simplifying assumptions, however, still remain. In our study, six assumptions are relevant. First, we assume that individual fishers maximize their economic performance while fully complying with management regulations. Non-compliance to quota regulations would result in a lower amount of high-grading and over-quota discarding if fish are landed illegally. Second, the model ignores quota leasing. Such quota leasing could reduce high-grading and over-quota discarding if fishers who are forced to discard can buy quota from vessels with excess quota because of low catch rates. This quota leasing would not occur in situations with low quota when all vessels are constrained by the quota, or in situations with high quota when no vessels are constrained. Third, the model does not incorporate any frequency or density dependent effects, such as exploitation and interference competition, which may negatively affect catch rates (Rijnsdorp et al. 2000, Gillis 2003), or price formation (as in e.g. Dowling et al. 2012). Fourth, only three target species (i.e. plaice, sole and cod) are included in our model of which only plaice has a catch quota affecting the behavior of a fisher while in reality, sole and cod are also managed by quota. In addition, location choice may also be affected by the availability of other components of the mixed fishery such as turbot (Scophthalmus maxima) and brill (Scophthalmus rhombus) (Gillis et al. 2008). Fifth, we assume that the hold capacity does not constrain the landings within a fishing trip. Finally, the model assumes that the proportional catch of different size categories is fixed within each area and season. In reality, the fishers may have the additional behavioral flexibility of changing the proportional catches of different size categories by changing the mesh size of the gear. However, in our case study the effect of changing the mesh size is substantially different for the different species. Increasing the mesh size has a much stronger effect on the catches of the more valuable sole than it has for plaice, because of the difference in shape between the two species (Van Beek et al. 1983).

Our model shows that fishers can respond to changes in individual quota by reallocation of effort and discarding part of their marketable catch. These results are in line with previous studies showing the adaptability of fishers in a mixed fishery to reallocate effort in space and time thereby optimizing their catch composition relative to the size of the quota (Poos et al. 2010; Batsleer et al. 2013). Our model results indicate that substantial high-grading may occur at the beginning of the year, long before quota are exhausted as a result of seasonal variation in the price of plaice. During the spawning period, the price of the larger size classes of plaice is relatively low as compared to the smaller size classes due to the presence of a large gonad and a lower meat quality of spawning fish (van Overzee and 
Rijnsdorp 2015). High-grading also occurs during other parts of the year, in particular in late summer and autumn when a new year class recruits to the fishery and the high catch rate of the smallest size class coincide with a relatively low price compared to the larger size classes. The amount of over-quota discarding is more limited and by definition concentrated at the end of the year. This over-quota discarding is the result of the uncertainty in the catch rates, preventing individuals from optimizing the use of quota by high-grading alone.

In the model, individual landing quotas are strictly enforced by means of high fines while high-grading is allowed. In reality, high-grading is prohibited in the North Sea since 2009. To test whether a ban on high-grading can be enforced effectively, we estimated the number of observed infringements from the campaign results of the joint deployment plan of the European Fisheries Control Agency (EFCA). All campaign results in terms of number of on board inspections, number of infringements of fisheries conservation measures, and the nature of the infringement are published on the EFCA website. Based on the reports from the period 2009-2012, it seems that inspections in the North Sea rarely detect high-grading: The 3000 inspections carried out, recorded approximately 350 infringements, of which only one was related to high-grading (EFCA 2014). Although this could indicate high-grading in these fisheries occurs rarely, we infer that it reflects the difficulty of detection because (i) high-grading can only be detected by fishery inspectors when fishers are caught in action and (ii) the time needed to process the catch on board is relatively short.

To our knowledge, our study is the first to model discarding of marketable fish while explicitly distinguishing between high-grading and over-quota discarding. Given the difficulties in obtaining reliable estimates of the amount of marketable fish that is discarded, modelling studies can provide the urgently required insight as to the quantity, the age and size structure as well as the conditions when this may be expected. This insight may guide inspection agencies to manage their inspection effort. More importantly, the insight as to the quantity as well as the size or age-structure of the discarded catch will allow fisheries scientists to explore the accuracy of their assessment of the stock (Dickey-Collas et al. 2007; Pawlowski and Lorance 2009; Harley et al. 2000; Heery and Berkson 2009) and the quality of the scientific advice (Daan 1997; Rijnsdorp et al. 2007; Ulrich et al. 2011).

\section{ACKNOWLEDGEMENTS}

This research was supported by the European Community's Seventh Framework Programme (FP7/2007-2013) under Grant Agreement No. 266445 for the VECTORS project and grant agreement no 289257 for the MYFISH project. We thank the two anonymous reviewers whose comments helped improve and clarify this manuscript.. 


\section{REFERENCES}

Aarts, G., Poos, J.J. (2009) Comprehensive discard reconstruction and abundance estimation using flexible selectivity functions. ICES Journal of Marine Science 66, 763-771.

Allain, V., Biseau, A. and Kergoat, B. (2003) Preliminary estimates of French deepwater fishery discards in the Northeast Atlantic Ocean. Fisheries Research 60, 185-192.

Anderson, L.G. (1994) An economic analysis of highgrading in ITQ fisheries regulation programs. Marine Resource Economics 9, 209-226.

Annala, J.H. (1996) New Zealand's ITQ system: Have the first eight years been a success or a failure? Reviews in Fish Biology and Fisheries 6, 43-62.

Arnason, R. (1993) The Icelandic individual transferable quota system: A descriptive account. Marine Resource Economics 8, 201-218.

Baelde, P. (2001) Fishers' description of changes in fishing gear and fishing practices in the Australian South East Trawl Fishery. Marine Freshwater Resources $52,411-17$.

Barnard, D.R. and Pengilly, D. (2006) Estimates of red king crab bycatch during the 2005/2006 Bristol Bay red king crab fishery with comparisons to the 1999-2004 seasons. Alaska Department of Fish and Game. Fishery data series No. 06-23. Anchorage.

Batsleer, J., Poos, J.J., Marchal, P., Vermard, Y., Rijnsdorp, A.D. (2013) Mixed fisheries management: protecting the weakest link. Marine Ecology Progress Series 479, 177-190.

Baudron, A., Ulrich, C., Nielsen, J.R., Boje, J. (2010) Comparative evaluation of a mixed-fisheries effort-management system based on the Faroe Islands example. ICES Journal of Marine Science 67 1036-1050.

Benoît, H.P., Allard, J. (2009) Can the data from atsea observer surveys be used to make general inferences about catch composition and discards? Canadian Journal of Fisheries and Aquatic Sciences 66, 2025-2039.

Bochenek, E.A., Powell, E.N. and DePersenaire, J. (2012) Recall bias in recreational summer flounder party boat trips and angler preferences to new approaches to bag and size limits. Fisheries Science $78,1-14$
Bök, T.D., Goktürk, D. and Kahraman, A.E. (2011) Bycatch in 36 and $40 \mathrm{~mm}$ PA Turkish twin rigged beam trawl codends. African Journal of Biotechnology 10, 7294-7302.

Borges, L., Van Keeken, O.A., Van Helmond, A.T.M. Couperus, B., Dickey-Collas, M. (2008) What do pelagic freezer-trawlers discard /CES Journal of Marine Science 65, 605-611

Borges, L., Zuur, A.F., Rogan, E. and Officer, R. (2006) Modelling discard ogives from Irish demersal fisheries. ICES Journal of Marine Science 63, 1086-1095.

Boyd, R.O., Dewees, C.M. (1992) Putting theory into practice: Individual transferable quotas in New Zealand's fisheries. Society \& Natural Resources 5, 179-198.

Branch, T.A. (2009) How do individual transferable quotas affect marine ecosystems? Fish and Fisheries 10, 39-57.

Branch, T.A., Hilborn, R. (2008) Matching catches to quotas in a multispecies trawl fishery: targeting and avoidance behavior under individual transferable quotas. Canadian Journal of Fisheries and Aquatic Sciences 65, 1435-1446.

Branch, T.A., Rutherford, K., Hilborn, R. (2006) Replacing trip limits with individual transferable quotas: implications for discarding. Marine Policy 30, 281-292.

Brewer, J.F. (2011) Paper fish and policy conflict: Catch shares and ecosystem-based management in Maine's groundfishery. Ecology and Society 16, 15.

Campbell, M.J., McLennan, M.F., Sumpton, W.D. (2014) Short-term survival of discarded pearl perch (Glaucosoma scapulare Ramsay, 1881) caught by hook-and-line in Queensland, Australia. Fisheries Research 151, 206-212.

Catchpole, T.L., Feekings, J.P., Madsen, N., Palialexis, A., Vassilopoulou, V., Valeiras, J., Garcia, T., Nikolic, N., Rochet, M.-J. (2014) Using inferred drivers of discarding behaviour to evaluate discard mitigation measures. ICES Journal of Marine Science 71, 12771285

Cetinić, P., Škeljo, F. and Ferri, J. (2011) Discards of the commercial boat seine fisheries on Posidonia oceanica beds in the eastern Adriatic Sea. Scientia Marina 75, 289-300. 
Christy, F. T. (1973). Fisherman quotas: a tentative suggestion for domestic management, Law of the Sea Institute, University of Rhode Island. 19:7 pp.

Clark, C.W., Mangel, M. (2000) Dynamic state variable models in ecology: Methods and applications, Oxford University Press, Oxford, Uk. 304 pp.

Clark, J.H. and Kahn, D.M. (2009) Amount and disposition of striped bass discarded in Delaware's spring striped bass gill-net fishery during 2002 and 2003: Effects of regulations and fishing strategies. North American Journal of Fisheries Management 29, 576-585.

Copes, P. (1986) A critical review of the individual quota as a device in fisheries management. Land Economics 62, 278-291.

Cullis-Suzuki, S., McAllister, M., Baker, P., Carruthers, T. and Tate, T.J. (2012) Red snapper discards in the Gulf of Mexico: Fishermen's perceptions following the implementation of individual fishing quotas. Marine Policy 36, 583-591.

Daan, N. (1997) TAC management in North Sea flatfish fisheries. J Sea Res 37, 321-341.

Davies, N.M. (1992) Fisheries management - a New Zealand perspective. South African Journal of Marine Science 12, 1069-1077.

Depestele, J., Vandemaele, S., Vanhee, W., et al. (2011) Quantifying causes of discard variability: an indispensable assistance to discard estimation and a paramount need for policy measures. ICES Journal of Marine Science 68, 1719-1725.

Dewees, C.M. (1989) Assessment of the implementation of individual transferable quotas in New Zealand's inshore fishery. North American Journal of Fisheries Management 9, 131-139.

Dewees, C.M. (1998) Effects of individual quota systems on New Zealand and British Columbia fisheries. Ecological Applications 8, S133-S138.

Dickey-Collas, M., Pastoors, M.A. and van Keeken, O.A. (2007). Precisely wrong or vaguely right: simulations of noisy discard data and trends in fishing effort being included in the stock assessment of North Sea plaice. ICES Journal of Marine Science 64, 1641-1649.

Dowling, N.A., Wilcox, C., Mangel, M., Pascoe, S. (2012) Assessing opportunity and relocation costs of marine protected areas using a behavioural model of longline fleet dynamics. Fish and Fisheries 13, 139-157.
EFCA (2014) Webpage for the Joint Deployment Plan (JDP) of the European Fisheries Control Agency for North Sea and Western waters. http://efca. europa.eu/pages/home/jdp_north.htm. Accessed 01-09-2014.

Eliasen, S.Q., Papadopoulou, K.-N., Vassilopoulou, V., Catchpole, T.L. (2014) Socio-economic and institutional incentives influencing fishers' behaviour in relation to fishing practices and discard. ICES Journal of Marine Science 71, 1298-1307.

Feekings, J., Bartolino, V., Madsen, N., Catchpole, T. (2012) Fishery discards: Factors affecting their variability within a demersal trawl fishery. PLOS ONE7, e36409.

Feekings, J., Lewy, P., Madsen, N. (2013) The effect of regulation changes and influential factors on Atlantic cod discards in the Baltic Sea demersal trawl fishery. Canadian Journal of Fisheries and Aquatic Sciences 70, 534-542.

Fujita, R.M., Foran, T., Zevos, I. (1998) Innovative approaches for fostering conservation in marine fisheries. Ecological Applications 8, S139-S150.

Gillis, D.M. (2003) Ideal free distributions in fleet dynamics: a behavioral perspective on vessel movement in fisheries analysis. Canadian Journal of ZOology 81, 177-187.

Gillis, D.M., Pikitch, E.K., Peterman, R.M. (1995) Dynamic discarding decisions - foraging theory for high-grading in a trawl fishery. Behavioural Ecology 6, 146-154.

Gillis, D.M., Rijnsdorp, A.D., Poos, J.J. (2008) Behavioral inferences from the statistical distribution of commercial catch: patterns of targeting in the landings of the Dutch beam trawler fleet. Canadian Journal of Fisheries and Aquatc Sciences 65, 27-37.

Gray, C.A. (2002) Management implications of discarding in an estuarine multi-species gill net fishery. Fisheries Research 56, 177-192.

Gray, C.A., Johnson D.D., Broadhurst M.K., Young D.J. (2005) Seasonal, spatial and gear-related influences on relationships between retained and discarded catches in a multi-species gillnet fishery. Fisheries Research 75, 56-72.

Gray, C.A., Kennelly, S.J. (2003) Catch characteristics of the commercial beach-seine fisheries in two Australian barrier estuaries. Fisheries Research 63, 405-422. 
Hamon, K.G., Thébaud, O., Frusher, S., Little, L.R. (2009) A retrospective analysis of the effects of adopting individual transferable quotas in the Tasmanian red rock lobster, Jasus edwardsii, fishery. Aquatic Living Resourses 22, 549-558.

Hannesson, R. (2013) Norway's experience with ITQs. Marine Policy 37, 264-269.

Hara, M.M. (2013) Efficacy of rights-based management of small pelagic fish within an ecosystems approach to fisheries in South Africa. African Journal of Marine Science 35, 315-322.

Harley, S.J., Millar, R.B., McArdle, B.H. (2000) Examining the effects of changes in the minimum legal sizes used in the Hauraki Gulf snapper (Pagrus auratus) fishery in New Zealand. Fisheries Research 45, 179-187.

Heery, E.C. and Berkson, J. (2009) Systematic errors in length frequency data and their effect on age-structured stock assessment models and management. T Am Fish Soc 138, 218-232.

Holden, M.J.T. (1994) The Common Fisheries Policy. Origin, Evaluation and Future, Fishing News Books, Oxford, UK.

Houston, A.l., McNamara, J.M. (1999) Models of Adaptive Behaviour, Cambridge University Press, UK.

Kaplan, I.C., Holland, D.S., Fulton, E.A. (2014) Finding the accelerator and brake in an individual quota fishery: Linking ecology, economics, and fleet dynamics of US West Coast trawl fisheries. ICES Journal of Marine Science 71, 308-319.

Kelleher, K. (2005) Discards in the world's marine fisheries. An update. FAO Fisheries Technical Paper No. 470, Food and Agricultural Organization of the United Nations, Rome, Italy, 131 pp.

Keskin, Ç., Ordines, F., Ates, C., Moranta, J. and Massutí, E. (2014) Preliminary evaluation of landings and discards of the Turkish bottom trawl fishery in the northeastern Aegean Sea (eastern Mediterranean). Scientia Marina 78, 213-225.

Kingsley, M. (2002) ITQs and the economics of high-grading. ICES Journal of Marine Science 59, 649.

Kraak, S.B.M., Bailey, N., Cardinale, M., Darby, C., De Oliveira, J.A.A., Eero, M., Graham, N., Holmes, S., Jakobsen, T., Kempf, A., Kirkegaard, E., Powell, J., Scott, R.D., Simmonds, E.J., Ulrich, C., Vanhee, W., Vinther, M. (2013) Lessons for fisheries management from the EU cod recovery plan. Marine Policy 37, 200-2013.
Kristofersson, D., Rickertsen, K. (2009) Highgrading in quota-regulated fisheries: evidence from the Icelandic cod fishery. American journal of agricultural economics 91, 335-346.

Lehmann, K. and Degel, H. (1991) An estimate of shrimp discard from shrimp factory trawlers in Davis Strait and Denmark Strait. NAFO SCR Doc. 91/40. $11 \mathrm{pp}$.

Liggins, G.W., Bradley, M.J., Kennelly, S.J. (1997) Detection of bias in observer-based estimates of retained and discarded catches from a multi species trawl fishery. Fisheries Research 32, 133-147.

Macdonald, P., Cleasby, I.R., Angus, C.H., Marshall, C.T. (2014) The contribution of quota to the discards problem: a case study on the complexity of common megrim Lepidorhombus whiffiagonis discarding in the northern North Sea. ICES Journal of Marine Science 71, 1256-1265.

Mace, P.M., Sullivan, K.J., Cryer, M. (2014) The evolution of New Zealand's fisheries science and management systems under ITQs. ICES Journal of Marine Science 71, 204-215.

Machias, A., Maiorano, P., Vassilopoulou, V., Papaconstantinou, C., Tursi, A. and Tsimenides, N. (2004) Sizes of discarded commercial species in the eastern-central Mediterranean Sea. Fisheries Research $66,213-222$.

Madsen, N., Feekings, J. and Lewy, P. (2013) Discarding of plaice (Pleuronectes platessa) in the Danish North Sea trawl fishery. Journal of Sea Research 75, 129-134.

Marçalo, A., Araújo, J., Pousão-Ferreira, P., Pierce, G.J., Stratoudakis, Y., Erzini, K. (2013) Behavioural responses of sardines Sardina pilchardus to simulated purse-seine capture and slipping. Journal of Fish Biology 83, 480-500.

McCay, B.J. (1995) Social and ecological implications of ITQs: an overview. Ocean and Coastal Management 28, 3-22.

Muse, B., Schelle, K. (1989) Individual fisherman's quotas: a preliminary review of some recent programs. CFEC Report 89-1.

Neher, P.A. (1994) Fishery management in Canda. In Managing fishery resources: proceedings of a symposium co-sponsored by the World Bank and Peruvian Ministry of fisheries held in Lima, Peru, June 1992, pp. 22-28. Ed. by E. A. Loayza. World Bank discussion papers 217. 
Olbers, J.M., Fennessy, S.T. (2007) Retrospective assessment of the stock status of Otolithes ruber (Pisces: Sciaenidae) as bycatch on prawn trawlers from KwaZulu-Natal, South Africa. African Journal of Marine Science 29, 247-252.

Parslow, J. (2010) Individual transferable quotas and the "tragedy of the commons". Canadian Journal of Fisheries and Aquatic Sciences 67, 1889-1896.

Pascoe, S. (1997) Bycatch management and the economics of discarding. FAO Fisheries Technical Paper370, 153.

Pawlowski, L., Lorance, P. (2009) Effect of discards on roundnose grenadier stock assessment in the Northeast Atlantic. Aquatic Living Resources 22, 573-582.

Pikitch, E.K., Erickson, D.L. and Wallace, J.R. (1988) An evaluation of the effectiveness of trip limits as a management tool. NWAFC Processed report 8827. $37 \mathrm{pp}$.

Poos, J.J., Bogaards, J.A., Quirijns, F.J., Gillis, D.M., Rijnsdorp, A.D. (2010) Individual quotas, fishing effort allocation, and over-quota discarding in mixed fisheries. ICES Journal of Marine Science 67, 323-333.

Poos, J.J., Turenhout, M.N.J., A. E. van Oostenbrugge, H., Rijnsdorp, A.D. (2013) Adaptive response of beam trawl fishers to rising fuel cost. ICES Journal of Marine Science 70, 675-684.

Press, W.H., Teukolsky, A.A.,Vetterling, W.T., Flannery, B.P. (2002) Numerical recipes in $\mathrm{C}++$. Cambridge University Press, Cambridge, UK.

Punt, A.E., Smith, D.C., Tuck, G.N., Methot, R.D. (2006) Including discard data in fisheries stock assessments: Two case studies from south-eastern Australia. Fisheries Research 79, 239-250.

Quirijns, F.J., Poos, J.J., Rijnsdorp, A.D. (2008) Standardizing commercial CPUE data in monitoring stock dynamics: Accounting for targeting behaviour in mixed fisheries. Fisheries Research 89, $1-8$.

R Core Development Team (2013) R: A language and environment for statistical computing. R Foundation for Statistical Computing, Vienna, Austria. ISBN 3-900051-07-0, URL http://www.R-project. org/.

Richards, L.J. (1994) Trip limits, catch, and effort in the British Columbia rockfish trawl fishery. North American Journal of Fisheries Management 14, 742-750.
Rijnsdorp, A.D., Broekman, P.L.V., Visser, E.G. (2000) Competitive interactions among beam trawlers exploiting local patches of flatfish in the North Sea. ICES Journal of Marine Science 57, 894-902.

Rijnsdorp, A.D., Daan, N., Dekker, W., Poos, J.J., Van Densen, W.L.T. (2007) Sustainable use of flatfish resources: Addressing the credibility crisis in mixed fisheries management. Journal of Sea Research 57, 114-125.

Rijnsdorp, A.D., Poos, J.J., Quirijns, F.J. (2011) Spatial dimension and exploitation dynamics of local fishing grounds by fishers targeting several flatfish species. Canadian Journal of Fisheries and Aquatic Sciences 68, 1064-1076.

Rijnsdorp, A.D., Poos, J.J., Quirijns, F.J., Hille Ris Lambers, R., De Wilde, J.W., Den Heijer, W.M. (2008) The arms race between fishers. Journal of Sea Research 60, 126-138.

Rijnsdorp, A.D., van Overzee, H.M.J., Poos, J. (2012) Ecological and economic trade-offs in the management of mixed fisheries: a case study of spawning closures in flatfish fisheries. Marine Ecology Progress Series 447, 179-194.

Robinson, C. and Pascoe, S. (1998) Fisher behaviour: exploring the validity of the profit maximising assumption. In Proceedings of the Ninth Conference of the European Association of Fisheries Economists, pp. 167-183. Ed. by J. P. Boude, and J. Boncoeur. Centre for the Economics and Management of Aquatic Resources (CEMARE), University of Portsmouth, UK, Discussion Paper 110.

Rochet, M.-J., Trenkel, V.M. (2005) Factors for the variability of discards: assumptions and field evidence. Canadian Journal of Fisheries and Aquatic Sciences 62, 224-235.

Rochet, M.J., Peronnet, I., Trenkel, V.M. (2002) An analysis of discards from the French trawler fleet in the Celtic Sea. ICES Journal of Marine Science 59, 538-552.

Salz, P. (1996) ITQs in the Netherlands: twenty years of experience. Document ICES CM 1996/P:18. 18 pp.

Sanchirico, J.N., Holland D., Quigley, K., Fina, M. (2006) Catch-quota balancing in multispecies individual fishing quotas. Marine Policy 30, 767-785.

Santojanni, A., Cingolani, N., Arneri, E., Kirkwood, G., Belardinelli, A. Giannetti, G., Coleella, S., Donato, F., Barry, C. (2005) Stock assessment of sardine (Sardina pilchardus, Walb.) in the Adriatic Sea, with an estimate of discards. Scientia Marina 69, 603-617. 
Sauls, B. (2014) Relative survival of gags Mycteroperca microlepis released within a recreational hook-and-line fishery: Application of the Cox Regression Model to control for heterogeneity in a large-scale mark-recapture study. Fisheries Research 150, 18-27.

Scott-Denton, E., Cryer, P.F., Gocke, J.P., Harrelson, M.R., Kinsella, D.L., Pulver, J.R., Smith, R.C. and Williams, J.A. (2011) Descriptions of the U.S. Gulf of Mexico reef fish bottom longline and vertical line fisheries based on observer data. Marine Fisheries Review 73, 1-26.

Smith, W.E., Scharf, F.S. (2011) Postrelease survival of sublegal southern flounder captured in a commercial gill-net fishery. North American Journal of Fisheries Management 31, 445-454.

Soliman, A. (2014) Using individual transferable quotas (ITQs) to achieve social policy objectives: A proposed intervention. Marine Policy 45, 76-81.

Squires, D., Campbell, H., Cunningham, S., et al. (1998) Individual transferable quotas in multispecies fisheries. Marine Policy 22, 135-159.

Squires, D., Kirkley, J. (1995) Resource rents from single and multispecies individual transferable quota programs. /CES Journal of Marine Science 52, 153-164.

Stratoudakis, Y., Fryer, R.J. and Cook, R.M. (1998) Discarding practices for commercial gadoids in the North Sea. Canadian Journal of Fisheries and Aquatic Sciences 55, 1632-1644.

ter Hofstede, R., Dickey-Collas, M. (2006) An investigation of seasonal and annual catches and discards of the Dutch pelagic freezer-trawlers in Mauritania, Northwest Africa. Fisheries Research 77, 184-191.

Tsagarakis, K., Vassilopoulou, V., Kallianiotis, A. and Machias, A. (2012) Discards of the purse seine fishery targeting small pelagic fish in the eastern Mediterranean Sea. Scientia Marina 76, 561-572.

Turner, M.A. (1997) Quota-Induced Discarding in Heterogeneous Fisheries. Journal of Environmental Economics and Management 33, 186-195.

Ulleweit, J., Stransky, C., Panten, K. (2010) Discards and discarding practices in German fisheries in the North Sea and Northeast Atlantic during 20022008. Journal of Applied Ichthyology 26, 54-66.

Ulrich, C., Reeves, S.A., Vermard, Y., Holmes, S.J., Vanhee, W. (2011) Reconciling single-species TACs in the North Sea demersal fisheries using the Fcube mixed-fisheries advice framework. ICES Journal of Marine Science 68, 1535-1547.
Van Beek, F.A., Rijnsdorp, A.D., Van Leeuwen, P.I. (1983) Results of the mesh selection experiments on sole and plaice with commercial beam-trawl vessels in the North Sea in 1981. Document ICES CM 1983/B: 16. 24 pp.

Van Beek, F.A., Van Leeuwen, P.I., Rijnsdorp, A.D. (1990) On the survival of plaice and sole discards in the otter-trawl and beam-trawl fisheries in the North Sea. Journal of Sea Research 26, 151-160.

van Marlen, B., Wiegerinck, J.A.M., van Os-Koomen, E., van Barneveld, E. (2014) Catch comparison of flatfish pulse trawls and a tickler chain beam trawl. Fisheries Research 151, 57-69.

Van Overzee, H.M.J. and Rijnsdorp, A.D. (2015) Effects of fishing during the spawning period: implications for management. Reviews in Fish Biology and Fisheries. DOI: 10.1007/s11160-014-9370-x.

Van Putten, I.E., Kulmala, S., Thébaud, O., Dowling, N., Hamon, K.G., Hutton, T., Pascoe, S. (2012) Theories and behavioural drivers underlying fleet dynamics models. Fish and Fisheries 13, 216-235

Welch, D.J., Mapstone, B.D. and Begg, G.A. (2008) Spatial and temporal variation and effects of changes in management in discard rates from the commercial reef line fishery of the Great Barrier Reef, Australia. Fisheries Research 90, 247-260.

Wood, S.N. (2006) Generalized Additive Models: an Introduction with R. Chapman and Hall/CRC Press, New York.

Wood, S.N. (2011) Fast stable restricted maximum likelihood and marginal likelihood estimation of semiparametric generalized linear models. Journal of the Royal Statistical Society: Series B 73, 3-36

Yergey, M.E., Grothues, T.M., Able, K.W., Crawford, C., DeCristofer, K. (2012) Evaluating discard mortality of summer flounder (Paralichthys dentatus) in the commercial trawl fishery: Developing acoustic telemetry techniques. Fisheries Research 115-116, 72-81.

Zimmermann, F., Heino, M. (2013) Is size-dependent pricing prevalent in fisheries? The case of Norwegian demersal and pelagic fisheries. /CES Journal of Marine Science 70, 1389-1395.

Zuur, A.F., leno, E.N., Walker, N.J., Saveliev, A.A., Smith, G.M. (2009) Mixed effect models and extensions in ecology in R, Springer, New York. 


\section{CHAPTER 4}

\section{MIXED FISHERIES MANAGEMENT: IS THE BAN ON DISCARDING LIKELY TO PROMOTE MORE SELECTIVE AND FUEL EFFICIENT FISHING IN THE DUTCH FLATFISH FISHERY?}

Batsleer J., Rijnsdorp A.D., Hamon K. G., Overzee H.M.J., Poos J.J. 


\section{ABSTRACT}

We model the potential effects of a discard ban on the annual fishing strategy of individual fishers in a mixed fishery under individual quota management. The North Sea beam trawl fishery, which catches large amounts of undersized plaice, is used as a model system. Under a discard ban, fishing is restricted to the fishing grounds and weeks where a maximum revenue can be realised with other species while catching the quota of the restricted species with a reduced bycatch of undersized fish. Model results suggest that, if properly enforced, a discard ban provides an incentive to implementation of more selective fishing gears that catch fewer small fish and are more fuel efficient (pulse trawl). If a discard ban is not properly enforced, restrictive quota do not necessarily result in the intended decrease in discarding as the fishery continues to fish while discarding the over-quota catch and least valuable size classes caught.

\section{KEYWORDS}

landing obligation,

4 beam trawl,

pulse trawl, sole, plaice,

North Sea,

TAC,

quota. 


\section{INTRODUCTION}

Among the concerns about sustainable exploitation is the discarding of part of the catch (Alverson et al., 1994; Jennings and Kaiser, 1998; Uhlmann et al., 2014). Because trawl fisheries are generally not fully selective for the marketable fish species and fish size categories, they can catch a large proportion of undersized target species, non-target species, and over-quota catches and lower valued fish of quota species. These catches are subsequently discarded (Gillis et al., 1995a; Catchpole et al., 2005). Discarding may occur because of a mismatch between fishing opportunities and fishing capacity (over-quota discarding and highgrading), or because of a mismatch between minimum landing size (MLS) and mesh size regulations for species caught in mixed fisheries. Many discarded fish do not survive the catching and sorting process (Van Beek et al., 1990; Kaiser and Spencer, 1995; Broadhurst et al., 2006). This additional mortality may jeopardise the sustainable use of marine resources, especially because they are not always well recorded and it can be difficult to account for it in fisheries management (Alverson et al., 1994; Crowder and Murawski, 1998; Dickey-Collas et al., 2007).

In response to the societal concerns about discarding, the 2013 reform of the Common Fisheries Policy (CFP) (Regulation (EU) 1380/2013) of the European Union (EU) includes a discard ban for quota regulated species which are not covered under the prohibited species list (Article 15, Regulation (EU) 1380/2013) (Borges, 2015). This discard ban aims at stopping discarding for commercial valuable species, much like in other countries such as Norway (Diamond and Beukers-Stewart, 2011), Iceland (Arnason, 1995) and New-Zealand (Annala,1996). If properly implemented and enforced, a discard ban could reduce discarding by encouraging the use of more selective gears and by forcing fishers to select fishing areas with lower discard catch rates (Condie et al., 2013; Batsleer et al., 2013). As the catch of undersized fish may not be completely avoided, a discard ban is expected to reduce the economic value of the landings for fisheries operating under catch quota since part of the landings will consist of undersized fish which cannot be sold for human consumption but will likely be sold at a lower price for fish meal (Diamond and Beukers-Stewart, 2011; Buisman et al., 2013). This may create an incentive for the fishing industry to use more selective fishing gears to avoid unwanted catch (Condie et al., 2013, Condie et al., 2014). Gear modifications such as an increase in cod-end mesh size or the deployment of escape panels and sieve nets have proven to reduce the discards of unwanted and undersized fish (Briggs et al., 1999; Revill and Holst, 2004; Catchpole and Revill, 2008).

The North Sea flatfish fishery is mainly carried out by Dutch beam trawlers targeting sole (Solea solea) and plaice (Pleuronectes platessa) with a bycatch of other bottom dwelling fish (Daan, 1997; Gillis et al., 2008) and managed with individual transferable quota (Salz, 1996; Rijnsdorp et al., 2007). Because of the small mesh size required to catch the slender sole, large numbers of undersized plaice are caught and discarded (van Beek, 1998; Aarts and Poos, 2009). The recent increase in the cost of fuel has reduced the economic profitability in this fleet (Rijnsdorp et al., 2008; Bartelings and Soma, 2010). To reduce fuel costs, 
vessels reduced their towing speed and replaced their heavy beam trawl gear with a pulse trawl gear (Beare and Machiels, 2012; Poos et al., 2013b). Pulse trawl gears requires about half of the amount of fuel per hour of fishing as the gear is towed at a lower speed and use electrical pulses to stimulate the flatfish out of the sea bed as compared to the conventional beam trawlers using mechanical stimulation with tickler chains (van Marlen et al., 2014; Soetaert et al., 2015).

In this paper we use the North Sea flatfish fishery as a model of a mixed fishery system to (i) investigate the consequences of a discard ban on the discarding decisions under individual quota management; (ii) test whether a discard ban may promote the transition towards the more selective and energy saving pulse trawl. We use a Dynamic State Variable model that was previously developed for this fishery (Poos et al. 2010). This model is adapted to allow studying how a discard ban will affect the discarding decisions and economic profitability of conventional beam trawlers and new pulse trawlers. The response of the fleet to a discard ban is compared to the situation where discarding is allowed. The latter situation reflects both the current management regime and the situation of a discard ban where fishers do not comply with the regulation. Although the model is parameterised for two gear types used within the Dutch flatfish fishery we make several simplifications that affect the numerical outcomes. Nevertheless, our results are informative of the potential effects of the discard ban on the discarding decisions and the transition towards a more selective and fuel efficient fishing gear.

\section{METHODS}

\section{SIMULATION MODEL}

We model bottom trawl fishers targeting three size-structured fish species (sole, plaice and cod). For each species we model 5 size categories, based on regulatory market categories. The fishers operate under individual landings quota for the target species using either conventional beam trawl gear or pulse trawl gear. The two gears differ in catch efficiency, species- and size-selectivity and cost structures (van Marlen et al., 2014). A Dynamic-State Variable Model (DSVM: Clark and Mangel, 2000, Houston and McNamara, 1999) is used to evaluate annual strategies for fishing vessels under annual landing quotas. Extending the DSVM of Poos et al. (2010) individual skippers maximise expected annual net profit by making weekly decisions: (i) to go fishing or not; (ii) where to fish; (iii) and how much to discard. The weekly time scale is chosen because most fishing trips last from Monday to Friday (Rijnsdorp et al., 2011). The choices depend on spatially and temporally varying catch rates for the different species and size classes, cost structures, and annual quotas.

The expected catch rates of each gear type are a function of fishing location and season. Because the ex-vessel price varies among species, size class and seasons, the size structure of the catch is an important determinant for the economic return of a catch. We assume 
that landings quota are restrictive for a single species; plaice. We chose plaice as an example of a choke species, because it is the target species of which the largest numbers of undersized fish are caught. Hence, plaice quota will likely be the limiting factor when undersized plaice will be counted against the quota.

\section{THE DYNAMIC-STATE VARIABLE MODEL}

The cumulative landings (in weight) of species $s$ of the total number of species $S$ and size class $n$ of $N$ size classes is denoted by $L_{s, n}$. The cumulative landings in weight of the quota constrained species, that we define by $s=1$, represents the state of the individual skipper, denoted by $L$ and equal to $\sum_{N} L_{1, n}$.

The optimal fishing strategy in each week of the year, denoted by $t$ depends on the state of the individual skipper. In our case, the cumulative landings of the quota constrained species affects the possibility to continue fishing and land fish without exceeding the annual individual quota. Dynamic state variable models find the optimal behavioural strategy by working backwards, starting at the end of the year. The expected net revenue at the end of the year is linked to the choices in the preceding weeks by means of a value function between time $t$ and the end of year $T$. The value function depends on the cumulative landings of the quota species $L$ for an individual skipper, the amount of individual quota $U$ for the quota species, the fine per unit weight for exceeding the individual quota $F$, and is expressed as $V(L, U, F, t)$. Individual quota are not transferable and individuals exceeding their quota get a fine that depends on the quota overshoot $(L-U)$, hence the state-dependent part of the revenue at the end of the year is defined by the fine at the end of the year for overshooting the quota:

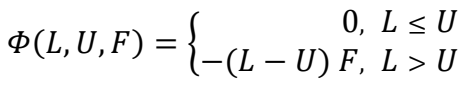

In addition, the expected net revenue is determined by the weekly gross revenue and the costs of fishing. Each week individuals choose to visit fishing area $a$ (including area 0: "staying in harbour") and to keep or discard any combination of the size classes caught of the quota species. This behaviour is defined by the vector $d=\left[d_{1}, d_{2}, \ldots, d_{N}\right]$, in which each element (size class) can take the value 0 (discard) or 1 (keep on board and land).

For all times $t$ preceding $T$ we use stochastic dynamic programming (Clark and Mangel, 2000) to find the optimal solution by backward iteration of:

$H(L, U, F, t ; a, d)=R(a, d, t) * \kappa-G(a)-C(a)+\mathbb{E}_{a, d}\left[V\left(L^{\prime}, U, F, t+1\right)\right]$

Where $R(a, d, t)$ is the expected immediate contribution of the gross revenue from the sales of fish in a week resulting from choices $a$ and $d . H(L, U, F, t ; a, d)$ is thus the utility value of an individual making choice $a$ and $d$, given its state at time $t$ behaving optimally from time $t+1$ onwards. The catches are modelled as a random variable having a negative binomial 
distribution with a mean $m_{s, n, a, t}$ per area, week, species and size class, and a dispersion parameter per species $r_{s}$. The means and dispersion parameters are estimated from logbook data from the case study fleet. The term $\kappa$ represents a factor accounting for the additional revenue obtained from landing marketable species that are not explicitly modelled but are caught while targeting the model species, e.g. turbot, brill, and whiting. The term $G(a)$ are the incurred fuel costs per trip resulting from the choice of fishing area $a$, while the term $C$ (a) represents the variable costs in a week resulting from the choice of fishing area $a$ including crew, landing and other variable costs. The term $L^{\prime}$ reflects the change of the state $L$ resulting from the weekly landings for the quota species. The term $\mathbb{E}_{a, d}\left[V\left(L^{\prime}, U, F, t+1\right)\right]$ denotes the expected value taken over all possible states resulting from choices $a$ and $d$. The future utility given that an individual behaves optimally from time t onwards is:

$V(L, U, F, t)=\max _{a, d}\{H(L, U, F, t ; a, d)\}$

Starting with $V(L, U, F, T)=\Phi(L, U, F)$ we can iterate backwards in time and find the optimal choice in terms of location and discarding behaviour for all possible states, combining the direct net revenue obtained in a fishing trip and the effect of the fines when exceeding annual quota.

The expected direct gross revenue $R(a, d, t)$ is a function of the landings of the of the 5 size classes within the 3 species. These landings result from location choice and the spatial and temporal distribution of the 5 size classes within the 3 species, as well as the discarding decisions. The gross revenue from the main species depends on the landings and the ex-vessel price for a size class of a species in a given week. The landings are determined by the discarding decision and the catches. The expected catches consist of two components: the marketable catches of fish that are larger than the minimum landings size, and the catches of fish that are smaller than the minimum landings size. The model is parameterized from logbook data on marketable catches and effort, discards estimates from Poos et al. (2013), pairwise comparisons of catch rates from beam trawls and pulse trawls, and economic data obtained from accountancy data.

\section{EXPECTED CATCH RATES OF MARKETABLE FISH}

Catch rates of marketable fish for this fishery can only be derived from logbook data on landings. We chose to use the data of the early 1970s because in this period the quality of the data was not affected by misreporting, over-quota discarding or high-grading that may have occurred since the introduction of restrictive quota in the mid 1970's (Daan, 1997; Poos et al., 2010). Weekly catch rates per fishing area for the different size classes of plaice, sole, and cod (Table 4.1) are estimated for 238 conventional large beam trawl vessels ( $>=300 \mathrm{hp}$ ). The engine power of the vessels ranged between 310 to $2500 \mathrm{hp}$, with a mean of $640 \mathrm{hp}$. Fishing areas were defined similar to (Rijnsdorp et al., 2012) (Fig. 4.1). Although estimates were made for all areas, the coastal areas 1,2 and 6-9 are excluded from the DSVM model because large beam trawlers are prohibited from fishing in those areas. 
Table 4.1 Size classes of the three target species. Size class 5 of plaice represents the undersized fish.

\begin{tabular}{cccc}
\hline Size class & Plaice & Sole & Cod \\
\hline 1 & $>41 \mathrm{~cm}$ & $>38 \mathrm{~cm}$ & $>88 \mathrm{~cm}$ \\
2 & $35-41 \mathrm{~cm}$ & $33-38 \mathrm{~cm}$ & $72-88 \mathrm{~cm}$ \\
3 & $31-35 \mathrm{~cm}$ & $30-33 \mathrm{~cm}$ & $55-72 \mathrm{~cm}$ \\
4 & $27-31 \mathrm{~cm}$ & $27-30 \mathrm{~cm}$ & $46-55 \mathrm{~cm}$ \\
5 & $<27 \mathrm{~cm}$ & $24-27 \mathrm{~cm}$ & $35-46 \mathrm{~cm}$ \\
\hline
\end{tabular}

Figure 4.1

Study area, with the fishing areas and the harbour from which the case study fleet operates (black dot).

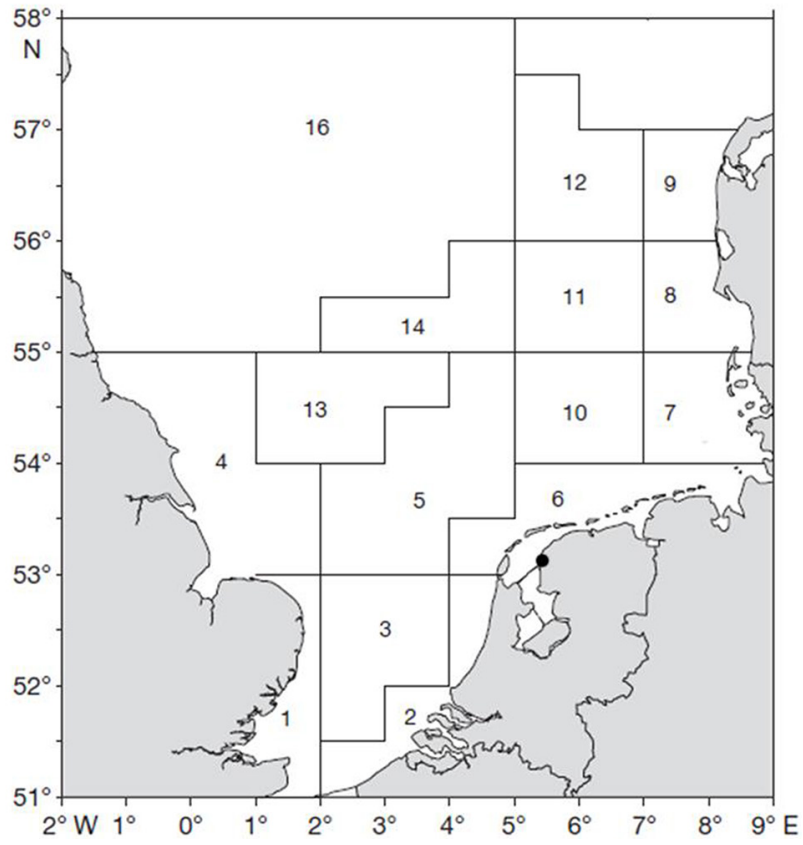

Expected catch rates in each of the fishing areas are statistically modelled using the observations from the logbooks with generalized additive models (GAM; Wood, 2006). The weight of the catches $(\mathrm{kg})$ per size class and species per fishing trip as a response variable while fishing effort (hr) is used as offset variable (Zuur, 2012). By using a negative binomial GAM with a logarithmic link function we allow for over-dispersion and allow zero-observations (Zuur et al., 2009). For each species s, the model is fit independently to data to estimate mean catch by size class and area per week $t$ :

$m_{s, n, a, t}=\alpha+f_{1}(n, a, t)+f_{2}(w n, n)+\beta \log ($ engine power $)+\log ($ effort $)$ 
where $\alpha$ is the model intercept, and $f_{1}$ and $f_{2}$ are smooth functions based on a tensor product smoother (Zuur, 2012). The tensor product smoother $f(n a$, week) is based on a cubic regression spline for size class and a cyclic cubic regression spline for week, by area. The cubic regression spline for week results in equal values and slopes at the beginning and end of the year (Wood, 2006). The covariate $w n$ within the second smoothing term is week number since the start of the data collection and captures the gradual changes in biomass for each size class over time as a result of recruitment and mortality. The maximum degrees of freedom for both smoothing terms is limited $(k=4)$ to prevent over-fitting. The effect of log-transformed covariate engine power (with units $\mathrm{kW}$ ) is estimated in parameter $\beta$ and is included because of its influence on the catch efficiency (Rijnsdorp et al., 2006). Effort is treated as model offset: as a column of the model matrix with associated parameter fixed at 1 (Wood, 2006). In addition to the estimates of the mean catches $m_{s, n, a, t}$ the model also returns the estimated dispersion parameter per species $r_{s}$. All analyses were done using the R statistical program (version 2.12.1; R Development Core Team, 2013).

The GAM model is used to estimate the spatial and temporal patterns in catch rates $\left(\mathrm{kg} \mathrm{week}^{-1}\right)$ for each size class of each target species in the period 1970-1974. To obtain catch rates representative for the current situation, the predictions are rescaled to the values of the spawning stock biomass (SSB) of 2004-2013 (ICES, 2013), multiplying the historic catch rates by the ratio of the SSB estimates in the two periods.

\section{SPATIAL AND TEMPORAL PATTERNS IN CATCH RATE OF UNDERSIZED PLAICE}

For plaice, one of the size classes represents undersized $(<27 \mathrm{~cm})$ fish. Predictions for these catches (in numbers) per $\mathrm{km}^{2}$ by age for the beam trawlers are obtained from (Poos et al., 2013a). The predictions are made for a location within each of the fishing areas. Predicted numbers by age are converted to weight $(\mathrm{kg})$ by applying a von Bertalanffy growth model taking account of the seasonal fluctuations in growth (Somers, 1988) to research survey data and commercial samples collected between 2005 - 2010, and a length-weight relationship estimated from discard samples collected between 2009 and 2011. Catch per week are subsequently calculated accounting for the gear-width (24 m), the towing speed, $\left(12 \mathrm{~km} \mathrm{~h}^{-1}\right)$, the haul duration ( $2 \mathrm{hr}$ ), and the number of hauls per week (40).

\section{CATCH EFFICIENCY OF BEAM TRAWL AND PULSE TRAWL GEAR}

Table 4.2 shows the relative catch efficiency of the pulse trawl and beam trawl. The results are based on the results of a comparative fishing experiment (van Marlen et al., 2014). The difference is partly due to the difference in towing speed: pulse trawl $\sim 5$ nautical miles $\mathrm{h}^{-1}$; conventional beam trawl $\sim 6.5$ nautical miles $\mathrm{h}^{-1}$ and the difference in the species and size selectivity of the gear. 
Table 4.2 Economic and relative catch efficiency $\left(\mathrm{kg} \cdot \mathrm{h}^{-1}\right)$ parameters of the beam trawl and pulse trawl gear used in the simulation.

\begin{tabular}{lll}
\hline Costs parameters & Beam trawl & Pulse trawl \\
\hline Fuel costs & $6400 € \mathrm{~d}^{-1}$ & $2400 € \mathrm{~d}^{-1}$ \\
Gear maintenance & $347 € \mathrm{~d}^{-1}$ & $347 € \mathrm{~d}^{-1}$ \\
Landing costs & $0.24 € \mathrm{~kg}^{-1}$ & $0.24 € \mathrm{~kg}^{-1}$ \\
Employment costs & $33 \%$ & $33 \%$ \\
Other variable costs & 0.05 & 0.05 \\
\hline Catch efficiency parameters & & \\
Sole & 1 & 0.86 \\
Cod & 1 & 0.31 \\
Marketable plaice & 1 & 0.71 \\
Undersized plaice & 1 & 0.52 \\
\hline
\end{tabular}

\section{ECONOMIC DATA}

The three species modelled contribute $82 \%$ to the gross revenue of the beam trawl fleet. Weekly mean ex-vessel price of the marketable size classes are calculated from sale slip data from 2003-2007 (Fig. 4.2). The price for undersized plaice in the discard ban scenario is derived from a market survey demonstrating a selling price between $0.15 € \mathrm{~kg}^{-1}$ and $0.30 € \mathrm{~kg}^{-1}$ can be expected (Buisman et al., 2013). In our study we assumed an average price fixed to $0.22 € \mathrm{~kg}^{-1}$ in the discard ban scenario and $0.00 € \mathrm{~kg}^{-1}$ in the scenario where discarding is allowed and landing undersized fish is prohibited. We ignored price elasticity to keep our model relatively simple. This is a reasonable assumption since in general fish have low elasticity as it can be substituted by other fish products on the world market (Nielsen et al., 2009).
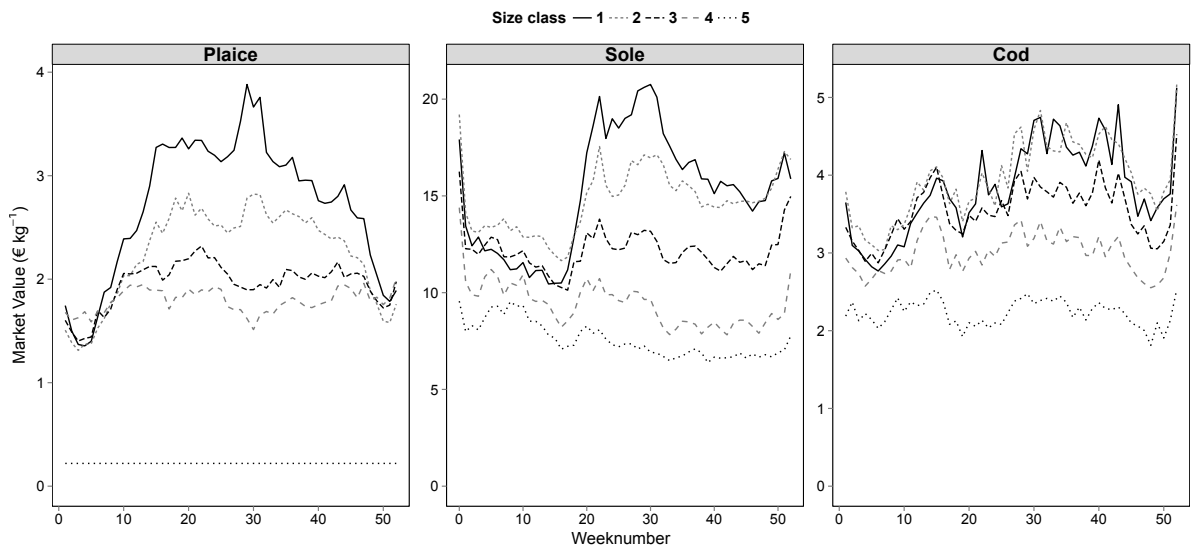

Figure 4.2

Seasonal variation in the ex-vessel price of the five size classes of (a) plaice; (b) sole and (c) cod. Size classes are ordered from 1 (large) to 5 (small). The smallest size class in plaice represents the undersized fish. Ex-vessel prices from the mar- ketable size classes are derived from the actual sales data from 2003 to 2007. Ex-vessel price for undersized plaice are constant and derived from a market analysis (Buisman et al., 2013). 
Information on the cost structure of large Dutch beam trawl vessels (2008-2010) is obtained from accounting data collected annually from a panel of vessels by LEl. The variable costs represent about $75 \%$ to $80 \%$ of the total annual costs and include fuel costs, gear maintenance costs, cost of handling and transportation of landings, crew shares and other variable costs, such as auction and harbour fees. Fuel costs depend on trip effort and fuel price and are estimated to be approximately $€ 6400$ day $^{-1}$ for a large beam trawler and $€ 2400$ day ${ }^{-1}$ for a pulse trawler (van Marlen et al., 2014). Fishing effort per week was estimated from the time spend at sea minus the travel time between the harbour and the fishing ground assuming a steaming speed of $12 \mathrm{n}$ miles $\mathrm{h}^{-1}$ (Poos et al., 2013b). Vessels in the model operate from a single harbour (Harlingen, see Fig. 4.1). Gear maintenance cost is assumed proportional with fishing effort, landing costs proportional to the total weight landed, and other variable costs proportional to the gross revenue (Table 4.2). Crew shares are determined by an agreement between the owner and his crew and is calculated from the gross revenue of which fuel, handling and transportation costs are deducted.

\section{MANAGEMENT SCENARIOS}

Simulations are run for a range of plaice quota (between 100 to 800 tonnes per year per vessel) to study how quota constraints affect discarding decisions and energy efficiency. Two scenarios were applied: one scenario in which discarding is allowed and a second scenario in which discarding is banned. No publicly available information exists on the amount of individual quotas per vessel in the Dutch fleet, hence we used the 2013 plaice landings from one of the main fishing fleets leaving from the harbour of Harlingen as a proxy for individual quotas. The landings ranged between 160 and $795 \mathrm{t}$, with a median of $629 \mathrm{t}$.

\section{RESULTS}

\section{SPATIAL AND TEMPORAL PATTERNS IN CATCH RATE}

Distinct spatial and seasonal patterns in catch rate are observed for the different size classes of plaice, sole and cod. Figure 3 shows the patterns in a selection of areas representing the main fishing areas of the fleet. Catch rates of undersized plaice (size class 5) are high in the eastern North Sea (areas 10 and 11) and show a clear seasonal pattern with high values in summer and early autumn. High catch rates for large plaice (size class 1 and 2) are observed in the eastern area (area 11) and central area (area 13) as well as in the winter period in more southern areas (areas 3 and 10).

Sole catch rates are highest in the southern (area 3) and eastern areas (areas 10 and 11). Catch rates in northern areas is low. Catch rates of the smaller size classes (size classes 3 , 4 , and 5) show a seasonal pattern with a peak in summer and early autumn. In contrast, the catch rates for the larger size classes peak in winter and early spring. 


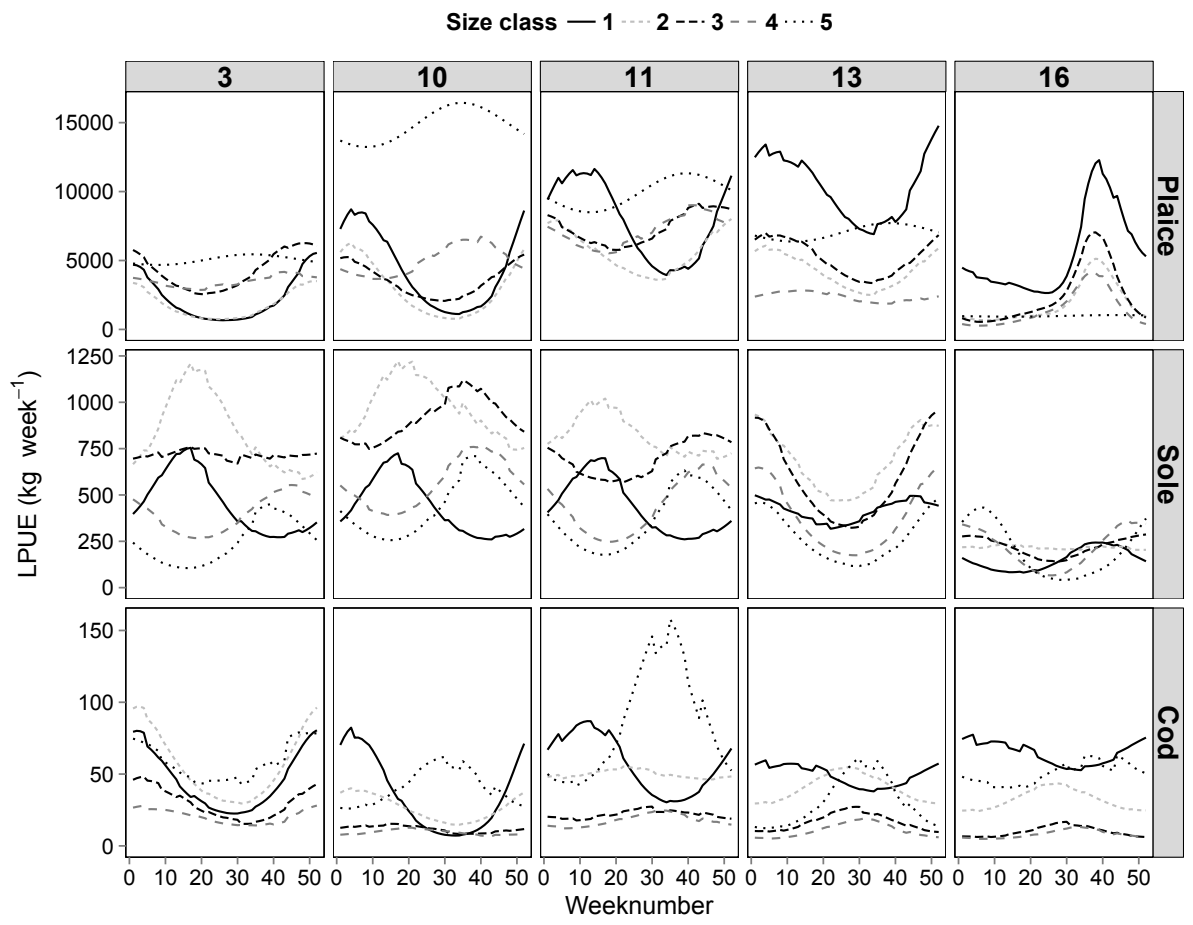

Figure 4.3

Seasonal variation in the landings per unit of effort (LPUE $\mathrm{kg} /$ week-1) of the five size classes of (a) plaice; (b) sole; (c) cod for a selection of fishing areas. Size classes from 1 (large) to 5 (small). The smallest size class in plaice repre- sents the undersized fish. The fishing areas shown are selected to illustrate the typical seasonal distribution pattern in the southern, eastern and central North Sea, and represent the important fishing grounds chosen in our model.

Cod catch rates in the southern North Sea (area 3) show a seasonal peak in winter. In the German Bight (area 10 and 11), catch rates of the smallest size class (size class 5) peak in late spring and summer, while large cod (size class 1 ) catch rates peak in winter and early spring. These patterns, although still present, are less distinct in most northern areas such as the Dogger Bank and Central North Sea (area 13 and 16). Catch rates of intermediate size classes ( 3 and 4 ) of cod are consistently low throughout the year for all areas.

\section{SIMULATED DISCARDING DECISIONS AND LOCATION CHOICE}

Under a discard ban, fishing effort (Fig. 4.4) and catches (Fig. 4.5) are limited by plaice quota, particularly for the conventional beam trawl. Pulse trawlers are less affected by the plaice quota and spend more days fishing and catch substantially more sole than beam trawlers, but less cod. The catch of undersized plaice is similar between both gears. At low plaice quota conventional beam trawlers remain in port in the beginning of the year when exvessel fish prices are low, and later when the catch rates of undersized plaice are relatively high. Pulse trawlers remain in port only in the first weeks of the year. 


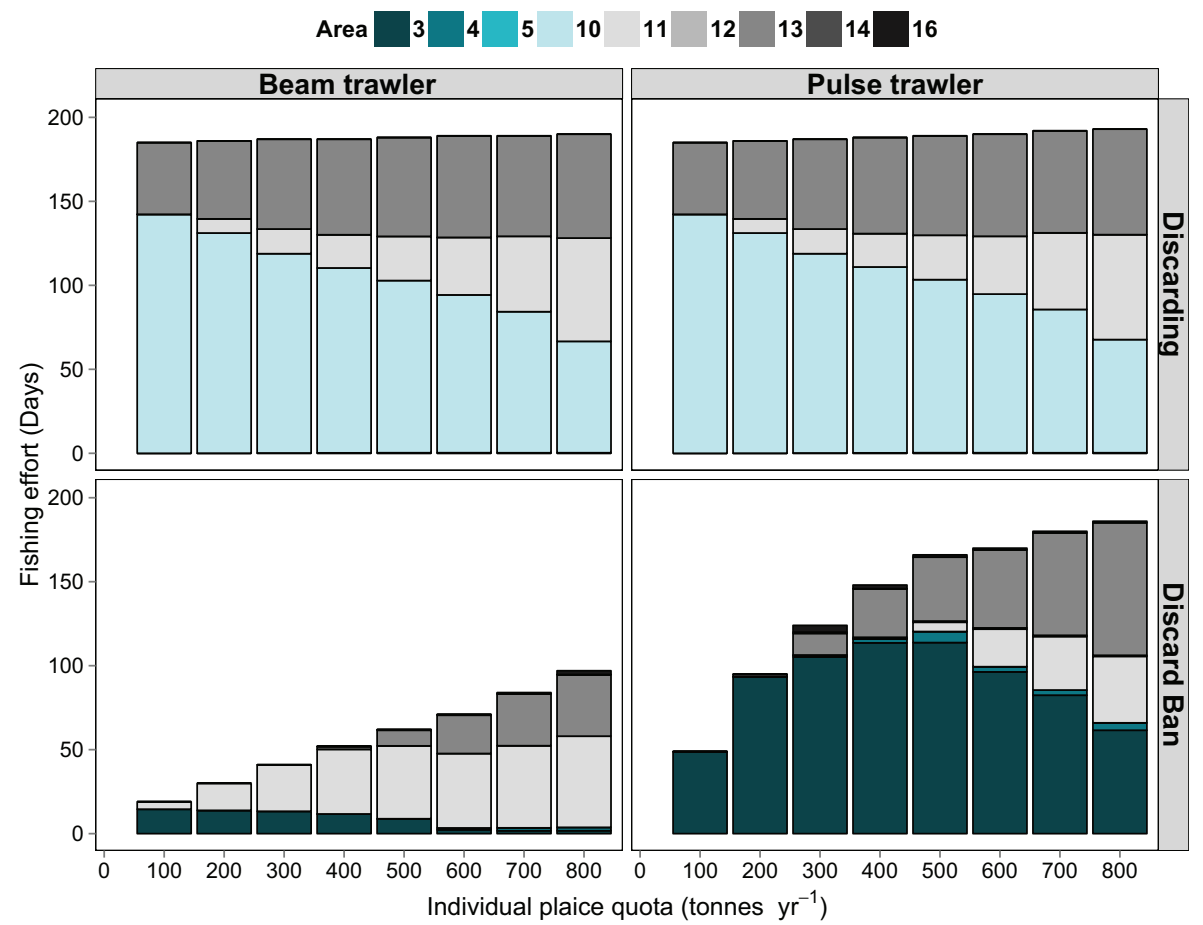

Figure 4.4

Annual fishing effort (days at sea) and fishing areas selected as a function of the plaice quota for a pulse trawler and a conventional beam trawler under a discard ban, and under a management regime where discarding is allowed.

The difference in response to quota between both gears is related to the higher selectivity of the pulse trawl, which catches fewer undersized plaice. This allows the pulse trawlers to deploy more effort in the Southern Bight (area 3) where the catch rate of sole is high (Fig. 4.3). The beam trawl fishes in the German Bight (area 10) where the catch rate of sole is slightly higher than in area 3, in spite of the higher catch rate of under sized plaice. At higher plaice quota, effort is shifted to areas (area 11 and 13) with higher catch rates of large plaice.

If discarding is allowed, a reduction of the plaice quota hardly affects fishing effort, but does affect the location choice (Fig. 4.4). At low plaice quota, both gears predominantly target sole in the German Bight (area 10). At higher plaice quota, the window of opportunity to target marketable plaice in northern areas is higher and more effort is allocated to these areas. As a consequence, a reduction in the plaice quota does not result in a proportional decrease in the catch of marketable plaice because the part of the catch that exceeds the quota will be discarded (Fig. 4.5 and 4.6). A reduction in the plaice quota results in a change in the species composition of the catch: the catch of sole and undersized plaice increases, while the catch of cod decreases. The annual catch of beam trawlers is higher than pulse trawlers (Fig. 4.5). 


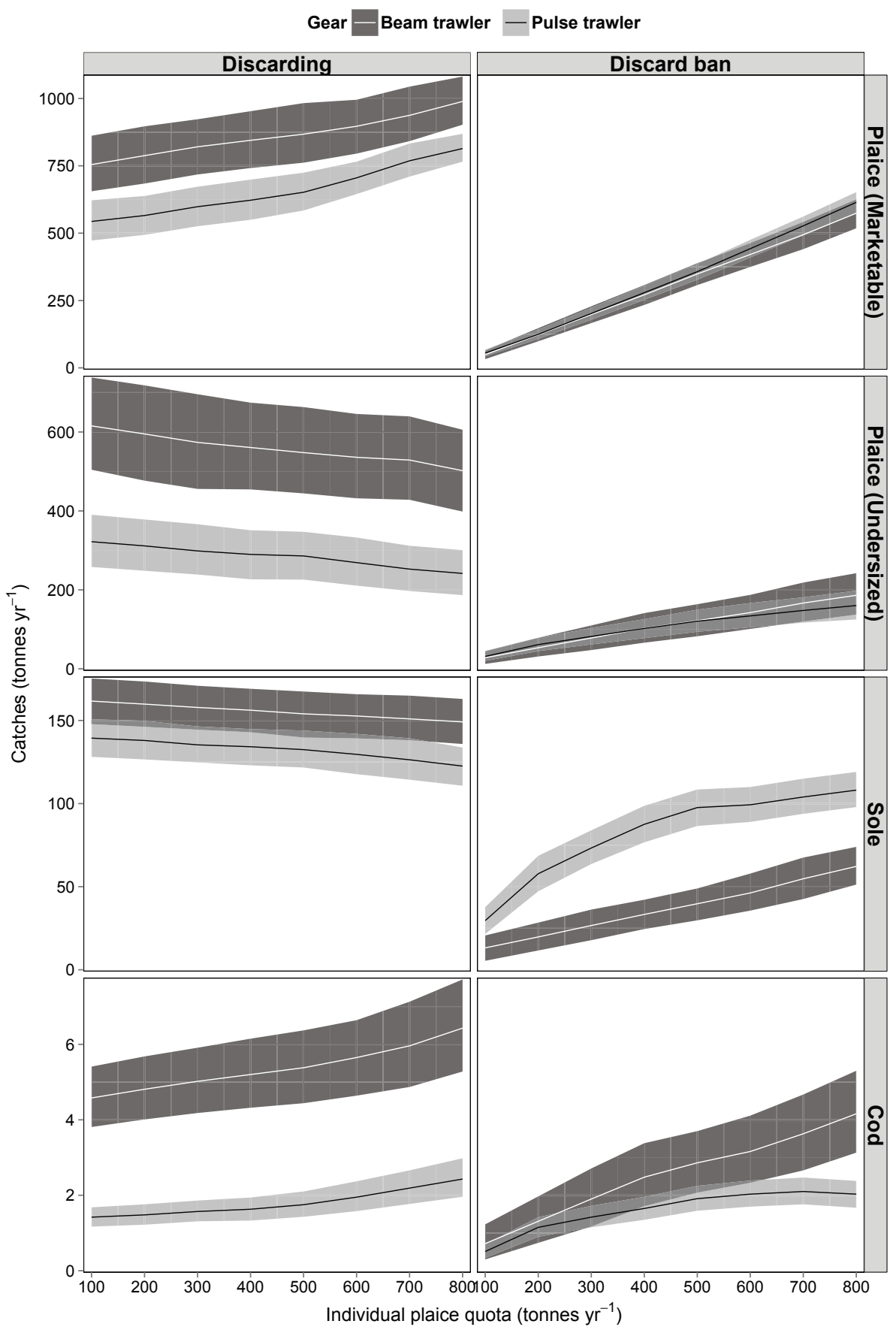

Figure 4.5

Catches (tonnes $y^{-1}$ ) of a pulse trawler and beam trawler

a regime where discarding is allowed: (a) marketable size as a function of the plaice quota under a discard ban and plaice; (b) undersized plaice; (c) sole; (d) cod. 


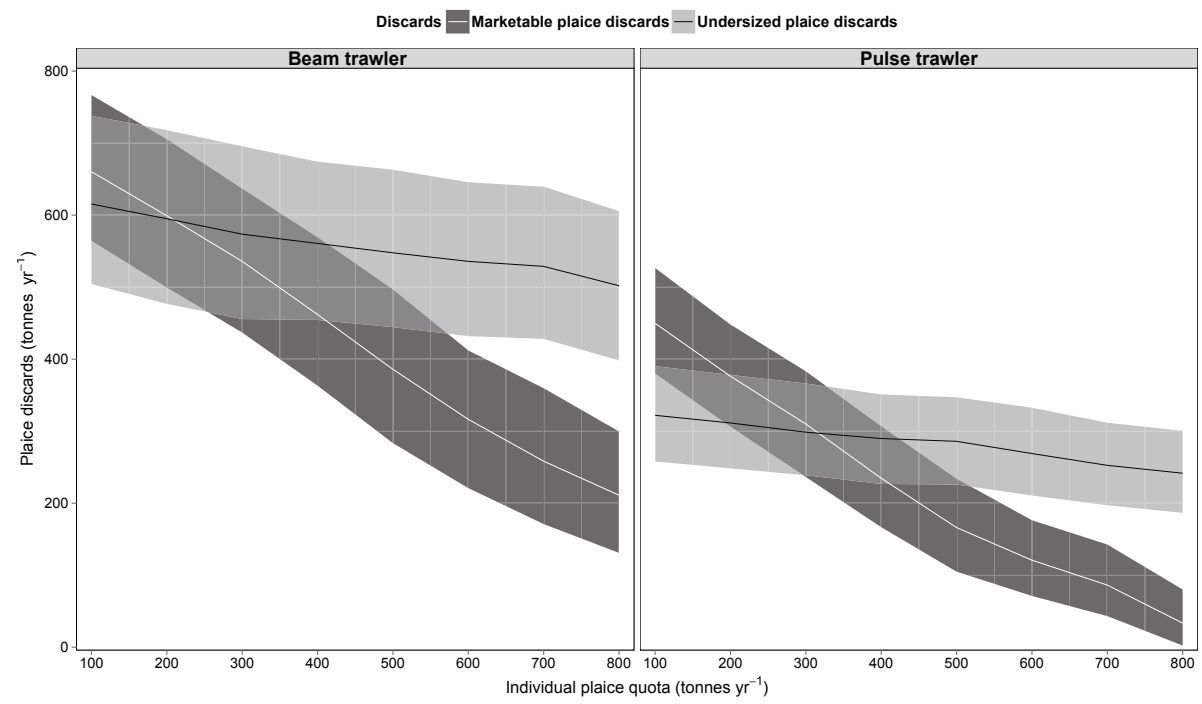

Figure 4.6

Annual discards of marketable plaice and undersized plaice for a beam trawl (left panel) and a pulse trawler (right panel) as a function of the plaice quota under a management regime allowing discards.

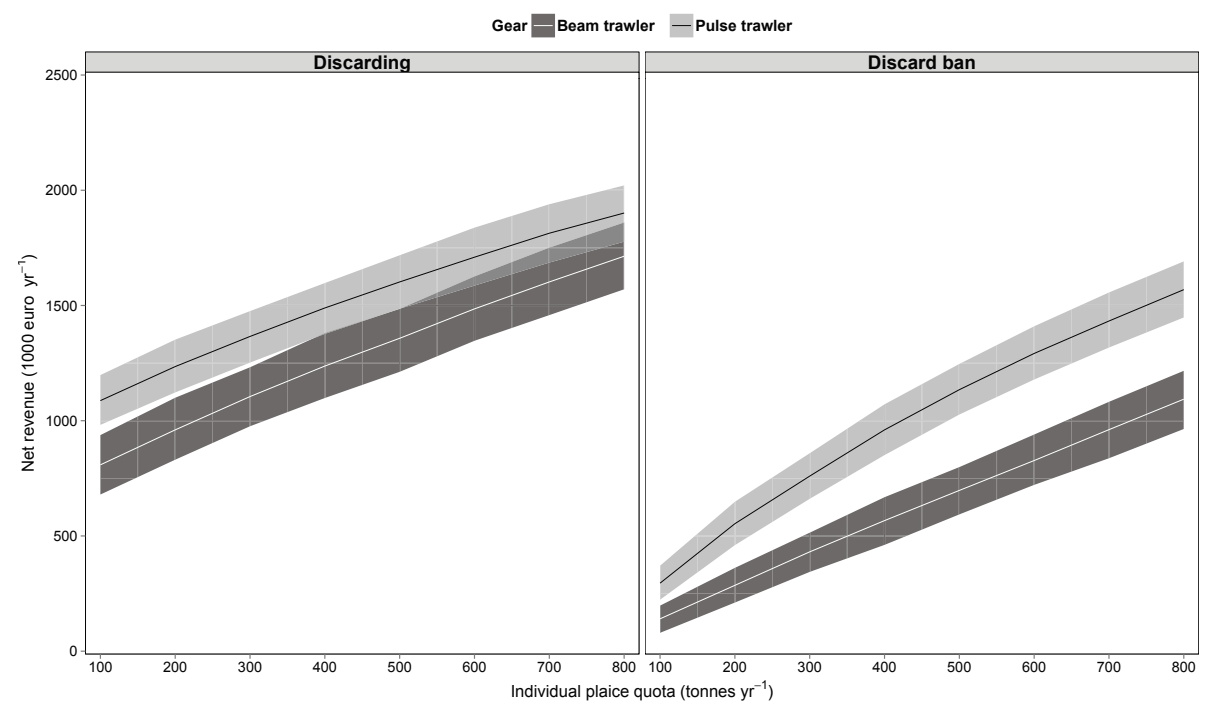

Figure 4.7

Net annual revenue (1000 Euro) of a pulse trawler and a beam trawler under a discard ban (right panel) and under a management regime allowing discarding (left panel). 
Gear —Beam trawler — Pulse trawler

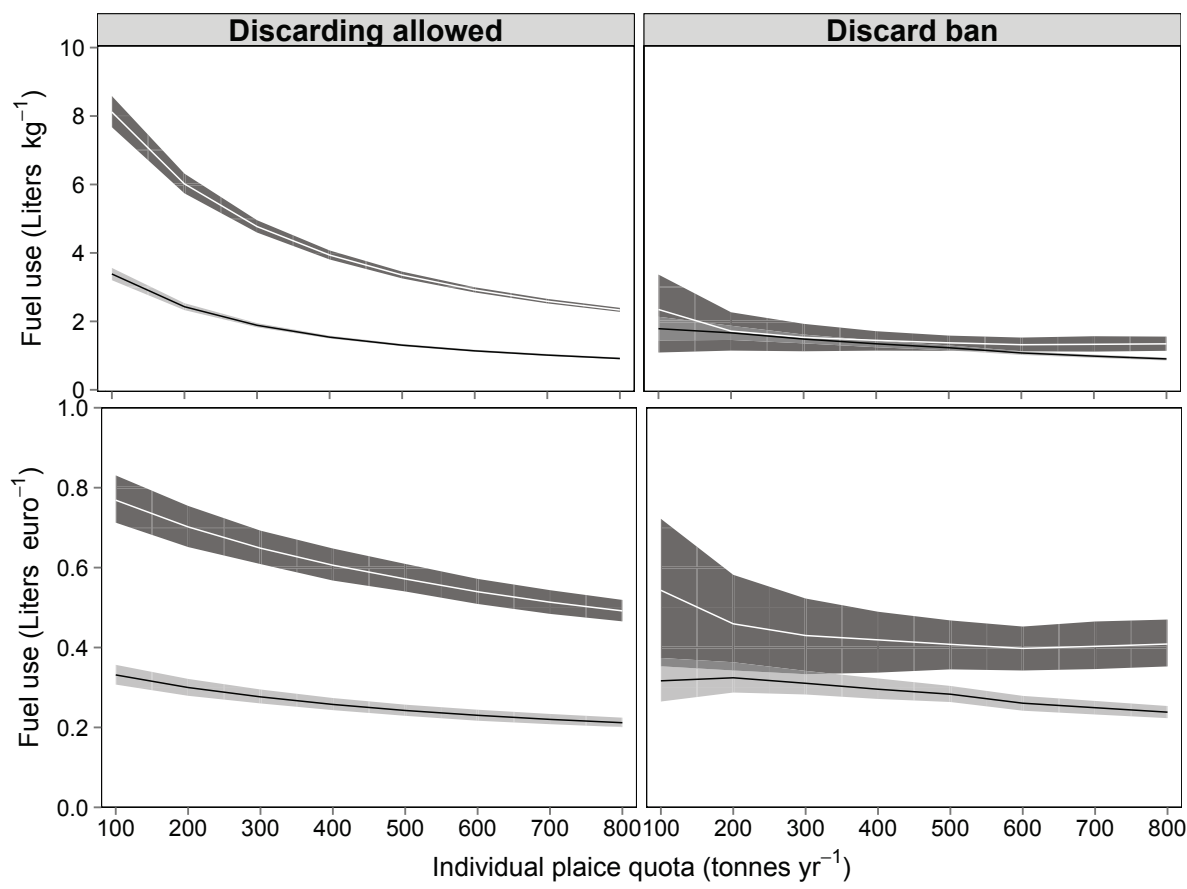

Figure 4.8

Fuel use per landed weight (upper panels) and revenue

(lower panels) for the management scenario that allows discarding (left panels) and the scenario (right panels).

\section{SIZE COMPOSITION OF LANDINGS AND DISCARDS}

If discarding is allowed, the plaice discards consist of undersized as well as marketable sized fish. The quantity and the size distribution is influenced by the quota and differs between both gear types (Fig. 4.6). At low quota, large quantities of both marketable and undersized plaice are discarded. If the quota increases, the quantity of discarded marketable sized plaice decrease. For a pulse trawl, the proportion of marketable sized plaice discards is greater at low quota, but smaller at high quota compared to a beam trawler. Quantities of undersized plaice discards only slightly decrease with increasing plaice quota despite the reallocating of effort to northern areas where catch rate of undersized plaice is low.

\section{ECONOMIC RETURNS AND FUEL EFFICIENCY}

The net revenue, resulting from the total revenue minus the variable costs, depends on the management scenario and differs between the beam trawl and the pulse trawl gears (Fig. 4.7). As is expected, net revenues increase for both gears with increasing plaice quotas. Re- 
gardless of having a ban or not, is a pulse trawler is economically more profitable under all plaice quotas. Implementation of a discard ban substantially reduces the net revenue for both gears. However, the discard ban causes a larger reduction in net revenues for the beam trawlers than for the pulse trawlers.

When allowing discards, both gears are able to maintain a net revenue above $700 \mathrm{k} €$ $\mathrm{y}^{-1}$. As the plaice quota increases, net revenue gradually increases as a result of an increasing contribution of plaice in addition to continuously high sole revenues. As plaice quota levels increase, the sole landings of a pulse trawler decreases because more effort is allocated to northern fishing grounds, causing net profit of both gears to approach each other.

In the scenario where discarding is allowed, the pulse trawler is about twice as efficient in its fuel use per Euro of revenue or kilogram of landings (Fig. 4.8). Fuel efficiency increase with increasing plaice quota. Under a discard ban, difference in fuel efficiency between the gears is smaller when expressed in terms of revenue and almost absent when the fuel efficiency is expressed in terms of the weight of the landings. The difference in fuel efficiency between the management scenarios is due to the lower fishing effort applied under a discard ban when vessels make fewer trips to fishing grounds where catch rate and revenue are close to their seasonal maximum.

\section{DISCUSSION}

\section{DISCARDING DECISIONS}

Under the assumption of full compliance, our model suggests that a discard ban results in a reduction of the catch of undersized plaice. The reduction depends on the plaice quota. Under the assumption of non-compliance, the amount of undersized plaice discards will remain high and is hardly affected by the plaice quota. A restrictive quota of plaice even result in an increase in plaice discarding (Fig. 4.6) because the fleet shift its fishing towards sole in areas where undersized plaice are abundant. In this situation, not only undersized plaice are discarded, but also low-value size classes of marketable sized plaice (Fig. 4.6). This high-grading occurs well before the quota are exhausted and is a result of the economic optimization given the available quota (Squires et al., 1998).

Because the pulse trawl is more efficient in catching sole than other species and catches less undersized fish (van Marlen et al., 2014), pulse trawling is expected to reduce (absolute) discarding of undersized fish. The expectation is supported by our simulation of the scenario allowing discards (Fig. 4.6). Under a discard ban, however, our model suggests that the catch of undersized plaice does not differ much between the conventional beam trawl and the pulse trawl (Fig. 4.5). This result is due to higher economic profitability that allow the pulse trawlers to spend more time fishing.

Under the discard ban regime, we assumed that fishers received a low price for the undersized plaice. At present, there is still uncertainty how market opportunities for under- 
sized fish would develop when the discard ban will be in effect (Buisman et al., 2013). A low market value may incentivise fishers to illegally discard small sized fish and land more high valued fish to cover their costs of fishing, while higher market prices can encourage fishers to start fishing for small sized fish, counteracting the actual intention of a discard ban to reduce the impact on unwanted catches (Buisman et al., 2013, Sardà et al., 2015).

\section{TRANSITION TO A MORE SELECTIVE AND FUEL EFFICIENT GEAR}

Our results show that a pulse trawler has higher net revenues than beam trawlers. Under a discard ban the difference in net revenue between the two gears increases, suggesting that a discard ban may increase the incentive for traditional beam trawlers to replace the tickler chain beam trawl by a pulse trawl.

The difference in profitability between the two gears is mainly due to the lower fuel cost of the pulse trawl. The difference in profitability may be overestimated, because data on the cost of gear maintenance and fixed cost of the pulse gear is not available. On the other hand, a discard ban may entail increased costs for handling (i.e. additional crew), storing and landing discards (Mangi and Catchpole, 2012, Sardà et al., 2015), which will predominately affect the variable cost of the conventional beam trawl that catches a larger amount of undersized fish.

The current developments in the fleet, where a large number of vessels have applied for a permit to replace the conventional beam trawl with a pulse trawl, provides support for our conclusion and shows that the current high fuel cost (Beare and Machiels, 2012, Poos et al., 2013b) is already a sufficient stimulus to replace conventional beam trawls with pulse trawls (Condie et al. 2014).

\section{MANAGEMENT IMPLICATIONS}

The EC has agreed to reduce unwanted catches and prevent discarding by means of progressively introducing a discard ban (EC, 2011). Studies by Feekings et al.(2012), Heath et al. (2014), Borges (2015) and Sardà et al. (2015), have argued to conduct more research on the effectiveness and consequences of the discard ban. Our study showed that a discard ban could stimulate the use of more selective gear. However, if not properly enforced, the consequences of a discard ban may be very different. Although these results are conditional on the model formulation, our approach is generally applicable to study the consequences of management scenarios for any mixed fishery for which sufficient biological and economic information is available.

Our results reflect the short term effects of a discard ban on the net revenues of the two gears. The long term effects remain to be studied. It is to be expected that the long term yields will differ under the different management scenarios as a result of the evolution of the resources. Such analyses are the domain of bio-economic management strategy evaluations where the feedback between fleet and stock dynamics are explicitly modelled (Andersen et 
al., 2010, Prellezo et al., 2012). In such models, effects of the changing selectivity of the fishing fleets on the reference points for sustainable exploitation, such as $F_{M S Y}$ can be evaluated.

It should be noted that our results only reflect the short term response of a fishery to the discards ban. If the ban indeed results in a change in selectivity, we also expect longer term changes to occur in fish populations and the economy of the fishery. If mortality in discarded fish is high, a reduction in plaice discarding following a properly enforced discard ban will likely result in an increase in recruitment to the fishery. In theory, this increase in recruitment could offset the short term economic losses. However, the extent to which the increase in recruitment of fish to the fishery will result in higher yields and spawning stock biomasses will depend on how density dependent feedback mechanism operate in the stocks. As a result of this uncertainty, the long term economic consequences are also uncertain.

\section{MODEL VALIDATION}

The Dynamic State Variable Model approach (Gillis et al., 1995b, Houston and McNamara, 1999, Clark and Mangel, 2000, Poos et al., 2010, Dowling et al., 2012) is particularly suitable to study effort allocation and discarding decisions of fishers under various management constraints and model assumptions. Here we studied the possible consequences of a discard ban that is currently being implemented in the European Union, using the North Sea flatfish fishery as a case study. The DSVM includes the characteristics relevant to the research question: seasonal variation in the availability of different size classes of three target species, including the undersized fish of one of the fish species, differences in ex-vessel prices among size classes and seasons and two fishing gears that differ in species- and size-selectivity and variable cost. Although our model was parameterised for the Dutch beam trawl and pulse trawl fleet, the results will only be indicative of the response of both fleets to the implementation of the discard ban because of the simplified assumptions and model formulation.

Our model simplifications with regard to maximising net revenue, perfect knowledge about the stochastic nature of catch rates, lack of transferability of individual quota, and lack of interference competition between fishers have been discussed by Poos et al. (2010). The assumption that all vessels operate from a single harbour (Harlingen) affects the predicted fishing effort and catches. Indeed, the simulated effort distribution is restricted to three fishing areas, while observation of the entire Dutch fleet indicate that fishing effort is distributed over a larger number of fishing areas (see Fig. 7b in Rijnsdorp et al., 2008). Also, we cannot expect that the simulated catches and the size distribution will accurately predict the present day catches because the seasonal distribution in the abundance was based on data collected in the 1970s. Not only may spatial patterns have changed, but also we made the assumption that the relationship between spawning stock biomass and catch rates was linear, similar to a Holling type 1 functional response (Holling, 1959). The validity of this assumption is untested, and alternative relationships, such as a Holling type II response could apply. We nevertheless chose to use the data of the early 1970s because in this period the 
quality of the data was not affected by misreporting, over-quota discarding or high-grading that may have occurred since the introduction of restrictive quota in the mid 1970's (Daan, 1997; Poos et al., 2010).

Despite these assumptions, the simulation model was in broad agreement with the observations. First, at a representative plaice quota of 350 tonnes the proportion of undersized plaice of the simulated catch (40\%) compares to an observed value of around $50 \%$ (Uhlmann et al., 2013). Second, the model shows a close similarity in the spatial distribution between the two gears in the scenario where discarding is allowed. This is in agreement with a strong positive linear correlation of fishing effort among our fishing areas $\left(r^{2}=0.82, n=15\right.$, $\mathrm{P}<0.01$ ) between the two gears observed in the field.

In the model, we used fairly large geographical areas, following Rijnsdorp et al. (2012). The spatial scale at which local concentrations of fish may occur may be much smaller than the fishing areas used in our model (Poos et al, 2007). We may thus underestimate the spatial flexibility that the fishery has in finding its optimal behaviour. Spatial measures on smaller scale are such as closures of small areas with high catch rates of undesirable species or size classes are another way to reduce discards (Needle and Catarino, 2011) that we did not explore here,

In this study we assume that plaice is the limiting quota species. Indeed, in the period 2004-2010, the plaice landings in the North Sea have matched the quotas, suggesting that the quota have been restrictive. The sole quotas have not been fully used in all years in the same period (ICES, 2013). Given the increased use of pulse trawls with a high catchability for sole, the sole quotas may become limiting in the near future. The $1^{\text {st }}$ phase of the implementation of the discard ban is focussed on the discarding of the target species of the fishery (e.g. sole and plaice). In the $2^{\text {nd }}$ phase, other bycatch species may also be included. This may seriously affect the effort allocation and discarding decisions as the catch weight of undersized dab is of the same order of magnitude as that of plaice (Uhlmann et al., 2013).

\section{COMPLIANCE OF THE FISHERY TO A DISCARD BAN}

Whether the introduction of a discard ban on the amount of discard produced in the flatfish fishery is critically dependent on the full compliance of the fishers to land all the fish they catch. Assuming full compliance, the model suggests that the amount of discards will be substantially reduced but at the cost of a substantial reduction in revenue. It is uncertain, however, whether this will apply to the European fisheries. Compliance will, e.g., depend on the frequency of inspection and the fine imposed when violating a regulation (Jagers et al., 2012, Batsleer et al., 2013). Experience in other countries showed that a full coverage observer programme can provide a strong incentive to comply to quota management in mixed fisheries (Branch and Hilborn, 2008). In the European Union, fisheries inspection is the responsibility of the national inspection services that carry out at sea inspections as well as inspections of the landings on land. The inspection frequency of individual vessels is unlikely to be sufficient to enforce full compliance. The lack of recovery of cod in the North 
Sea, for instance, has been related to high-grading, which is already prohibited in the North Sea (Ulrich et al., 2011). Such high-grading is expected in mixed fisheries with individual quota and price differences among size classes. The ex-vessel price is positively related to fish size in a broad variety of pelagic and demersal species (Zimmermann and Heino, 2013). Also in flatfish fisheries, there are indications for over-quota discarding and high-grading (Poos et al., 2010). Pilot experiments on the implementation of fully documented fisheries in Denmark and the UK indicate that this method may improve compliance (Kindt-Larsen et al. 2011; Mangi et al., 2015).

\section{ACKNOWLEDGEMENTS}

The study was supported by KBWOT Implications of a discard ban for Dutch fisheries (4301900368). KH and ADR were supported by the FP7-project BENTHIS (312088). JJP was supported by the FP7-project MYFISH (289257). We are grateful to two anonymous reviewers for their very useful comments that contributed to greatly improve an earlier version of this manuscript. 


\section{REFERENCES}

Aarts, G., Poos, J.J., 2009. Comprehensive discard reconstruction and abundance estimation using flexible selectivity functions. ICES Journal of Marine Science 66, 763-771.

Alverson, D.L., Freeberg, M.H., Murawski, S.A., Pope, G.J., 1994. A global assessment of fisheries bycatch and discards. FAO Fisheries Technical Paper.

Andersen, B.S., Vermard, Y., Ulrich, C., Hutton, T., Poos, J.J., 2010. Challenges in integrating shortterm behaviour in a mixed-fishery Management Strategies Evaluation frame: A case study of the North Sea flatfish fishery. Fisheries Research 102 26-40.

Annala, J.H. (1996) New Zealand's ITQ system: have the first eight years been a success or a failure? Reviews in Fish Biology and Fisheries 6, 43-62.

Arnason, R. (1995) The /celandic fisheries: evolution and management of a fishing industry. Fishing News Books, Oxford (UK).

Bartelings, H., Soma, K., 2010. A study on overcapacity in the Dutch flatfish sector. LEl report 2010-046. The Hague, The Netherlands.

Batsleer, J., Poos, J.J., Marchal, P., Vermard, Y., Rijnsdorp, A.D., 2013. Mixed fisheries management: protecting the weakest link. Marine Ecology Progress Series $479,177-190$

Beare, D., Machiels, M. 2012., Beam trawlermen take feet off gas in response to oil price hikes. /CES Journal of Marine Science 69, 1064-1068.

Borges, L. 2015., The evolution of a discard policy in Europe. Fish and Fisheries 16, 534-540

Branch, T.A., Hilborn, R., 2008. Matching catches to quotas in a multispecies trawl fishery: targeting and avoidance behavior under individual transferable quotas. Canadian Journal of Fisheries and Aquatic Sciences 65, 1435-1446.

Briggs, R.P., Armstrong, M.J., Rihan, D., 1999. The consequences of an increase in mesh size in the Irish Sea Nephrops fishery: an experimental approach. Fisheries Research 40, 43-53.

Broadhurst, M.K., Suuronen, P., Hulme, A., 2006. Estimating collateral mortality from towed fishing gear. Fish and Fisheries 7, 180-218.
Buisman, E., Oostenbrugge, v. H., Beukers, R., 2013. Economische effecten van een aanlandplicht voor de Nederlandse visserij. LEl-report 2013-062. The Hague.

Catchpole, T.L., Frid, C.L.J., Gray, T.S., 2005. Discards in North Sea fisheries: Causes, consequences and solutions. Marine Policy 29, 421-430.

Catchpole, T.L., Revill, A.S., 2008. Gear technology in Nephrops trawl fisheries. Reviews in Fish Biology and Fisheries 18, 17-31.

Clark, C.W., Mangel, M., 2000. Dynamic state variable models in ecology: Methods and applications, Oxford University Press, Oxford, UK.

Condie, H.M., Grant, A., Catchpole, T.L., 2013. Does banning discards in an otter trawler fishery create incentives for more selective fishing? Fisheries Research 148, 137-146.

Condie, H.M., Grant, A., Catchpole, T.L., 2014. Incentivising selective fishing under a policy to ban discards; lessons from European and global fisheries. Marine Policy 45, 287-292.

Crowder, L.B., Murawski, S.A., 1998. Fisheries bycatch: Implications for management. Fisheries 23, 8-17.

Daan, N., 1997. TAC management in North Sea flatfish fisheries. Journal of Sea Research 37, 321-341.

Diamond, B., Beukers-Stewart, B.D., 2011. Fisheries Discards in the North Sea: Waste of Resources or a Necessary Evil? Reviews in Fisheries Science 19, 231-245.

Dickey-Collas, M., Pastoors, M.A., van Keeken, O.A., 2007. Precisely wrong or vaguely right: simulations of noisy discard data and trends in fishing effort being included in the stock assessment of North Sea plaice. /CES Journal of Marine Science 64, 16411649.

Dowling, N.A., Wilcox, C., Mangel, M., Pascoe, S., 2012. Assessing opportunity and relocation costs of marine protected areas using a behavioural model of longline fleet dynamics. Fish and Fisheries 13, 139-157.

EC, 2011 Proposal for a regulation of the European Parliament and of the Council on the Common Fisheries Policy. COM(2011) 425 final. Brussels, European Commission. 
Feekings, J., Bartolino, V., Madsen, N., Catchpole, T., 2012. Fishery Discards: Factors Affecting Their Variability within a Demersal Trawl Fishery. PLOS ONE 7, e36409.

Gillis, D.M., Peterman, R.M., Pikitch, E.K., 1995a. Implications of Trip Regulations for High Grading - a Model of the Behavior of Fishermen. Canadian Journal of Fisheries and Aquatic Sciences 52, 402415.

Gillis, D.M., Pikitch, E.K., Peterman, R.M., 1995b. Dynamic discarding decisions - foraging theory for high-grading in a trawl fishery. Behavioral Ecology 6, 146-154.

Gillis, D.M., Rijnsdorp, A.D., Poos, J.J., 2008. Behavioral inferences from the statistical distribution of commercial catch: patterns of targeting in the landings of the Dutch beam trawler fleet. Canadian Journal of Fisheries and Aquatic Sciences 65, 27-37.

Heath, M.R., Cook, R.M., Cameron, A.I., Morris, D.J., Speirs, D.C., 2014. Cascading ecological effects of eliminating fishery discards. Nature Communications 5, doi:10.1038/ncomms4893

Holling, C.S., 1959. Some characteristics of simple types of predation and parasitism. The Canadian Entomologist 91, 385-98.

Houston, A.I., McNamara, J.M., 1999. Models of Adaptive Behaviour, Cambridge University press, Cambridge, UK.

ICES, 2013. Report of the ICES Advisory Committee 2013:. Book 6. Copenhagen.

Jagers, S.C., Berlin, D., Jentoft, S., 2012. Why comply? Attitudes towards harvest regulations among Swedish fishers. Marine Policy 36, 969-976.

Jennings, S., Kaiser, M. J., 1998. The Effects of Fishing on Marine Ecosystems. Advances in Marine Biology 34, 201-212, 212e, 213-352

Kaiser, M.J., Spencer, B.E., 1995. Survival of by-catch from a beam trawl. Marine Ecology Progress Series 126, 31-38.

Kindt-Larsen, L., Kirkegaard, E., Dalskov, J., 2011. Fully documented fishery: a tool to support a catch quota management system. ICES Journal of Marine Science 68, 1606-1610.

Mangi, S., Catchpole, T.L., 2012. Utilising discards not destined for human consumption in bulk outlets. Final report, Centre for Environment, Fisheries and Aquaculture Science, Lowestoft, UK.
Mangi, S.C., Dolder, P.J., Catchpole, T.L., Rodmell, D., de Rozarieux, N., 2015 Approaches to fully documented fisheries: Practical issues and stakeholder perceptions. Fish and Fisheries 16, 426 - 452.

Needle, C. L., Catarino, R., 2011. Evaluating the effect of real-time closures on cod targeting. ICES Journal of Marine Science 68, 1647-1655.

Nielsen, M., Smit, J., Guillen, J., 2009. Market integration of fish in Europe. Journal of Agricultural Economics 60, 367-385.

Poos, J.J., Bogaards, J.A., Quirijns, F.J., Gillis, D.M., Rijnsdorp, A.D., 2010. Individual quotas, fishing effort allocation, and over-quota discarding in mixed fisheries. ICES Journal of Marine Science 67, 323333.

Poos, J.J., Aarts, G., Vandemaele, S., Willems, W., Bolle, L.J., van Helmond, A.T.M., 2013a. Estimating spatial and temporal variability of juvenile North Sea plaice from opportunistic data. Journal of Sea Research 75, 118-128.

Poos, J.J., Turenhout, M.N.J., van Oostenbrugge, H.A.E., Rijnsdorp, A.D., 2013b. Adaptive response of beam trawl fishers to rising fuel cost. ICES Journal of Marine Science 70, 675-684.

Prellezo, R., Accadia, P., Andersen, J.L., Andersen, B.S., Buisman, E., Little, A., Nielsen, J.R., et al. 2012. A review of EU bio-economic models for fisheries: The value of a diversity of models. Marine Policy 36, 423-431.

R Development Core Team, 2013. R: A language and environment for statistical computing. R Foundation for Statistical Computing Vienna, Austria. URL http://www.R-project.org/.

Revill, A., Holst, R., 2004. The selective properties of some sieve nets. Fisheries Research 66, 171-183.

Rijnsdorp, A.D., Daan, N., Dekker, W., 2006. Partial fishing mortality per fishing trip: a useful indicator of effective fishing effort in mixed demersal fisheries. ICES Journal of Marine Science 63, 556-566.

Rijnsdorp, A.D., Daan, N., Dekker, W., Poos, J.J., Van Densen, W.L.T., 2007. Sustainable use of flatfish resources: addressing the credibility crisis in mixed fisheries management. Journal of Sea Research 57, 114-125

Rijnsdorp, A.D., Poos, J.J., Quirijns, F.J., Hille Ris Lambers, R., De Wilde, J.W., Den Heijer, W.M., 2008. The arms race between fishers. Journal of Sea Research 60, 126-138. 
Rijnsdorp, A.D., Poos, J.J., Quirijns, F.J., 2011. Spatial dimension and exploitation dynamics of local fishing grounds by fishers targeting several flatfish species. Canadian Journal of Fisheries and Aquatic Sciences 68, 1064-1076.

Rijnsdorp, A.D., van Overzee, H.M.J., Poos, J.J., 2012. Ecological and economic trade-offs in the management of mixed fisheries: a case study of spawning closures in flatfish fisheries. Marine Ecology Progress Series 447, 179-194.

Salz, P., 1996. ITQs in the Netherlands: 20 years of experience. ICES CM 1996/P: 18

Sardà, F., Coll, M., Heymans, J.J., Stergiou, K.I., 2015. Overlooked impacts and challenges of the new European discard ban. Fish and Fisheries 16, 175-180.

Soetaert, M., Decostere, A., Polet, H., Verschueren, B., Chiers, K., 2015.Electrotrawling: a promising alternative fishing technique warranting furtherexploration. Fish and Fisheries 16, 104-124.

Somers, I.F., 1988. On a seasonally oscillating growth function. Fishbyte 6: 8-11.

Squires, D., Campbell, H., Cunningham, S., Dewees, C., Grafton, R.Q., Herrick Jr, S.F., Kirkley, J., et al. 1998. Individual transferable quotas in multispecies fisheries. Marine Policy 22, 135-159.

Uhlmann, S.S., Coers, A., van Helmond, A.T.M., Nijman, R.R., Bol, R.A., van der Reijden, K., 2013. Discard sampling of Dutch bottom-trawl and seine fisheries in 2012. Centre for Fisheries Research Report 13.015. IJmuiden

Uhlmann, S.S., van Helmond, A.T.M., Kemp Stefánsdóttir, E., Sigurðardóttir, S., Haralabous, J., Bellido, J.M., Carbonell, A., et al. 2014. Discarded fish in European waters: general patterns and contrasts. ICES Journal of Marine Science 71, 1235-1245.
Ulrich, C., Reeves, S.A., Vermard, Y., Holmes, S.J., Vanhee, W., 2011. Reconciling single-species TACs in the North Sea demersal fisheries using the Fcube mixed-fisheries advice framework. ICES Journal of Marine Science 68, 1535-1547.

van Beek, F.A., Van Leeuwen, P.I., Rijnsdorp, A.D., 1990. On the survival of plaice and sole discards in the otter-trawl and beam-trawl fisheries in the North Sea. Netherlands Journal of Sea Research 26 151-160.

van Beek, F.A., 1998. Discarding in the Dutch beam trawl fishery. ICES Document CM 1998/ BB:5. Copenhagen

van Marlen, B., Wiegerinck, J. A. M., van Os-Koomen, E., van Barneveld, E., 2014. Catch comparison of flatfish pulse trawls and a tickler chain beam trawl. Fisheries Research 151, 57-69.

Wood, S. N. 2006. Generalized Additive Models: an Introduction with R., Chapman and Hall/CRC Press, New York.

Zimmermann, F., Heino, M., 2013. Is size-dependent pricing prevalent in fisheries? The case of Norwegian demersal and pelagic fisheries. ICES Journal of Marine Science 70, $1389-1395$

Zuur, A.F., leno, E.N., Walker, N.J., Saveliev, A.A., Smith, G.M., 2009. Mixed effect models and extensions in ecology in $R$, New York.

Zuur, A.F., 2012. A beginners guide to generalized additive mode/s with $R$, Highland Statistics Ltd., UK. 


\section{CHAPTER 5}

\section{EXPLORING HABITAT CREDITS TO MANAGE THE BENTHIC IMPACT IN A \\ MIXED FISHERY}

Batsleer J., Poos J.J., Marchal P., Vaz S.,Vermard Y., Rijnsdorp A.D. 


\section{ABSTRACT}

The performance of a combined catch quota and habitat credit system is explored to manage the sustainable exploitation of a mix of demersal fish species and minimise the benthic impacts of bottom trawl fisheries using a dynamic state variable model approach. The model is parameterised for the eastern Channel demersal mixed fishery using otter trawls or dredges. The target species differ in their association with habitat types. Restricting catch quota for sole and cod does not reduce the benthic impact, except when reduced to very low values forcing the vessels to stay in port. Quota management has a minimal influence on fishing behaviour and hence results in a minimal reduction of benthic impact. Habitat credits are required to manage the benthic impact. Indirectly, these restrict the possibilities to exploit the fish species. However, when reducing habitat credits from high to low, the net revenue only decrease slightly at first, and more steeply at low Individual Habitat Credits. There is thus room to reduce habitat impacts of these fisheries with limited effect on the net revenue. 


\section{INTRODUCTION}

The impact of bottom trawl fisheries on benthic habitats and ecosystems is a matter of global concern (Kaiser et al. 2006). Such bottom trawl fisheries use towed gears that make direct physical contact with the seafloor to catch species living or feeding close to the bottom substrate (Valdemarsen et al., 2007). As a consequence, these fisheries potentially reduce structural complexity of habitats, injure or kill target and non-target species, alter species composition, and modify ecosystem processes such as benthic production (Dayton et al., 1995; Collie et al., 1997; Thrush et al., 1998 ; Kaiser et al., 2002).

The extent to which bottom trawl fisheries disturb benthic ecosystems depends on the type of fishing gear used, the frequency and distribution of fishing activities in an area ( Kaiser et al., 2006; Rijnsdorp et al. 2016) as well as the sensitivity of habitats and benthic ecosystems to fishing disturbance (Collie et al., 2000; Eno et al., 2013). This sensitivity differs across habitats as a result of differences in natural disturbance (bottom shear stress, effects of waves), bottom typology (e.g. slope and depth), sediment composition, and species composition (Hall, 1994; Jennings and Kaiser, 1998; Snickars et al., 2014, van Denderen et al., 2014). Complex biogenic habitats with emergent structures are likely to be more affected compared to naturally disturbed soft sedimentary habitats (Jennings and Kaiser, 1998; Lindholm et al., 2015).

Fish species caught by bottom trawl fisheries differ in their preference to habitat types, because of their morphological and behavioural characteristics. Habitat preference generally changes along the life cycle of species, because of ontogenetic niche shifts (Thouzeau et al., 1991; Le Pape et al., 2003; Atkinson et al., 2004). Adult roundfish species, for example, have a preference for hard bottom habitats with a high structural complexity providing food and shelter (Tupper and Boutilier, 1995; Wieland et al., 2009), while flatfish species such as plaice and sole prefer soft bottom habitats in which they can burry themselves to avoid predation (Gibson and Robb, 2000). As a result, the impact of a fishery on the seabed habitat and benthic ecosystem depends on the linkage between the habitat preference of the different species, and the species preference of the fishery.

Many fisheries management systems around the world historically focussed on the conservation and sustainable exploitation of commercial fish and shellfish stocks by setting Total Allowable Catches (TACs) but ignoring the potential wider ecosystem effects of fishing (Pikitch et al., 2004; Chu 2009; Holland and Schnier 2006). Policy developments such as the amendments to the Magnuson-Stevens Act in the U.S. and the reform of the Common Fishery Policy (CFP) in Europe have recognised the importance of safeguarding ecosystem composition, structure and functioning and have embraced an ecosystem-based approach. This objective requires managers to assure a sustainable use of natural resources while minimising impacts of fishing activities on the structure and functioning of seabed habitats and benthic ecosystems.

The conventional approach of fisheries managers to maintain or restore ecosystem processes focusses on technical measures including limitations on fleet capacity and fishing effort, gear restrictions and spatial measures (Rice et al., 2012). While spatial measures (e.g. 
marine reserves or marine protected areas) can support the conservation of biomass and diversity of organisms (Halpern, 2003; Lester et al., 2009) the socioeconomic benefits for the fishery are often limited (Caveen et al., 2015). Several studies have proposed the use of a credit system as an alternative management approach (Holland and Schnier, 2006; Kraak et al., 2012). These credit systems try to balance economic and environmental values associated with fisheries by addressing specific conservation goals with limited effects for the fishery (Van Riel et al., 2015).

Our study explores the performance of individual catch quota combined with a habitat credit system to manage the sustainable exploitation of a mix of demersal species and to minimise the benthic impacts of bottom trawl fisheries. Results are compared to traditional quota management for two commercial valuable species, cod and sole, which have different habitat associations. We apply an individual based simulation model of the effort allocation and discarding decisions in a mixed fishery (Poos et al., 2010; Batsleer et al. 2013). The model is adapted to include individual habitat credits (IHC) and is parameterised for the French multipurpose bottom trawl fleet in the eastern English Channel. This fleet may switch between dredging for scallops and otter trawling for a mix of demersal fish species (Carpentier et al., 2009). We then evaluate the extent to which the incorporation of habitat credits in a quota management system can be a tool for ecosystem based management, in terms of benthic impacts reduction and sustainable exploitation of fish.

\section{METHODS}

\section{STUDY AREA}

The Eastern English Channel (ICES division VIId) is a narrow and relatively shallow shelf-sea. A strong east-west tidal current affects seabed habitats in this area (Coggan and Diesing, 2011). The Eastern English Channel consists of 15 ICES rectangles $(\sim 30 \times 30$ nautical miles), which we have divided into grid cells of $3 \times 3$ nautical miles each. Spatial distribution of habitats is derived from a detailed map of Eastern English Channel seabed habitats in Coggan and Diesing (2011) (Fig. 5.1). Each grid cell was assigned the dominant habitat type present within that cell. We distinguished five habitats based on grain size and depth (soft, infralittoral coarse, circalittoral coarse, deep coarse, and rock). Soft sediment habitats consisted of fine sand or muddy sediments, found along the coast and in the eastern part where the English Channel borders the North Sea. Coarse sediment habitats were the predominant type in the eastern English Channel. Rocky seabed habitats were a combination of infralittoral and circalittoral rock and other hard substrates occurring towards the west along the coast with an extensive reef found in the western part of the study area (Diesing et al., 2009). Adjacent cells of the same habitat type were merged and counted as a single fishing area, resulting in 126 fishing areas. This is done within each ICES rectangle, in order to be used with the available fisheries data. 


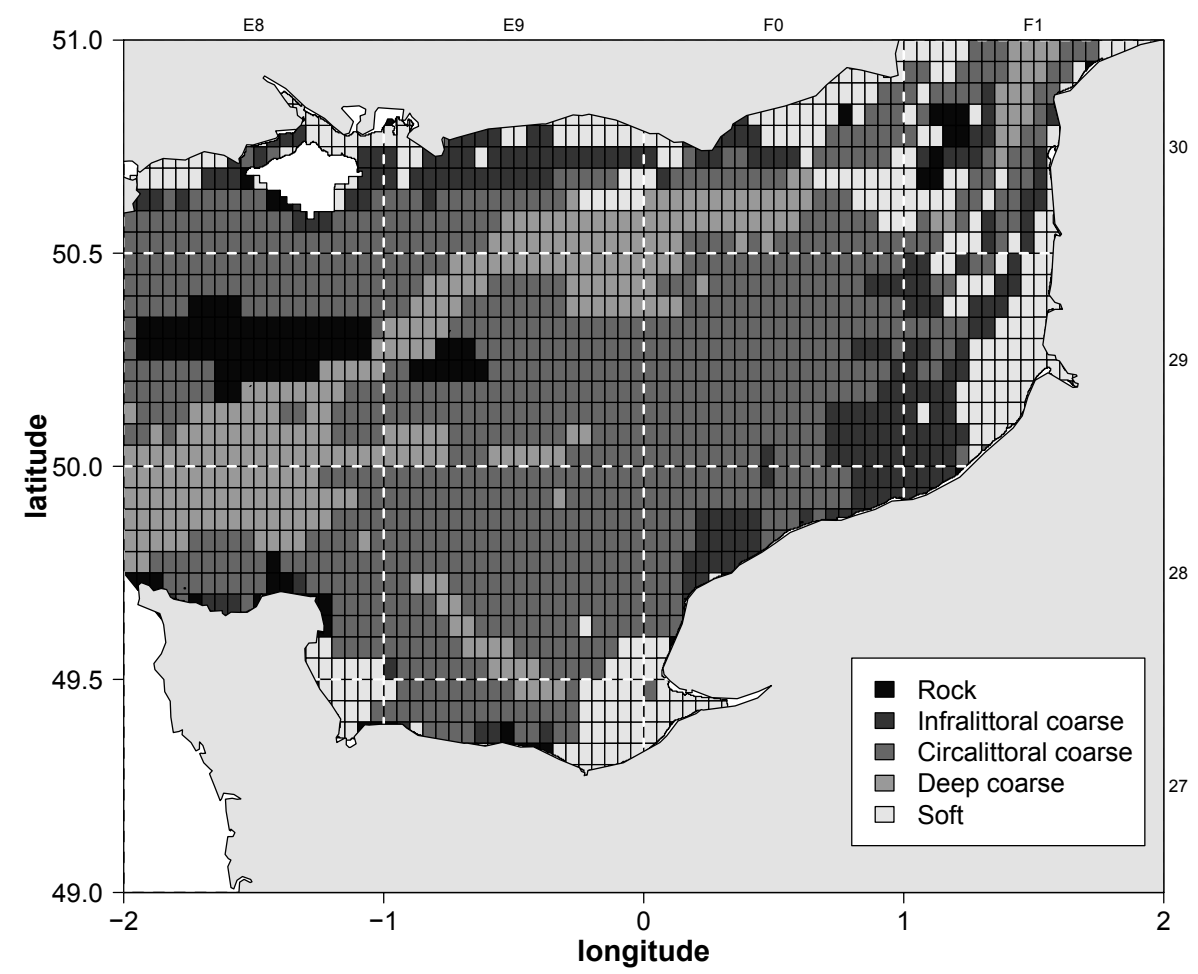

Figure 5.1

Habitat distribution map based on Coggan and Diesing (2011), with the main French fishing harbours used in this study. ICES rectangles are delineated by the white dashed lines.

Habitat impact credits were assigned to each fishing area based on the sensitivity of habitats to fishing activities. Rock habitat and deep coarse sediment habitat support emergent epibenthos such as sponges, bryozoans and hydroids, making them more vulnerable to trawling compared to more shallow and dynamic soft sedimentary habitats (Jennings and Kaiser, 1998; Kaiser et al., 2006; Eno et al., 2013; Boulcott et al., 2014). Impacts credits were divided into three arbitrary classes (2,5 and 10 credits). Rock and deep coarse habitats received 10 habitat impact credits, circalittoral received 5 credits, while infralittoral coarse and soft sediment habitat received 2 credits (Table 5.1).

\section{STUDY FLEET}

The French multipurpose bottom trawl fleet comprises of vessels between 12 and $18 \mathrm{~m}$ long, with an average engine power of 240 horse power. These vessels are allowed to fish inside and outside the 12 nautical mile zone (Carpentier et al., 2009). Vessels make daily trips to 
Table 5.1 Habitat types, associated habitat impact credits and fishing effort distribution (\%) over habitat types.

\begin{tabular}{lccc}
\hline Habitat & Habitat impact credit & Effort OTB (\%) & Effort DRB (\%) \\
\hline Rock & 10 & 1.0 & 0.2 \\
Deep Coarse & 10 & 14.9 & 16.4 \\
Circalittoral Coarse & 5 & 68.4 & 71.3 \\
Infralittoral Coarse & 2 & 9.2 & 5.7 \\
Soft & 2 & 6.6 & 6.4 \\
Total $\left(\mathrm{h} \mathrm{yr}^{-1}\right)$ & & 394385 & 46545 \\
\hline
\end{tabular}

their fishing grounds, operating from several ports around the eastern English Channel, mainly Boulogne-sur-Mer and Dieppe.

Logbooks and sales slip data were available for the period 2006 to 2010. The data set included information of individual vessels by fishing trip on vessel length, engine power, gear type, mesh size, fishing ground (ICES rectangle), fishing effort (hours fished), and the weight and value of the landings per species. Aggregated fishing effort estimates per fishing area were derived at the fine scale resolution $(3 \times 3 \mathrm{nmi})$ for 2008 from Delavenne (2012) (Table 5.1).

We selected vessels that can switch between demersal otter trawling (OTB) and dredging for scallops (Pecten maximus). The scallop fishery is fully open between November and April (Guyader et al., 2004). Demersal otter trawling is generally operated with $80 \mathrm{~mm}$ mesh size nets, targeting a variety of demersal species. The scallop dredge (DRB) lands few other commercial valuable species. The Bay of Seine is the most important scallop fishing ground in the eastern English Channel and some fishers temporarily change harbour to reduce their journey to the scallop fishing grounds.

\section{SPATIAL AND TEMPORAL SHIFTS IN CATCH RATE}

Five species (scallops - Pecten maximus, sole - Solea solea, plaice - Pleuronectes platessa, cod - Gadus morhua, sea bass - Dicentrarchus labrax) and one assemblage of cephalopods (cuttlefish - Sepia officinalis; squids - Loligo vulgaris and L. forbesii) will be considered here due to their economic importance for this fleet. These will from now on be referred to as six "species", for the sake of simplicity, keeping in mind that one of these "species" really represents a group of cephalopods. Catches in the present study were estimated on the basis of landings per unit effort of French commercial vessels. For each of the species the mean and variance of catches were estimated from the logbooks at their spatial (ICES rectangle) and temporal (week) scale (Fig. 5.2). These mean and variance in catches $(\mathrm{kg})$ were estimated using generalized additive models (GAMs) (Wood, 2006). In the GAMs, fishing effort (hr) was used as model offset (Zuur, 2012). This use of effort as model offset allows predicting catch rates $(\mathrm{kg} / \mathrm{hr})$ from the GAM results. A negative binomial response with a logarithmic link function was applied, allowing for over-dispersion and zero-observations (Zuur et al., 2009). Scallop catch rates were analysed only including trips with dredges, while catch rates of the other 


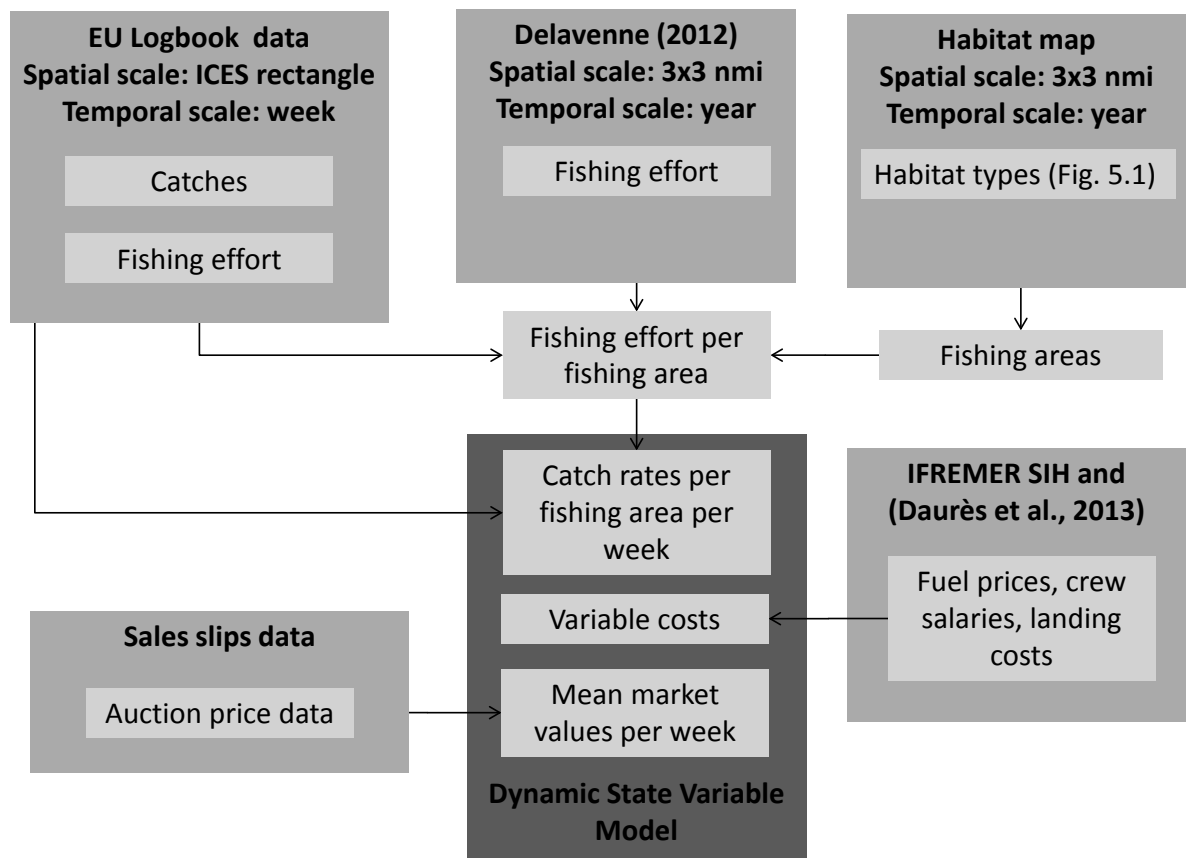

Figure 5.2

Schematic representation of the methodology and data used in this study.

five species were analysed for trips done by demersal otter trawls. The model estimating the catch $C$ per species $s$ by area per day is given by:

$C_{s}=\alpha+\beta($ year $)+f_{1}($ engine power $)+f_{2}($ mesh size $)+f_{3}($ lat,lon, $D O Y)+\log ($ effort $)$

Where $a$ is the model intercept and $f_{1^{\prime}} f_{2}$ and $f_{3}$ are smooth functions based on a tensor product smoother (Zuur, 2012). The differences in catch rates among years is estimated in the parameter $\beta$ (year). The tensor product smoother $f_{1}$ (engine power) is included due to its influence on the catch efficiency (Rijnsdorp et al., 2006) and $f_{2}$ (mesh size) is included as the choice of mesh size may indicate the species the fishery is targeting. The interaction term $f_{3}($ lat,lon, $D o Y$ ) fits the effects of space (latitude and longitude based in geographic midpoint of the ICES rectangle) and time as day of year ( $D o Y$ ). The term is based on a thinplate spline (Wood, 2003) for the space variables and a cyclic cubic regression spline for DoY. The cyclic cubic regression spline was chosen to receive equal values and slopes at the beginning and end of the year (Wood, 2006). For scallops the cyclic cubic regression spline for DoY was changed into a cubic regression spline because of the closed season from May to October. The Akaike Information Criterion (AIC) was used to assess the model fit, whereby 
the model with the lowest AIC was selected as best candidate. The best models included a limited degree of freedom for the $f_{1}$ and $f_{2}$ smoothing terms $(\mathrm{k}=4)$, but a higher degree of freedom for the $f_{3}$ smoothing term of the space * time interaction $(\mathrm{k}=9)$. All analyses were done using the mcgv package within the $\mathrm{R}$ statistical program (version 2.12.1; R Core Development Team 2013; mgcv description).

\section{CATCH RATES BY FISHING AREA}

The GAM provides estimates of catch rates per species per ICES rectangle. The rectangles are composed of mosaics of habitats (Fig. 5.1). To estimate catch rates by fishing area within ICES rectangles, catch rates were assumed to be positively correlated with effort per fishing area (Fig. 5.2). This assumption is supported by observations that fishing effort is not homogeneously distributed within an ICES rectangle, but is distributed on a finer spatial scale, concentrating within areas of high fish densities (Rijnsdorp et al. 2011).

Observed fishing effort per fishing area on the fine scale resolution ( $3 \times 3 \mathrm{nmi})$ were derived from combining weekly effort from logbooks by ICES rectangle with fine-scale effort distribution (Table 5.1) as follows: First, the fraction of effort distributed over the habitat types within each ICES rectangle was calculated from VMS data for each gear type. Multiplying these fractions with the effort distribution by ICES rectangle in the logbooks resulted in a distribution of effort in habitat type $h$ within an ICES rectangle a by week $w\left(E_{\text {haw }}\right)$.

Catch rate at the resolution of the habitat type $h$ within each ICES rectangle $a\left(L_{h a}\right)$ was not directly available but calculated from catch rates in the logbooks at the ICES rectangle scale:

$L_{h a}=\frac{\left(\left(L_{a} * \sum E_{\text {haw }}\right) *\left(\frac{E_{\text {haw }}\left(\frac{E_{\text {haw }}}{S_{\text {ha }}}\right)^{\propto}}{\sum\left(E_{\text {haw }}\left(\frac{E_{\text {haw }}}{S_{\text {ha }}}\right)^{\alpha}\right)}\right)\right)}{E_{\text {haw }}}$

Where $E_{\text {haw }}$ is the effort per week $w$ in habitat type $h$ in ICES rectangle $a$ and $S_{h a}$ is the surface area of habitat type $h$ in ICES rectangle $a$. The $\alpha$ is a scaling-factor to aggregate the highest fish density within habitat types with the highest effort by area ratio. When $\alpha$ is set to zero, catch rates are equal over each habitat type within an ICES rectangle. Increasing $\alpha$ results in a differentiation in catch rates over habitat types, with larger catch rates in habitat types with the highest aggregation of effort (Fig. 5.3). The value of $a$ is arbitrarily set to 0.5 , assuming fishing activities concentrate within areas and habitat types with a high density of target species (Rijnsdorp et al. 2011).

To scale the catch rates by week, estimates are rescaled to reflect the average fishing effort per week. Fishing effort per week was estimated from the logbooks; resulting in the average time spent at sea $\left(10\right.$ day $\left.^{-1}\right)$ and average number of trips per week (4 trips week ${ }^{-1}$ ). 


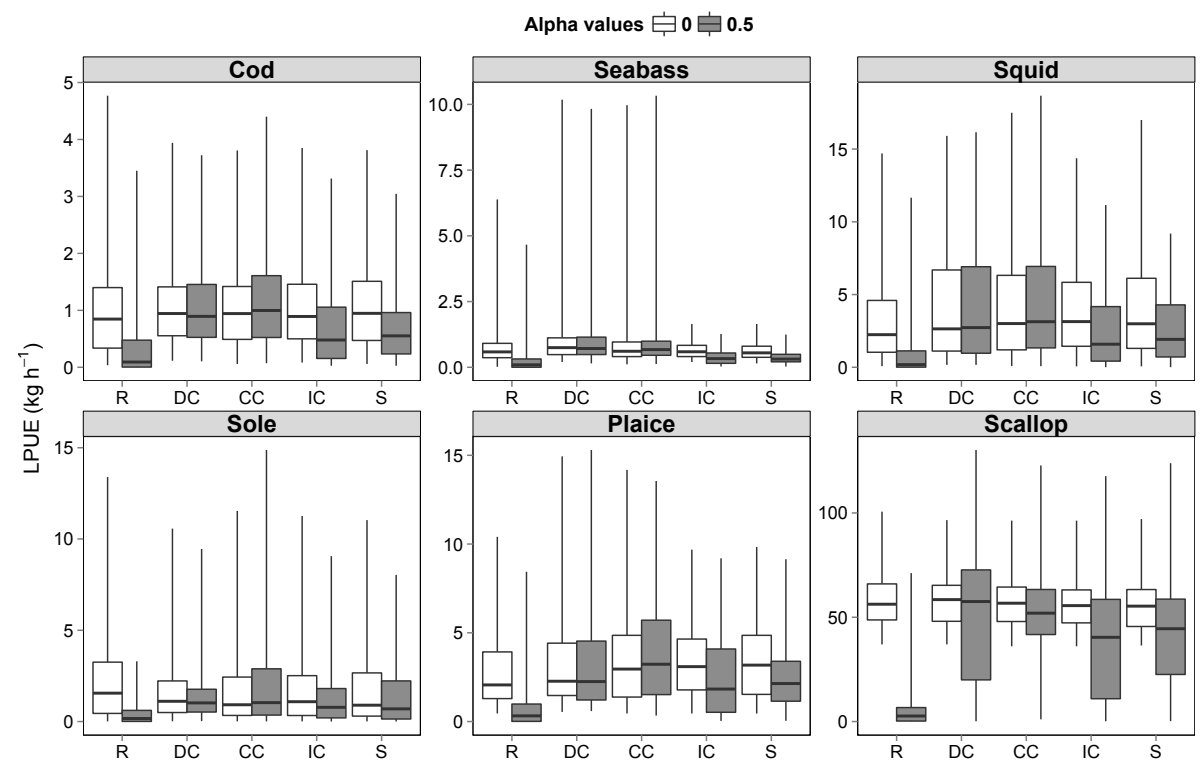

Figure 5.3

Variation in catch rates ( $\left(P \cup E, \mathrm{~kg} \mathrm{~h}^{-1}\right)$ for 6 target species on different substrates. Rock (R), deep coarse sediment (DC), circalittoral coarse sediment (CC), infralittoral coarse sediment (IC) and soft sediment (S).

\section{ECONOMIC DATA}

Mean weekly market values for the six species are calculated from auction price data in the period 2006-2010 (Fig. 5.4). During the scallop season, scallops contribute to more than $85 \%$ of the gross revenue and account for almost $40 \%$ of the annual income of the fleet (Carpentier et al., 2009). The five other species included in our study account for another $27 \%$ of the total annual income. The six species combined thus contribute $67 \%$ of the total annual income.

The model includes a fine for overshooting individual landings quota or individual habitat credits. The fines have been set to arbitrarily high values of $1950 € \mathrm{~kg}^{-1}$ and $5000 € \mathrm{IHC}$ ${ }^{1}$ to ensure vessels compliance with the management regulations within the model.

Variable costs for this fleet include fuel costs, landing costs, and crew salaries (Table 5.2). Fuel costs depend on the type of vessel and gear used. Fuel costs were available in the IFREMER SIH (2011) database and estimated to be approximately $440 €$ day $^{-1}$ when operating a dredge and $730 €$ day $^{-1}$ when operating a demersal otter trawl (mean 2008-2010). Landing costs are defined as the fees paid by the vessel when catches are landed and depends on the total revenue the vessel obtained. Salary costs depend on the total revenue obtained at the end of the fishing trip. Other variable costs are mostly related to fishing effort. Landing costs, salary costs and other variable costs are derived from a study of (Daurès et al., 2013) and assumed to be independent of the gear type used during a fishing trip. 

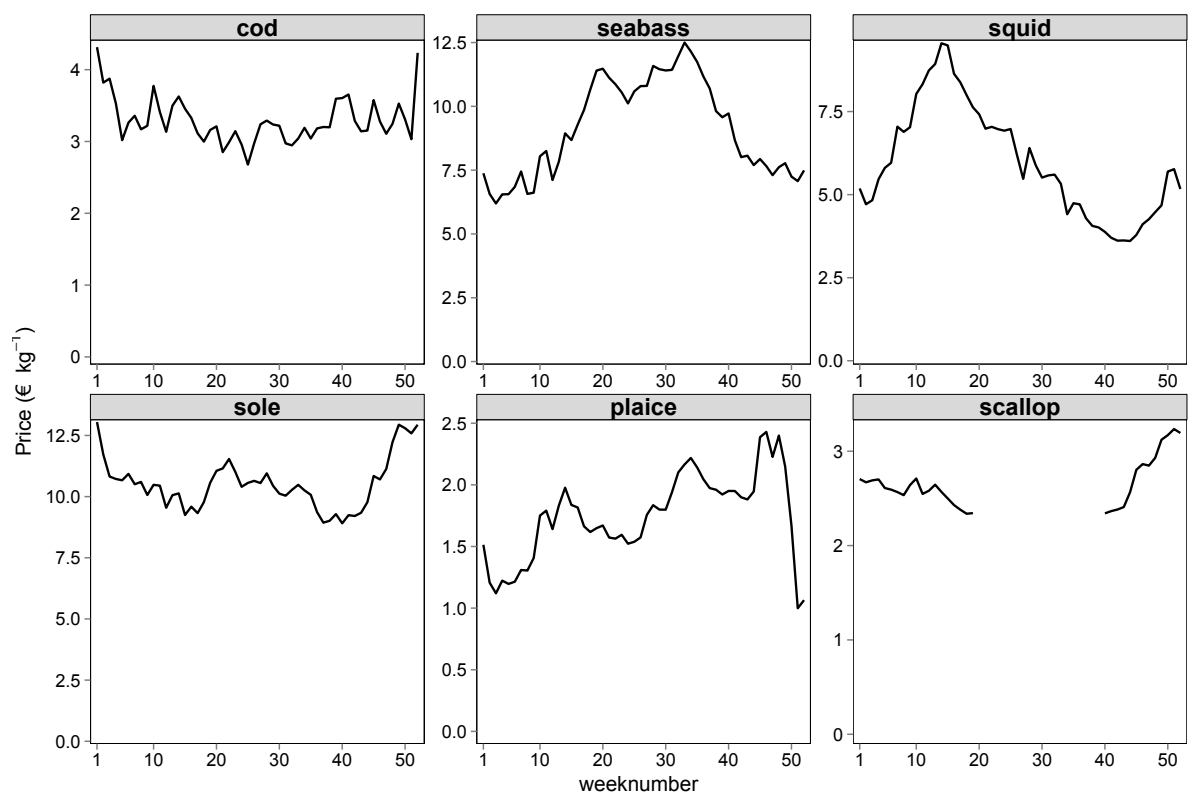

Figure 5.4

Average ex-vessel price per week for each of the target spe-

cies. No prices are available for scallops outside the open

season.

Table 5.2 Variable cost of the scallop dredgers and demersal otter trawl used in the simulation.

\begin{tabular}{lcc}
\hline Variable costs & OTB & DRB \\
\hline Fuel $\left(€ \mathrm{DAS}^{-1}\right)$ & 730 & 440 \\
Crew costs (\% of revenue) & 40 & 40 \\
Landing costs (\% of revenue) & 6 & 6 \\
Other variable costs (€DAS-1) & 40 & 40 \\
\hline
\end{tabular}

\section{SIMULATION MODEL}

The performance of a combined catch quota and habitat credits system is forecasted using a Dynamic State Variable Model (DSVM) (Houston and McNamara, 1999; Clark and Mangel, 2000). Such models have been applied in fisheries research to forecast fishing strategies under different management and market constraints (Gillis et al., 1995; Poos et al., 2010; Dowling et al., 2012).

The model is parameterized for vessels in Boulogne with the predicted spatial and temporal catch rates of the 6 species under consideration (scallops, sole, plaice, cod, sea bass and cephalopods), ex-vessel prices, and variable costs. Two gear types are modelled that can be used interchangeably: demersal otter trawls can be used throughout the year targeting the 4 finfish and cephalopod species, while scallop dredges can only be used during the 
scallop season. The model assumes individual skippers will maximize their expected annual net revenue by making weekly decisions on (1) whether to go fishing or not; (2) what type of gear to use and (3) where to fish. These choices are affected by their annual catch quota and habitat credits.

The optimal fishing strategy in each week of the year, denoted by $t$, depends on the state of the individual skipper. In our case, the cumulative uptake of habitat credits as well as cumulative landings of the quota constrained species affects the possibility to continue fishing without exceeding the annual habitat credits or landing quota. To simplify model results, simulations were done assuming catch quota are restrictive for two species: cod and sole. These species were chosen on the premise that they differ in their preference of habitat types.

DSVMs find the optimal behavioural strategy by working backwards, starting at the end of the year. The expected net revenue at the end of the year is linked to the choices in the preceding weeks by means of a value function between time $t$ and the end of the year $T$. The value function for an individual skipper depends on the cumulative landings of the quota species $L$, the amount of quota $U$ for cod or sole, the cumulative uptake of habitat credits $I$, the amount of habitat credits available $C$ and the fine for exceeding the quota or habitat credits $D$ and is expressed as $V(L, U, I, C, D, t)$. Individuals exceeding their quota or habitat credits pay a fine that depends on the quota $(L-U)$ or credit $(I-C)$ overshoot and the fine per unit weight $\left(d_{1}\right)$ and per credit $\left(d_{2}\right)$. The state-dependent part of the revenue at the end of the year, after all fishing has been completed, is defined by the fine of overshooting quota and/or credits as:

$$
\Phi(L, U, I, C, D)=\left\{\begin{aligned}
0, & L \leq U \text { and } I \leq C \\
-(L-U) d_{1}, & L>U \text { and } I \leq C \\
-(I-C) d_{2}, & L \leq U \text { and } I>C \\
-(L-U) d_{1}-(I-C) d_{2}, & L>U \text { and } I>C
\end{aligned}\right.
$$

For each week before $T$, the expected net revenue is determined by the value function, the weekly gross revenue from the catch and the cost of fishing. Each week individuals choose to use a type of gear $g$ and to visit a fishing area $a$ (including area 0: "staying in harbour"). For all time $t$ preceding $T$ we use stochastic dynamic programming to find the optimal solution by backward iteration of the net expected revenue $H$ from $t$ to the end of the year considering the choices $a$ and $g$ and the states $L$ and $I$ at $t$ and optimal choices in subsequent weeks:

$H(L, U, I, C, D, t ; a, g)=R(a, g, t) *\left(\frac{100}{\kappa}\right)-C(a)+\mathbb{E}_{a, g}\left[V\left(L^{\prime}, U, I^{\prime}, C, D, t+1\right)\right]$

Where $R(a, g, t)$ is the expected immediate contribution of the gross revenue from the sales of the catch in a week resulting from choices $a$ and $g$. The term $\kappa$ represents the percentage that the six species contribute to the total income (67\%). The term represents the variable costs in a week resulting from choosing fishing area $a$ and using gear type $g$ including fuel, crew, landing costs and other variable costs. The term $L^{\prime}$ reflects the change of the state $L$ 
resulting from the weekly landings for the quota species. The term I' reflects the change of state $I$ as a result of the weekly choice of fishing in an area with a given amount of habitat credits. The term $\mathbb{E}_{a, g}\left[V\left(L^{\prime}, U, I^{\prime}, C, D, t+1\right)\right]$ denotes the expected value taken over all possible states resulting from choices $a$ and $g$. The future utility given that an individual behaves optimally from time t onwards is:

$V(L, U, I, C, D, t)=\max _{a, g}\{H(L, U, I, C, D, t ; a, g)\}$

Starting with $V(L, U, I, C, D, T)=\Phi(L, U, I, C, F)$ we can iterate backwards in time and find the optimal choice in terms of location and gear type for all possible states, combining the direct net revenue obtained in a fishing trip and the effect of the fines when exceeding annual quota or habitat credits.

The expected direct gross revenue $R(a, g, t)$ from the sale of the six target species for any choice depends on the catch and the ex-vessel price in a given week. The catch is determined by the choice of gear and the spatial and temporal distribution of the target species.

\section{MANAGEMENT SCENARIOS}

This study explores the performance of individual quota management for sole and cod in combination with a habitat credit system to sustainably exploit resources and minimize the impact of the fishery on the benthic ecosystem. First, the performance of traditional quota management for sole and cod is evaluated in relation to benthic impact. Individual quota for sole are gradually increased from 2 to 16 tonnes per year. Given the low observed quotas for cod under the cod recovery plan, individual quota for cod are lower and increase from 0.2 to 1.6 tonnes per year. Second, management scenarios were explored that combined individual catch quota and habitat credits. Habitat credits varied from 20 to 300 per year, while quota varied from 1 to 15 tonnes and 0.1 to 1.5 tonnes per year for sole and cod, respectively. The maximum of 300 habitat credits per year was based on the maximum uptake of habitat credit by fishers in unconstrained model simulations.

\section{RESULTS}

\section{CATCH QUOTA SIMULATIONS}

First we explored the effect of individual catch quota on habitat impact by estimating the fishing effort in different habitat types (Fig. 5.5a). Reduction of sole quota hardly affects the

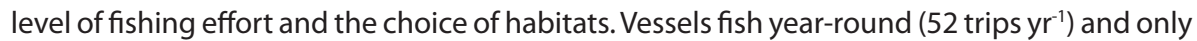
reduce the number of trips when sole quota is reduced to 2 or 4 tonnes per year. The majority (ca $80 \%$ ) of trips are occurring in low impact circalittoral coarse and soft sediment habitats. As a result, the influence of sole quota on the amount of IHCs used by a vessel is minimal. 
(a)

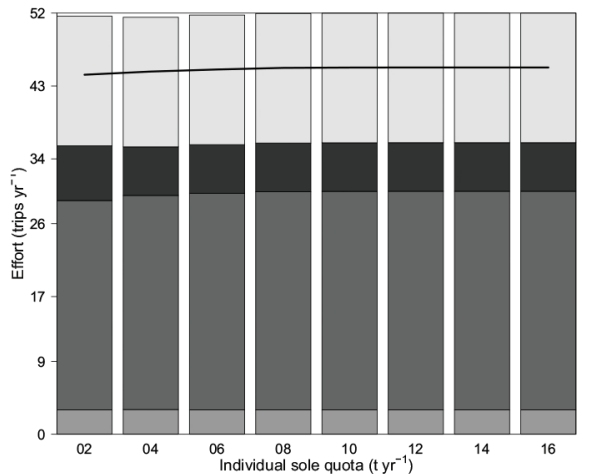

(b)

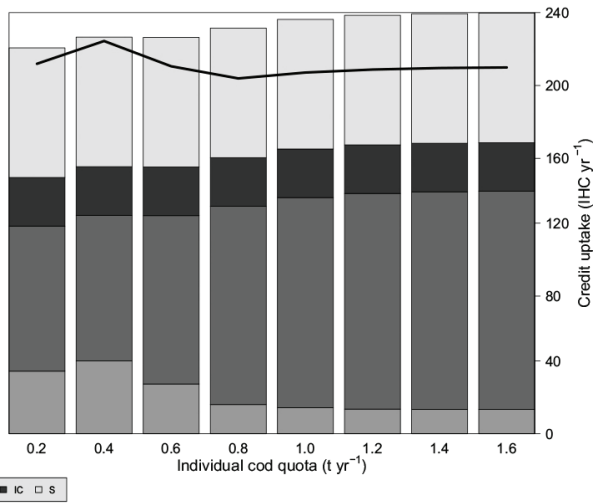

Figure 5.5

Average number of trips in a year to a substrate-type $(D C=$ Deep coarse, $C C=$ Circalitoral coarse, $I C=$ Infralittoral coarse and $S=$ Soft sediment), depending on the quota of plaice

(a) and cod (b). The black line shows the average impact (credit uptake).

In contrast, a reduction of cod quota affects both the level of effort and the choice of habitats (Fig. 5.5b). At the highest cod quota, a vessel will fish year-round, allocating the majority of trips over circalittoral coarse and soft sediment habitats. A decrease in cod quota results in a gradual decrease to 48 trips per year at the lowest cod quota and a slight increase in fishing in the more sensitive deep coarse habitats. This reallocation results in an increase in $\mathrm{IHC}$ used over the year in spite of the reduction in the number of trips.

\section{CATCH QUOTA AND HABITAT CREDIT SIMULATIONS}

Because a reduction in the catch quota for sole and cod does not result in a reduction of the impact on benthic habitat, and in the case of cod quota even in a slight increase, additional management measures are required to reduce the benthic impact. In this section we explore how a habitat credit system can mitigate benthic impact in a fisheries managed by individual catch quota for the main target species.

Habitat credits constrain the fishery if the IHC are less than $220 \mathrm{IHC} \mathrm{Hear}^{-1}$, but the effect is largely independent of the sole or cod quota (Fig. 5.6a, f). When combined with sole quota, a decrease to $100 \mathrm{IHC}$ results in a switch from OTB to DRB (Fig. 5.6c \& d). The overall effort is maintained or even increased when the OTB effort is already high and complemented with a high DRB effort. The latter is observed when high sole quota are combined with a small reduction of habitat credits $(180 \mathrm{IHC})$. A further reduction of $\mathrm{IHC}(<100 \mathrm{IHC})$ will cause a reduction in the overall effort, whereby vessels continue to fish for scallops but stop fishing with the OTB. The influence of individual sole quota on the overall effort is limited. A decrease in quota to 3 tonnes per year results in slight reduction in overall effort. This reduction can be explained by the decrease of effort by OTB due to the constraining effect of low sole quota. 

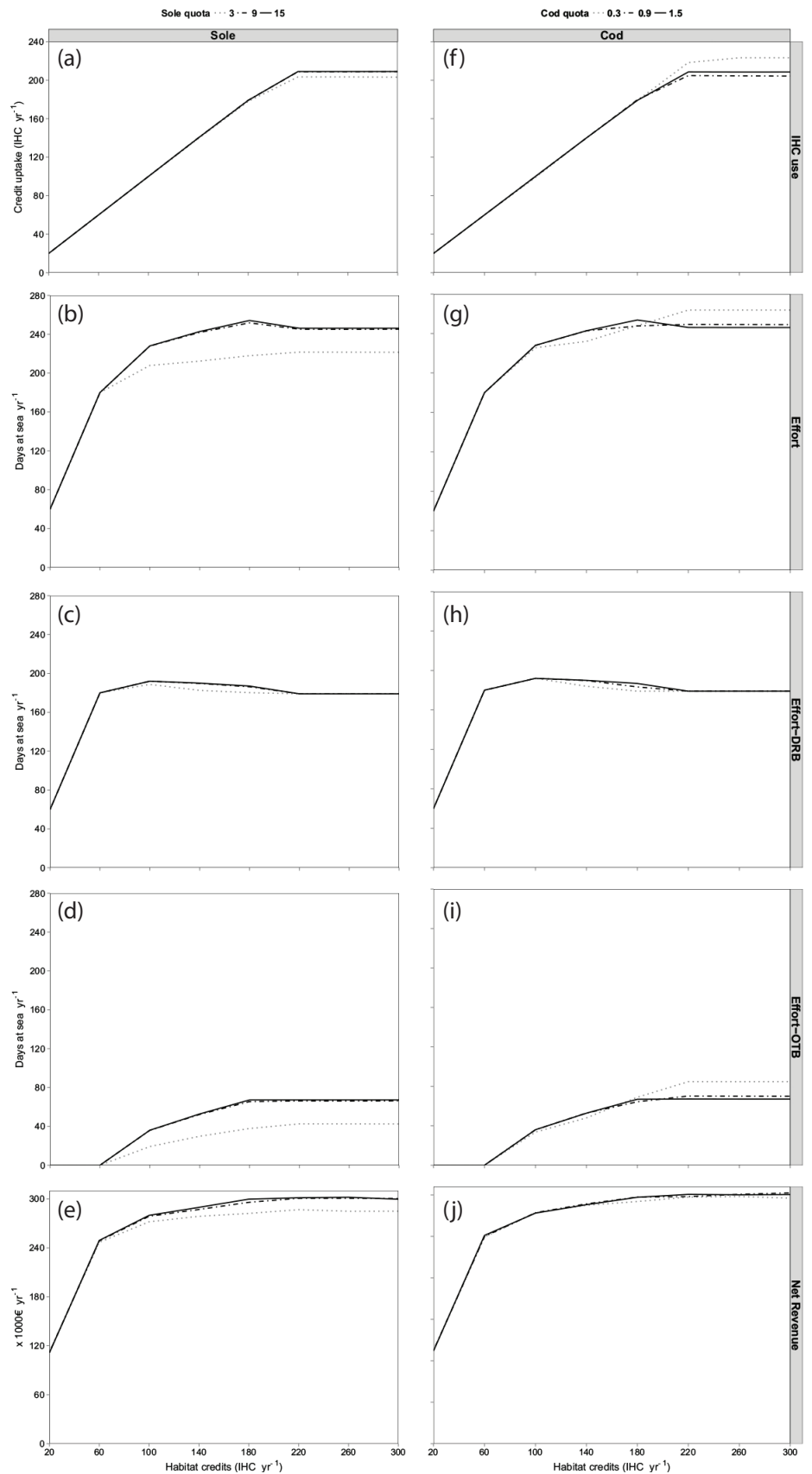

\section{Figure 5.6}

Average credit use, total effort, otter trawl effort, dredge effort and net revenue in relation to the individual habitat credits in combination with three levels of individual catch

quota for plaice (panels a to e) and cod (panels $f$ to $j$ ). Sole quota range from 3 to 15 tonnes per year and cod quota range from 0.3 to 1.5 tonnes per year 
Net revenue is rather stable and starts to decrease steeply when credits are reduced below $100 \mathrm{IHC}$ (Fig. 5.6e). A reduction in sole quota has a minor effect on the revenue as it is partially compensated by landings of other species. When IHC are very low, the influence of sole quota is negligible because a vessel will choose to dredge for scallops. Costs, however, will be lower given the lower amount of effort being used. Hence, the fishery can still remain profitable despite a reduction in habitat credits and sole quota.

When habitat credits are combined with cod quota, a decrease in habitat credits has a limited influence on the overall effort of the fishery (Fig. 5.6g). At high IHC, effort will be divided over both metiers, with most effort being allocated to the DRB (Fig. 5.6h \& 5.6i). A decrease in IHC results in a reduction of OTB effort and an increase in DRB effort, irrespective of the quantity of cod quota. Hence, the overall effort is maintained. Only when IHC are low $(<100 \mathrm{IHC})$ effort is reduced and vessels no longer choose to fish using OTB, but only fish with the DRB (as long as IHC > 60). Decreasing IHC results in a modest reduction of net revenue. This is largely the result of an increase in DRB effort that compensates the lower OTB effort. Only when IHC are very low and the fishery is fully focussed on the scallop fishery, net revenue sharply declines below $€ 200 \mathrm{~K}$. Because cod has a relatively lower economic value and a lower catch rate, compared to the other target species, the loss in revenue from cod at reduced catch quota is compensated by switching to economically more valuable species and increasing the level of DRB effort. Our results thus suggest that when reducing habitat credits from high to low, the net revenue only decrease slightly at first (Fig. 5.6e \& j), and more steeply at low IHCs. This result is largely independent of the individual catch quota available.

\section{TRIP ALLOCATION OVER HABITAT TYPES}

When habitat credits are combined with sole quota, the choice where to fish is mainly determined by the IHC available (Fig. 5.7a). Regardless of the quantity of sole quota, high IHC results in an allocation of trips predominantly to circalittoral coarse and soft sediment habitats. Few vessels will fish in areas with more sensitive deep coarse sediments. A reduction in IHC pushes vessels away from circalittoral coarse sediments to less sensitive infralittoral coarse and soft sediments. The shift from more sensitive to less sensitive habitat types is influenced by the amount of individual sole quota. At high sole quota, fishing in deep coarse sediments stops when habitat credits are slightly reduced, whereas at low sole quota, trips to deep coarse sediments decline but continue until $\mathrm{IHC}$ are very low $(<100 \mathrm{IHC})$ and trips to these sensitive habitats are no longer made.

In addition to the IHC available, low cod quota influence the choice of where to fish (Fig. 5.7d). At high IHC and low cod quota vessels will allocate more trips to sensitive deep coarse sediment habitats and less trips to fishing grounds with circalittoral coarse sediment habitat. Nevertheless, circalittoral coarse and soft sediment habitats still remain the dominant fishing grounds. At high cod quota, fishing in more sensitive habitat types decreases if $\mathrm{IHC}$ are reduced (Fig. 5.7f). At low cod quota a decrease in $\mathrm{IHC}$ initially result in a small 
Habitat type ... Deep coarse - - - Circalittoral coarse - - - Infralittoral coarse —- Soft
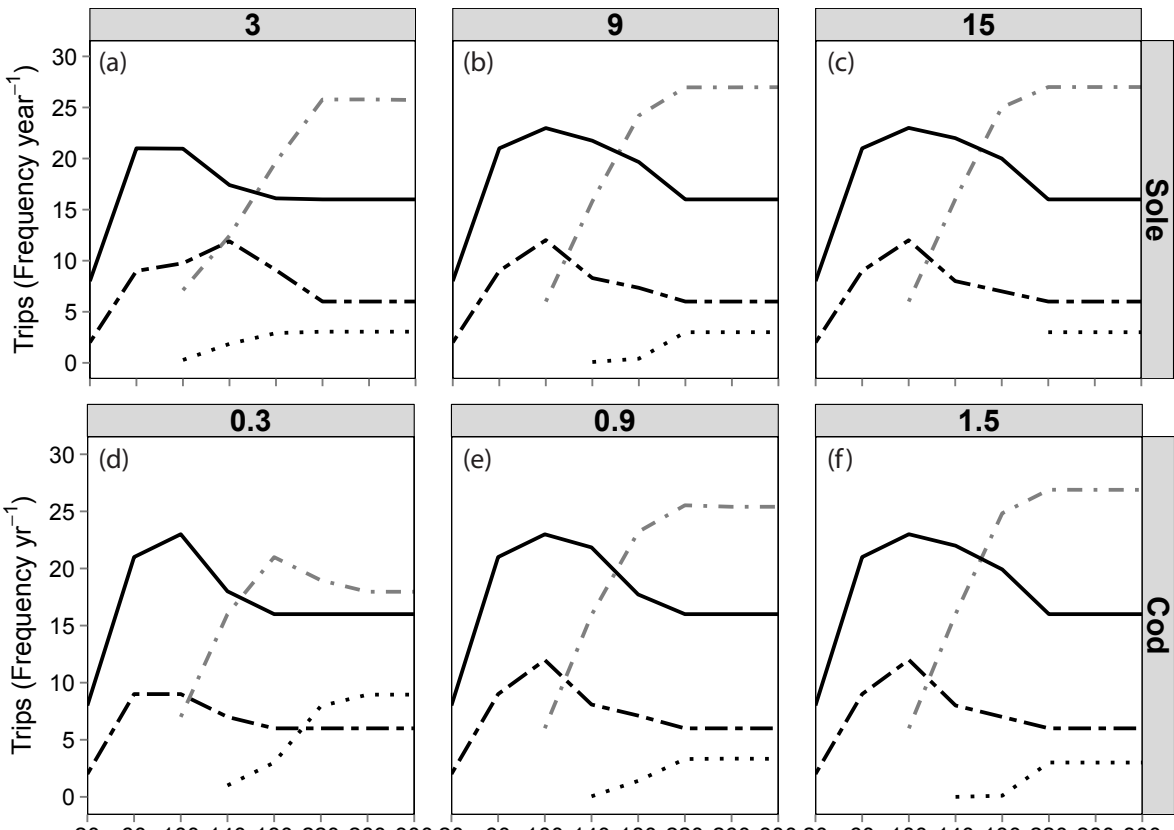

206010014018022026030020601001401802202603002060100140180220260300 Habitat credits (IHC year ${ }^{-1}$ )

\section{Figure 5.7}

The average number of trips made to a certain habitat type for the different impact scenarios. Top panels (a-c) are a fishery under sole quota from 3 (left) to 15 (right) tonnes per

increase in the number of trips to circalittoral fishing grounds and a decrease in the number of trips allocated to fishing grounds with deep coarse sediment habitats. A further decrease in IHC will push vessels away from sensitive habitat types and as a result, all effort is concentrated in infralittoral coarse and soft sediment habitats.

\section{DISCUSSION}

\section{OVERVIEW OF FINDINGS}

The model results indicate that reducing individual catch quota does not necessarily reduce benthic impact exerted by French bottom trawlers in the eastern English Channel. Reduction of individual catch quota could even result in an increase in the benthic impact as vessels could reallocate effort towards fishing grounds towards more vulnerable habitats to 
avoid catching quota-restricted species. In the model, a reduction of benthic impact is only achieved when individual habitat credits are reduced. A reduction in $\mathrm{IHC}$ by $50 \%$ results in a small reduction in total effort and net revenue. Vessels are able to reallocate their effort to less vulnerable fishing grounds while maintaining their effort and revenue. When IHC are reduced more than $50 \%$, vessels cannot make any profit out of fishing and they have to stay in port to not exceed their habitat credits.

\section{SIMULATION MODEL}

The simulation model was parameterized for the eastern English Channel French bottom trawl fleet. Results of the fleet response are indicative for this particular fleet given the necessary simplifications made. Model simplifications include the assumptions that: (1) fishers are profit maximizers and comply fully with management regulations given severe sanctions for non-compliance, (2) individuals have perfect knowledge about the temporal and spatial distribution of catch rates, (3) the quota for a single species (sole or cod) is constraining the fishery, and these quota are not transferable, and (4) there is no competition among fishers. The hypothesized effects of these simplifying assumptions have been discussed in Poos et al. (2010) and Batsleer et al. (2013). We further assume that vessels did not move from Boulogne to other harbours at the opening of the scallop season. In the model the scallop season was assumed to be open from November to April throughout the eastern English Channel. In reality the opening of the season depends on annual scientific advice and the opinion of authorities, and may be different among areas (Carpentier et al., 2009). Given that scallops are a valuable species, vessels may temporarily move to harbours close to the best scallop fishing grounds (Bay of Seine) to reduce steaming time.

Although we had to make a large number of simplifying assumptions, as discussed above, these assumptions will not affect the qualitative results showing that within mixed fisheries the seasonally and spatially variable availability of target species allows a variety of effort allocation patterns that yield similar net revenue with widely different benthic impacts. A habitat credit system will provide an incentive for fishers to reduce the benthic impact at a minimal economic cost.

Currently, catch data are not collected at the scale where fishing within different habitats can be detected. Hence, an arbitrary scaling factor $(\alpha)$ had to be used to estimate CPUE within different habitats. This scaling factor distributes the highest catch rates within an ICES rectangle to the subareas with the highest fishing effort. Information on the fine scale distribution (interval of $2 \mathrm{~h}$ ) of fishing effort for vessels $>15 \mathrm{~m}$ can be obtained from Vessel Monitoring Systems (VMS) (European Commission, 2003). Although catch data in logbooks can be distributed over fishing positions recorded in VMS data, such procedures generally assume that catches are uniformly distributed over VMS positions (Dinmore et al., 2003; Gerritsen and Lordan, 2011; Hintzen et al. 2012).

In this study, habitat impact credits are independent of the historic fishing activities in the habitat. However, historic fishing activities can be an important factor determining fish- 
ing impact on the benthic ecosystem (Kaiser, 2005). Reducing habitat credits in response to the frequency of fishing may lead to a concentration of fishing activities in that specific area, given the reduced cost of fishing (Holland and Schnier, 2006). The exact dynamics of making a frequency dependent habitat credit system could be investigated in a future study.

The habitat credits in the model do not vary by gear type. Empirical studies, however, indicate that gear type strongly affects the magnitude of fishing impact (Collie et al., 2000; Kaiser et al., 2006; Eigaard et al., 2016). Sensitivity matrices synthesize these results, describing the sensitivity of habitats to different gears based on the physical bottom of each gear and the sensitivity of the benthic community to the additional mortality caused by the bottom contact. These sensitivity matrices can be used by policy makers to assign gear-specific habitat credits (Eno et al., 2013).

\section{PRACTICAL APPLICATION AND BROADER RELEVANCE}

There is a growing awareness on effects of fisheries on ecosystems beyond the obvious reductions in population biomass as a result of fisheries catches. An ecosystem-based approach to fisheries management aims at mitigating these effects and strives to restore and conserve the composition, structure and functioning of ecosystems. Management approaches, such as credit management systems, have been suggested as a mean to protect or improve ecosystem structures and functions (Holland and Schnier, 2006; Kraak et al., 2012), in complement to traditional measures (Winter and May, 2001; Raakjær Nielsen, 2003; Smith et al., 2010; Abbott and Haynie, 2012; Caveen et al., 2015). Such systems build on incentivizing responsible fishing practices, constraining fishers with a number of credits or a share of the property while allowing them to adjust their behaviour and chose freely when and where to fish to make optimal use of their credits or share. However, management objectives in such systems will only be achieved if credits or quota are set at the right target or limit reference point (Van Riel et al., 2015). Setting these targets or limit reference points will depend on the availability of data and knowledge. In addition, the decision will be a process where policy-makers, scientists, fishing industry and other stakeholders need to be engaged and agree on the specific goals of the management system.

Our study shows that a complementary use of habitat credits with catch quota could minimize benthic impact, while the fishery can continue to sustainably exploit a mix of resources. The development of credit systems, however, is still in its infancy and requires more knowledge on the relationship between different ecosystem components, improved data collection at the right scale and extensive monitoring and enforcement (Holland and Schnier, 2006; Kraak et al., 2012; Van Riel et al., 2015). The collection of more detailed information and data gathering would require more effort from the fishing industry in terms of privacy and investments on board, but then again fishers will retain their freedom to choose when and where to fish. Hence, for spatial measures to meet ecological objectives and to be cost-effective, an understanding of the adaptive behaviour of fishers to these measures is critical. 


\section{ACKNOWLEDGEMENTS}

The contribution of JJP and ADR was funded by the European Union's Seventh Framework Programme (FP7/2007-2013) under grant agreement $n^{\circ} 312088$ (BENTHIS). The contribution of Paul Marchal, Sandrine Vaz and Youen Vermard was funded by European Union's Seventh Framework Programme (FP7/2007-2013) under grant agreement $n^{\circ} 266445$ for the project Vectors of Change in Oceans and Seas Marine Life, Impact on Economic Sectors (VECTORS). 


\section{REFERENCES}

Abbott, J.K., Haynie, A.C. (2012) What are we protecting? Fisher behavior and the unintended consequences of spatial closures as a fishery management tool. Ecological Applications 22, 762-777.

Atkinson, C.J.L., Bergmann, M., Kaiser, M.J. (2004) Habitat selection in whiting. Journal of Fish Biology 64, 788-793.

Batsleer, J., Poos, J.J., Marchal, P., Vermard, Y., Rijnsdorp, A.D. (2013) Mixed fisheries management: protecting the weakest link. Marine Ecology Progress Series 479, 177-190.

Boulcott, P., Millar, C.P., Fryer, R.J. (2014) Impact of scallop dredging on benthic epifauna in a mixed-substrate habitat. ICES Journal of Marine SCience 71,834-844.

Carpentier, A., Martin, C.S., Vaz, S., (Eds.) (2009) Channel Habitat Atlas for marine Resource Management, final report (CHARM phase II). In: INTERREG 3a Programme. IFREMER, Boulogne-sur-mer, France, 626 pp. \& CD-rom.

Caveen, A., Polunin, N., Gray, T., Stead, S.M. (2015) The Controversy over Marine Protected Areas Science Meets Policy. Springer London. 162 pp.

Chu, C. (2009) Thirty years later: The global growth of ITQs and their influence on stock status in marine fisheries. Fish and Fisheries 10, 217-230.

Clark, C.W., Mangel, M. (2000) Dynamic state variable models in ecology: Methods and applications, Oxford University Press. 304 pp.

Coggan, R., Diesing, M. (2011) The seabed habitats of the central English Channel: A generation on from Holme and Cabioch, how do their interpretations match-up to modern mapping techniques? Continental Shelf Research 31, S132-S150.

Collie, J.S., Escanero, G.A., Valentine, P.C. (1997) Effects of bottom fishing on the benthic megafauna of Georges Bank. Marine Ecology Progress Series $155,159-172$.

Collie, J.S., Hall, S.J., Kaiser, M.J., Poiner, I.R. (2000) A quantitative analysis of fishing impacts on shelf-sea benthos. Journal of Animal Ecology 69, 785-798.

European Commission, (2003) Regulation (EC) No. 2244/2003 of 18 December 2003 laying down detailed provisions regarding satellite-based vessel monitoring systems. Official Journal of the European Union, L. (Ed.).
Daurès, F., Trenkel, V.M., Guyader, O. (2013) Modelling the fishing costs of French commercial vessels in the Bay of Biscay. Fisheries Research 146, 74-85.

Dayton, P.K., Thrush, S.F., Agardy, M.T., Hofman, R.J. (1995) Environmental effects of marine fishing. Aquatic Conservation: Marine and Freshwater Ecosystems 5, 205-232.

Delavenne, J. (2012) Conservation of marine habitats under multiple human uses: Methods, objectives and constraints to optimize a Marine Protected Areas network in the Eastern English Channel. $\mathrm{PhD}$ thesis Agricultural sciences. Université du Littoral Côte d'Opale.

Diesing, M., Coggan, R., Vanstaen, K. (2009) Widespread rocky reef occurrence in the central English Channel and the implications for predictive habitat mapping. Estuarine Coastal and Shelf Science 83, 647-658.

Dinmore, T.A., Duplisea, D.E., Rackham, B.D., Maxwell, D.L., Jennings, S. (2003) Impact of a large-scale area closure on patterns of fishing disturbance and the consequences for benthic communities. ICES Journal of Marine Science 60, 371-380.

Dowling, N.A., Wilcox, C., Mangel, M., Pascoe, S. (2012) Assessing opportunity and relocation costs of marine protected areas using a behavioural model of longline fleet dynamics. Fish and Fisheries 13, 139-157.

Eigaard, O.R., Bastardie, F., Breen, M., Dinesen, G.E., Hintzen, N.T., Laffargue, P., and others (2016) Estimating seafloor pressure from trawls and dredges based on gear design and dimensions. /CES Journal of Marine Science 73(suppl 1), i27-i43.

Eno, N.C., Frid, C.L.J., Hall, K., and others (2013) Assessing the sensitivity of habitats to fishing: from seabed maps to sensitivity mapsa. Journal of Fish Biology 83, 826-846.

Gerritsen, H., Lordan, C. (2011) Integrating vessel monitoring systems (VMS) data with daily catch data from logbooks to explore the spatial distribution of catch and effort at high resolution. ICES Journal of Marine Science 68, 245-252.

Gibson, R.N., Robb, L. (2000) Sediment selection in juvenile plaice and its behavioural basis. Journal of Fish Biology 56, 1258-1275. 
Gillis, D.M., Pikitch, E.K., Peterman, R.M. (1995) Dynamic discarding decisions - foraging theory for high-grading in a trawl fishery. Behavioral Ecology 6, 146-154.

Guyader, O., Daures, F., Fifas, S. (2004) A Bioeconomic Analysis of the Impact of Decommissioning Programs: Application to a Limited-Entry French Scallop Fishery. Marine Resource Economics 19 225-242.

Hall, S.J. (1994) Physical Disturbance and Marine Benthic Communities - Life in Unconsolidated Sediments. Oceanography and Marine Biology: An Annual Review 32, 179-239.

Halpern, B.S. (2003) The impact of marine reserves: Do reserves work and does reserve size matter? Ecological Applications 13, 117-137.

Hintzen, N.T., Bastardie, F., Beare, D., Piet, G.J., Ulrich, C., Deporte, N., Egekvist, J., Degel, H. (2012) VMStools: Open-source software for the processing, analysis and visualisation of fisheries logbook and VMS data. Fisheries Research 115-116, 31-43.

Holland, D., Schnier, K.E. (2006) Individual habitat quotas for fisheries. Journal of Environmental Economics and Management 51, 72-92.

Houston, A.I., McNamara, J.M. (1999) Models of Adaptive Behaviour. Cambridge University press. 378 pp.

Jennings, S., Kaiser, M.J. (1998) The Effects of Fishing on Marine Ecosystems. In: Advances in Marine Biology. Volume 34. Academic Press, pp. 201-352.

Kaiser, M.J. (2005) Are marine protected areas a red herring or fisheries panacea? Canadian Journal of Fisheries and Aquatic Sciences 62, 1194-1199.

Kaiser, M.J., Clarke, K.R., Hinz, H., Austen, M.C.V., Somerfield, P.J., Karakassis, I. (2006) Global analysis of response and recovery of benthic biota to fishing. Marine Ecology-Progress Series 311, 1-14.

Kaiser, M.J., Collie, J.S., Hall, S.J., Jennings, S., Poiner, I.R. (2002) Modification of marine habitats by trawling activities: prognosis and solutions. Fish and Fisheries 3, 114-136.

Kraak, S.B.M., Reid, D.G., Gerritsen, H.D., and others (2012) 21st century fisheries management: a spatio-temporally explicit tariff-based approach combining multiple drivers and incentivising responsible fishing. ICES Journal of Marine Science 69, 590-601.
Le Pape, O., Chauvet, F., Mahévas, S., Lazure, P., Guérault, D., Désaunay, Y. (2003) Quantitative description of habitat suitability for the juvenile common sole (Solea solea, L.) in the Bay of Biscay (France) and the contribution of different habitats to the adult population. Journal of Sea Research 50, 139-149.

Lester, S.E., Halpern, B.S., Grorud-Colvert, K., and others (2009) Biological effects within no-take marine reserves: a global synthesis. Marine Ecology-Progress Series 384, 33-46.

Lindholm, J.B., Gleason, M., Kline, D., and others (2015) Ecological effects of bottom trawling on the structural attributes of fish habitat in unconsolidated sediments along the central California outer continental shelf. Fisheries Bulletin 113, 82 - 96.

Pikitch, E.K., Santora, C., Babcock, E.A., and others (2004) Ecosystem-Based Fishery Management. Science $305,346-347$.

Poos, J.J., Bogaards, J.A., Quirijns, F.J., Gillis, D.M., Rijnsdorp, A.D. (2010) Individual quotas, fishing effort allocation, and over-quota discarding in mixed fisheries. ICES Journal of Marine Science 67, 323-333.

R Core Development Team (2013) R: A language and environment for statistical computing. R Foundation for Statistical Computing, Vienna, Austria. ISBN 3-900051-07-0, URL http://www.R-project. org/.

Raakjær Nielsen, J. (2003) An analytical framework for studying: compliance and legitimacy in fisheries management. Marine Policy 27, 425-432.

Rice, J., Arvanitidis, C., Borja, A., and others (2012) Indicators for Sea-floor Integrity under the European Marine Strategy Framework Directive. Ecological Indicators 12, 174-184.

Rijnsdorp, A.D., Bastardie, F. Bolam, S.G., BuhlMortensen L., and others (2016) Towards a framework for the quantitative assessment of trawling impacts on the sea bed and benthic ecosystem. ICES Journal of Marine Science 73(suppl 1), i127-i138.

Rijnsdorp, A.D., Daan, N., Dekker, W. (2006) Partial fishing mortality per fishing trip: a useful indicator of effective fishing effort in mixed demersal fisheries. ICES Journal of Marine Science 63, 556-566.

Rijnsdorp A.D., J.J. Poos, Quirijns, F.J. (2011) Spatial dimension and exploitation dynamics of local fishing grounds by fishers targeting several flatfish species. Canadian Journal of Fisheries and Aquatic Sciences 68, 1064-1076. 
Système d'Informations Halieutiques (2011) Synthèse des flottilles de pêche 2011: Flotte de la façade Mer du Nord - Manche. IFREMER.

Smith, M.D., Lynham, J., Sanchirico, J.N., Wilson, J.A. (2010) Political economy of marine reserves: Understanding the role of opportunity costs. Proceedings of the National Academy of Sciences of the United States of America 107, 18300-18305.

Snickars, M., Gullström, M., Sundblad, G., and others (2014) Species-environment relationships and potential for distribution modelling in coastal waters. Journal of Sea Research 85, 116-125.

Thouzeau, G., Robert, G., Smith, S.J. (1991) Spatial variability in distribution and growth of juvenile and adult sea scallops Placopecten magellanicus (Gmelin) on eastern Georges Bank (Northwest Atlantic). Marine Ecology Progress Series 74, 205-218.

Thrush, S.F., Hewitt, J.E., Cummings, V.J., and others (1998) Disturbance of the marine benthic habitat by commercial fishing: impacts at the scale of the fishery. Ecological applications 8, 866-879.

Tupper, M., Boutilier, R.G. (1995) Effects of habitat on settlement, growth, and post-settlement survival of Atlantic cod (Gadus morhua). Canadian Journal of Fisheries and Aquatic Sciences 52, 1834-1841.

U.S. (2006) Magnuson-Stevens Fishery Conservation and Management Reauthorization Act of 2006. Retrieved from http://www.nmfs.noaa.gov/sfa/ magact/MSA_Amended_2007\%20.pdf.

Valdemarsen, J.W., Jørgensen, T., Engås, A. (2007) Options to mitigate bottom habitat impact of draged gears. FAO Fisheries Technical Paper 506, 29.
Van Denderen P.D., Hintzen N.T., Rijnsdorp A.D., Ruardij P., van Kooten T. (2014) Habitat-specific effects of fishing disturbance on benthic species richness in marine soft sediments. Ecosystems 17, 12161226.

Van Riel, M.C., Bush, S.R., van Zwieten, P.A.M., Mol, A.P.J. (2015) Understanding fisheries credit systems: potentials and pitfalls of managing catch efficiency. Fish and Fisheries, 16, 453-470.

Wieland, K., Pedersen, E.M.F., Olesen, H.J., Beyer, J.E. (2009) Effect of bottom type on catch rates of North Sea cod (Gadus morhua) in surveys with commercial fishing vessels. Fisheries Research 96, 244-251.

Winter, S.C., May, P.J. (2001) Motivation for Compliance with Environmental Regulations. Journal of Policy Analysis and Management 20, 675-698.

Wood, S.N. (2003) Thin plate regression splines. Journal of the Royal Statistical Society: Series B (Statistical Methodology) 65, 95-114.

Wood, S.N. (2006) Generalized Additive Models: an Introduction with R. Chapman and Hall/CRC Press, New York.

Zuur, A.F. (2012) A beginners guide to generalized additive models with R, Highland Statistics Ltd., UK.

Zuur, A.F., leno, E.N., Walker, N.J., Saveliev, A.A., Smith, G.M. (2009) Mixed effect models and extensions in ecology in $R$, New York. 
Exploring habitat credits to manage the benthic impact in a mixed fishery 


\section{GENERAL DISCUSSION}

The adverse side effects of fisheries have increasingly raised societal concern, in particular the bycatch and impact on the seafloor and benthic ecosystem. Criticism on the Common Fisheries Policy for failing to implement fisheries regulations which conserve (European) fisheries resources and protect ecosystem structure and functions have lead to the European Commission to adopt an ecosystem approach to fisheries management. In response to the societal concern the EU has introduced a ban on discarding in the latest reform of the CFP to reduce this wasteful practice. The effectiveness of this ban depends on the adaptive behaviour of the fishers.

This thesis developed a spatial explicit model of the behaviour of fishers to study how management measures influence the behavioural responses of fishers in terms of effort allocation and discarding decisions and the ecosystem and economic impacts thereof. The model was used to study how the discarding and benthic impacts of bottom trawl fisheries could be reduced and applied to the Dutch North Sea flatfish fisheries and the French mixed demersal fisheries in the Channel.

In chapter $\mathbf{2}$ of this thesis I evaluated the performance of individual quota management as well as a combination of individual quota with a ban on discarding to improve the regulation of fishing mortality for a depleted stock exploited in a mixed fishery. Our findings show that a management system with individual quota that allows fishers to discard will increase the discarding. Individual vessels continue fishing for other species while discarding marketable fish of the species for which quota are fully exploited. As such, quota management does not limit fishing mortality to the level specified for conserving a particular stock. These findings are in line with observations on over-quota discarding in mixed fisheries (Pascoe, 1997, Poos et al., 2010) and supports the criticism on landings quota management being an ineffective measure to control fishing mortality in mixed fisheries (Daan, 1997). Combining the individual quota with a discard ban, individual fishers reallocated their effort away from areas and weeks with high catch rates of the quota constrained species, targeting other species, reducing the amount of discarding. Such behaviour, i.e. the ability to align the species mixture of their catch with the availability of quota by reallocation fishing activities has been observed (Branch and Hilborn, 2008, Branch, 2009). When properly enforced, a discard ban can reduce over-quota discarding, control fishing mortality, and thus contribute to the conservation of vulnerable species. However, measures to reduce discarding coincided with a reduction in the economic performance and may jeopardise the compliance as fishers may trade-off economic gains of non-compliance against the costs. Achieving acceptance and compliance to the measures may require high penalties.

Policy and market forces are the main drivers in the decision making of fishers to discard marketable fish. In chapter $\mathbf{3}$ I elaborate on the conditions under which discarding of marketable fish may occur by reviewing literature on observations on high-grading and over-quota discarding. Empirical evidence suggest that high-grading, i.e. discarding low valued fish to make room for more valuable fish, occurs under different management systems for a large variety of fisheries worldwide. Yet, discarding of marketable fish while quota is still available 
mainly occurs in mixed fisheries managed by an individual quota system. Following the literature review I applied a simulation model exploring discarding decisions in a mixed fishery constrained by annual individual quota. Model results illustrate that high-grading is strongly linked to the availability of quota, while over-quota discarding occurs on a rather constant level. This difference can be explained by the ability of fishers to strategically plan their fishing activities throughout the year. Fishers adapt their fishing activities to optimize the composition of their catch taking account of the availability of quota and seasonal price variations. In addition our findings show a clear difference between the size composition in the landed catch and the actual catch (i.e. including discards). Quantifying the differences in age and size structure as a result of discarding as well as the conditions under which discarding occurs can improve the quality of the stock assessments and the sustainable management of exploited fish stocks.

Chapter $\mathbf{4}$ is exploring the potential of the discard ban to reduce catches of undersized target species and to incentivise a transition towards more selective gears. A simulation model was applied to the Dutch flatfish fishery in the North Sea which is an ideal case study given the current transition from conventional beam trawling with tickler chain towards pulse trawling using an electrical stimulus. Similar to our study in chapter $\mathbf{2}$ a discard ban, assuming full compliance, forces fishers to reallocate their fishing activities in space and time where they can achieve maximum revenue by targeting other species while exploiting the restrictive quota with reduced catch rates of undersized fish. While reallocation reduces the amount of undersized fish, the catch of undersized fish does not differ much between the conventional beam trawl and the pulse trawl. Due to their improved fuel efficiency and different species specific catch efficiencies compared to traditional beam trawlers, pulse trawlers are economically more profitable providing more flexibility in the time spend fishing. As such, a discard ban can incentivise the use of more selective gear to reduce the catch of undersized fish which would otherwise be counted against the quota, fetching a low price and reducing the economic value of the landings.

Within the ecosystem approach to fisheries context, the impact of fisheries goes beyond the mortality on target and non-target species as a result of the catching process, but also includes the impact of fishing activities on benthic habitats and ecosystems. Gear type, frequency, and distribution of fishing activities as well as the sensitivity of habitats to fishing disturbance determine the extent of the benthic impact (Collie et al., 2000, Kaiser et al., 2006, Rijnsdorp et al., 2016). The conventional approach to protect the benthic ecosystem from fishing activities is through spatial measures. Such measure have proven to support conservation objectives in overfished situations. However, they often lack acceptance from the fishing industry as these measures are often associated with socioeconomic losses (Caveen et al., 2015). Chapter 5 of this thesis explores the potential of a habitat credit system (Holland and Schnier, 2006) as a tool for ecosystem based management, balancing conservation goals with economic profitability for the fishery. The performance of catch quota and a habitat credits system is predicted using a simulation model parameterized for French multipurpose bottom trawl vessels. Model results suggest quota management has a limited effect on fishing behaviour and does not reduce benthic impact of the fishery. In contrary, 
managers have to be aware restrictive quota can increase the benthic impact. Vessels may reallocate effort to more vulnerable habitats trying to avoid areas of high catch rates of the quota restricted species. A habitat credit system has the potential to reduce the benthic impact and maintain profitable fisheries as vessels can adjust their behaviour and chose freely to reallocate their fishing activities to make optimal use of the available credits. However, in order for the fisheries to maintaining effort and revenue credits should not be reduced to very low levels. Currently credits systems are still in their infancy and require more detailed knowledge on setting appropriate targets and limits before they can be implemented as an operational fisheries management system.

The fishing industry, environmental organisations and the general public are increasingly demanding (science based) support for management decisions made by fisheries managers. Under current fisheries policy, managers need to ensure management measures contribute to the sustainable use of natural resources, while minimizing the ecosystem impact of fishing activities and maintaining economic resilient fisheries. However, management measures may not always result in expected outcomes, as demonstrated for TAC management in mixed fisheries (Daan, 1997) or when spatial measures implemented to protect spawning or nursery areas fail because of changes in the spatial and temporal fish distributions (Rijnsdorp et al., 2001, Beare et al., 2013). Also, management measures aimed at improving the sustainability of one component on the ecosystem can have negative ecosystem impacts elsewhere, such as when area closures lead to effort displacement to previously unfished areas (Dinmore et al. 2003). This thesis contributes to the ecosystem approach to fisheries management as an innovative spatial explicit simulation model is developed to deliver insights into complex socioeconomic and ecological trade-offs resulting from management measures. I show adaptive behaviour of a fishing fleet is certainly a factor which can influence the outcome, but which is easily overlooked. Hence, fleet dynamics is an essential element to understand the effectiveness of management measures.

\section{MODELLING FISHERS BEHAVIOUR}

The dynamic state variable model used in this thesis was developed from the model used in Poos et al. (2010). The model was extended to include size-structured fish populations with seasonal changes in their distribution as well as seasonal variation in the ex-vessel price of the different species and size classes. The integration of these elements into our model enabled us to evaluate fleet responses to opportunity costs (rationale of fishing now or later) and explore the consequences of a number of new management scenarios, such as the discard ban. The model was applied to several mixed demersal fisheries which would be impacted by the evaluated scenarios. The model outcomes are generally applicable to the fisheries studied. However, since several simplifying assumptions had to made, results cannot be directly implemented in management of the fisheries. The key assumptions will be highlighted and discussed. 


\section{MAXIMIZING ECONOMIC PERFORMANCE}

Many studies on fisheries behaviour include profit as the currency fishers will aim to maximize (Hilborn and Walters, 1987, Gillis et al., 1995, Babcock and Pikitch, 2000, Poos et al., 2010). The legitimacy of using profit maximization as the driving force has received support from observations and interviews (Hilborn and Kennedy, 1992, Robinson and Pascoe, 1997). While these studies acknowledge fishers are well aware of wealth and profit, they also indicate non-monetary considerations are valued by individuals. The validity of modelling fishers behaviour driven by profit maximization has been questioned and alternative influential factors with less emphasis on economic interests have been put forward (Eggert and Martinsson, 2004, Salas and Gaertner, 2004).

An example of an alternative factor could be the drive to maximize landings. Maximization of landings, whereby fishers will catch as much as their capacity allows them to, may be valid as long as there are no catch restrictions, large costs or heavy fines for exceeding quota involved. However, management restrict catches and implement heavy fines exceeding limits, reducing the incentive to harvest resources at full capacity. Other factors are the tendency to follow traditional patterns and the attitude of individuals towards taking risks (Holland and Sutinen, 2000, Eggert and Tveteras, 2004, Marchal et al., 2009). In both cases, fishers choose their fishing strategy by deliberating potential benefits versus potential consequences of their choices.

Modelling fisheries behaviour requires a better understanding of the different monetary and non-monetary incentives driving decision-making in fisheries. One approach to obtain empirical information explaining behavioural choices in fisheries is by conducting surveys and interviews with individual or a group of fishers (Robinson and Pascoe, 1997, Holland and Sutinen, 2000). Robison and Pascoe (1997) however, acknowledge difficulties substantiating the reliability of the information received from interviews or surveys. Given the competitiveness within fisheries, individuals may be reluctant to share, often sensitive and private, information on the reasoning behind the decisions they make. Despite this drawback interviews can yield valuable information on decision making in fisheries, provided care is taken to the way interviews are set up, e.g. individuals or focus groups, as well as clarity on the questions formulated (Holland and Sutinen, 1999).

Empirical information from interviews can be used as a basis to construct and validate models. Discrete-choice models in particular are well suited for modelling decisions between several discrete alternatives. This type of modelling has been applied in a variety of disciplines within behavioural sciences such as traffic and marketing preferences (De La Barra, 1989) and found its way in fisheries science as well. A commonly used variant of discrete-choice models are Random Utility Models (RUM). These models assume individuals have to make a choice between a finite set of alternatives (e.g. fishing area, gear type). Each alternative has an expected utility based on a variety of explanatory variables (e.g. past experience, tradition, expected revenue) and an error term, representing the stochastic component of unobserved variables which affect preferences of an individual (Holland and Sutinen, 1999). By observing which alternatives are chosen by individuals, it is assumed 
those alternatives are generating the highest expected utility. RUMs have been applied to predict individuals location, gear and species choices as well as entry and exit decisions in commercial fisheries (Holland and Sutinen, 1999, Holland and Sutinen, 2000, Marchal et al., 2009, Tidd et al., 2011).

RUMs have a retrospective approach, being driven by observations on historical patterns making them less well suited to predict behavioural adaptations in relation to changing conditions (Dowling et al., 2012). In this context, DSVMs have an advantage over RUMs as they lack dependency on historical patterns to predict future choices. In addition, these models allow individuals to cope with opportunity cost such as the decision to discard marketable fish early in the year taking into account the potential future benefits of landing marketable fish later in the year fetching a higher price (chapter 4). These aspects make the DSVM an ideal tool to evaluate the influence of new or unknown measures such as the landing obligation or a credit system on behavioural adaptations of a fishing vessel.

Decision on the fishing operation, i.e. when, where and what to fish for as well as what to discard are mainly made by the skipper. In most fisheries the crew and sometimes the skipper as well are paid on the basis of the revenue, being the gross revenue minus the variable costs. Hence, a remuneration system where the income of the crew and skipper depend on the gross revenue creates an incentive to maximize the monetary value of the catch. While profit maximization may not cover the full range of behavioural consideration in a fleet, there is a strong incentive for economic optimization in the fleets we have studied. Yet, we can not excluded the fact that other factors will play a role in decision making. Provided we can develop a better understanding of the different drivers influencing the behaviour of a fleet, adaption of our utility function to include these alternative utilities can only improve the outcomes. However, we have to keep in mind that in the light of new management measures it will always remains difficult to validate the behavioural adaptations of the fleet.

\section{COMPLIANCE BEHAVIOUR}

Fisheries have increasingly been faced with catch and effort limitations, claims for space by other users and pressure from public and environmental organizations to reduce the impact on the environment. Hence, commercial fisheries have become highly regulated in the past decades. Many fishers perceive regulations as major limitations on the way they can perform their fishing activities, thereby potentially creating an economic incentive not to comply with adopted regulations (Frailey and Taylor, 1987, Hatcher et al., 2000).

Failure to comply with regulations may interfere with achieving proposed management objectives. For example, quota management should prevent fishers from taking more than their share of available quota. However, if quota are limited, these can be fully exploited early in the year. In order to circumvent such early exhaustion of quota a fisher may decide to discard marketable catch to preserve quota for more valuable fish later in the year (i.e. high-grading) or he can catch land a larger amount of fish than his quota allows (i.e. quota busting) (Copes, 1986). Because both activities are illegal fishers will fail to report these dis- 
cards or additional catches which in turn may increase the uncertainty of stock assessments. This is of particular concern for stocks which are already at a low levels.

The example above indicates the importance to increase our knowledge on the reasons of non-compliance behaviour in fisheries. Compliance behaviour in fisheries was initially analysed using models applying an economic approach (Sutinen and Andersen, 1985, Anderson and Lee, 1986). The models used the study of Becker (1968) as a starting point. He was the first to develop a theoretical framework to explain decision-making for committing a crime. His model assesses the levels of enforcement and severity of the punishment required to minimize social loss (i.e. economic costs to the society) due to illegal behaviour. In his model he assumes individuals behave rationally, making a trade-off between the expected utility, being monetary costs and benefits, for committing a crime against the utility received from complying with the regulations. The utility of committing a crime is assumed to be a function of the probability of conviction (i.e. being detected, apprehended and convicted) and the punishment that goes with the commission of a crime. While illegal behaviour decreases as the level of both enforcement and punishment increases, the response to commit a crime is larger by changes in the risk of being convicted than the changes to the level of punishment.

Analysis of compliance behaviour based solely on an economic perspective has been criticised for ignoring the influence of normative and socials aspects on compliance behaviour (Cameron, 1988, Tyler, 1990, Garoupa, 2003). In fisheries only a few studies have attempted to analyse compliance behaviour including monetary and non-monetary motives into a model (Sutinen and Kuperan, 1999, Hatcher et al., 2000). Non-monetary motives are integrated in the models by extending the utility function to include variables such as morals (i.e. one feels the regulation is justified) towards illegal behaviour, social pressure and the effect of an individual's perspective to the legitimacy (i.e.one accepts that the authority enforcing the regulation has the right to do so) of regulations. Results of these studies provide indication of the influence non-monetary motives can have on compliance behaviour and support the idea that besides increasing monitoring, control and enforcement activities, policymakers should be aware of the normative commitment (i.e. morality and legitimacy) of individuals to the policy. In addition, integration of both monetary and non-monetary motivations in studies on compliance behaviour will be more consistent with theories on human behaviour (Tyler, 1990). Although non-monetary motivations can be included in the utility function of the DSVM, the parameterization will not be straight forward.

Understanding the normative commitments of individual fishers to regulations is complex, because of the variation among their objectives. Including non-monetary aspects in the utility function of the model would require extensive and detailed information from the fleet on the morality and perception of the legitimacy of regulations, in particular quota restrictions, the landing obligation and spatial measures. In fisheries, monetary fines are more rule than exception and fishers often regard fines as part of their business (Branch et al., 2006). The response of individuals to monetary fines derived for the model studies (chapter 2) are in line with observations that compliance will increase when the level of the 
expected fine becomes more severe. In addition, I assume fully enforced regulations which is achieved by increasing the fines up to a level that poses an unacceptable high risk of exceptionally high costs. This type of deterrence has been used in the Northeast American multispecies fisheries management plan as a countermeasure for low detection rates (Frailey and Taylor, 1987). Therefore, I believe economic motivations, as applied in this thesis, are a valid approach to address compliance under short-term decision-making.

\section{INDIVIDUAL QUOTA MANAGEMENT}

Catch quotas or "total allowable catches" (TAC) are the predominant strategies to manage fisheries. Catch quotas can be exploited by a common-pool or a rights based approach. Under a common-pool approach there is a fishery-wide TAC for which fishers compete until the TAC is fully exploited. This ensues a race to fish, creating an incentive to invest in more powerful vessels and more efficient gear and technology to outcompete others. As such, the common-pool approach is criticised to lead to unsustainable exploitation levels and economic inefficient fisheries (Grafton, 2000). A right based approach allocates individual rights to a predetermined share of the catch, ensuring an individual owns a secured portion of the allowable catch. This approach should encouraging stewardship over the resources and providing more flexibility in time and space to harvest the resources, because fishers do not have to account for the catches of others (Grafton et al., 2006). Rights based management approaches have been increasingly recognised to be core to achieve biologically and economically sustainable fisheries (Hilborn et al., 2005, Branch, 2009).

Individual quota are the most commonly used right based approach to manage fisheries. Individual transferable quota ((Christy, 1973), ITQ) are an extended form allowing fishers to sell, lease or buy quota. By allowing the transfer of quota, ITQs are believed to reduce the incentive to discard (i.e. high-grading and over-quota discarding) and increase the economic efficiency of fishing activities (Little et al., 2009). Discarding can be reduced when fishers who would be forced to discard because they have (almost) fully exploited their share of quota (before the end of the year) can buy quota from fishers who know they will not make full use of their share. In addition, quota transfers between individuals can increase net revenue of both vessels.

Since the introduction of ITQs in the 1970's many fisheries worldwide are currently managed by ITQs (Costello et al., 2008, Chu, 2009) (figure 6.1). Within the European Union specifically, Member States are being encouraged to establish a system of transferable fishing rights (EU Regulation 1380/2013). While most Member States have already implemented some kind of rights based management approach (e.g. community catch quotas; individual (transferable) effort or catch quotas; vessel catch limits; and territorial use rights (MRAG et al., 2009), some Member States are reluctant to adopt an ITQ system for their fisheries. Member States are opposed to transferability of quotas, because they fear the rights to the property will be concentrated in the hands of a few corporations or individuals. France, for example, has non-transferable quota in order to prevent quota from being considered as 
Figure 6.1

Assessment of the increased use of the ITQ system globally (copyright, Chu, 2009).

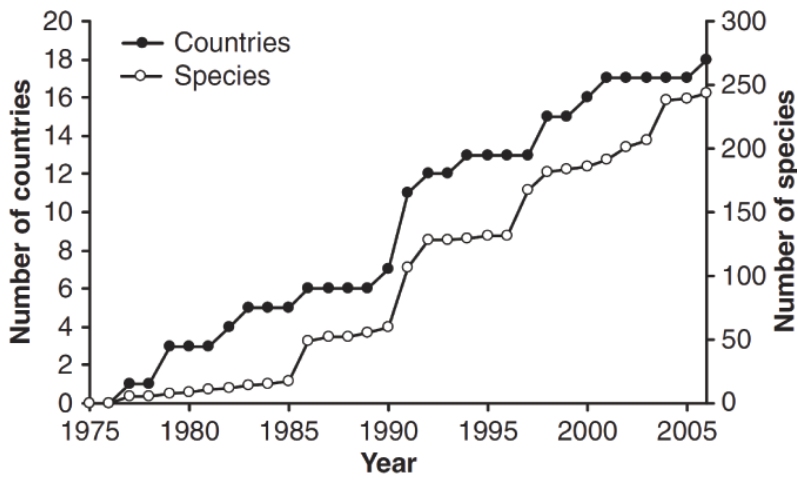

assets, thereby protecting their traditional fishing communities and maintaining economic and social equilibrium in fishery-dependent coastal zones (MRAG et al., 2009).

In this thesis, I have assumed the fisheries are managed by individual non-transferable quota. This implies the model does not allow quotas to be transferred from one fisher to another during a year. While this assumption holds true for the fisheries in France, the Dutch mixed-fisheries for flatfish was one of the first fisheries to adopt ITQs to manage their fisheries on plaice and sole (Chu, 2009, van Hoof, 2013). Examining the impact of adopting an ITQ system in fisheries have been studied by either a retrospective analysis (Arnason, 1995; Annala, 1996; Hamon et al., 2009) or by modelling trading behaviour within a simulated ITQ market (Dupont, 2000, Little et al., 2009, Marchal et al., 2011). Little et al. (2009) for example, have included trading of quota into an agent-based model to evaluate fishing strategies under right-based management. The model simulates choices individual vessels in a multi-species fisheries make in terms of fishing location and quota trading in order to maximize their profit. The main elements determining whether a vessel will engage in quota trading are the amount of quota available and the quota price. The quota price is assumed to be equal to the average marginal profit (i.e. the profit of harvesting a unit of fish) across vessels or fleets. Buying additional quota is only in the interest of a vessel when the difference between its expected marginal profit of catching fish and the costs of obtaining additional quota is positive (Guyader and Thébaud, 2001). For a vessel willing to sell quota this difference should be negative. Model results showed that transferability of quota increases profitability of the fleet; even less efficient vessels are able to make substantial profits by leasing their quotas. However, when there are no trading opportunities for species for which quota are already filled, fishing will continue until most quota (often of the most valuable species) are fully exploited. Hence, quota transferability may improve the match between catches and quota, but does not necessarily alleviate discarding.

Due to the lack of quota transferability in our model, the outcomes may not fully correspond to actual observations. In particular, within the context of the discard ban future projections are uncertain. Under the discard ban the transition from landing quota to catch quota may become problematic. Especially in mixed fisheries, potential restrictive quota 
may lead to severe restrictions in fishing activity when these quota are fully exploited at an early stage (i.e. choke species). Quota transfer may partially prevent the early cessation of fishing activities due to choke species. However, quota owners may want to retain their quota to prevent their own company or fleet to be restricted in their fishing activities. In addition, the new discard regulation provides opportunities for flexibility in dealing with quotas through inter-annual quota and inter-species (i.e. counting the catch of one species to the quota of other species) flexibilities, as well as exemptions from landing discards based on survivability and de minimis (i.e. an exemption when increased selectivity is difficult to achieve or when handling discards on board generates disproportionate costs). To date, it remains uncertain how these flexibilities and exemptions will be implemented and influence future fishing opportunities. Hence, it is difficult to predict how quota trading will develop under the discard ban. Including quota transfer into the model will make it more operational for practical use, however, this would require a more detailed knowledge on the actual implementation of the management regulations.

\section{VARIABILITY IN CATCHES}

The dynamic state variable models that are used extensively in this thesis allow for decisions to be made in a stochastic environment. The catches that can be obtained in any season and at any location are uncertain and modelled as random variables. In essence, I used the assumption that the statistical distribution of future catches in any area are perfectly known to the fishers. This is not to say that future catches are known, only their stochastic nature is known. Indeed, in reality, fishers have a certain degree of knowledge on the seasonal distribution of the different target species, that results from ontogenetic and seasonal spawning migration (Poos and Rijnsdorp, 2007). In our models we have parameterized the variability using long time series of catches, estimating means and variances of catch rates, using spatial and temporal covariates, while also correcting for vessel characteristics. Using the estimated means and variances from such a statistical model implies that the means and variances of catches in December are already known at the beginning of the year, and no further "learning behaviour" occurs in which fishers update their knowledge of the environment. In reality fishers likely update their knowledge on the spatial and temporal distribution, using their long term catch histories as priors. The information is then updated using observations on catch rates in the different areas, in a Bayesian manner. The individual integrates new information with its prior expectation and forms a revised, posterior expectation about catch opportunities (Van Gils, 2010). The effectiveness of such a strategy depends on the autocorrelation that may occur over time and among locations on top of the seasonal variations. Indeed, spatial and temporal autocorrelations on top of the annual variability caused by migrations is known to exist (Poos and Rijnsdorp, 2007). This autocorrelation can result from e.g. the existence of local patches of high food abundance, or inter-annual differences in the contribution of different nursery grounds to the fishable stock. 
Knowledge on the spatial and temporal distribution of the main target species is most likely built up from personal experience combined with information exchange with other fishers (Wilson, 1990, Gillis et al., 2006). Information-sharing networks are not uncommon within fishing communities. Especially fishers who are closely connected, i.e. friends or family, will share information about the abundance and locations of resources (Palmer, 1991, Ramirez-Sanchez and Pinkerton, 2009). Consequently, fishers may adapt their fishing strategies to increase their fishing success. Acquiring information on the best fishing grounds may thus provide an advantage over other fishers competing for the same resources. Sharing information used to be face-to-face in the harbour or through radio conversations when being at sea (Palmer, 1991). Technological advances, however, have made it easier to obtain information on the fishing locations and activities of other vessels. The Automatic Identification System (AIS) for example, while implemented for maritime safety and security, allows fishers to follow each other's activities while being at sea, acquiring information that is traditionally not shared. It is clear that acquiring information, either by sharing, learning or observing, will affect decision making behaviour of individuals within the fleet. Incorporating such behaviour into simulation models requires a deviation from models using fixed behavioural strategies toward a more flexible modelling approach allowing individuals to learn and adapt their behaviour, e.g. artificial neural networks (Dreyfus-León, 1999, Gaertner and Dreyfus-Leon, 2004). Such models assume fishers have incomplete information on the distribution of the resources but gain experience when fishing, sharing their experience of the different fishing grounds with individuals in the same group. These models result in complex model behaviour but contribute to the interpretation of behavioural decision making processes under uncertain environmental conditions.

\section{A CHANGING POLICY ENVIRONMENT}

\section{THE EMERGENCE OF A DISCARD BAN IN EUROPEAN WATERS}

Discarding, i.e. throwing a part of the catch back to sea, is common practice in many fisheries (Kelleher, 2005). This practice can be largely attributed to policy regulations which obliges fishers to discard the part of the catch that does not meet legal prescriptions. For example catches below the minimum landing size, i.e. the smallest size measurement for a fish or shellfish to be legally landed and sold, have to be discarded. Similarly, due to quota regulations catches of species for which quotas have already been exhausted before the end of the year (over-quota) have to be discarded at sea (chapter 2, 3 and 4). In addition, market drivers, such as fish price or consumer demands, may incentivise fishers to discard certain species or size classes having no or a low economic value (high-grading) (Gillis et al., 1995). By discarding the size classes with a low economic value, fishers retain their quota for landing more valuable size classes (chapter $\mathbf{3}$ ). 
Discarding in commercial fisheries has received an increased amount of (negative) attention. Public campaigns, such as Hugh Fearnley-Whittingstall's Fish Fight campaign, raised public awareness to the undesirable ecological and ethical effects of discarding by stressing discarding is a wasteful and disruptive practice as natural resources are extracted from the ecosystem only to be thrown back to sea dead (Borges, 2015). It was clear that fisheries management failed to reduce discarding in European fisheries. In response, discard reduction in commercial fisheries became an essential objective within European fisheries management. In July 2011 the European Commission presented their proposal for the reform of the Common Fisheries Policy (CFP). This reform included the enforcement of a discard ban in European waters, obliging all European fishing vessels to retain and land their entire catch, including small sized individuals, of all species subject to quota management. In 2013 the European Parliament agreed on the reformed CFP (EU regulation 1380/2013), which includes article 15 referring to the landing obligation. The term "landing obligation" is more frequently used to reduce the negative connotation with the word "ban". The reformed CFP came into force in January 2014. The discard ban, however, is implemented progressively as of 2015, starting with the Baltic and pelagic fisheries and followed by the demersal fisheries in 2016. For demersal fisheries the discard ban will be implemented in phases, commencing with the species defining the fisheries (table 6.1). For example, beam trawlers fishing in the North Sea using $80 \mathrm{~mm}$ to $119 \mathrm{~mm}$ mesh size will have to land their entire catch of sole (Solea solea), whereas beam trawlers rigged with a mesh size larger then $119 \mathrm{~cm}$ are allowed to discard sole, but have to land plaice (Pleuronectes platessa) catches. Gradually more species will fall under the discard ban the following years, being fully implemented, i.e. covering all species subject to total allowable catches, in 2019.

\section{IMPLEMENTATION OF THE DISCARD BAN}

One of the major changes under the discard ban is the transition of landing quota to catch quota. This transition should ensure fishing opportunities reflect the total catch instead of the landings of a stock. Catch quota are based on landing quota which receive an uplift by adding a discard component. Since 2014, the International Council for the Exploration of the Sea.(ICES), which is an intergovernmental organisation requested to provide advice on the fishing opportunities, started providing advice on fishing opportunities in terms of both catches and landings for several stock including North sea plaice and sole.

The quantity and composition of discards is highly variable by fisheries. It is expected that for some fisheries a quota uplift for a given stock may not suffice to cover the total annual catch for that particular stock. In that case, an early exhaustion of quota may cause the fishery to "choke" (i.e. a full stop of fishing activities) regardless the availability of sufficient quota for other species. Hence, species for which insufficient quota is available to cover their catches are referred to as "choke species". In mixed fisheries in particular, where many species are caught simultaneously, multiple choke species may occur and close the fishery (Borges, 2015). For example species such as plaice (Pleuronectes platessa), dab (Limanda li- 
Table 6.1 Phased approach of the discard ban by species and gear.

\begin{tabular}{|c|c|c|c|c|c|c|c|c|c|}
\hline & mesh size & Cod & Plaice & Sole & Whiting & Hake & Saithe & Nephrops & $\begin{array}{l}\text { Northern } \\
\text { prawn }\end{array}$ \\
\hline Trawls (TR1) & $\geq 100 \mathrm{~mm}$ & $\begin{array}{l}2017 \\
\text { (if cod recov- } \\
\text { ery plan is } \\
\text { removed) }\end{array}$ & 2016 & 2017 & $\begin{array}{l}2017 \\
\text { (if cod recov- } \\
\text { ery plan is } \\
\text { removed) }\end{array}$ & 2019 & $\begin{array}{c}2016 \\
(50 \%) \\
2018 \text { (rest) }\end{array}$ & 2017 & 2016 \\
\hline Trawls (TR2) & $70-90 \mathrm{~mm}$ & 2018 & 2018 & 2016 & 2017 & 2019 & 2018 & 2016 & 2016 \\
\hline Trawls & $32-69 m m$ & 2018 & 2018 & 2017 & 2017 & 2019 & 2018 & 2017 & 2016 \\
\hline Beamtrawl (BT1) & $\geq 120 \mathrm{~mm}$ & 2018 & 2016 & 2017 & 2017 & 2019 & 2018 & 2017 & 2016 \\
\hline Beamtrawl (BT2) & $80-99 \mathrm{~mm}$ & 2018 & 2018 & 2016 & 2017 & 2019 & 2018 & 2017 & 2016 \\
\hline $\begin{array}{l}\text { Gillnets \& entangling } \\
\text { nets }\end{array}$ & & 2017 & 2018 & 2016 & 2017 & 2019 & 2018 & 2017 & 2016 \\
\hline Hooks \& lines & & 2017 & 2018 & 2017 & 2017 & 2016 & 2018 & 2017 & 2016 \\
\hline Handline & & 2017 & 2018 & 2017 & 2017 & 2019 & 2018 & 2017 & 2016 \\
\hline Pots & & 2018 & 2018 & 2017 & 2017 & 2019 & 2018 & 2016 & 2016 \\
\hline Traps & & 2018 & 2018 & 2017 & 2017 & 2019 & 2018 & 2016 & 2016 \\
\hline
\end{tabular}

manda), turbot (Scophthalmus maximus) and brill (Scophthalmus rhombus) could potentially become choke species for the mixed demersal fisheries in the North Sea, while hake (Merluccius merluccius) and saithe (Pollachius virens) are species that could potentially choke the North Sea mixed whitefish trawl fishery. Fishers should ensure having sufficient quota for the species they are exploiting or adapt their fishing strategies (i.e. technical or behaviour) to prevent an early stop to the fishing activities.

Within article 15 (describing the landing obligation) of the CFP (EU regulation $1380 / 2013$ ) provisions are included that allow some flexibility to alleviate an early cessation of fishing activities due to potential choke-species. First, there is some flexibility in the uptake of quotas by allowing Members States to "bank" or "borrow" up to $10 \%$ of the quota of a species (inter-annual quota flexibility) or to deduct up to $9 \%$ of quota of target species to cover catches of species exceeding their quota or for which no quota are owned (inter-species quota flexibilities). The latter will only be allowed when the species which is being counted against the target quota is within "safe biological limits", i.e. the size of the stock and fishing mortality should be at a level preventing the stock from impaired recruitment (Blim and Flim). Second, the regulation specifies situations (art. 15(4)) which exempt species from the discard ban. Exemptions apply to (1) species on the prohibited species list (e.g. the common skate (Dipturus batis)), (2) by-catch of species for which high survival after the catching process has been scientifically demonstrated, and (3) catches under a de minimis exemption. Under a de minimis exemption $5 \%$ of the catch can be discard under the conditions that it is very difficult to improve the selectivity of a gear or when using selective fishing gear handling of unwanted catches on board leads to "disproportionate costs".

While these provisions allow some flexibility to deal with unavoidable catches and potential choke species, there is much uncertainty on how these provisions will be implemented in practice (STECF, 2014). The wording used in the regulation to specify the applicability 
of these provisions allows for subjective interpretation. The most well-known example is the inconclusive debate on what constitutes "scientific evidence demonstrating high survival rates". Is a survival rate of $>50 \%$, i.e. a greater proportion of fish is returned alive than dead after the catching process, a scientific sound argumentation? Or is the reasoning that all fish which are returned alive directly contribute to the stock biomass more appropriate, and thus favours that a much lower percentage should suffice to obtain an exemption. Similarly, how should both criteria "very difficult to improve selectivity" and "disproportionate costs" be interpreted and scientifically demonstrated to support a de minimis exemption. Additionally, within the regulation it is not specified whether a de minimis applies to the TAC of a species or to the total catch of all quota species of a vessel, fleet or Member State. Given the existing uncertainties in the precise implementation of the discard ban, the results presented in this thesis will not precisely correspond to future observed changes in the dynamics of the fleet. Our model, however, is particularly suitable to evaluate conservation and economic trade-offs and visualize consequences of management scenarios. The model can be used to evaluate the consequences and explore the scope of responses in fisheries behaviour under different survival, de minimis or inter-species flexibilities scenarios. Eventually, science often cannot provide a single "true" value, but can provide insight in the potential consequences of choices, leaving the decision whether something is high, difficult or disproportionate with the fisheries managers.

\section{A DRIVER FOR MORE SELECTIVE FISHERIES}

Under a discard ban undersized or low value catches of quota regulated species will be deducted from their annual quota at the expense of quota for marketable fish. This should be an incentive for fisheries to improve their species and size selectivity in order to reduce catches of unwanted fish. This reduction should lead to more sustainable exploitation of the resources, prevent the wasteful practice of discarding and improve the economic efficiency of the fisheries.

Studies on gear selectivity have largely been focused on reducing the vulnerability of fish to be retained in the gear by technical modifications or the way the gear is operated (e.g. towing speed or tow duration) (Dahm et al., 2002, Catchpole and Gray, 2010). Gear modifications may consist of changing the configuration of the net by increasing mesh sizes (Briggs et al., 1999, van Marlen, 2003, Erzini et al., 2006) or by inserting square- or diamond-mesh escape panels (Stewart and Ferrell, 2002, Suuronen et al., 2005, Catchpole and Revill, 2008, Briggs, 2010) and separator and sorting grids (Polet, 2002, Graham and Fryer, 2006), but can also lead to the development of alternative fishing techniques such as the pulse trawl in the Dutch demersal fisheries (chapter 4) (van Marlen et al., 2014, Soetaert et al., 2015). In mixed fisheries the development of gear modifications can be challenging as improving the selectivity for a given species or size class can coincide with losses or additional retention of others (Polet, 2002, Stewart and Ferrell, 2002). For example, the use of a sorting grid in the North Sea brown shrimp fishery resulted in a large reduction of fish (70\%) and benthos 
(65\%) in the catch, but commercial fishers were not inclined of using the grid because the loss of marketable brown shrimp exceeded acceptable levels (Polet, 2002). Hence, a loss of marketable catches, and thus (in the short-term) a loss in economic profitability of the fishery is of particular concern as this may discourage fishers to use modified or alternative gears as well as to continue innovating. On the other hand, in chapter 4 I showed that pulse trawlers could spent more time at sea due to their higher economic profitability, resulting in a minimal differences in undersized catches with the conventional beam trawl. While the innovation provides the fleet with an economic advantage the expected ecological advantage of having a more selective fishing gear was reduced.

Besides technical adaptations, selectivity can be improved by adapting fishing behaviour. Adaptations mainly relate to the spatial and temporal reallocation of fishing activities. The spatial and temporal distribution of a fishing fleet is concordant with areas of high density of their target species, and thus targeting behaviour is reflected in the spatial distribution of the fleet relative to that of the fish stock (Quirijns et al., 2008). It is expected fisheries can reduce unwanted catches by actively reallocating fishing activities in relation to the spatial and temporal distribution of certain species, size or age classes. Fishers will gain knowledge on the annual migrations between spawning and feeding areas of their target species and can, to some extent, predict the large scale patterns in resource availability (Poos and Rijnsdorp, 2007). On a smaller scale, fish aggregate very likely in response to their food, which may only persist for a period of a few days up to two weeks (Poos and Rijnsdorp, 2007). Predicting the location of these patches is much more difficult and fishers have to sample the environment to find them. Indeed, many fishers have acquired knowledge and information on the distribution of marketable fish (Catchpole et al., 2005) but have obtained limited information on the distribution of by-catch species or undersized fish. This is not surprising given unwanted catches could be discarded legally and thus had no added economic and informative value. In order to avoid and relocate fishing activities, knowledge and information on areas with high catch rates of juvenile or non-target species will need to be acquired and exchanged among fishers, as is observed in Scottish Fisheries (Eliasen et al., 2014). Also changes in the fishing process itself, , i.e. number of hauls or haul duration, could potentially reduce the amount of bycatch. However, such changes will find very little support from the fishing industry as they are expected to reduce the yield and increase labour on board the vessel.

\section{A FISHERS PERSPECTIVE}

Developing mitigation measures without taking account of the context in which the problem occurs could have unexpected and unwanted consequences, and undermine compliance (Eliasen et al., 2014). In case of the discard ban, the European Parliament adopted the ban presuming it to be a remedy for the symptom of discarding, which often results from fisheries management itself, while insufficiently taking account of the driving factors that make fishers discard a part of their catch (Borges, 2015, Trapman and Kraan, 2015). In this 
context, policy makers view the discard ban as a "tool" to change current fishing practices in order to reduce wasteful practices, achieve more sustainable exploitation of resources and improve economic profitability of the fleet (Kraan and Verweij, 2016 ). While fishers may agree it is in their interest to reduce unwanted catches, they see no justification in doing so by having to land all catches of the quota managed species.

As opposed to policy makers, fishers see neither ecological nor economic benefits resulting from a discard ban. From an ecological point of view, landing undersized fish is against the norms and values of fishers as they are concerned about the additional mortality on the stocks, reducing potential future yield. Studies have shown that the probability of fish surviving the catching and sorting process on board is generally low and depends on factors such as gear type, substrate, tow duration and depth (Van Beek et al., 1990, Kaiser and Spencer, 1995, Yergey et al., 2012; Sauls, 2014). Fishers, however, argue a large part of the catch must survive given the liveliness of the fish during processing on board as well as the ongoing increase in stock-sizes despite the high levels of discarding taking place. Also, discards are a food source for many scavenging seabirds, mammals and benthic fauna (Cook, 2003) and fishers are concerned that retaining the entire catch may have negative consequences for the population of these species. Heath et al. (2014) showed that cascading effects within the ecosystem may occur, but that the direction (i.e. positive or negative) of the cascading effects are much dependent on the exact implementation of the regulation as well as changes in fishing practices (e.g. improved selectivity). The ecological impact of the discard ban is poorly studied and as such poorly understood, which potentially fends envisaged benefits.

Economically, fishers fear the discard ban will have a big influence on the profitability of their business and the industry as a whole. Undersized fish cannot be sold for human consumption and will be mainly processed into animal feed, fetching a low price (see chapter 4) (Buisman et al., 2013). The revenue from selling these fish will not suffice to cover the additional costs incurred from processing the fish on board (i.e. labour, storing and icing) as well as on shore (i.e. unloading, sorting and transportation). Processing the entire catch on board will increase workload and force vessel owners to hire additional crew. Because in many fisheries the crew receives a fixed share of the net revenue the question is raised how additional crew will be remunerated. On one hand, dividing the fixed share among a larger crew will result in lower wages for individual crew members. Consequently, the costs for labour will remain largely unchanged, but it will be more difficult to hire crew. On the other hand, maintaining the wages of individual crew members will create additional costs for labour. Also, it is expected capacity problems will arise because the total catch exceeds the maximum capacity of the fish hold, resulting in increased costs from steaming back and forth to the fishing grounds. Finally, the fear of choke species ending fishing activities early in the year, losing catches and yield from other species for which quota are still available (chapter $\mathbf{2}$ and 4). In response policy makers and environmental organisations refer to the, in their opinion, objective of the discard ban, which is to incentivise more selective fisheries. However, as mentioned before improved selectivity is often associated with a loss of marketable catches, and thus profitability of the fishery. 
Fisheries highly value tradition and independence, facing change with suspicion or even fear as change is often associate with an unknown future (Eayrs et al., 2015). They need to be convinced that changes as a result of management measures positively contribute to achieving ecological goals and will not result in economic losses or additional constraints. Uncertainty about the aim of measures or their own future gives rise to a feeling of tension and a reluctance to accept change (Verweij et al., 2010). In turn, reluctance to accept management measures can lead to non-compliance (Eayrs et al., 2015). Chapter 3 of this thesis adds to the concern about the implications of the discard policy of the European Union (Borges, 2015, Sardà et al., 2015). As small fish generally fetch a low price (Zimmermann and Heino, 2013), imposing a discard ban will increase the incentives for illegal discarding. If quota are adjusted to include the formerly unaccounted bycatch, the discard ban may even result in an increase of fishing mortality jeopardising sustainable management. Behavioural decisions in terms of compliance with regulations is influenced by the perception of the severity of the fine complemented with the probability of being detected (Garoupa, 2001). Ensuring compliance to implemented measures or regulations requires effective and often stringent control and enforcement procedures by means of electronic monitoring (EM) using on board cameras (CCTV), large observer coverage or intense port monitoring. In some fisheries such as the British Columbia groundfish fishery (Branch and Hilborn, 2008) and New Zealand fisheries (Pierre et al., 2014 ) on board observers have been a critical component of maintaining the integrity of the fisheries management regime. The drawback, however, is that such procedures are labour intensive and expensive (Kraan et al., 2013), raising the question whether such procedures will be financed by the industry or government. Ultimately, fisheries management regimes that facilitate effective control and enforcement and minimize the incentive to non-comply will be most effective in achieving management objectives.

Clearly, the fish fight campaign has put a finger on the weak spot in fisheries management and brought the attention of the general public to the "wasteful practice" of discarding. As a result the discard ban is a regulation based on a political response to societal concerns instead of science based argumentation. As such, potential consequences are not well understood, which impedes a common understanding between policy makers and stakeholders on how best to address the issue of discarding. The different and sometimes opposing perspectives on the aims and potential ecological and socioeconomic consequences of the regulation creates a parallel monologue between policy makers, environmental organisations and fishing industry (Kraan and Verweij, 2016 ). Different opinions in combination with the many uncertainties on the details of implementation frustrates the support of fishers and exposes fisheries managers to the risk the regulation results in unforeseen effects. The DSVM is a solid tool to analyse unexpected effects and therefore, can make an important contribution to the science based support of fisheries management which is aimed at reducing discarding. In addition, by making stakeholders part of the implementation process in an early stage (as well as after implementation) they can identify themselves with the problem, establishing a more general understanding of the urgency and improve acceptance of the measures being taken. 


\section{OUTLOOK}

Since Hilborn's (1985) seminal paper on fleet dynamics and individual variation within a fleet, fisheries scientist have acknowledged the importance of fisheries dynamics to achieving successful fisheries management. However, to date policy makers and fisheries managers have largely neglected this component in their decision making. This thesis contributes and advocates the need to develop innovative analytical methodologies which deliver sufficiently robust insights into complex socioeconomic and ecosystem issues to improve the basis of decision making.

As a contribution to the scientific underpinning of the ecosystem approach to fisheries management I developed a simulation model which is generically applicable to study the implications of different management scenarios on the yield and impact of fishing activities. The models developed in this thesis provide a strong basis to explore possible unexpected effects of management measures resulting from the adaptive behaviour of fishers to these measures. It also provides an opportunity to involve fishers in the process by developing a common understanding of fishers behaviour.

The simulation model is only indicative on the short term dynamics. Because these dynamics will act on the system, they may potentially influence the long-term performance of management scenarios. To evaluate this influence, short term predictions should feed back into the model to inform the management system. For example, in this thesis predictions could be linked to existing stock assessment models and contribute to the improvement of mixed fisheries management. Exploring such interactions and feedbacks within the system as a whole is the goal of Management Strategy Evaluations (MSEs), which are essential to advice fisheries managers on the potential long-term performance of management measures (Sainsbury et al., 2000, Kell et al., 2007). 


\section{REFERENCES}

Anderson, L.G., Lee, D.R. (1986) Optimal Governing Instrument, Operation Level, and Enforcement in Natural Resou-rce Regulation: The Case of the Fishery. American Journal of Agricultural Economics 68 678-690.

Annala, J.H. (1996) New Zealand's ITQ system: have the first eight years been a success or a failure? Reviews in Fish Biology and Fisheries 6, 43-62.

Arnason, R. (1995). The /celandic Fisheries: Evolution and Management of a Fishing Industry. Oxford: Fishing News Books.

Babcock, E.A., Pikitch, E.K. (2000) A dynamic programming model of fishing strategy choice in a multispecies trawl fishery with trip limits. Canadian Journal of Fisheries and Aquatic Sciences 57, $357-$ 370

Beare, D., Rijnsdorp, A.D., Blaesberg, M., et al. (2013) Evaluating the effect of fishery closures: Lessons learnt from the Plaice Box. Journal of Sea Research $84,49-60$.

Becker, G. S. C. (1968). "Crime and Punishment: An Economic Approach." Journal of Political Economy 76, 169-217.

Borges, L. (2015) The evolution of a discard policy in Europe. Fish and Fisheries 16, 534-540.

Branch, T.A. (2009) How do individual transferable quotas affect marine ecosystems? Fish and Fisheries 10, 39-57.

Branch, T.A., Hilborn, R. (2008) Matching catches to quotas in a multispecies trawl fishery: targeting and avoidance behavior under individual transferable quotas. Canadian Journal of Fisheries and Aquatic Sciences 65, 1435-1446.

Branch, T.A., Hilborn, R., Haynie, A.C., and others (2006) Fleet dynamics and fishermen behavior: lessons for fisheries managers. Canadian Journal of Fisheries and Aquatic Sciences 63, 1647-1668.

Briggs, R.P. (2010) A novel escape panel for trawl nets used in the Irish Sea Nephrops fishery. Fisheries Research 105, 118-124.

Briggs, R.P., Armstrong, M.J., Rihan, D. (1999) The consequences of an increase in mesh size in the Irish Sea Nephrops fishery: an experimental approach. Fisheries Research 40, 43-53.
Buisman, E., Oostenbrugge, v.H., Beukers, R. (2013) Economische effecten van een aanlandplicht voor de Nederlandse visserij. LEl-rapport 2013-062.

Cameron, S. (1988) The Economics of Crime Deterrence: A Survey of Theory and Evidence. Kyklos 41, 301-323.

Catchpole, T.L., Frid, C.L.J., Gray, T.S. (2005) Discarding in the English north-east coast Nephrops norvegicus fishery: the role of social and environmental factors. Fisheries Research 72, 45-54.

Catchpole, T.L., Gray, T.S. (2010) Reducing discards of fish at sea: a review of European pilot projects. Journal of Environmental Management 91, 717723.

Catchpole, T.L., Revill, A.S. (2008) Gear technology in Nephrops trawl fisheries. Reviews in Fish Biology and Fisheries 18, 17-31.

Caveen, A., Polunin, N., Gray, T., Stead, S.M. (2015) The Controversy over Marine Protected Areas Science Meets Policy, Springer Cham Heidelberg New York Dordrecht London.

Christy, F.T. (1973) Fisherman quotas: a tentative suggestion for domestic management, Law of the Sea Institute, University of Rhode Island.

Chu, C. (2009) Thirty years later: the global growth of ITQs and their influence on stock status in marine fisheries. Fish and Fisheries 10, 217-230.

Collie, J.S., Hall, S.J., Kaiser, M.J., Poiner, I.R. (2000) A quantitative analysis of fishing impacts on shelf-sea benthos. Journal of Animal Ecology 69, 785-798.

Cook, R. (2003) The magnitude and impact of bycatch mortality by fishing gear, In: M. Sinclair, \& G. Valdimarsson (Eds.), Responsible Fisheries in the Marine Ecosystem, Oxford.

Copes, P. (1986) A Critical Review of the Individual Quota as a Device in Fisheries Management. Land Economics 62, 278-291.

Costello, C., Gaines, S.D., Lynham, J. (2008) Can catch shares prevent fisheries collapse? Science 321, 1678-1681.

Daan, N. (1997) TAC management in North Sea flatfish fisheries. Journal of Sea Research 37, 321-341. 
Dahm, E., Wienbeck, H., West, C.W., Valdemarsen, J.W., O'Neill, F.G. (2002) On the influence of towing speed and gear size on the selective properties of bottom trawls. Fisheries Research 55, 103-119.

De La Barra, T. (1989) Integrated land use and transport modelling. Decision chains and hierarchies, Cambridge Urban and Architectural Studies, Cambridge University Press

Dinmore, T. A., et al. (2003). Impact of a large-scale area closure on patterns of fishing disturbance and the consequences for benthic communities. ICES Journal of Marine Science 60, 371-380.

Dowling, N.A., Wilcox, C., Mangel, M., Pascoe, S. (2012) Assessing opportunity and relocation costs of marine protected areas using a behavioural model of longline fleet dynamics. Fish and Fisheries 13, 139-157.

Dreyfus-León, M. J. (1999) Individual-based modelling of fishermen search behaviour with neural networks and reinforcement learning. Ecological Modelling 120, 287-297.

Dupont, D.P. (2000) Individual transferable vessel quotas and efficient restructuring of the primary harvesting sector. Annals of Operations Research 94, 275-294.

Eayrs, S., Cadrin, S.X., Glass, C.W. (2015) Managing change in fisheries: a missing key to fishery-dependent data collection? ICES Journal of Marine Science 72, 1152-1158.

Eggert, H., Martinsson, P. (2004) Are commercial fishers risk-lovers? Land Economics 80, 550-560.

Eggert, H., Tveteras, R. (2004) Stochastic production and heterogeneous risk preferences: Commercial fishers' gear choices. American Journal of Agricultural Economics 86, 199-212.

Eliasen, S.Q., Papadopoulou, K.-N., Vassilopoulou, V., Catchpole, T.L. (2014) Socio-economic and institutional incentives influencing fishers' behaviour in relation to fishing practices and discard. ICES Journal of Marine Science 71, 1298-1307.

Erzini, K., Goncalves, J.M.S., Bentes, L., et al. (2006) Size selectivity of trammel nets in southern European small-scale fisheries. Fisheries Research 79, 183-201.

Frailey, M.H., Taylor, R.A. (1987) Rationalizing sanctions for fisheries violations. In: East coast fisheries law and policy. Proceedings from the June 17-20, 1986, Marine Law Institute, Portland, Maine, pp. 215-234.
Gaertner, D., Dreyfus-Leon, M. (2004) Analysis of non-linear relationships between catch per unit effort and abundance in a tuna purse-seine fishery simulated with artificial neural networks. /CES Journal of Marine Science 61, 812-820.

Garoupa, N. (2001) Optimal magnitude and probability of fines. European Economic Review 45, 1765-1771.

Garoupa, N. (2003) Behavioral Economic Analysis of Crime: A Critical Review. European Journal of Law and Economics 15, 5-15.

Gillis, D.M., Pikitch, E.K., Peterman, R.M. (1995) Dynamic discarding decisions - foraging theory for high-grading in a trawl fishery. Behavioral Ecology 6, 146-154.

Gillis, D.M., Wade, E., Swain, D.P. (2006) Spatial evidence for information exchange and competition in the Gulf of St. Lawrence snow crab (Chionoecetes opilio) fishery. Canadian Journal of Fisheries and Aquatic Sciences 63, 254-267.

Grafton, R.Q. (2000) Governance of the Commons: A Role for the State? Land Economics 76, 504-517.

Grafton, R.Q., Arnason, R., Bjørndal, T., et al. (2006) Incentive-based approaches to sustainable fisheries. Canadian Journal of Fisheries and Aquatic Sciences 63, 699-710.

Graham, N., Fryer, R.J. (2006) Separation of fish from Nephrops norvegicusinto a two-tier cod-end using a selection grid. Fisheries Research 82, 111-118.

Guyader, O., Thébaud, O. (2001) Distributional issues in the operation of rights-based fisheries management systems. Marine Policy 25, 103-112.

Hamon, K.G., Thébaud, O., Frusher, S., Little, L.R. (2009) A retrospective analysis of the effects of adopting individual transferable quotas in the Tasmanian red rock lobster, Jasus edwardsii, fishery. Aquatic Living Resources 22, 549-558.

Hatcher, A., Jaffry, S., Thébaud, O., Bennett, E. (2000) Normative and Social Influences Affecting Compliance with Fishery Regulations. Land Economics 76, 448-461.

Heath, M. R., et al. (2014). "Cascading ecological effects of eliminating fishery discards." Nature Communications 5 .

Hilborn, R. (1985) Fleet Dynamics and Individual Variation - Why Some People Catch More Fish Than Others. Canadian Journal of Fisheries and Aquatic Sciences 42, 2-13. 
Hilborn, R., Kennedy, R.B. (1992) Spatial pattern in catch rates - a test of economic-theory. Bulletin of Mathematical Biology 54, 263-273.

Hilborn, R., Parrish, J.K., Litle, K. (2005) Fishing rights or fishing wrongs? Reviews in Fish Biology and Fisheries 15, 191-199.

Hilborn, R., Walters, C.J. (1987) A general-model for simulation of stock and fleet dynamics in spatially heterogeneous fisheries. Canadian Journal of Fisheries and Aquatic Sciences 44, 1366-1369.

Holland, D., Schnier, K.E. (2006) Individual habitat quotas for fisheries. Journal of Environmental Economics and Management 51, 72-92.

Holland, D.S., Sutinen, J.G. (1999) An empirical model of fleet dynamics in New England trawl fisheries. Canadian Journal of Fisheries and Aquatic Sciences 56, 253-264.

Holland, D.S., Sutinen, J.G. (2000) Location choice in New England trawl fisheries: Old habits die hard. Land Economics 76, 133-150.

Kaiser, M.J., Clarke, K.R., Hinz, H., Austen, M.C.V., Somerfield, P.J., Karakassis, I. (2006) Global analysis of response and recovery of benthic biota to fishing. Marine Ecology Progress Series 311, 1-14.

Kaiser, M.J., Spencer, B.E. (1995) Survival of by-catch from a beam trawl. Marine Ecology Progress Series $126,31-38$.

Kell, L.T., Mosqueira, I., Grosjean, P., et al. (2007) FLR: an open-source framework for the evaluation and development of management strategies. ICES Journal of Marine Science 64, 640-646.

Kelleher, K. (2005) Discards in the world's marine fisheries. An update. FAO Fisheries Technical Paper T470, 131

Kraan, M., Uhlmann, S., Steenbergen, J., Van Helmond, A.T.M., Van Hoof, L. (2013) The optimal process of self-sampling in fisheries: lessons learned in the Netherlands. Journal of Fish Biology 83, 963-973.

Kraan, M., Verweij, M. (2016 ) Implementing the landing obligation in the Netherlands; an analysis of the gap between fishery and the ministry. In: In P. Holm, M. Hadjimichael and S. Mackinson, (eds) Bridging the gap: Collaborative research practices in the fisheries. Springer.

Little, L.R., Punt, A.E., Mapstone, B.D., Begg, G.A., Goldman, B., Williams, A.J. (2009) An agent-based model for simulating trading of multi-species fisheries quota. Ecological Modelling 220, 3404-3412.
Marchal, P., Lallemand, P., Stokes, K. (2009) The relative weight of traditions, economics, and catch plans in New Zealand fleet dynamics. Canadian Journal of Fisheries and Aquatic Sciences 66, 291311.

Marchal, P., Little, L.R., Thebaud, O. (2011) Quota allocation in mixed fisheries: a bioeconomic modelling approach applied to the Channel flatfish fisheries. ICES Journal of Marine Science 68, 1580-1591.

MRAG, IFM, CEFAS, AZTI Tecnalia \& PolEM (2009) An analysis of existing Rights Based Management (RBM) instruments in Member States and on setting up best practices in the EU. Final Report 117 pages.

Palmer, C.T. (1991) Kin-selection, reciprocal altruism, and information sharing among Maine lobstermen. Ethology and Sociobiology 12, 221-235.

Pascoe, S. (1997) Bycatch management and the economics of discarding. FAO Fisheries Technical Paper370, 153.

Pierre, J.P., Thompson, F.N., Mansfield, R. ( 2014 ) Optimisation of protocols employed by New Zealand government fisheries observers for protected species data collection. Draft Report prepared for the Department of Conservation: Conservation Services Programme project INT2013-04., 79 pages.

Polet, H. (2002) Selectivity experiments with sorting grids in the North Sea brown shrimp (Crangon crangon) fishery. Fisheries Research 54, 217-233.

Poos, J.J., Bogaards, J.A., Quirijns, F.J., Gillis, D.M., Rijnsdorp, A.D. (2010) Individual quotas, fishing effort allocation, and over-quota discarding in mixed fisheries. ICES Journal of Marine Science 67, 323333.

Poos, J.J., Rijnsdorp, A.D. (2007) The dynamics of small-scale patchiness of plaice and sole as reflected in the catch rates of the Dutch beam trawl fleet and its implications for the fleet dynamics. Journal of Sea Research 58, 100-112.

Quirijns, F.J., Poos, J.J., Rijnsdorp, A.D. (2008) Standardizing commercial CPUE data in monitoring stock dynamics: Accounting for targeting behaviour in mixed fisheries. Fisheries Research 89, 1-8.

Ramirez-Sanchez, S., Pinkerton, E. (2009) The impact of resource scarcity on bonding and bridging social capital: the case of fishers' information-sharing networks in Loreto, BCS, Mexico. Ecology and Society 14,22 
Rijnsdorp, A.D., Bastardie, F., Bolam, S.G., and others (2016) Towards a framework for the quantitative assessment of trawling impact on the seabed and benthic ecosystem. ICES Journal of Marine Science 73, i127-i138.

Rijnsdorp, A.D., Piet, G.J., Poos, J.J. (2001) Effort allocation of the Dutch beam trawl fleet in response to a temporarily closed area in the North Sea. ICES CM 2001/N:01.

Robinson, C., Pascoe, S. (1997) Fisher behaviour. exploring the validity of the profit maximising assumption. CEMARE Res. pap. 110, 16.

Sainsbury, K.J., Punt, A.E., Smith, A.D.M. (2000) Design of operational management strategies for achieving fishery ecosystem objectives. ICES Journal of Marine Science 57, 731-741.

Salas, S., Gaertner, D. (2004) The behavioural dynamics of fishers: management implications. Fish and Fisheries 5, 153-167.

Sardà, F., Coll, M., Heymans, J.J., Stergiou, K.I. (2015) Overlooked impacts and challenges of the new European discard ban. Fish and Fisheries 16, 175-180.

Sauls, B. (2014). Relative survival of gags Mycteroperca microlepis released within a recreational hook-and-line fishery: Application of the Cox Regression Model to control for heterogeneity in a large-scale mark-recapture study. Fisheries Research 150, 18-27.

Soetaert, M., Decostere, A., Polet, H., Verschueren, B., Chiers, K. (2015) Electrotrawling: a promising alternative fishing technique warranting further exploration. Fish and Fisheries 16, 104-124.

Scientific, Technical and Economic Committee for Fisheries (STECF) (2014) - Landing Obligations in EU Fisheries - part 4 (STECF-14-19). 96 pp.

Stewart, J., Ferrell, D.J. (2002) Escape panels to reduce by-catch in the New South Wales demersal trap fishery. Marine and Freshwater Research 53, 1179-1188.

Sutinen, J.G., Andersen, P.C. (1985) The Economics of Fisheries Law Enforcement. Land Economics 61, 387-397.

Sutinen, J.G., Kuperan, K. (1999) A socio-economic theory of regulatory compliance. International Journal of Social Economics 26, 174-193.

Suuronen, P., Lehtonen, E., Jounela, P. (2005) Escape mortality of trawl caught Baltic cod (Gadus morhua) - the effect of water temperature, fish size and codend catch. Fisheries Research 71, 151-163.
Tidd, A.N., Hutton, T., Kell, L.T., Padda, G. (2011) Exit and entry of fishing vessels: an evaluation of factors affecting investment decisions in the North Sea English beam trawl fleet. ICES Journal of Marine Science 68, 961-971.

Trapman, B., Kraan, M. (2015) De vormgeving van beleid in een Multi-level Governance setting - VIP Rapport: analyse van bijeenkomsten tussen vissers en EZ over de omstreden aanlandplicht 2013, 2014 en 2015, IJmuiden, IMARES Wageningen UR

Tyler, T.R. (1990) Why people obey the law, New Haven: Yale University Press.

Van Beek, F.A., Van Leeuwen, P.l., Rijnsdorp, A.D. (1990) On the survival of plaice and sole discards in the otter-trawl and beam-trawl fisheries in the North Sea. Netherlands Journal of Sea Research 26, 151-160.

Van Gils, J.A. (2010) State-dependent Bayesian foraging on spatially autocorrelated food distributions. Oikos 119, 237-244.

van Hoof, L. (2013) Design or pragmatic evolution: applying ITQs in EU fisheries management. ICES Journal of Marine Science 70, 462-470.

van Marlen,.B. (2003) Improving the selectivity of beam trawls in The Netherlands - The effect of large mesh top panels on the catch rates of sole, plaice, cod and whiting. Fisheries Research 63, 155-168.

van Marlen, B., Wiegerinck, J.A.M., van Os-Koomen, E., van Barneveld, E. (2014) Catch comparison of flatfish pulse trawls and a tickler chain beam trawl. Fisheries Research 151, 57-69.

Verweij, M.C., van Densen, W.L.T., Mol, A.J.P. (2010) The tower of Babel: Different perceptions and controversies on change and status of Norths Sea fish stocks in multi-stakeholder settings. Marine Policy 34, 522-533.

Wilson, J.A. (1990) Fishing for Knowledge. Land Economics 66, 12-29.

Yergey, M.E., Grothues, T.M., Able, K.W., Crawford, C., DeCristofer, K. (2012) Evaluating discard mortality of summer flounder (Paralichthys dentatus) in the commercial trawl fishery: Developing acoustic telemetry techniques. Fisheries Research 115-116, 72-81.

Zimmermann, F., Heino, M. (2013) Is size-dependent pricing prevalent in fisheries? The case of Norwegian demersal and pelagic fisheries. ICES Journal of Marine Science 70, 1389-1395. 


\section{ADDENDUM}

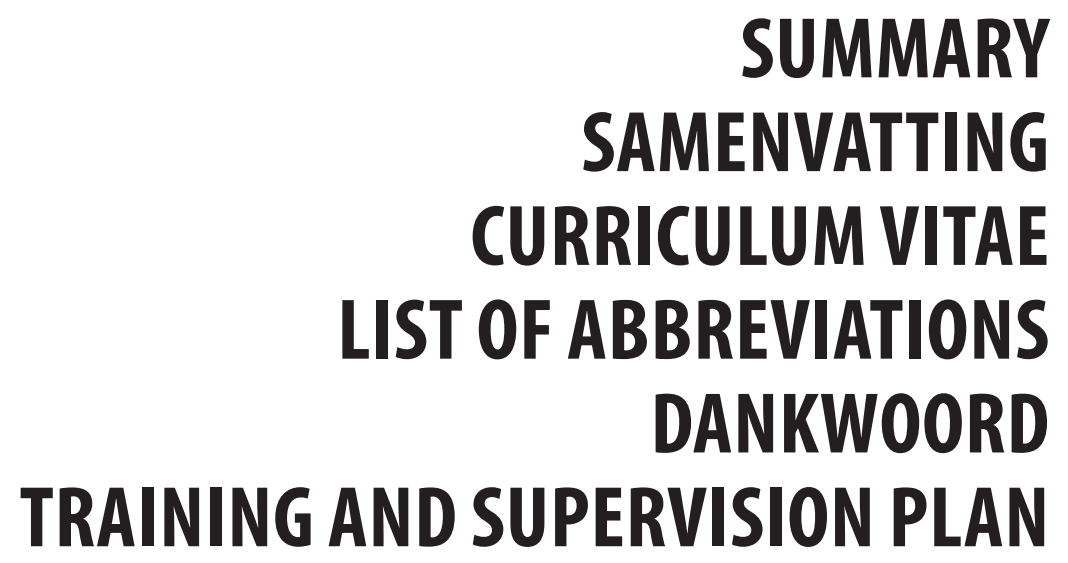




\section{SUMMARY}

The European Common Fisheries Policy has received much criticism. In the first place for failing to implement effective management measures aimed at rebuilding and maintaining fish stocks at a sustainable level. In addition, it is said current fisheries policy fails to integrate the wider ecosystem effects of fishing into policy making, such as reducing pressure on nontarget species and habitats. Especially discarding (i.e. throwing back unwanted catches at sea) in commercial fisheries has received an increased amount of negative attention. Public campaigns stressed discarding is a wasteful and disruptive practice as natural resources are extracted from the ecosystem only to be thrown back to sea dead. In response, the European Commission agreed to enforce a discard ban for European fisheries, obliging all European fishing vessels to retain and land their entire catch, including small sized individuals, of all species subject to quota management.

This thesis explores how management measures can mitigate the adverse effects of fishing to support the development of an ecosystem-based approach to fisheries management. I evaluate how fleet dynamics, i.e. the decision of individual skippers on when and where to fish, while competing for similar resources, may influence the performance of management measures. In particular the thesis focusses on how location choice and discard decisions made by individual fishers in a mixed fishery are influenced by management, resource distribution and technological innovations. Using a generic dynamic state variable model (DSVM), specific applications are built to address the behavioural dynamics for the Dutch North Sea flatfish fisheries and the French mixed demersal fisheries in the Channel in response to new management regulations and economic opportunities.

The first research chapter of this thesis (Chapter 2) explores how a combination of quota management with a discard ban may improve the regulation of fishing mortality for a depleted stock that is exploited in a mixed fishery. Our finding show that under a discard ban, when properly enforced, individual fishers reallocate fishing effort away from areas and weeks with high catch rates of the quota constrained species, reducing over-quota discarding and thus contributes to the conservation of vulnerable species. However, discard reduction measures which coincide with a reduction in the economic performance of the fishery may jeopardise compliance as fishers may trade-off economic gains of non-compliance against the costs.

Fishers will discard marketable fish when quota are exhausted (over-quota discarding) or by trying to optimize their economic return by discarding size or age classes with the lowest economic value (high-grading). In chapter 3 observations of over-quota discarding and high-grading are reviewed to gain insight in the conditions under which discard decisions may occur. The review suggest that high-grading occurs under different management systems for a large variety of fisheries worldwide. In addition, outcomes of the simulation model illustrate fishers have the ability to strategically plan their fishing activities to optimize the composition of their catch taking account of the availability of quota and seasonal 
price variations. As a result, the size composition of the high-graded catch differs from the landed catch. Difficulties in accounting for this difference may undermine the accuracy of the stock assessments and quality of scientific advice.

Chapter $\mathbf{4}$ addresses the question how a ban on discarding may promote the transition towards more selective fishing gears. Model results suggest that under a discard ban, fishing activities are restricted and reallocated away from areas and weeks of high catches of small fish constrained by quota. Activities are allocated to areas and weeks where a maximum revenue can be realised landing other species and economically more valuable length classes of the quota restricted species. When using more selective fishing gear, fishing activities will be less restricted. Fewer small fish are landed which would otherwise be counted against the quota, fetching a low price and reduce the economic value of the landings. Hence, there is an economic advantage and fishers can continue fishing for a longer period of time, including areas where a higher density of small fish as well as more economically valuable fish co-occur. As such, if properly enforced, a discard ban can incentivise the use of more selective gear to reduce the catch of undersized fish.

Trawl fisheries targeting demersal fish and shellfish cause mortality on target and non-target species, but impact benthic ecosystems. Fisheries managers mainly resort to technical management measures, such as gear restrictions or spatial measures to mitigate these impacts. Chapter $\mathbf{5}$ explores the potential of a habitat credit system as an alternative management approach to achieve sustainable exploitation of target species while minimizing the impact on the benthic ecosystem. Results show that a habitat credit system has the potential to reduce the benthic impact and maintain profitable fisheries as vessels can adjust their behaviour by reallocating fishing activities to make optimal use of the available credits.

Fishers can adapt and change their behaviour in relation to imposed constraints, which can lead to unintended and unexpected consequences of fisheries management. To date, the effect of behavioural adaptations of individual fishers on the success of fisheries management is often overlooked by policymakers. The models developed in this thesis provide a strong basis to explore possible unexpected effects of management measures resulting from the adaptive behaviour of fishers to these measures. Outcomes of this thesis draw attention to the importance of making fleet dynamics an integral part of fisheries management and the need to develop innovative analytical methodologies which deliver sufficiently robust insights into complex socioeconomic and ecosystem issues to improve the basis of decision making. 


\section{SAMENVATTING}

Het Europees Gemeenschappelijk Visserijbeleid heeft veel kritiek te verduren. In de eerste plaats omdat de genomen beheersmaatregelen onvoldoende zouden bijdragen aan het herstel en behoud van visbestanden. Daarnaast slaagt men er niet in om de ecosysteemeffecten van visserij in het visserijbeleid te integreren, zoals het verminderen van de bijvangst van niet commerciële soorten en de impact op de zeebodem. Met name het teruggooien van ongewenste vangsten in zee (discarden) in de commerciële visserij krijgt in toenemende mate negatieve aandacht. Publieke campagnes benadrukte de voedselverspilling en verstorende effecten in het ecosysteem door het onttrekken van natuurlijke hulpbronnen om ze daarna weer terug, vaak dood, terug te gooien in zee. Als reactie heeft de Europese Commissie in 2013 ingestemd met de invoering van een teruggooiverbod voor de Europese visserij. Dit houd in dat de meeste Europese visserijen verplicht worden om alle vangsten van soorten waarvoor een vangstbeperking is ingesteld zowel de marktwaardige als nietmarktwaardige vis aangeland moet worden.

Dit proefschrift verkent hoe beheersmaatregelen negatieve effecten van de visserij kunnen beperken en bij kunnen dragen aan de ontwikkeling van een ecosysteembenadering van het visserijbeheer. Echter, de effectiviteit van beheersmaatregelen kan beïnvloed worden door de dynamiek van de vloot. Deze dynamiek komt tot stand door keuzes die individuele schippers maken met betrekking tot welke soorten, waar en wanneer te bevissen. Het is dus van belang om te begrijpen hoe de beheersmaatregelen de dynamiek van de vloot beïnvloed. Dit proefschrift beschrijft voornamelijk hoe de locatiekeuze van de visserijactiviteit en de beslissing wanneer en welk gedeelte van de vangst te discarden beïnvloed wordt door maatregelen in het visserijbeleid, de ruimtelijke en tijdelijke verspreiding van de visbestanden en technologische innovaties. Er is een "dynamic state variable model" gebrui$\mathrm{kt}$, en specifiek toegepast om het effect van nieuwe beheersmaatregelen en economische kansen voor de Nederlandse platvisvisserij op de Noordzee en de Franse gemengde bodemvisserij in het Kanaal inzichtelijke te maken.

Het tweede hoofdstuk van dit proefschrift (hoofdstuk 2) beschrijft hoe een combinatie van vangstbeperkingsmaatregelen (quota) met een teruggooiverbod kan leiden tot een betere regulatie van visserijsterfte voor een uitgeput visbestand geëxploiteerd in een gemengde visserij (visserij waar meerdere soorten tegelijk bevist worden). Onze bevindingen tonen aan dat onder het teruggooiverbod individuele vissers hun activiteit verplaatsen weg uit gebieden en weken met hoge bijvangsten van soorten met een strikte vangstbeperking. Als gevolg werd er ook minder gediscard en kunnen we stellen dat een teruggooiverbod, mits goed gehandhaafd, bij kan dragen aan het behoud van kwetsbare soorten. Echter, vissers zullen de economische voordelen van het niet-naleven van de regelgeving afzetten tegen de kosten. Discard reductie maatregelen die gepaard gaan met een afname in de economische prestaties van de vloot kunnen dan ook de naleving van de regelgeving in gevaar brengen. 
Vissers zullen marktwaardige vis discarden wanneer het quota uitgeput is (over-quota discarding) of wanneer ze trachten hun economische rendement te optimaliseren door de lengte en leeftijdsklassen met de laagste economische waarde (high-grading) gedurende het jaar te discarden. Om inzicht te krijgen in de voorwaarden waarbij over-quota discards en high-grading mogelijk plaatsvinden, bevat hoofdstuk 3 een literatuuronderzoek naar observaties van beide vormen van discarden. Het literatuuronderzoek suggereert dat high-grading onder verschillende vormen van visserijbeheer en ook wereldwijd voorkomt. Daarnaast laat een modelsimulatie zien dat vissers hun activiteiten strategisch kunnen plannen. Ze zijn in staat de vangstsamenstelling te optimaliseren door rekening te houden met de beschikbaarheid van quota en seizoensgebonden prijsschommelingen. Als gevolg is de grootte samenstelling van de vangst anders dan de samenstelling van de vis die daadwerkelijk aangevoerd wordt. Moeilijkheden bij het vaststellen van deze verschillen, kunnen de nauwkeurigheid van de bestandsschattingen en de kwaliteit van het wetenschappelijk advies ondermijnen.

In hoofdstuk 4 wordt beschreven hoe een teruggooiverbod de transitie naar selectiever vistuig kan bevorderen. Resultaten uit het simulatiemodel tonen aan dat een teruggooiverbod de visserijactiviteiten beperkt. Visserijactiviteiten verplaatsen zich weg uit gebieden en weken met hoge bijvangsten van kleine vis voor soorten met een vangstbeperking naar gebieden en weken waar een maximale opbrengst gerealiseerd kan worden door het aanlanden van andere soorten en economisch meer waardevolle lengteklassen. Vissers die gebruik maken van een selectiever vistuig zullen minder beperkt worden in hun activiteiten. Er wordt minder kleine vis aangevoerd waardoor het quotum langer behouden blijft en gebruikt kan worden voor aanvoer van economische meer waardevolle lengteklassen. Er is dus een economisch voordeel en vissers kunnen langer doorgegaan met vissen, waarbij ook gebieden bevist kunnen worden waar zowel een hogere dichtheid aan klein vis alsook economisch meer waardevolle vis voorkomen. Als zodanig, mits goed gehandhaafd. kan een teruggooiverbod het gebruik van selectiever vistuig stimuleren om de vangst van ondermaatse vis te beperken.

De trawlvisserij, boomkor-, dredge- en bordenvisserij gericht op demersale vis- en schelpdieren heeft naast directe sterfte op doelsoorten en soorten die geen commerciële waarde hebben ook een effect op het bodemecosysteem. Het beheren van deze effecten gebeurt vaak aan de hand van technische maatregelen. Er zijn ook alternatieve beheersmaatregelen voorgesteld. In hoofdstuk 5 zijn de mogelijkheden van een “habitat credit systeem" als een alternatieve benadering voor het minimaliseren van de effecten van visserij op het bodemecosysteem onderzocht. Het onderzoek laat zien dat bij een habitat credit systeem schippers optimaal gebruik kunnen maken van de beschikbare credits door hun locatiekeuze aan te passen. Een habitat credit systeem heeft dus de potentie om effecten van visserij op het bodemecosysteem te verminderen en daarbij ook de economische prestaties van de visserij te behouden. 
Vissers zijn in staat zich aan te passen en andere keuzes te maken als gevolg van beperkingen die er opgelegd worden door het visserijbeheer. Dit kan onverwachte en onbedoelde gevolgen hebben. Echter, beleidsmakers zien de invloed van gedragsaanpassingen op de effectiviteit van het visserijbeheer vaak over het hoofd. De simulatiemodellen in dit proefschrift bieden een sterke basis om mogelijke onverwachte effecten van maatregelen als gevolg van adaptief gedrag van vissers te verkennen Uitkomsten van dit proefschrift vestigen de aandacht op het belang om de dynamiek van de vissersvloot een integraal onderdeel te maken van het visserijbeheer. Ook benadrukt het proefschrift de noodzaak om innovatieve analytische methoden te ontwikkelen die inzicht kunnen leveren in complexe sociaaleconomische en ecosysteem vraagstukken zodat er een betere besluitvorming kan plaatsvinden en effectieve beheersmaatregelen ontwikkeld kunnen worden. 


\section{CURRICULUM VITAE}

Jurgen Batsleer is born on the 9th of September 1981, in Antwerp, Belgium. From an early age he was fascinated by fish, with a special fondness for sharks. In 2000 he obtained his high-school diploma in languages and sciences from Xaverius College, Borgerhout, Belgium. After graduating high-school he trades in Belgium for the Netherlands to study biology at the University of Groningen where the opportunity is provided to study marine biology. The first research project supervised by Prof. dr J.J. Videler was not quite what he had expected when he started his education to become a marine biologist. His supervisor was convinced that the understanding of how birds fly had to be revised. Hence, the research project entailed the study on how a leading-edge vortex lifts swifts. In 2005, Jurgen started his second research project supervised by Prof. dr S.H. Gruber (University of Miami) and prof. Dr W.T. Stam (University of Groningen). It was a six month research project to study the temperature preference of juvenile lemon sharks in Bimini, Bahamas. In January 2008 he finishes his Masters. After one year of administrative jobs in the Netherlands and a temporary job as a guide at African shark eco-charters in South Africa he starts his PhD research at IMARES Wageningen University supervised by Prof. dr A.D. Rijnsdorp and dr J.J. Poos. In 2014 Jurgen starts working as a scientist for the Dutch demersal fisheries, VisNed. 


\section{LIST OF ABBREVIATIONS}

The following table describes the significance of various abbreviations and acronyms used throughout the thesis.

\begin{tabular}{ll}
\hline Abbreviation & Meaning \\
\hline AIC & Akaike Information Criterion \\
BIC & Bayesian Information Criterion \\
CAP & Common Agricultural Policy \\
CFP & Common Fisheries Policy \\
CPUE & Catch per unit of effort \\
DAS & Days at Sea \\
DCF & Data Collection framework \\
DSVM & Dynamic state variable model \\
EAF & Ecosystem-based approach to fisheries \\
EU & European Union \\
FAO & Food and Agricultural Organisation \\
GAM & Generalized Additive Model \\
GES & Good Environmental Status \\
HD & Habitat Directive \\
ICES & International Council for the Exploration of the Sea \\
IHC & Individual habitat credits \\
IQ & Individual quota \\
ITQ & Individual transferable quota \\
LPUE & Landings per unit of effort \\
MAGPS & Multi-annual guidance programs \\
MLS & Minimum Landing Size \\
MSFD & Marine Strategy Framework Directive \\
RAC & Regional Advisory Council \\
RUM & Random Utility Model \\
SSB & Spawning stock biomass \\
STECF & Scientific, Technical and Economic Committee for Fisheries \\
TAC & Total allowable Catch \\
VMS & Vessel Monitoring System \\
\hline &
\end{tabular}




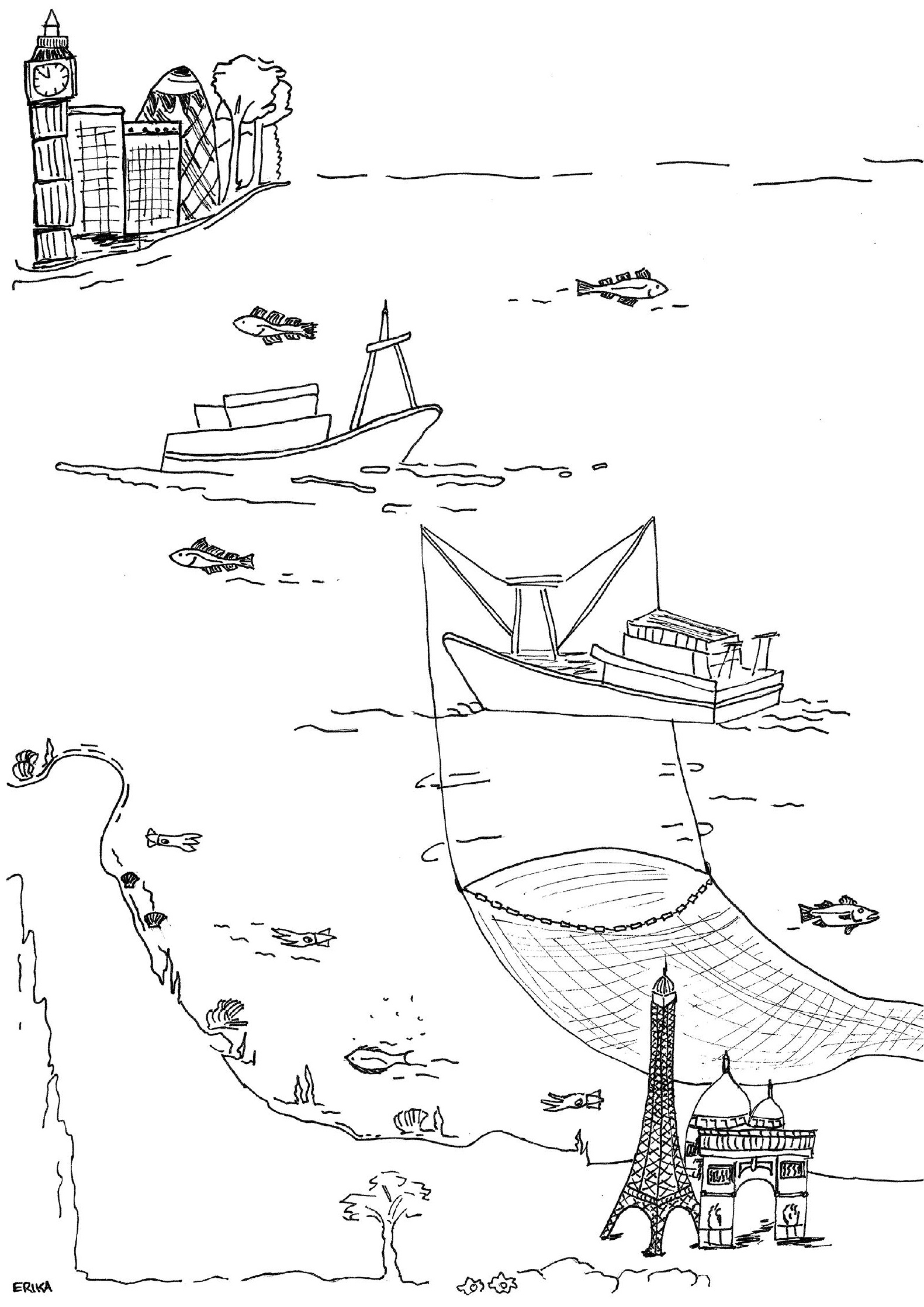




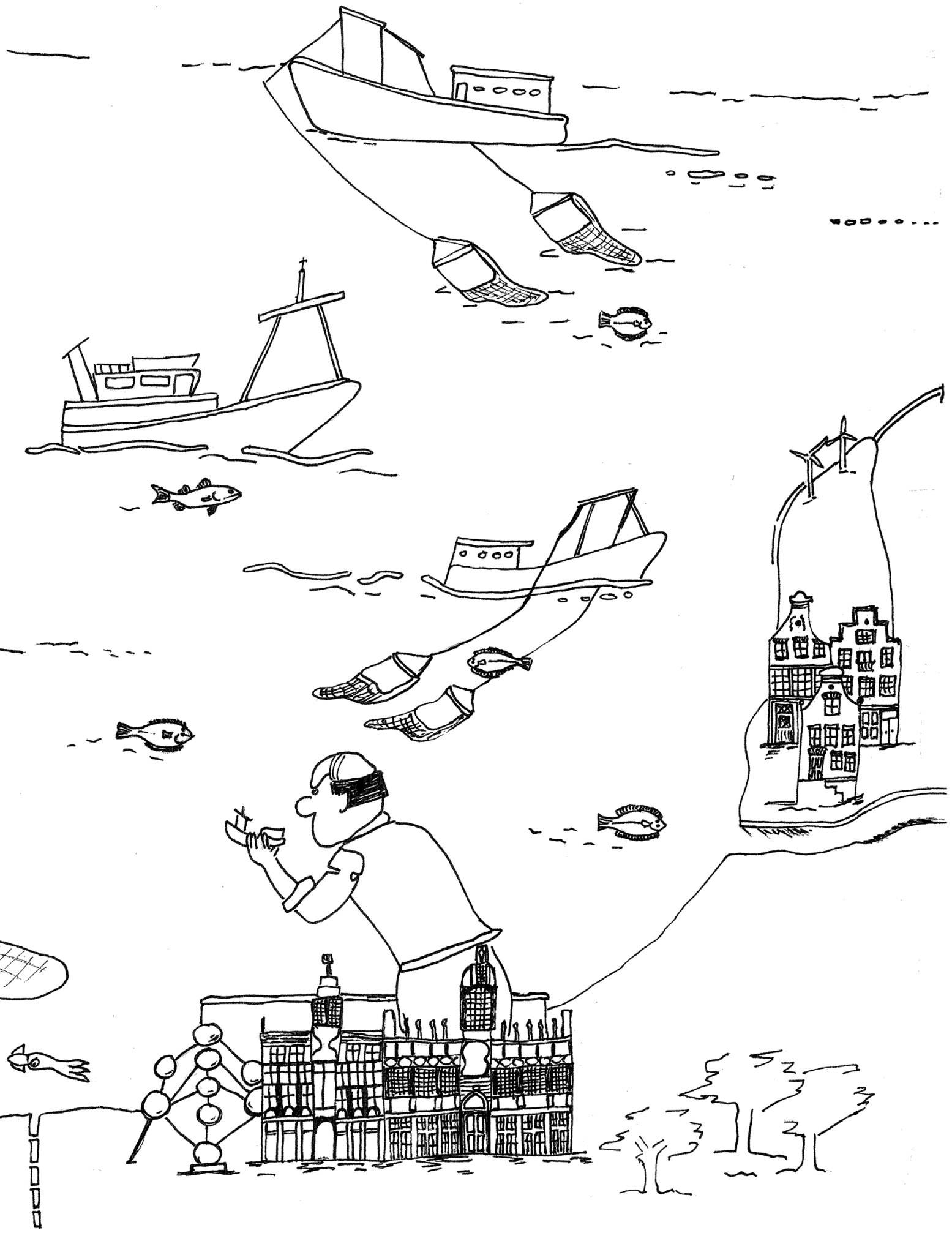




\section{DANKWOORD}

"Hallo Jurgen, met Adriaan Rijnsdorp van IMARES. Ik moet je teleurstellen je bent het net niet geworden. We hebben een andere kandidaat gevonden die mathematisch beter onderlegd is. Maar, we hebben nog een PhD-positie waarin gekeken zal worden naar vloot dynamica. We krijgen deze niet echt ingevuld, heb je daar toevallig interesse in? Je kunt hiervoor een afspraak maken met Jan Jaap Poos, hij kan je hier meer over vertellen." Dit was het begin van mijn PhDavontuur. Jan Jaap, ik ben blij dat ik toen de keuze gemaakt heb contact met je op te nemen en het gesprek aan te gaan. Je bent een goede leermeester voor me geweest en je hebt altijd de tijd genomen om me door het model en het proces van publiceren te leiden. Je bent gedreven en een perfectionist met het gevolg dat ik nu nog steeds alle figuren perfect op elkaar probeer aan te laten sluiten in een presentatie. Het is voor mij als promovendus ook bijzonder geweest om de promotie van mijn eigen begeleider mee te maken. Mijn voornemen was dus ook om mijn PhD in iets meer dan de helft van jouw tijd af te ronden. Adriaan, het is bijzonder dat we juist na m'n tijd bij IMARES samen een onderzoeksreis met de TX43 hebben kunnen maken. Het was mooi om te zien dat je nog steeds met een enorm enthousiasme met je vak bezig bent. Het mooie hiervan is dat je deze eigenschap ook weet uit te stralen naar anderen. Kortom, ik wil jullie beide dan ook bedanken voor de vele uren die jullie in mij geïnvesteerd hebben, jullie rust en geduld, zeker de laatste twee jaar. Ik heb enorm veel van jullie geleerd en dat ik doe ik nog steeds en ik hoop dat we in de toekomst nog vaker samen gaan werken.

Ik wil Harriet en Katell bedanken voor de hulp en tijd die jullie hebben weten vrij te maken voor hoofdstukken 3 en 4. Also, I would like to thank my co-authors from IFREMER. Paul, Youen and Sandrine thank you very much for your contributions to chapters 2 and 5. I'm very grateful I was able to join you in Boulogne-sur-Mer and would like to thank the PhD-students (Xo and Raphaël) as well as all the other staff for their hospitality. Paul, many thanks to you and your family for making sure my family and I felt welcome and had a nice place to stay. Youen and Sigrid thank you for showing us Boulogne-sur-Mer and to introduce me to this very popular dish: Welsh.

Ook wil ik alle IMARES collega's van de afdeling Vis en Visserij bedanken voor de fijne tijd die ik in IJmuiden heb gehad. Ik voel me er nog steeds kind aan huis. Lorna, je zag me alweer binnenkomen met een vragende blik of er nog ergens budget in VECTORS beschikbaar was om naar een meeting of conferentie te kunnen gaan. Ik wil je niet alleen hiervoor bedanken natuurlijk, maar ook voor je luisterend oor en steun tijdens m'n PhD. Natuurlijk bedank ik ook alle IMARES PhD-ers. Voor de mensen met wie ik in de PhD-council zat (Wouter, Jacob, Santi en Ilona); wat hebben we die IMARES PhD-Science Day toch goed en gestructureerd weten te organiseren. Daniël, ik vind het echt knap hoe jij door je PhD bent gestoomd. Bedankt voor de vele gesprekken, brainstormsessies, hulp en gezelligheid bij conferenties. Maarten, tussen alle verhuizingen door heb je toch maar lekker je boekje af weten te maken. Achteraf hadden we in Alkmaar toch vaker een biertje moeten doen en even "chillen" op een terrasje. 
Marieke, my roomie, het zijn vier bewogen jaren geweest bij IMARES met veel ups en downs voor ons beide. Gelukkig hadden we standaard op maandagochtend voor het werkoverleg een ik uit-mijn-frustraties momentje. Gelukkig werden we daarna snel rustig van de yoga-muziek die regelmatig op de gang te horen was. Toch blijft één van de memorabele momenten dat je op een ochtend in januari op kantoor kwam met een te grote glimlach op je gezicht. Mijn conclusie was snel getrokken, je had in ieder geval een leuke IMARES kerstborrel gehad met Wouter!

Natuurlijk kan ik ook m'n carpool-buddy's niet vergeten te bedanken. Doug, Henk, Martin, Sebastian en Stijn. Het was een plezier om met jullie in de auto te mogen zitten. Henk die zomaar door rood reed bij de sluizen in IJmuiden, of Doug die wat moeite had om aan de goede kant van de weg te blijven rijden. Met Martin was het ook altijd veel plezier, voornamelijk wanneer je al om 7uur in de ochtend enthousiast over de stand van zaken omtrent het aalbeheerplan begon te vertellen en natuurlijk kon je het niet laten om op de terug weg ons uitvoerig bij te praten over de ontwikkelingen van die dag. Vermoedelijk waren dit enkele redenen voor Sebastiaan om via alternatieve routes bij IMARES op te duiken (trein, fiets, bus, boot).

Ook wil ik mijn collega's in de visserijsector en de visafslag in Den Helder bedanken. Pim, je bent zowat de beste multi-tasker die ik ken. Tijdens een overleg bellen, mailen en appen tegelijkertijd zijn geen uitzondering. Ik vind het erg knap hoeveel verschillende dossiers je in je hoofd hebt zitten en hoe snel je hierin weet te schakelen. Geert, jij bent in mijn ogen een lopende visserij-encyclopedie. Je schudt antwoorden op vragen zomaar uit je mouw! Maarten, ik waardeer je rust en directheid, dat werkt heel erg prettig. Ik heb in deze drie jaar bij de visserijsector enorm veel geleerd en heb deze kennis ook nog eens in dit proefschrift toe kunnen passen. Wouter, wij kennen elkaar natuurlijk al vanuit onze studententijd in Groningen. Via wat omzwervingen ook nog eens samen als PhD'er bij IMARES en wie had ooit gedacht dat we ook nog eens samen als wetenschappers in de visserijsector zouden werken. Ik wil je hier ook echt even persoonlijk bedanken voor de fijne samenwerking bij VisNed. Ik zal het niet vaak gezegd hebben, maar je was een echte steun tijdens de laatste loodjes van dit proefschrift waarbij je wat zaken van mijn bord af wist te halen, bedankt hiervoor!

Natuurlijk wil ik ook Bram en Endam, Jurre en Ronja, en Joep en Sylvana bedanken voor de gezellige uitstapjes, weekendjes weg, borrels en feestjes. De meeste van ons zijn iets minder vlot in de dance-moves geworden, maar weten dan wel weer perfect hoe je luiers moet verschonen en hoe warm melkflesjes moeten zijn. Percy, while we live far apart, have busy lives and have much less contact then we used to have, our friendship is special. We don't need much words to understand each other. I want to thank you for your believe in my ambitions and support in reaching my goals in live. Ook mijn schoonouders wil ik bedanken voor hun betrokkenheid en Hans blijf die relevante lectuur maar naar mij doorsturen. Daarnaast wil ik alle jongens van onder 18 bij de Alkmaar Guardians Basketball bedanken. Jullie hebben voor behoorlijk wat (ont)spanning weten te zorgen. Ik heb jullie twee jaar met heel veel plezier gecoached en hoop jullie ook iets bijgebracht te hebben zoals eet geen pizza voor een training. 
Ik denk dat mijn passie voor het onderwaterleven is ontstaan door de vele rondjes vissen kijken in de dierentuin van Antwerpen. Ik wil m'n familie (Myriam en Frits, Erna en Frank, grootouders en Yves) bedanken voor alle steun en de deur die altijd voor mij open staat. Nu ik het dankwoord schrijf, is het een groot gemis dat mijn vader deze promotie niet meer bij kan wonen. Hij zei altijd dat hij graag onderzoeker had willen worden, maar dan het liefst iets met de Noordpool want daar was het tenminste lekker fris. Ik ben dan geen onderzoek begonnen in het arctische gebied, maar hoop met deze PhD toch iets van zijn droom gerealiseerd te hebben. Mama, je bent een enorme steun geweest en ik wil je bedanken dat je me altijd aangespoord hebt om mijn droom te blijven volgen.

Margreet, hoe kan ik jou nu bedanken in een paar korte zinnen. Er zijn bijna geen woorden voor wat jij de afgelopen jaren voor mij betekend hebt. Je hebt jezelf grotendeels opzij gezet zodat ik mijn ambities waar kon maken. Je was altijd bereid om stukjes door te lezen, presentaties met me door te nemen en verhalen over visserijmodellen aan te horen. Ondertussen hebben we twee geweldige dochters gekregen. Maar, wanneer Norah ons begint te vertellen dat het geen waterslang maar een murene is en één van de eerste woorden van Maud "vis" is, dan concludeer ik dat er bij ons thuis de laatste jaren misschien iets teveel over mijn werk gesproken is geweest. De laatste maanden waren erg hectisch en ik weet zeker dat door het afronden van m'n PhD en de start in ons nieuwe huis er meer rust voor ons gezin komt. Bedankt voor al jullie steun, geduld en liefde. 
Training and Supervision Plan

Name PhD student

Project title

Group

Daily supervisor(s)

Supervisor(s)

Project term

\section{Jurgen Batsleer}

Ecosystem approach to fisheries: Modelling the dynamics and ecosystem impacts of mixed demersal fisheries.

Wageningen Marine Research/ WUR AFI

Dr Jan Jaap Poos

Prof. Dr Adriaan Rijnsdorp

1-nov-2009 - 01-dec-2013
Graduate School WIAS

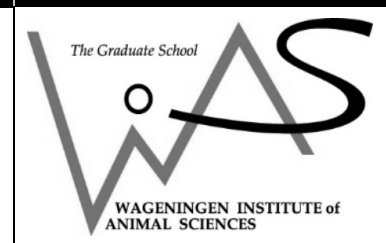

EDUCATION AND TRAINING

The Basic Package

WIAS Introduction Course

Course on philosophy of science and/or ethics

2009

2010

1.5

1.5

\section{Scientific Exposure}

International Flatfish symposium, IJmuiden (oral)

ICES Annual Science Conference, Bergen (oral)

ICES Annual Science Conference, Reykjavik (oral)

Netherlands Annual Ecology meeting, Lunteren (poster)

WIAS Science day, Wageningen (poster, oral)

IMARES PhD-day, Texel (oral, poster)

MARIFISH plenary meeting, Boulogne-sur-Mer (oral)

VECTOR WP 2.3 meeting, Aalborg (oral)

VECTOR WP 2.3 meeting, Paris (oral)

English Channel Flyshoot meeting, Paris

$\begin{array}{cc}2011 & 2.5 \\ 2012 & 2.5 \\ 2013 & 2.5 \\ 2012 & 1.3 \\ 2011,2013 & 2.0 \\ 2011-2013 & 1.0 \\ 2010,2012 & 1.0 \\ 2011 & 0.5 \\ 2012 & 0.5 \\ 2012 & 0.5\end{array}$

\section{In-Depth Studies}

Fisheries ecology course, Iceland

2010

2010

2011

Mathematical modelling, Wageningen

Ecosystem modelling for fisheries management, Copenhagen

Data exploration, regression, GLM and GAM in R, IJmuiden

Mixed modelling course Highland Statistics, IJmuiden

2011

2011

2013
2010

2010

2010

2012

2010

2013

Preparing own $\mathrm{PhD}$ research proposal

External training: IFREMER, France

2011

2,0

Didactic Skills Training

Supervising Msc thesis

Management Skills Training

Organisation of IMARES PhD science day

2011-2013

3.0 


\section{COLOFON}

\section{GRAPHIC DESIGN COVER AND INSIDE:}

Rachel van Esschoten, DivingDuck Design (www.divingduckdesing.nl)

\section{PHOTOGRAPHY:}

Photo cover: iStock (www.istockphoto.com)

DRAWING PAGE 164-165:

Erika Nentwich

PRINTED BY:

Printed by: Proefschriftmaken.nl, Uitgeverij Boxpress 



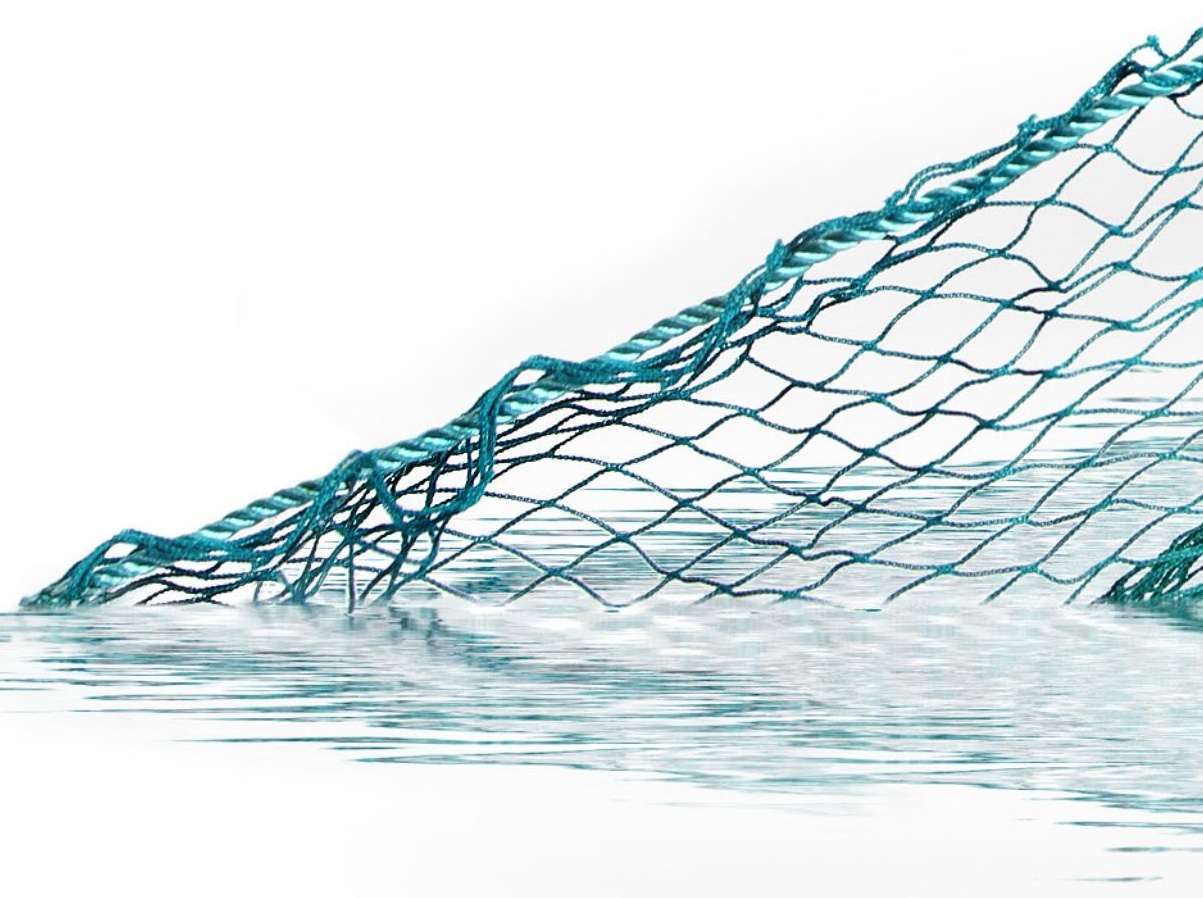

